$\frac{5.07(74.71)}{45}$ 



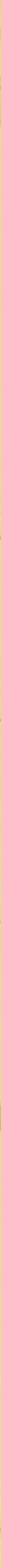




. 



\title{
gemeral
}

GIIIIS

\section{to THE}

\section{AMEIBICAN}

\author{
MUSEUN
}

DF NATUIBal.

HISTOIRY

SCIENCE GUIDE NO. 118

Revised Edition published by

MAN AND NATUIE PUIBLCATIONS

The American Museum of Natural History

New York 24, N. Y. 


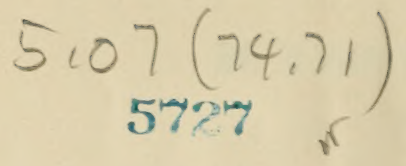

JAN 291954 


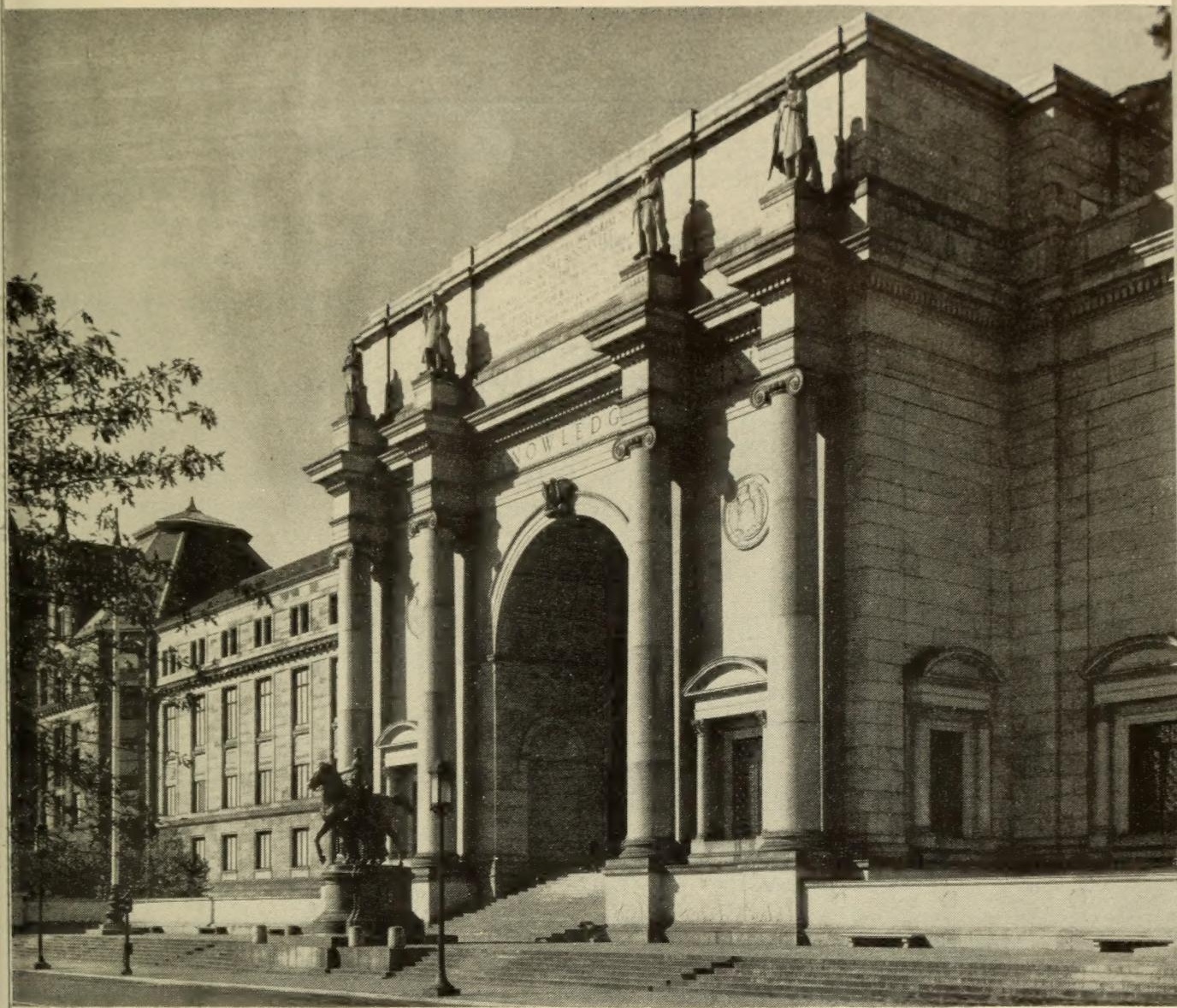

EXTERIOR OF THE THEODORE ROOSEVELT MEMORIAL BUILDING. 


\section{CONTENTS}

NATURE - THE ENVIRONMENT OF MAN 7

AN INTRODUCTION TO THE AMERICAN MUSEUM OF NATURAL HISTORY $\mathbf{7}$

GENERAL INFORMATION 9

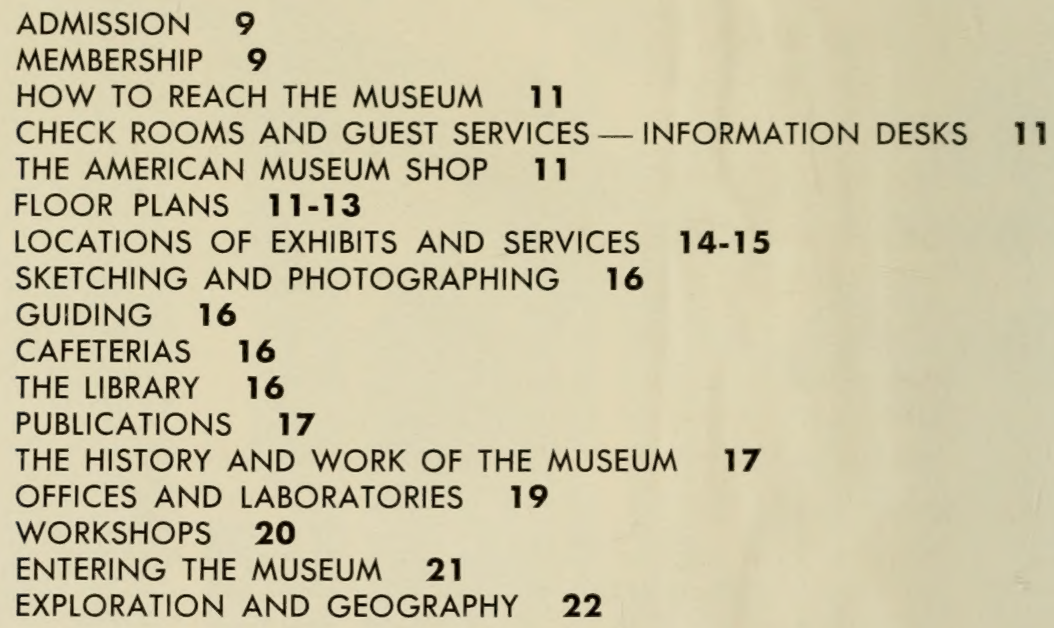

MAKING THE EXHIBITION HALL 29

ASTRONOMY AND THE AMERICAN MUSEUM-HAYDEN PLANETARIUM 35 


\section{GEOLOGY AND PALENTOLOGY 41}

MINERALS AND GEMS 44

TIME SCALE OF EARTH HISTORY 51

FIRST FOSSIL HALL - Fishes to Early Dinosaurs

SECOND FOSSIL HALL - Late Dinosaurs $\mathbf{5 9}$

THIRD FOSSIL HALL - Age of Mammals 64

FOURTH FOSSIL HALL - Age of Mammals 67

FIFTH FOSSIL HALL - Ice Age Mammals 71

MICROPALEONTOLOGY $\mathbf{7 4}$

\section{INVERTEBRATES $\mathbf{7 5}$}

THE SYNOPTIC SERIES $\mathbf{7 5}$

HABITAT GROUPS $\mathbf{8 0}$

INSECTS AND SPIDERS 83

THE EXHIBITS $\mathbf{8 6}$

\section{FISHES 93}

THE EXHIBITS 93

AMPHIBIANS AND REPTILES 97

THE EXHIBITS 99

\section{BIRDS 107}

THE WHITNEY WING 108

BIRDS OF THE WORLD HALL 118

HALL OF NORTH AMERICAN BIRD GROUPS 121

\section{MAMMALS 125}

THE HALL OF NORTH AMERICAN MAMMALS 125

AKELEY MEMORIAL HALL OF AFRICAN MAMMALS 132

VERNAY-FAUNTHORPE HALL OF SOUTH ASIATIC MAMMALS 141

NORTH ASIATIC MAMMALS 145

THE HALL OF OCEAN LIFE 146

SYNOPTIC HALL OF MAMMALS 149

MAMMALS OF NEW YORK STATE 150

\section{ANIMAL BEHAVIOR 151}

\section{ANTHROPOLOGY 155}

MAN AND HIS ORIGINS 155

HALL OF PRIMATES 155

HALL OF THE NATURAL HISTORY OF MAN 157

OSBORN HALL OF THE AGE OF MAN 160

LIVING RACES OF MAN 163

CONSERVATION AND GENERAL ECOLOGY 205

FELIX M. WARBURG MEMORIAL HALL 207

NORTH AMERICAN FORESTS 215

POPULAR VERSUS SCIENTIFIC WORDS 217 WORD LIST $\mathbf{2 1 9}$ 



\section{NATURE -}

\section{THE ENVIRONMENT OF MAN}

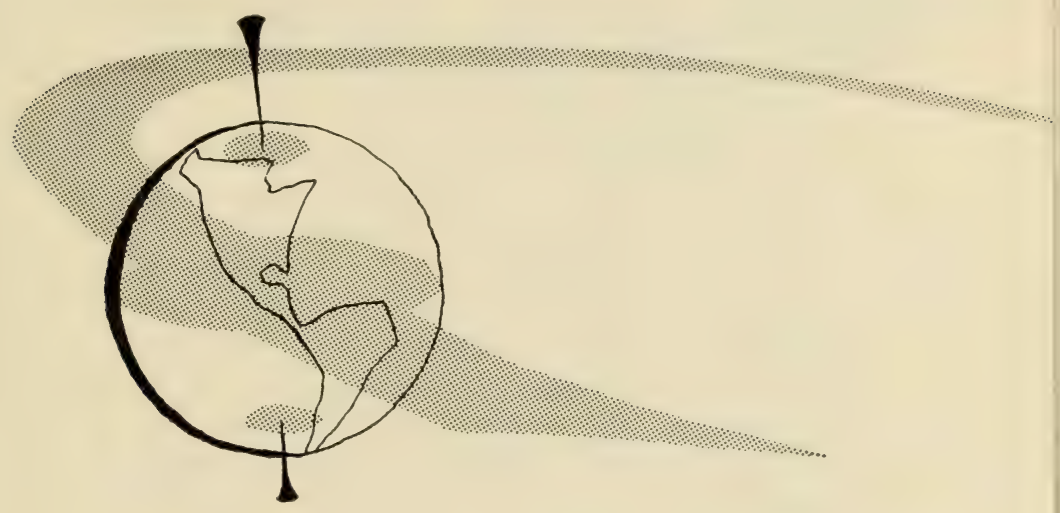

\section{AN INTRODUCTION TO THE AMERICAN MUSEUM OF NATURAL HISTORY}

The ideal museum has been dreamed of but has not yet been built. The ideal museum presents, in logical order, the entire story of the universe, the earth, and its inhabitants, together with their total relation to each other. Practical limitations prevent such a museum from becoming a reality but the goal is there.

The American Museum of Natural History works constantly toward that goal. A study of the table of Contents of this General Guide will give the Museum visitor a key to an appreciation of its offerings in both a logical and a chronological order.

Astronomy mirrors the universe and states the theories of the earth's origin. The hardened rocks furnish the material of geology and the life-forms trapped in that rock are the objects of the paleontologist's search. From fossils we advance to forms that are familiar today - living creatures without backbones, insects, fishes, reptiles, birds, and mammals - all leading to the study of man himself.

With the growth of man from primitive savagery to what we call civilization, come changes in his relation to his surroundings. The first living thing was affected by its environment and affected it in turn. Man 
is no exception. He is one of a species of animals, among which he is no more necessary to the continuance of life than are the insects, the birds or the dinosaurs. His very existence in the future may depend on his understanding of the world in which he finds himself.

Man is still a part of nature, although he controls much on earth. He is still subject to great basic laws and forces that restrict and restrain him within marked boundaries. A shift in climate from marine temperate to glacial cold could wipe out the traces of man and his works over a continent. A movement of the ocean bed could send a tidal wave to destroy coastal towns thousands of miles away.

Closer to man's fate than great carth changes are the difficulties he makes for himself through lack of understanding of the consequences of his acts. Because he is the only living organism with the powers of reason developed to a relatively high degree, he is able to engage in thought processes and actions that create in him needs and desires that were not shared by his early ancestors. In the satisfaction of these needs and desires he cuts down whole forests for his industries. He mines the soil and uses up resources he cannot hope to replace. He waters the desert and reaps his harvest. He plows the plains and sows the dust bowls.

The Museum is aware of the urgency of the problems of soil, water, forest, mineral and wild life conservation and of the conservation of man himself. As you read through this General Guide or walk through the Museum halls, note the theme expressed by those who represent the man! departments of science and of education. This idea is plain in their research, in their writings and in their exhibits for the public. The scientist-educator is concerned with the interpretation of nature rather than with its mere presentation. The day of the thousand stuffed animals in one long case is gone. The scientist-educator knows that man must see nature as a whole since he must live as a whole being within its framework.

'The American Museum of Natural History is one of the most wonderful places in the world. It houses the priceless objects of the earth. displayed in dramatic settings that amaze and delight all who come to see.

But it is more, much more, than a treasure trove of the rare, the exotic, the beautiful and the unusual. It is a great teacher who can tell man what has gone before, what exists in the present, and what the future holds, depending on man's choice of direction. It would not be a great teacher if it did not indicate the best direction for him to take.

The Museum should be all things to all men. It should meet the needs of the housewife, the farmer, the industrialist, the teacher, the college student, the child. Each must find. among its offerings, an answer to his questions, an understanding of daily living and an appreciation of his own place in a highly complex and interrelated world.

Unless museums work toward that objective, they fail in their obligation to mankind. This museum realizes that responsibility and asks you, the visitor, to pass judgment on the fruits of its labors and to take some of those fruits with you. 


\section{GENERAL INFORMATION}

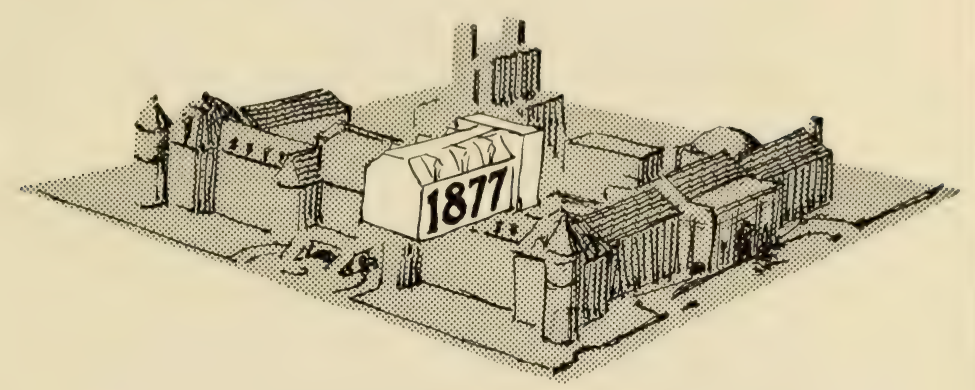

The American Museum of Natural History is located in Manhattan Square and occupies most of the space between Central Park West, Columbus Avenue, 77 th Street, and 81 st Street. The main entrances are on Central Park West, through the Roosevelt Memorial, at three levels: street, vehicle (driveway under the steps) and subway. There is also an entrance on West 77 th Street (foot and vehicle) in the center of the block.

The Planetarium may be entered from West 81 st Street (foot and vehicle) and through the Museum. Cars may be parked at the curb on the streets surrounding the Museum Square.

\section{ADMISSION}

There is no charge for admission except to The American Muscum Hayden Planetarium. The Museum is open to the public from 10:00 A.M. to 5:00 P.M. daily except Sundays, Thanksgiving Day, Christmas, New Year's Day and July 4th, when it opens from 1:00 P.M. to 5:00 P.M.

\section{MEMBERSHIP}

There are about 37 thousand members of the American Museum of Natural History who believe that the Museum is doing a useful service to science and to education and who are contributing to this work. Through its explorations the Museum brings together rare and valuable collections from all over the world. It makes these wonders of nature easily available through its exhibition halls, its lectures, its work with school children, and its publications. The continuance and growth of this work is, in large measure, dependent upon the contributions of friends.

The Trustees invite you to lend your support by becoming a member.

Membership blanks may be obtained at the information desks, in 
the American Museum Shop, or by dropping a postcard to the Membership Secretary, The American Muscum of Natural History. Central Park West at 79th Street, New York 24, N. Y.

Memberships may start at any time. Associate, Annual, Sustaining, Contributing and supporting memberships continue for a full vear's period from the date annual dues are paid. Iife and higher class memberships are valid throughout the lifetime of the member.

The various classes of membership, with the dues payable by and the privileges accorded to each class, are as follows:

\begin{tabular}{|c|c|c|}
\hline Class & Dues & Privileges \\
\hline Associate & $\$ 5$ yearly & 1 through 5 \\
\hline Annual & 15 yearly & $\begin{array}{l}1 \text { through } 6 \text { plus } \\
\text { choice of } 7 \text { or } 8\end{array}$ \\
\hline Sustaining & 25 yearly & 1 through 8 \\
\hline Contributing & 50 yearly & 1 through 8 \\
\hline Supporting & 100 yearly & 1 through 8 \\
\hline Life & 300 & 1 through 10 \\
\hline Associate Patron & 1,000 & 1 through 10 \\
\hline Patron & 5,000 & 1 through 10 \\
\hline Associate Benefactor & 10,000 & 1 through 10 \\
\hline Associate Founder & 25,000 & 1 through 10 \\
\hline Benefactor & 50,000 & 1 through 10 \\
\hline Founder & 100,000 & 1 through 10 \\
\hline
\end{tabular}

\section{Privileges}

1. A Membership Card.

2. A year's subscription to Natural History magazine.

3. Ten per cent discount on all books on sale in the American Museum Shop.

4. Admission to the Members' Room.

5. A copy of the President's Annual Report on request (Life and higher class members receive the Annual Report automatically).

6. Two admissions vearly to performances of the American MuseumHayden Planetarium.

7. Admission to all Members Lectures (10 or more annually), with guest tickets permitting members to invite one guest to each lecture.

8. Admission to all Lectures in the Adventure Series for children of members (10 or more ammually). with two guest tickets for each lecture.

9. A handsomely congraved Certificate of Membership. suitable for framing.

10. Admission to special staff functions arranged for higher class members. 
HOW TO REACH THE MUSEUM

By Bus: Eighth Arenue or Columbus Avenue Bus to 77 th Street. 79th Street Crosstown Bus to 81st Street and Central Park West.

By Subway: Broadway-Seventh Avenue Line to 79th Street and Broadway Station (local stop). Walk two blocks east to Columbus Avenue and 77 th Street.

Sixth and Eighth Avenue Lines to 81st Street Station (local stop).

Lexington Avenue Line to 77 th Street Station (local stop), then Crosstown Bus from East 79th Street directly to 81st Street and Central Park West.

Groups coming by bus should direct the bus driver to let them out at the 77 th Street entrance. Busses can be parked in the area next to the American Museum-Hayden Planetarium. When leaving, busses should pick up their groups at the 77 th Street entrance.

Visitors arriving in private cars may park in the area next to the American Museum-Hayden Planetarium. There is room for about one hundred and fifty cars.

\section{CHECK ROOMS AND GUEST SERVICES - INFORMATION DESKS}

The main check room is on the right as one enters the main entrance on the first floor of the Roosevelt Memorial (driveway under the steps). Coats and packages may be left here. Wheel chairs are available free of charge. There is also a check room at the left of the 77 th Street entrance. There is no charge for checking.

Information desks are located on the main (second) floor of the Roosevelt Memorial, in the 77 th Street foyer, and facing the entrance to the Eighth Avenue Subway.

\section{THE AMERICAN MUSEUM SHOP}

The entrance to the American Museum Shop is near the 77 th Street entrance, next to the elevators. Unusual gifts from all over the world authentic examples of native handicraft, pottery, masks, Indian silver jewelry, dolls and carved objects - are on display. Specimens for the shell and mineral collector are kept in stock. A representative list of books, covering the many fields of the natural sciences, is also available.

\section{FLOOR PLANS}

Pictorial plans of the Museum exhibits are posted near the elevators and at convenient points throughout the Museum to guide visitors to the various halls. Also see the next four pages. 

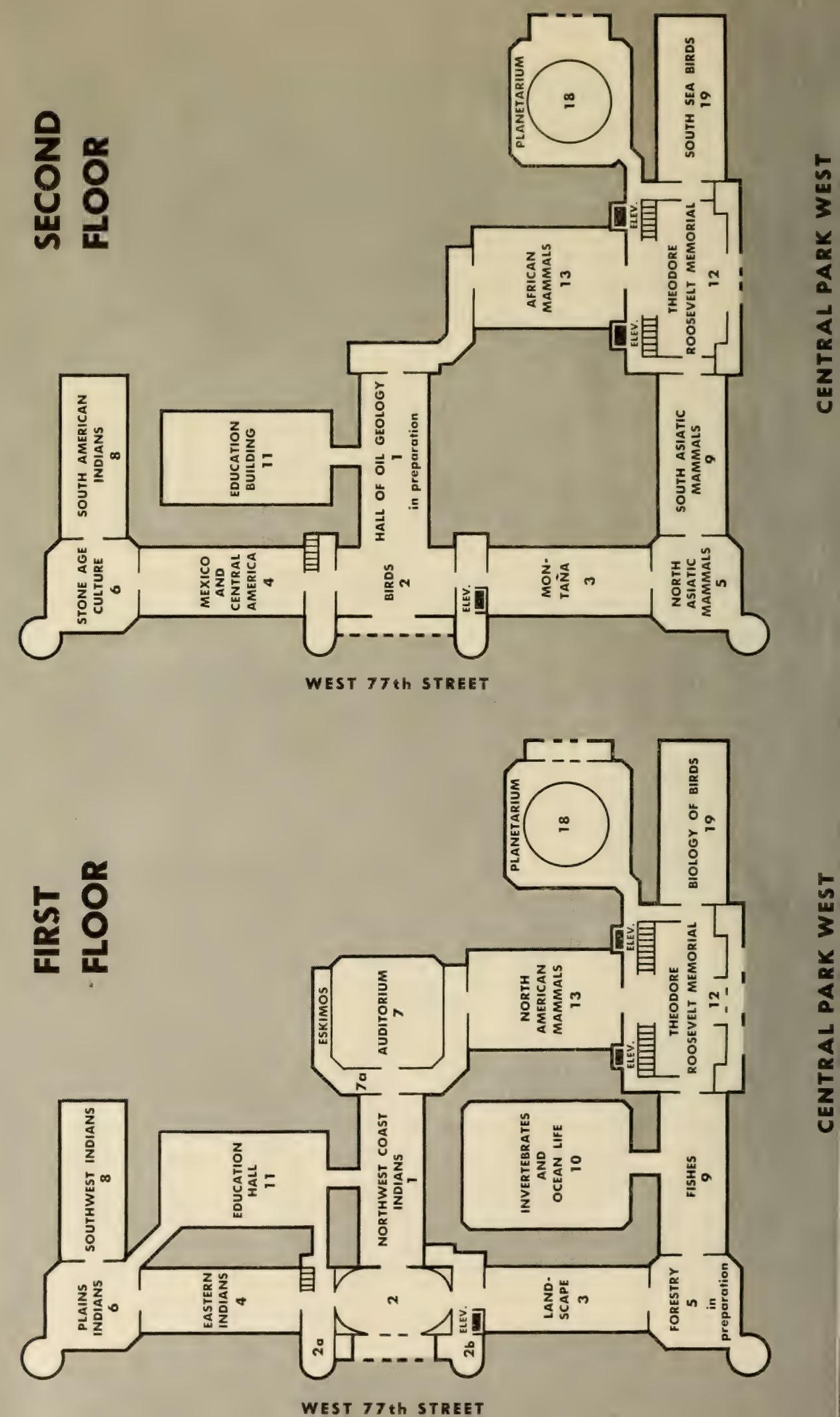


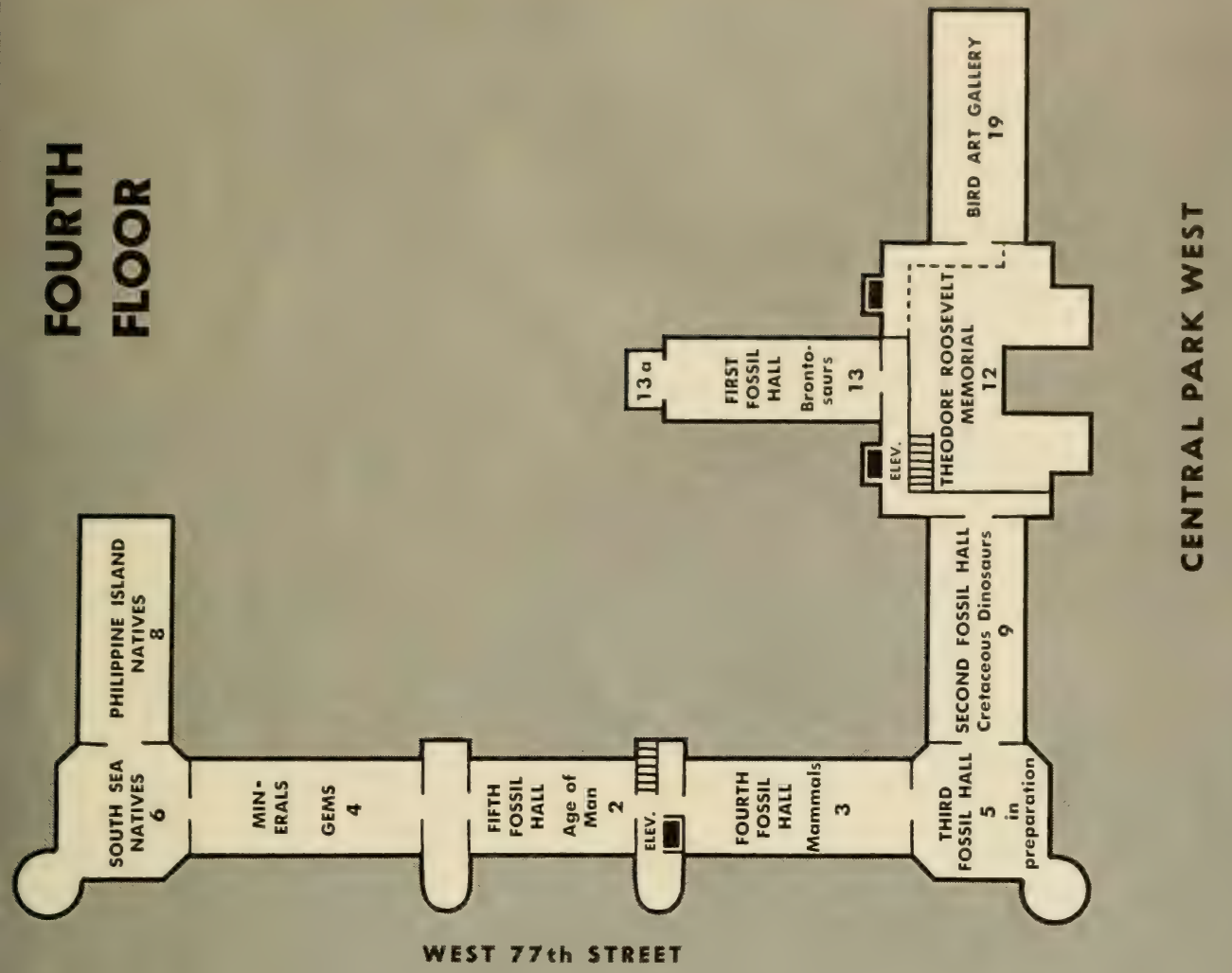

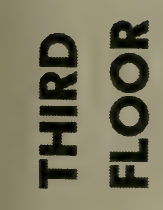

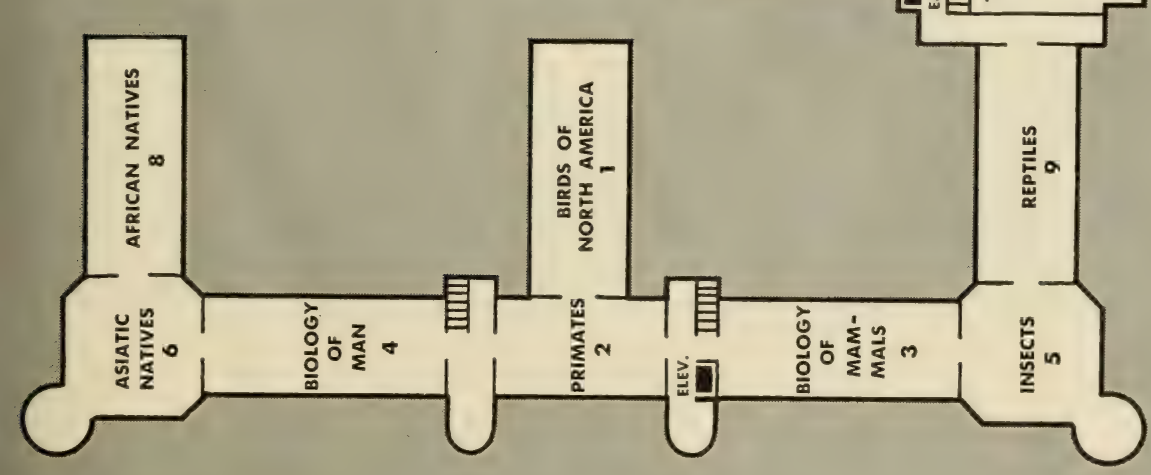

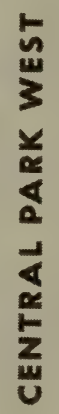




\section{LOCATIONS OF EXHIBITS AND SERVICES}

AFRICAN MAMMALS. 2nd \& 3rd Floors, Halls 13.

AFRICAN NATIVES. 3rd Floor, Hall 8.

AMERICAN MUSEUM-HAYDEN PLANETARIUM. 1st Floor, Hall 18. (Main entrance from 81 st St.).

AMPHIBIANS (FOSSIL). 4th Floor, Hall 13.

AMPHIBIANS AND REPTILES (LIVING). 3rd Floor, Hall 9.

ANTHROPOLOGY.

African Natives: 3rd Floor, Hall 8.

Age of Man: 4th Floor, Hall 2.

Asiatic Natives: 3rd Floor, Hall 6.

Biology of Man: 3rd Floor, Hall 4.

Eskimo: 1st Floor, Hall 7a.

Indians of North America: 1st Floor, Halls 1, 4, 6 and 8.

Indians of Mexico \& Cent. America: 2nd Floor, Hall 4.

Indians of South America: 2nd Floor, Hall 8.

New Zealand Natives: 4th Floor, Hall 8.

Philippine Natives: 4th Floor, Hall 8.

South Sea Natives: 4th Floor, Hall 6.

Southeast Asia Natives: 4th Floor, Hall 8.

Stone Age Culture: 2nd Floor, Hall 6.

Tibetan Exhibit: 3rd Floor, Hall 6.

ARCHAEOLOGY. 2nd Floor, Halls 4,6 and 8.

ASIATIC MAMMALS. 2nd Floor, Halls 5 and 9.

ASIATIC NATIVES. 3rd Floor, Hall 6.

AUDITORIUM. 1st Floor, Hall 7.

BIRDS (FOSSIL). 1st Floor, Hall 19.

BIRDS (LIVING).

Biology of Birds: 1st Floor, Hall 19.

Birds of North America: 3rd Floor, Hall 1.

Birds of the World: 2nd Floor, Hall 2.

Local Birds: 1st Floor, Hall 12.

Pacific Bird Life: 2nd Floor, Hall 19.

BUtTERFLIES. 3rd Floor, Halls 3 and 5.

CAFETERIA. Basement, Hall 12. For teachers and children, Basement, Hall 11. See also Snack Bar.

CONSERVATION. Ist Floor, Halls 3 and 5 .

CORNER GALLERY. 2nd Floor, Hall 5.

DINOSAURS. 4th Floor, Halls 9, 12 and 13.

DRUMMOND COLLECTION OF JADE. 4th Floor, Hall 6.

DUPLEX HALL. 2nd Floor, Hall 11.

ECOLOGY. 1st Floor, Hall 3 and 5.

EDUCATION HALL. 1st Floor, Hall 11.

ELEVATORS. Halls 2 and 12.

ESKIMO. 1st Floor, Hall 7a.

FISHES (FOSSIL). 4th Floor, Halls 5 and $13 a$.

FISHES (LIVING). 1st Floor, Hall 9.

FORESTS. 1st Floor, Hall 5.

GEMS AND MINERALS. 4th Floor, Hall 4.

GEOLOGY OF DUTCHESS COUNTY. 1st Floor, Hall 3.

HAYDEN PLANETARIUM. 1st Floor, Hall 18. (Main entrance from 81 st St.).

INDIANS OF MEXICO \& CENTRAL AMERICA. 2nd Floor, Hall 4.

INDIANS OF NORTH AMERICA. 1st Floor, Halls 1, 4, 6 and 8.

INDIANS OF SOUTH AMERICA. 2nd Floor, Hall 8.

INFORMATION DESKS. Basement, Hall 12; 1st Floor, Hall 2;

2nd Floor, Hall 12; and by all elevators, Halls 2 and 12.

INVERTEBRATES (FOSSIL). In preparation. 
INVERTEBRATES (LIVING). 1st Floor, Hall 10.

INSECTS AND SPIDERS. 3rd Floor, Halls 3 and 5; 1st Floor, Hall 12.

JADE, DRUMMOND COLLECTION OF. 4th Floor, Hall 6.

LANDSCAPE HALL. 1st Floor, Hall 3.

LECTURE AND MEETING ROOMS.

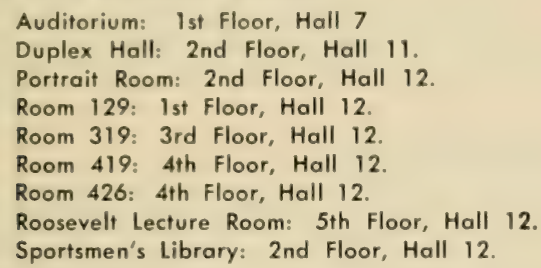

LIBRARY. 5th Floor, Hall 2.

MAMMALS (FOSSIL). 4th Floor, Halls 2, 3 and 5.

MAMMALS (LIVING).

African: 2nd and 3rd Floors, Hall 13.

Asiatic: 2nd Floor, Halls 5 and 9.

Biology of Mammals: 3rd Floor, Hall 3.

Hall of Ocean Life: Ist Floor, Hall 10.

New York State: 1st Floor, Hall 12.

North American: 1st Floor, Hall 13.

Primates: 3rd Floor, Hall 2.

MAN.

Age of: 4th Floor, Hall 2.

Biology of: 3rd Floor, Hall 4.

Origin of: 4th Floor, Hall 2; 3rd Floor, Hall 4.

MEXICAN \& CENTRAL AMERICAN ARCHAEOLOGY. 2nd Floor, Hall 4.

MINERALS AND GEMS. 4th Floor, Hall 4.

MONTAÑA, MEN OF THE. 2nd Floor, Hall 3.

MUSEUM SHOP. 1st Floor, Hall $2 b$.

NEW ZEALAND NATIVES. 4th Floor, Hall 8.

NORTH AMERICAN MAMMALS. Ist Floor, Hall 13.

OCEAN LIFE, HALL OF. 1st Floor, Hall 10.

PACIFIC BIRD LIFE. 2nd Floor, Hall 19.

PHILIPPINE NATIVES. 4th Floor, Hall 8.

Planetarium. 1st Floor, Mall 18. (Main entrance from 81st St.).

PLANT COMMUNITIES. Ist Floor, Halls 3 and 5.

POLAR EXPLORATION. Ist Floor, Hall 2.

PRIMATES. 3rd Floor, Hall 2.

PUBLIC INSTRUCTION. 3rd Floor, Hall 11. (And Basement).

REPTILES (FOSSIL). 4th Floor, Halls 5, 9, 12 and 13.

REPTILES (LIVING). 3rd Floor, Hall 9; 1st Floor, Hall 12.

SCHOOL SERVICE. 3rd and 4th Floors, Hall 11. (And Basement).

SHOP. 1st Floor, Hall $2 b$.

SNACK BAR. 2nd Floor, Hall 2.

SOUTH AMERICAN INDIANS \& ARCHAEOLOGY. 2nd Floor, Hall 8.

SOUTH SEA NATIVES. 4th Floor, Hall 6.

SOUTHEAST ASIA NATIVES. 4th Floor, Hall 8.

SPIDERS. 3rd Floor, Hall 5.

SUBWAY. Basement, Hall 12.

THEODORE ROOSEVELT MEMORABILIA. 2nd Floor, Hall 12.

THEODORE ROOSEVELT MEMORIAL. 1st to 5th Floors, Hall 12.

TIBETAN EXHIBIT. 3rd Floor, Hall 6.

WHALE MODEL (LIFE SIZE). 3rd Floor, Hall 3. 


\section{SKETCHING AND PHOTOGRAPHING}

Chairs for artists and students who wish to draw from exhibits may be had by asking the nearest attendant. Amateur photographers may get permission from any information desk to take pictures in the Museum halls. Professional photographers may get permission from the Division of Photography. The use of a tripod and careful exposure with a light meter is recommended for most Museum photography.

\section{GUIDING}

Free Guiding Service: In addition to the regularly scheduled educational programs of the Department of Public Instruction, free guiding is given to Members of the Museum and their friends, upon presentation of Members' tickets. An appointment should be made at least two weeks in advance, stating the day and hour desired, the number to be guided and any special exhibits to be seen.

Paid Guiding Service: This is available for non-members of the Museum according to the following schedule:

$\begin{array}{cc}1-4 & \text { persons } \\ 4-9 & \text { persons } \\ & \\ 10-30 & \text { persons } \\ 30-60 & \text { persons } \\ & \\ 60-90 & \text { persons }\end{array}$

minimum charge $\$ 2$ per hour

$\$ 2$ per hour plus $50 \phi$ each additional person up to and including 9 persons $\$ 5$ per hour

$\$ 10$ per hour (services of 2 Museum instructors)

$\$ 15$ per hour (services of 3 Museum instructors)

Guiding is available on weekdays after 2 P.M. There is no guiding on Saturdays, Sundays and holidays. For appointments call TRafalgar 3-1300, Extension 255.

\section{CAFETERIAS}

The Main Cafeteria is convenient to the subway entrance in the Roosevelt Memorial. It is open from 11:30 A.M. to 4:30 P.M. daily and from 1:00 P.M. to 4:30 P.M. on Sundays. It is closed on the following holidays: Christmas Day, New Year's Day and Thanksgiving Day.

On Saturdays, Sundays and holidays, except those mentioned above, the Auxiliary Cafeteria on the second floor, above the 77 th Street Entrance, is open as a snack bar from 1:30 P.M. to 4:30 P.M.

\section{THE LIBRARY}

The Library is on the fifth floor of the Museum. It is devoted to works on natural science, exploration and travel and contains some 145,000 volumes which comprise not only the important periodicals of our own and foreign countries but also all representative and standard works on zoology, physical anthropology, ethnology, pre-history, archae- 
ology. geology, and paleontology. The collection on vertebrate paleontology forms the Osborn Library of Vertebrate Paleontology, founded by President Henry Fairfield Osborn.

The Reading Room of the Library is open to the public from 10:00 A.M. until 4:00 P.M., except on Sundays and holidays. The I ibrary is also closed on Saturdars from June to September. Those interested in consulting books and periodicals are welcome to do so during the arailable hours.

\section{PUBLICATIONS}

The publications of the American Nuscum fall into two groups: technical and popular.

The technical publications, comprising the Bulletin, Anthropological Papers, Memoirs and American Muscum Norilates, contain information gathered by the various expeditions or derived from the study of material collected. The Bulletin contains the larger sciontific papers, covering records of exploration and collections of the Museum. The Anthropological Papers are deroted to researches in the study of man, supervised by the Museum's Department of Anthropology. The Memoirs, quarto in size, contain monographs, many of which require large illustrations. The Noritates include the shorter scientific contributions, descriptions of species, etc., which demand immediate publication. The scientific publications are distributed to libraries of scientific institutions and societies throughout the world, largely on an exchange basis. Inquiries may be directed to Editor - Scientific Publications.

The popular publications include Natural History magazine, Junior Natural History (a children's magazine), and Man and Nature Publications. The purpose of all these publications is to give the public accurate and interesting information in all fields of natural science.

Man and Nature Publications deal with exhibits of particular interest and with the many natural science ficlds, edited for reading by the layman. More than 140 of these booklets, guides and leaflets have been issued and new ones are constantly in preparation. The Handbooks, fifteen of which have been issued, deal with themes related to the collections and are frequently used as textbooks.

A catalogue of the popular publications of The American Museum of Natural History will be sent free on request. (Address: Man and Nature Publications, The American Museum of Natural History, Central Park West at 79th Street, New York 24, N. Y.)

An Annual Report is issued yearly.

\section{THE HISTORY AND WORK OF THE MUSEUM}

The American Museum of Natural History was founded and incorporated in 1869 for the purpose of establishing a Museum and Library of Natural History; of encouraging and developing the study of Natural Science; of advancing the general knowledge of kindred subjects and of furnishing popular instruction. For eight years its home was in the Arsenal in Central Park. 
The comerstone of the present building in Manhattan Square was laid in 187.4 he President Ulysses S. Grant. In 187\%, the first section (South Central Wing) was completed and on December 22nd, 1877. it was formally opened by President Rutherford B. Haves.

The educational work with the schools was begun in 1880 by Professor Albert Bickmore.

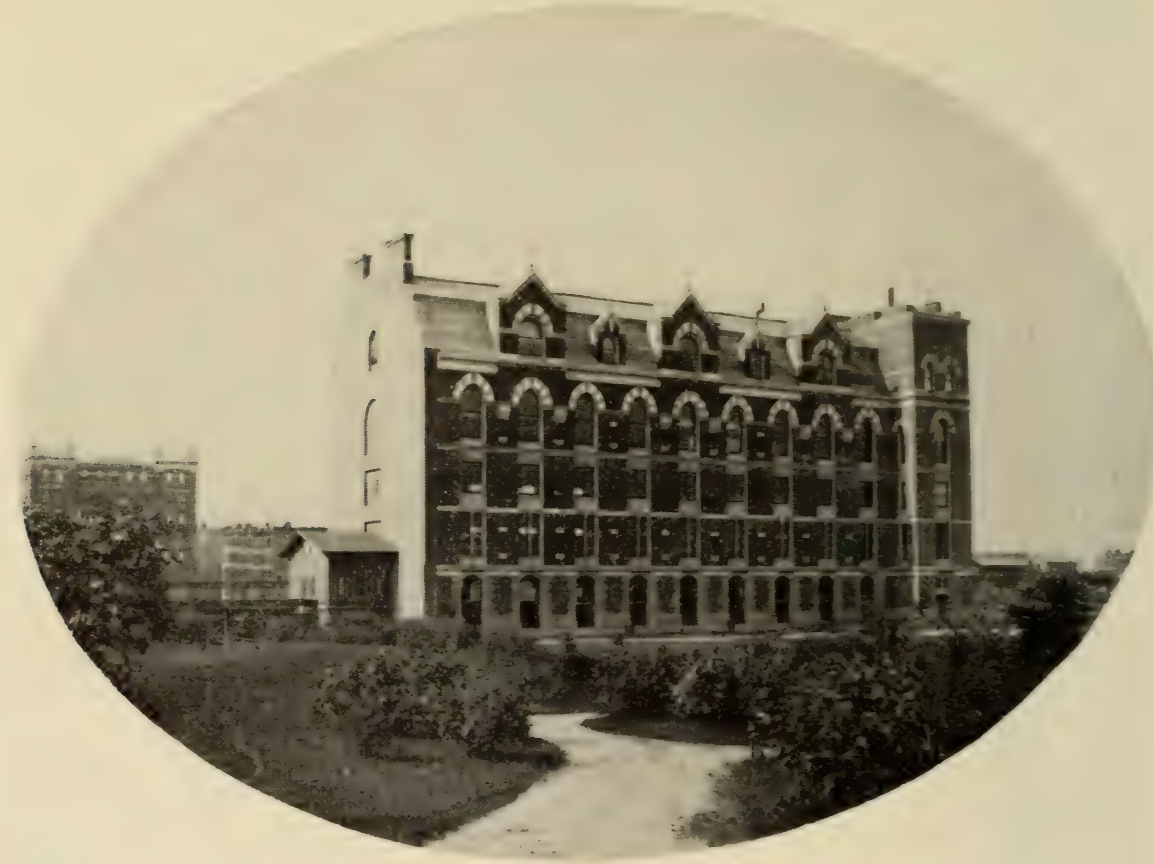

THE MUSEUM'S FIRST UNIT, COMPLETED IN 1877.

The Museum building is onc of the largest municipal structures in the Cits of New York. The South Facade is 710 feet in length and the present East Facade, on Central Park West, is 600 feet. When completed, the building is designed to occupy all of Manhattan square.

The building is largely erected and maintained by the City, through the Department of Parks. The Rooserelt Memorial section was the gift 10 the City by the State of New York as its monument to Theodore Roosevelt. The Whitney Wing was built jointly by the late Harry Payne Whitney and the City of New York. The American Museum-Hayden Planetarium was financed by funds loaned by the Reconstruction Finance Corporation of the Federal government. The annual City appropriation. known as the Maintenance Fund, is devoted to the care and upkeep of the building and the safeguarding of the collections. 
The Museum is under the control of a self-perpetuating Board of Trustees, which gives its services.

The scicutific and educational work is carried on by twelve departments. each headed by a Chairman or Curator, under the leadership) of the Director.

The funds through which specimens are purchased, exhibits made, explorations carried on and scientific investigations conducted are contributed by the Trustees, members and other friends. The scientific and popular publications of the Museum and the cnlargement of the Library are also made possible through these contributions.

For the benefit of the public, the halls of the Museum are given crer to the large series of exhibits which are partially described in this guide book. These are supplemented by lectures and publications of a popular nature. Special motion picture showings are given on W'ednesday and Saturday afternoons except from June through September. An important course of evening lectures is given every Spring and Fall for the members, also Saturday morning courses of special lectures for children of members. All lectures are illustrated by motion pictures or Kodachrome slides, many of which have been taken on Museum expeditions. Two auditoriums within the Museum are in use for public showings - the Main Auditorium on the first floor and the Roosevelt Lecture Room on the fifth floor of the Roosevelt Memorial.

\section{OFFICES AND LABORATORIES}

The fifth floor of the Museum houses administrative offices, work rooms and the laboratories of most of the Scientific Departments. On this floor are the work rooms of the Department of Vertebrate Paleontology, where the skeletons of fossil animals are prepared and mounted and the beautiful models of invertebrates are made. These, like the other laboratories, are, of necessity, not open to the public.

On the sixth floor of the African section are the well-equipped laboratories devoted to experimental biological research and to physiology and life histories based on the study of living animals.

Most of the scientific study collections are on the fifth floor. These are for the benefit of investigators and to preserve the evidences and records of our vanishing animal life and the lives and customs of primitive peoples.

The vast majority of the Museum's natural science specimens is in study collections to protect them from damage and for ready use by scientific investigators. A careful selection is made of objects of greatest educational value and these form the basis of the Museum di plays in its exhibition halls.

\section{The Lerner Marine Laboratory}

The Lerner Marine Laboratory was established in 1947 by Mr. Michael Lerner to further field studies in marine biology through the 
Department of Fishes and Aquatic Biology. Iocated on the island of Bimini, almost sixty miles due east of Miami, Florida, the laboratory occupies about two and one-third acres on which are the laboratory building, a residence for workers, a storchouse and a power house.

The laboratory building contains four laboratories, a study, two combined aquarium and lab rooms, an animal room a refrigerator room, a constant temperature room and a photographic dark room. Glass bottomed boats, diving equipment, seines and nets and other facilities are available for researchers. A limited number of applications are accepted yearly by the Museum for workers who wish to use the laboratory facilities.

\section{Genetics Laboratory}

Another laboratory within the Museum is engaging in experiments on the hereditary patterns of tropical fish, the results of which are being used to determine the influence of heredity in cancer.

Fish-raising enthusiasts, familiar with the problems of cross-breeding Mexican platyfish and common swordtails, know that the spotted hybrids often develop tumors. Experiments have been going on for over twentyfive years to find the source of these tumors.

When two pure strains of the platy were bred - one with black pigmented spots and the other unspotted - the first-generation platyfish would necessarily be spotted. The spotted pattern is a dominant trait and the unspotted pattern recessive. The black spots are inherited in accordance with Mendel's law of heredity. A cross-bred hybrid from an unspotted platy of the second generation and an unspotted swordtail is unspotted and normal.

When a spotted platy is crossed with an unspotted swordtail, the hybrids have tumors identified as black cancer or melanoma. The findings show that the swordtails carry dominant modifying genes which interact with the blackspot-carrying genes of the platy, so that the black cells of the hybrid develop cancer.

The next experiments were made with one species, the platy, and proved that black cancer in fish is hereditary. The facts derived from such experiments are being used to determine a possible basis for control of those types of cancer that are inherited in man.

The laboratory for this research is housed in the American Museum and is directed by the geneticist of the New York Zoological Society and supported by a grant from the National Cancer Institute of the U. S. Public Health Service.

\section{WORKSHOPS}

An important part of the Museum not seen by the public are the workshops in the basement of the building. Provided with machinery of the latest pattern, workmen make the various types of cases used, build and repair the Museum's furniture and make required installations for the exhibition halls. 


\section{ENTERING THE MUSEUM}

Fifty-eight halls of the Musem are now open to public exhibition. The visitor begins his trip through this immense treasure house of natual science from one of three directions: through the Rooscredt Memorial (page 3), through the American Muscum-Hayden Planctarium (page 3), or through the South, or 77 th Street Entrance.

\section{The Theodore Roosevelt Memorial}

The Theodore Roosevelt Memorial forms the main entrance to the Musem on Central Park West. Its graceful architecture follow's a statcly Romanesque design.

The facade of the Memorial is set off by four Ionic columms 54 feet high, representing Boone, Audubon, Clark and Lewis, pioncers in the early exploration of our country. A massive equestrian bronze of Theodore Roosevelt by J. E. Fraiser, stands before the entrance arch. On either side of him stand an American Indian and an African native.

Passing through the central archway, the visitor stands in the great Memorial Hall. Above the marble mosaic floor, walls of cream-colored marble and limestone rise to an elaborate Corinthian cornice over-arched by an octagonal coffered barrel-vault 100 feet above the floor. The

THE THEODORE ROOSEVELT MEMORIAL HALL.

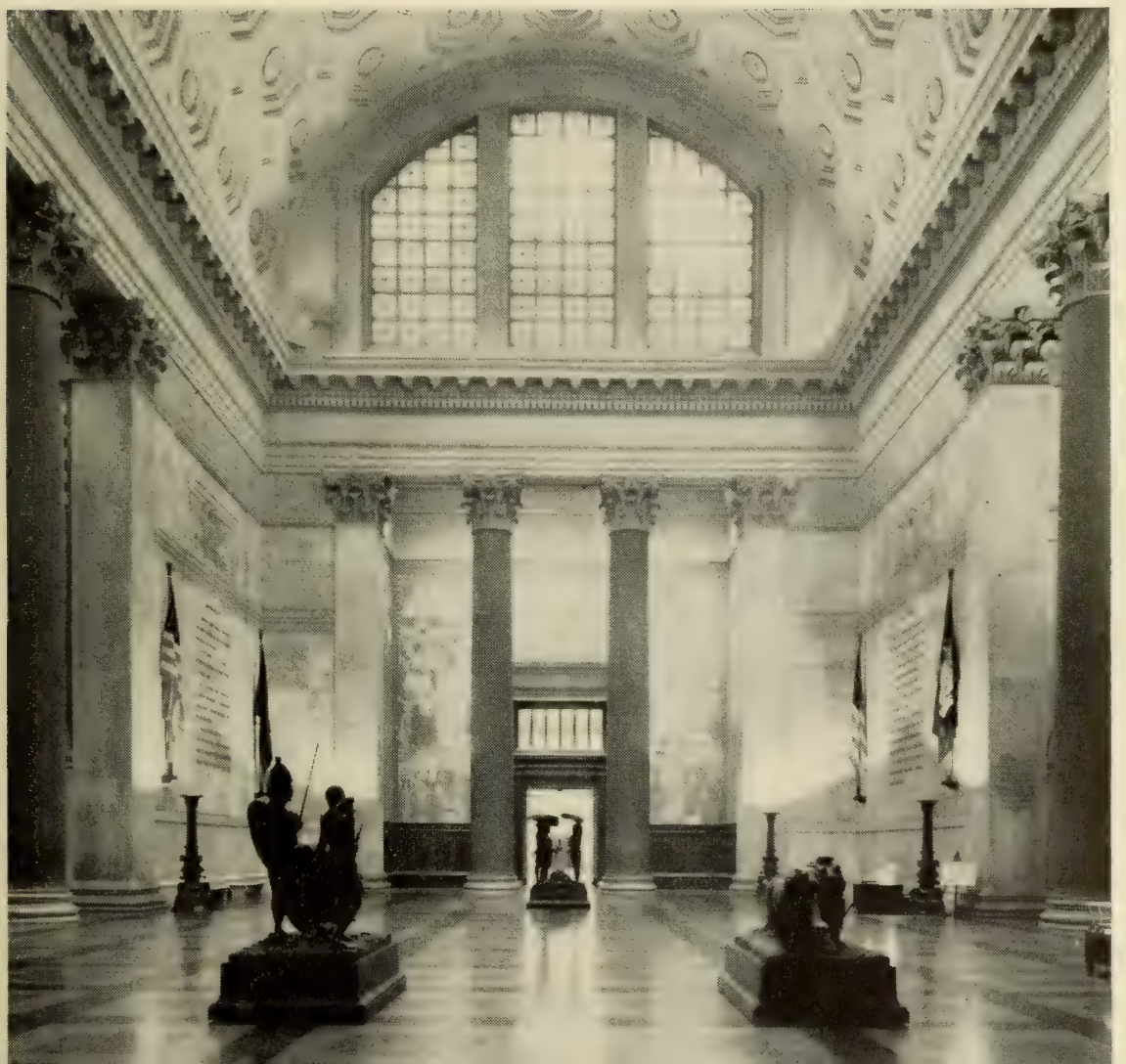


central part of each wall is recessed and divided into three parts by two Roman Corinthian columns 48 feet high supporting the entablature. Three of these recesses are adorned with great mural paintings symbolic of the varied career of Theodore Roosevelt. On the wall, quotations from his writings are given in bronze letters.

The Theodore Roosevelt Memorial was erected by the people of the State of New York in memory of the man whose name it bears.

\section{South Entrance Archway}

Under the arch on 77 th Street, before entering the Museum doorway, may be seen the Bench Mark established by the United States Geological Survey in 1911, on which are inscribed the latitude and longitude, $40^{\circ} 46^{\prime} 47.17^{\prime \prime} \mathrm{N}$., $73^{\circ} 58^{\prime} 41^{\prime \prime} \mathrm{W}$. and height above sea level, 86 feet.

On the right is a GLACIAL POT HOLE from Russell, St. Lawrence County, $\mathrm{N}$. Y., formed by an eddy in a stream beneath the melting ice of the glacier that once covered northern New York State. Pebbles, whirling around the eddy, cut and ground this hole which is two feet across and four feet deep.

GLACIAL GROOVES. On the left is a large slab of fossil-bearing limestone from Kelly Island in Lake Erie, near Sandusky, whose surface has been smoothed, grooved, and scratched by the stones and sand in the bottom of the vast moving ice sheet that covered northeastern North America during the Glacial Epoch.

On either side of the archway are the two largest beryl crystals ever quarried. They were cut in Albany, Maine. These six-sided crystals show the typical aquamarine color in their clearest portions.

\section{Memorial Hall}

Memorial Hall is entered through the lobby from the South Entrance. In this hall are placed temporary exhibits of current interest. Many of these exhibits represent research in various departments of the Museum and recent results of exploration by Museum expeditions.

\section{EXPLORATION AND GEOGRAPHY}

Exhibits showing equipment of polar expeditions made in cooperation with the Museum are located in the corridor leading to the elevators.

Here are sledges with which PEARY (1909) and AMUNDSEN (1911) reached the North and South Poles respectively; also souvenirs of the AMUNDSEN-ELLSWORTH expeditions of 1925 and 1926. Maps of the Polar Regions show the routes of various explorers and the polar air flights. 


\section{MUSEUM HIGH SPOTS}

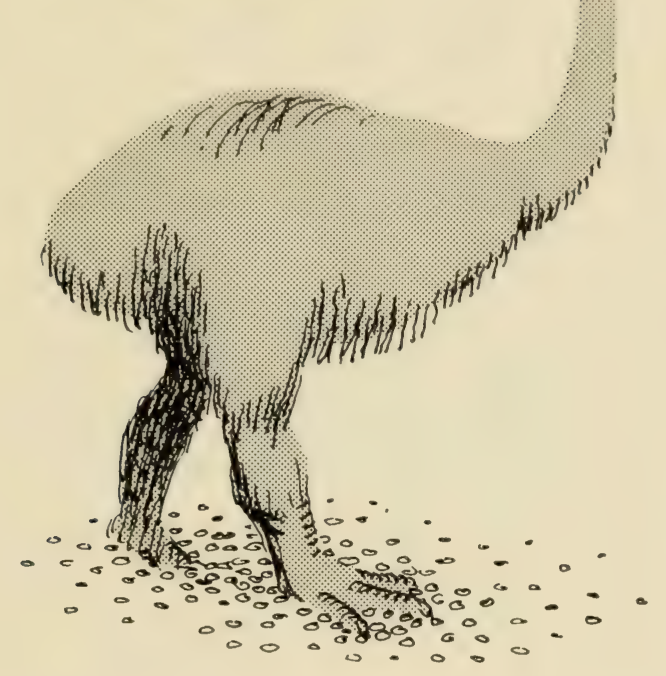

RARE AND EXTINCT BIRDS - including reconstruction of the Dodo and a skeleton of the Mammoth Moa - in the Leonard C. Sanford Hall of the Biology of Birds, 1st floor.

MOA-reconstruction of this giant extinct bird, New Zealand Noa group - Whitney Memorial Hall of South Pacific Birds, 2nd floor.

ALASKA BROWN BEAR - largest bear in the world - Hall of North American Mammals, 1st floor.

"AN OCTOBER AFTERNOON NEAR STISSING MOUNTAIN" strikingly realistic habitat group of the Pine Plains area of Dutchess County, N. Y. - Felix M. Warburg Memorial Hall, Ist floor.

METEORITES - one of the world's largest meteorites: the Ahnighito $361 / 2$ tons - brought from Greenland in 1897 by Admiral Peary American Museum-Hayden Planetarium, 1st floor.

DROP OF WATER - magnified a million times - depicted in a blownglass model - Hall of Living Invertebrates - Gallery of the Hall of Ocean Life, lst floor.

MEN OF THE MONTAÑA - the story of life in a Peruvian Rain Forest - authentic, recorded sound effects - Special Exhibition Hall, 2nd floor. 
I.IT ILE DIOMEDE AND BIG DIOMEDE - islands in Bering Strait International Bomdary Iine passes between them. Big I)iomede is Russian, Liule Diomede Imerican - South Sea Birds, 2nd floor.

AFRIC.IN ELEPH.INT HERI) - Akeley Ifrican Hall, 2nd floor.

SIONE HE ID OF OLMEC STYLE - Mexican and Central American Hall, 2nd floor.

THE "COPPER MAN" MUMMY AND SHRUNKEN HEADS - South American Indian Hall, 2nd floor.

MOIHS INI) BUTTERFLIES - from all parts of the world - Insect Hall, 3rd floor.

I)R. IGON LIZARDS OF KOMOIOO - the world's largest living lizards - Reptile Hall, 3rd floor.

IVORY COLLECTION - African Ethnolog! Hall, 3rd floor.

TYR.INNOSALRUS REX - king of dinosaurs - Cretaceous Dinosaur Hall, 4th floor.

BRONTOSAURUS - great plant-eating dinosaur - dinosaur footprints - Brontosaur Hall, 4th floor.

I)INOS.AUR EGGS - 60 MILLION YEARS OLD - from the Gobi Desert - Cretaceous Dinosaur Hall, 4th floor.

TOPAZ CRYST AL - 600 POUNDS - largest in the world - Morgan Hall of Minerals and Gems, 4th floor.

WILD DOG GROUP - a hunting pack of African wild dogs looking across the plains - Akeley African Hall gallery, 3rd floor.

\section{MUSEUM FACTS}

The gross area of the American Museum is approximately 40 acres; of this, 23 acres are open to the public.

i,022,000 square feet of floor must be cleaned. It takes 125 men to do the job.

Electric mopping machines soap the floor, scrub it, rinse it and dry it. One mopping machine does the work of eight men.

There are 58 halls open to the public, with a total of 2.302 exhibit cases.

The arerage exhibit case contains 68 square feet of glass. If all the glass in all the cascs were spread out flat, it would cover an area of $31 / 2$ acres. It takes two men to change the 31.000 light bulbs in use in the Museum. The Museum contains 348 rooms. including offices, shops, meeting places, work rooms and laboratories. 


\section{PUBLIC INSTRUCTION}

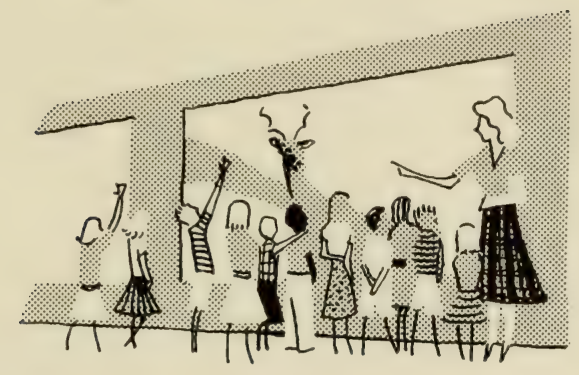

The week-day visitor to the American Museum will see eager groups of children standing with an instructor before various exhibits. Some of these groups may be classes with their own teachers but most of them will be part of the Department of Public Instruction's "World We Live In" program, designed for children of elementary school grades. Subjects or "themes" have been cooperatively planned with the school authorities.

The program, scheduled for each school day from 10:00 A.M. to 2:00 P.M., gives the children a complete day in the Museum, with subjects and teaching aimed at helping them to a more meaningful understanding of the world in which they live.

This is done with motion pictures, lessons in the halls, question and answer periods, physical demonstrations of principles or facts to be stressed and the actual handling of objects of natural science interest. If a group is studying Pan-America, for example, the children watch movies about Mexico, listen to Mexican music and even wear Mexican costumes and take part in dancing.

Special attention is given to classes or groups of children with visual and other physical handicaps. For full information, write or phone the Registrar, Department of Public Instruction, The American Museum of Natural History, New York 24, N. Y., Telephone, TRafalgar 3-1300, Extension 255. 


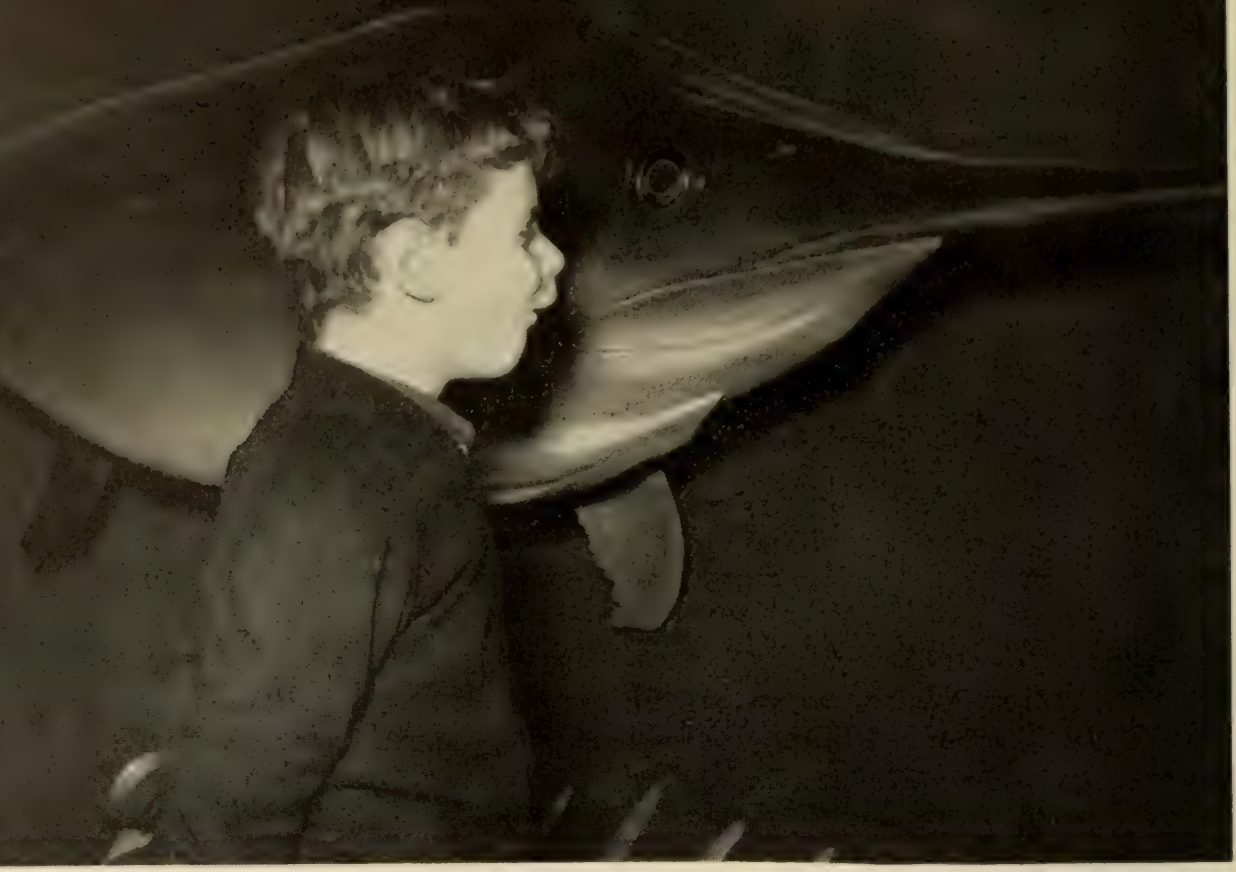

LITTLE BOY WITH SWORDFISH.

SCHOOL CLASSES VISITING THE MUSEUM. Cooperating with the school authorities, the Museum offers a planned, full-day teaching program for school classes. The scene below, in the Museum's auditorium, shows a part of this program.

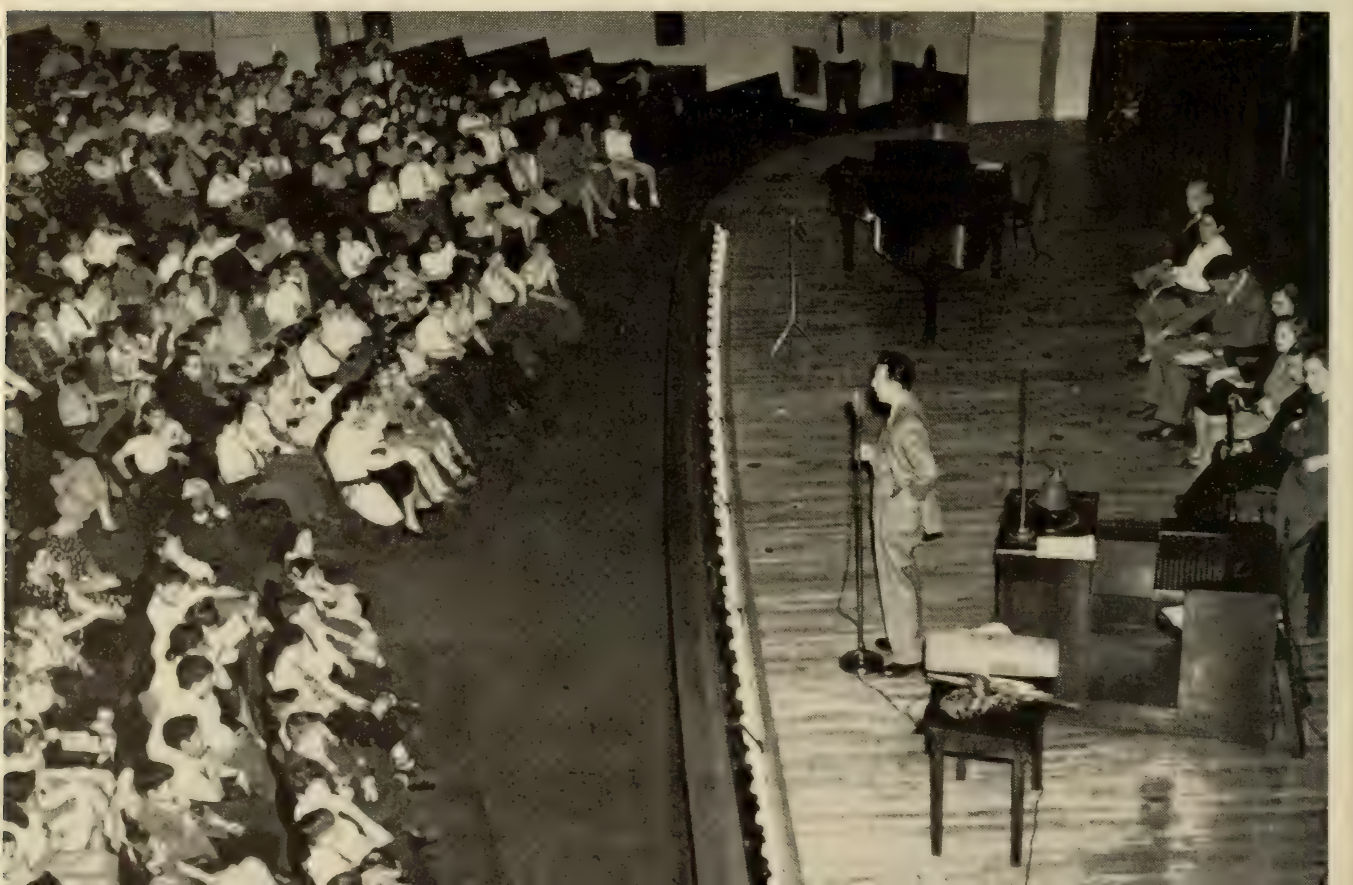




\section{TEACHERS' COURSES}

Each semester as many as five different courses for teachers-in-service are offered by the Department. These courses, designed to improve the educational use of Museum resources by (ity teachers, are accredited by the College of the Cits of New York and Hunter College and are approved In-Service courses of the Superintendent of Schools. For full information, write the Registrar.

\section{NATURAL SCIENCE FOR THE LAYMAN}

This course is given each semester and is a series of field trips to nearby localities. It gives adults a chance to become acquainted with plant and animal life and the important Man-Nature relationships. Service charge for the course is $\$ 1.00$ per trip for non-Members and $\$ .75$ for Museum Members. For complete information, write or phone Miss Farida A. Wiley, Department of Public Instruction.

\section{CAMP NATURE COUNSELLOR'S COURSE}

This course is given each spring to increase the efficiency of group nature work in summer camps. Service charge is $\$ 10.00$. Write or phone the Registrar.

\section{STORY HOUR CLUB FOR PRE-SCHOOL CHILDREN}

The Story Hour Club, offered several times each year, introduces pre-school children from $31 / 2$ to 5 years of age to natural science and museums. Visits to exhibition halls are held in conjunction with the telling of stories concerned with natural science. The service charge is $\$ 5.00$ per series of ten story-hour sessions. For further information write or phone Miss Marguerite Ross, Department of Public Instruction.

\section{FREE MOTION PICTURE PROGRAMS}

Museum visitors are invited to attend free motion picture programs on natural science subjects. The Wednesday series runs throughout the year and begins at 3:30 P.M. The Saturday series is from October to May and begins at 2:00 P.M

\section{INDOOR TRAILS}

Young visitors may get more than twelve different Indoor Trails at information desks. These question-and-answer games, to be played in the halls, are well-illustrated and contain much accurate scientific information. The Trails, pencil included, are for sale at a modest price. Answers may be checked at the information desks.

\section{DIVISION OF CIRCULATING EXHIBITS}

This collection of educational exhibits and specimens in the field of natural science is carried to schools for classroom use. Materials are 
selected to meet subject requirements in science. social studies and related subjects. A fleet of Museum trucks services the schools on a regular schedule. For full information, wite or phone the Supervisor of Circulating Exhibits.

\section{ADVISORY SERVICES}

On request. the Department provides advisory services on the educational use of museum resources. A model Nature Room is kept for the benefit of interested persons who wish to start one of their own in the classroom or in a small museum. This room is not open to the general public but may be seen, on advance request, on schoolday afternoons, after 2:00 P.M.

From a one-man lecture service, begun in 1884 by Albert S. Bickmore, the Department has expanded until over $10.000,000$ persons are reached each year by its programs and services. 


\section{MAKING THE EXHIBITION HALL}

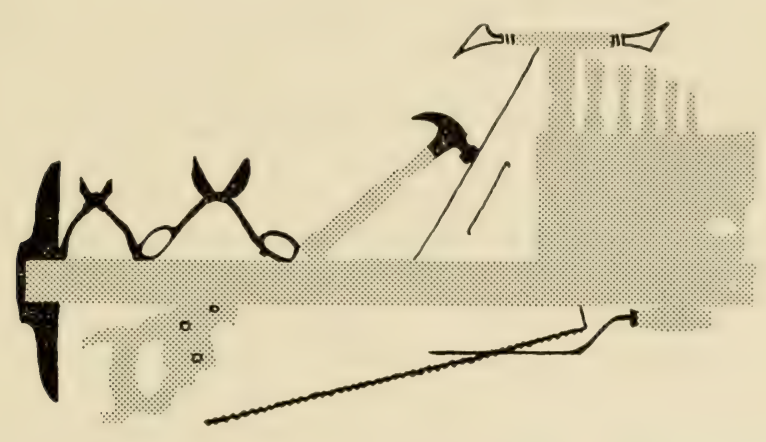

The construction of the beautiful exhibits in The American Museum of Natural History is, in itself, as interesting as the viewing of them by the more than two million persons who visit the Museum annually. At the request of many visitors, we have included in the General Guide just what goes on before an exhibition hall is open to the public.

We will take the Felix M. Warburg Memorial Hall as an example. This hall depicts an area from early ages to the present, with all the interrelationships of environment, plant, animal and human life. Its method of presentation is a radical departure from the hitherto accepted method of museum exhibition.

First, the basic idea of the Hall is outlined in synopsis form. It is the complete story which the Hall will convey that the scientists think ought to be included in it, together with the emphasis they want made in the displays.

A committee of the Director, Board members, scientists and educational advisers studies the synopsis and passes on it. A lively discussion determines what can be added to make the exhibition as valuable as possible. The committee also decides on the location of the new Hall.

After the idea and the location are approved, the synopsis is analyzed from a display angle and the Assistant Director for Program Administration, together with his designers, draws up plans for the exhibits which are then submitted to the Director and his committee for approval. When the necessary funds are found, the work begins.

Metal workers, masons, electricians, carpenters and painters build the structures that will house the habitat groups, dioramas, models and 
other kinds of display and the Department of Exhibition is working on the exhibits themselves.

As you enter the Warburg Memorial Hall from the 77th Street Foyer, you will note a large, eye-catching exhibit entitled "An October Afternoon Near Stissing Mountain." It shows the brilliant autumn coloring typical of this region, together with some animals found there. As an example of the building of the larger group, let us see how it was made.

Using sketches and Kodachromes made at the scene, the artist roughs out his picture on the curved background. Because there are no corncrs, the visitor is given a feeling of depth, perspective and reality that is not possible with a flat painted surface. After the sketch is rendered in charcoal, the artist fixes it with a shellac spray. Then, with fine oil pigments, he paints in the background of the group. He may employ as many as thirteen shades of blue in painting a sky from the horizon to the zenith.

One of the artist's difficult jobs is to make it appear as though the foreground objects continue into the vertical background. You will notice that he places clumps of red-leaved sumac against the background, then paints more sumac as though it grew beyond the real plants. W'hen his careful color-matching and artistry are finished, the visitor has trouble telling where the foreground ends and the painted background begins.

If you look at the foreground, you will see that it is not flat, but rolling, as is the natural conformation of the land at this particular site near Stissing Mountain. This foreground, or terrain, is made by first determining the character of the actual ground, then cutting wooden forms or contours to match it. These forms are then covered with heary wire netting, then burlap and plaster-of-paris, strong enough to hold up the weight of the men who are working on the group. This foreground is the foundation for the earth, plant and animal life in the exhibit.

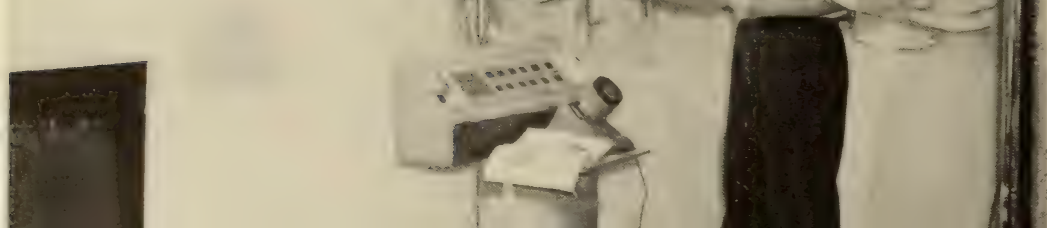


While construction work and background painting are going on, the Department of Exhibition has been making accessorics, exhibits, models and special eflects for the Hall. Accessories include artificial leaves and flowers, trees, bushes, manufactured rocks, fruits, berries, preserved plants and mosses. At the same time, preparators are tanning skins, getting them ready to be mounted.

Some plants can be used as they grow in nature. Members of the pine family, mosses, and grasses are soaked in a solution of formaldehyde and glverine. The glycerine prevents the plant from drying out and keeps it pliable. The formaldehvde preserves the material, but because it also tends to fade natural colors, the technicians must bring back the original hue by spraying with an air brush and lacquer of the right shade.

Clumps of grass are mounted on plaster-of-paris bases and sprayed with lacquer if the natural color is desired. In the group you may see some of this grass, each bunch standing close to the next, with earth patted down between the bases.

Most leaves are made by tracing the leaf pattern on a thick pad of crepe paper. The pattern is cut out with a fine-toothed band saw. Hundreds of leaves are turned out at one time by this method. An order may call for as many as ten thousand leaves. Each leaf must be handled separately after being cut out, as veins must be drawn or embossed, insect holes simulated and color applied to match the original. Even the midribs, of iron wire, are carefully tapered by dipping bundles of wire into nitric acid. The dripping-down of the acid thins the wires toward their ends.

Flowers may be molded from thin sheets of cellulose acetate, a noninflammable plastic material. The acetate sheets are "limped" in a solution of acetone, placed in the mold where they take form, are removed, trimmed and delicately painted by hand. Even the tiniest pistils and stamens are painstakingly made so that the flowers will be as botanically accurate as possible.

There are no artificial rocks in "An October Afternoon Near Stissing Mountain." Artificial rocks are used when the real ones would be too heary. Samples of real rocks and photographs of them help the technician to copy nature. He makes his rocks from wire netting, burlap, plasterof-paris, papier mache and coloring materials. Should he be required to produce a "wet" rock, he runs shellac or varnish down the side and lets it dry.

In the "October Afternoon" group, you can see a red fox looking at a bluejay sitting in a canoe birch. The fox and the bird, as well as other small animals shown in the Hall, are mounted by putting their skins on artificial bodies made of wrapped excelsior.

There are no animals in the Warburg Memorial Hall that are mounted on hollow manikins. But this is such an interesting process that we have included it in our description. First, it must be understood that the Museum animals are not stuffed. The larger ones are mounted 
on manikins, similar to those human forms found in the show windows of New York shops.

The manikin is begun by putting the animal's bones together on a wood and wire framework in the natural position desired, then patting sculptor's clay over the whole assembly. A statue is modelled by the sculptor. who is an expert animal anatomist. Making the statue is a long task and when the artist goes home at night or over the weekend, he wraps his work in woolen blankets, soaked with water. This keeps the clay fresh and impressionable. The statue is made as though the animal had just lost its skin - that is, the muscles, tendons, prominent veins and ribs are shaped in the clay so that they will show under the tanned skin when it is fitted to the manikin.

When the statue is finished and the skin has been tried on for size, the sculptor makes a plaster cast of it. When the cast is taken off, it is lined with overlapping strips of burlap. This rough fabric is coated with liquid plaster-of-paris, about as heary as cream. When the plaster hardens in the burlap lining, the "shcll" is removed, braced, put together,

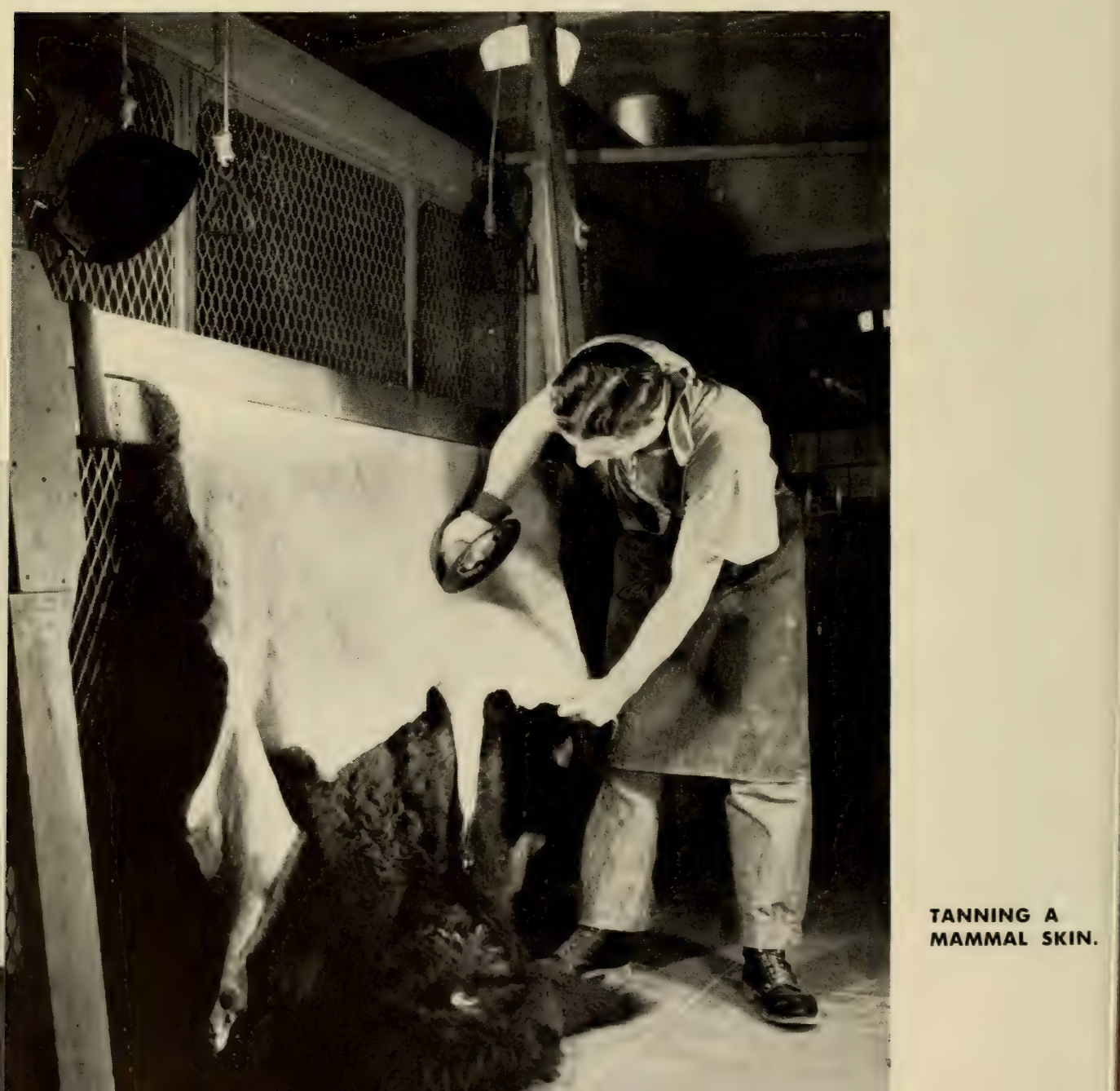




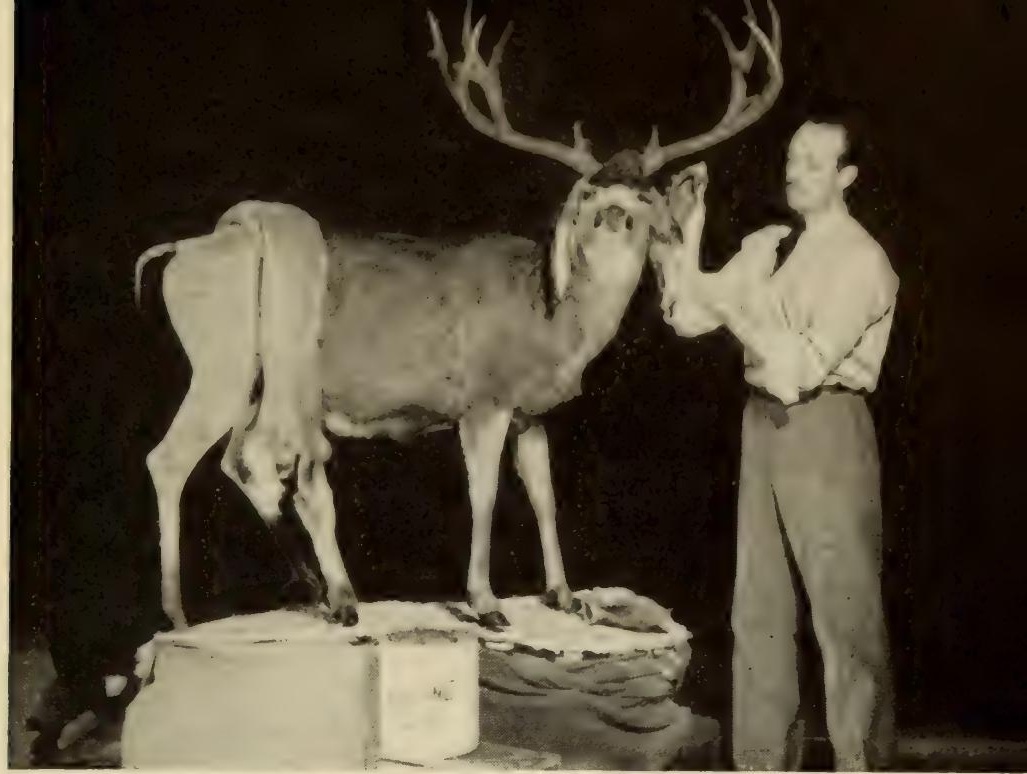

coated with a preservative and is now a manikin, waiting for the animal's kin.

Fitting the skin to the manikin is a delicate process. An adhesive is placed on the under side of the skin as it goes on the manikin. The skin is sewed up with needle and thread. The stitches do not show because they are on the under side.

To make sure that all the muscles, veins, ribs and hollows are prominent, the technician drives hundreds of small nails or pins through the sin into the manikin, to keep the skin tight around key points. When the adhesive is "set" in two or three days, the nails or pins are taken out. The animal now seems to have rippling muscles, his ribs show as they should, and even veins in his mumle are as plain as thev would be in a living specimen.

Good examples of such large mounts may be found in the Giant Eland Group or the Giant Sable Group in the Akeley African Hall on the second floor.

Now our background is painted, the terrain is covered with plants, the animals have been placed and the "October Afternoon Near Stissing Mountain" is complete. But the Department of Exhibition has been busy making many more display's for the Hall, other than the accessories for "An October Afternoon."

It has made farm buildings, farm machinery, small dioramas and cut-outs, mirrorscopes through which the visitor sees a remarkably realistic presentation of landscapes in many aspects, soil profiles, scientific nodels of root systems, apple blossoms, the hind leg of a bee with its oollen basket, the life history of the codling moth that attacks apples, itudies of photosynthesis and respiration for the "Cycle of Nutrition 
and Decay" and man! other displays and models requiring scientific accuracy and infinite attention to detail and exact coloration.

The groups. displays and models have been checked by the Scientific Departments concerned. Geology advised how the mountains looked curing various time periods, as shown in the displays "Geological History and Structure." The Iepartment of Conservation advised on "The Water Cricle," "Soils and Soil Conservation," and "Life in the Soil."

Paleontology checked the accuracy of dioramas and objects that how the prehistoric plants and animals that lived in this place many lihousands of years ago.

The Bird and Mammal I)epartments saw to it that the bluejas, the fox, the chipmunks, muskrat and other animals in the Hall were carefully installed in authentic positions and relationships.

The Iepartment of Insects and Spiders supervised the placement of dragonflies. butterflies and beetles, to be found in "An October Afternoon," "From Field to Lake," and "Crcle of Nutrition and Decay."

The Iepartment of Amphibians and Reptiles and the Department of Fishes worked with the technicians and the preparators to insure the accuracy of the use of turtles. trout, catfish, perch and pickerel shown in "From Field to Lake."

The Iepartment of Anthropology made its recommendations as to the best way to show man's part in this environmental exhibition. It checked on house and farm styles, tools, machinery, and agricultural methods of the various times depicted. All Scientific Departments concerned in the Hall helped in the writing of labels and other informative material.

At last the Felix M. Warburg Memorial Hall is completed. Into it has gone much of the Museum's time, moner, talent and effort. The Director. Board members, advisory committees, the Scientific Staff, architects, exhibition personnel. artists. preparators, tanners, technicians. metal workers, masons. carpenters, painters, bookkecpers, public relations people. photographers, attendants - all have given of the best that is in them to make an exhibition hall of lasting beauty, scientific accuracy and educational importance.

For a description of these exhibits see the chapter entitled ECOLOGI AND CONSERVATION. 


\section{ASTRONOMY AND THE}

\section{AMERICAN MUSEUM-}

\section{HAYDEN PLANETARIUM}

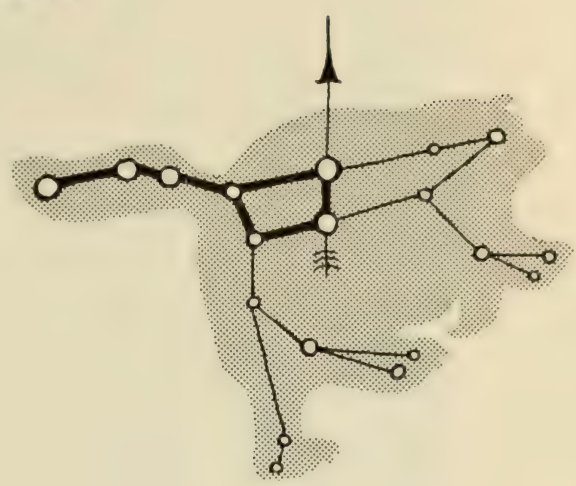

The American Muscum-Hayden Planetarium, adjoining the Roosevelt Memorial, with its main entrance on 81 st Street and Central Park W'est, constitutes the Museum's Department of Astronomy. Since the complete story of natural science begins with the story of the universe, it is fitting that the Planetarium's description begin the General Guide.

The establishment of the Planetarium in 1935 marked the culmination of a ten-vear effort to secure for The American Muscum of Natural History a planetarium projector. This complicated piece of precision equipment was developed for visual education and entertaimment by the firm of Carl Zeiss at Jena, Germany, to present the fascinating and ever-changing drama of the skies.

In 1933 the Trustees of the American Museum formed a separate corporation under the Reconstruction Finance Corporation to construct and equip a planetarium. Mr. Charles Hayden, after whom the building is named, donated both the projection instrument and the Copernican planetarium on the first floor.

The high spot of the Planetarium is the great Zeiss projector, installed in a hemispherical dome 75 feet in diameter. The main body of the instrument is 12 feet long, with a large globe at either end containing projectors that show the fixed stars of the northern and southern sky on the inner surface of the dome. Individual projectors for the sun, moon and five naked-eye planets are mounted in the latticed cylinder that supports these globes.

Each of the large star globes contains sixteen separate lens systems in which are incorporated copper foil plates with holes of various sizes 
for stars of different magnitudes, so that a central light source causes the star images to appear on the dome. These fit together in such a way as to reproduce the constellations exactly as seen in the real sky under ideal weather conditions. These projectors reveal images of all the fixed stars visible to the unaided eye from any part of the earth. Each of the thirty-two star field projectors is also provided with a device which automatically celipses the star images when they are below the horizon.

The projector also contains special instruments for projecting the Milky Way, comets, important variable stars and the various reference circles used by the astronomer in describing the positions and motions of the celestial bodies.

The main projector turns independently on any one of three axes. First, it may turn on an axis parallel with the polar axis of the earth. This simulates the apparent westward motion of the heavenly bodies due to the earth's rotation.

Second, it may rotate on an axis perpendicular to the plane on which the earth itself moves around the sun. The effect of this is to swing the north pole of the heavens around a circle that is completed every 25,800 years. This motion, known to the astronomer as "precession," introduces a long period of change in the sky picture. By its use, the Planetarium lecturer can set the instrument back some 5,000 years to $3,000 \mathrm{~B}$.C. when Alpha Iraconis, a dim star in the constellation of the Dragon, was our North Star. Or, by running the instrument ahead some 12,000 years, we see Vega marking the north pole of the heavens and the Southern Cross visible from the latitude of New York.

Third, the instrument mav also be turned about an east-west axis to simulate the change that occurs in the sky picture as one changes latitude

MAIN ENTRANCE TO AMERICAN MUSEUM-HAYDEN PLANETARIUM.

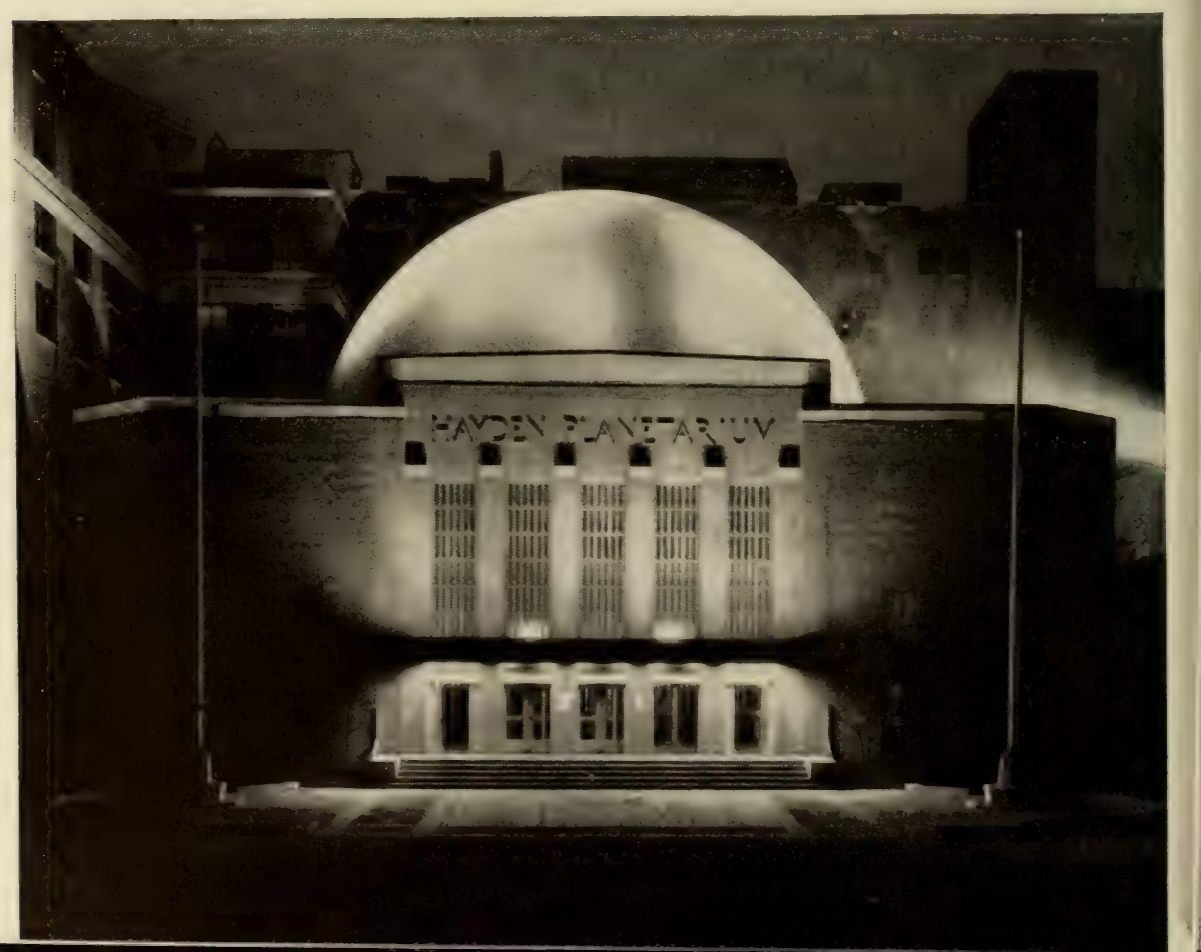




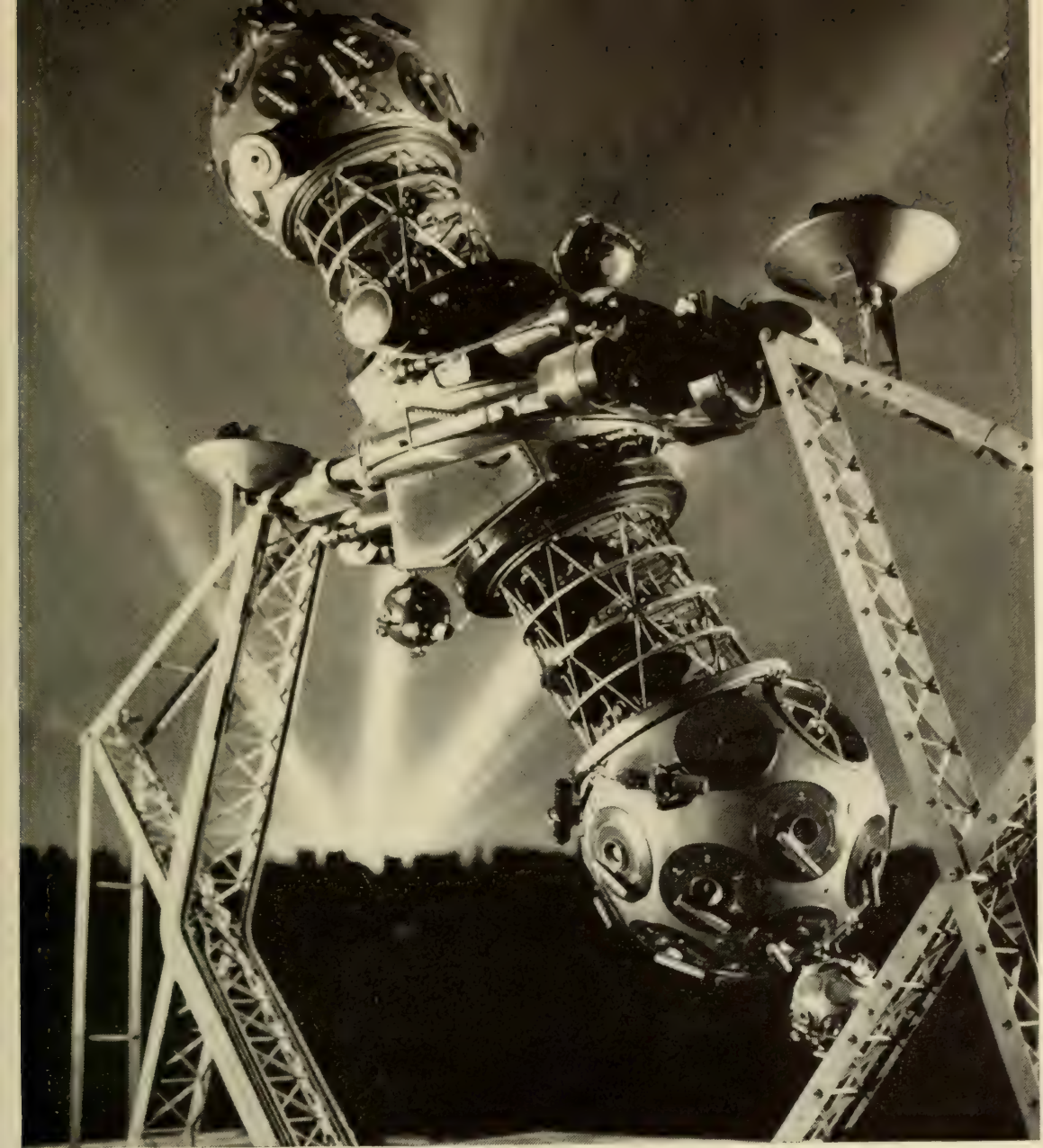

\section{THE ZEISS PROJECTOR OF THE PLANETARIUM.}

on the earth. Thus, it may show the sky as seen from the North Pole, or, traveling south, one may see the Magellanic Clouds or the Southern Cross. Use of this motion enables the lecturer to carry his audience around the world in about five minutes.

The motions of the sun, moon and planets are effected through a complex arrangement of motors and gears so that they may be set in any position relative to the stars for any date and hour for many centuries backward or forward in time. This so-called annual motion also sets the moon at its proper phase for any given time.

The dome itself, upon which the stars are seen, is made of perforated steel, painted white on the inside, enclosed in an outer shell of copper Under this great dome, the lecturer, with a complicated series of buttons. dials and switches to control, and with over two thousand possible combinations at his command, is virtually master of the universe. 
A mere phrsical description of this amazingly complex instrument does not do justice to the breath-taking effect of a Planetarium showing. To the visitor, it seems as if the walls of the great domed room have disappeared, revealing the very depth and feeling of a star-studded sky as the unclouded night slowly falls.

The Planetarium projector does not bring the entire sweep of the sky story to the audience. Supplementary effects and techniques are constantly developed to widen the range of action. Horizon scenes, a rocket-ship interior, a swirling snow storm, eclipses, the radiance of northern lights, thunderstorms and a host of accessory effects are created. When combined with controlled lighting, music and special sound effects, the result is what has frequently been called the most dramatic of theatre productions.

Almost half a million persons visit the Planetarium each vear to see such performances as "Rocket to the Moon," "The Beginning and the End of the W'orld," "Color in the Sky." "The Conquest of Space," "Destination Saturn" and the Christmas show, "The Star of Bethlehem." There is usually a change of show theme on the first day of each month and demonstrations at scheduled times during the afternoons and evenings of every day in the year.

The Hall of the Sun is on the first floor. Suspended from the ceiling of this circular room, known as the Copernican Room, is a 48 -foot model of the solar system in which the naked-eye planets are seen moving about the sun at their proper relative positions and speeds.

On the walls of this room are the constellations of the Zodiac whose stars, in luminous paint, scem to scintillate against the deep blue background of the night sky.

The actual demonstration begins in this room with a preliminary talk preparing the audience for the "sky show" in the dome on the second floor. The floor of the Hall of the Sun is enriched by a reproduction in terrazzo of the Aztec Calendar Stone. It was made by Victor Foscato and symbolizes the sun which was to the Aztecs the most important of the heavenly bodies.

I fine collection of astronomical paintings hangs on the Planetarium walls. Opposite the main entrance on the first floor the visitor sees a large mural painting and two panels by Charles R. Knight, depicting many of the sky legends and myths of the American Indian. On the second floor are the astronomical paintings of the late Howard Russell Butler of Princeton. Perhaps his most striking canvases are the three eclipse subjects shown orer the southeast entrance to the dome. They are lighted by a method devised by Mr. Butler which makes them appear as realistic transparencies rather than as opaque paintings. The first represents the eclipse of June 8, 1918, observed at Baker. Oregon; the second, that of September 10. 1923. at Lompoc. California: and the third, that of January 24, 1925, at Middletown, Connecticut. 
Reflector; the 18th-century observatory at Jaipur, India; the ancient observatory at Peking, China; and Sir Isaac Newton's discovery that sunlight is composed of the colors of the spectrum. Another group of dioramas near the exit to the Roosevelt Memorial shows the various phases of weather, explaining such phenomena as the formation of rain, the action of a cold front and the mechanics of a hurricane.

Of constant interest to visitors are semi-permanent exhibits, as "The Time Capsule," "Your Weight on Other Worlds" and the "World Clock." Supplementary exhibits also include contemporary paintings, special blow-up photographs, models, maps, charts, books and instruments.

The combination of Planetarium projector and dome is ideal for instructional purposes and unique courses for laymen are given during the fall and spring seasons. Six courses in astronomy and navigation are offered to the public, with sessions held once a week during the evening hours. Special school-group showings provide supplementary background for studies in astronomy. Other instructed groups include West Point Cadets, U. S. Power Squadron units, engineering classes from nearby colleges, Scout groups and a variety of visiting convention groups. The Planetarium is also available for special lectures at hours when there are no regular performances.

The Book Corner is located near the main entrance to the Plane. tarium on the first floor. Here visitors may receive expert help in the choice of publications on astronomy, star identification, navigation and meteorology. Also available are seasonal star-charts, star-atlases, revolving star-finders, post cards, prints, astronomical gadgets, pamphlets, children's books designed to stimulate their interest in star-gazing and the "Sky Reporter," a monthly bulletin describing the current Planetarium demonstration, with sky maps and interesting information about celestial events.

Planetarium staff members are frequently called upon for explanations and advice about various astronomical, navigational, and meteorlogical problems. With the recent heightened public interest in sky phenomena, the Planetarium serves as a clearing house for information to the public via the press, radio and television.

Thus, by well-integrated programs and active participation in school and community functions, the American Museum-Hayden Planetarium carries out its major purpose - that of helping the public to interpret for itself the vast body of scientific knowledge about astronomy and the allied sciences in terms of its own need and desire to understand the universe. 


\section{GEOLOGY AND PALEONTOLOGY}

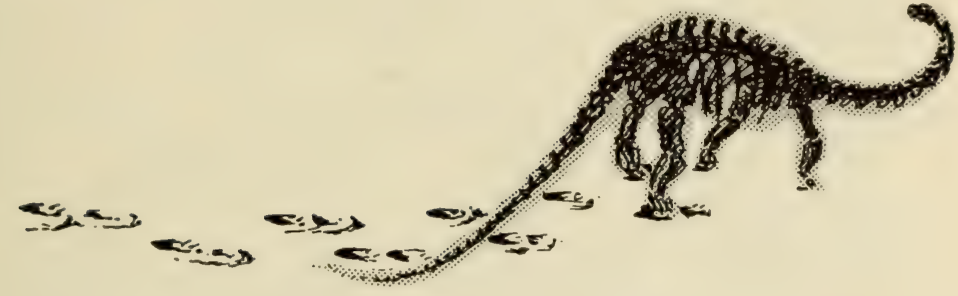

Geology is the study of the earth in its present condition and as it was in past ages, back to the time of its origin as a planet. It is concerned with the materials composing the minerals and rocks of the earth and with the forces that have shaped these rocks into mountains, hills, valleys, lakes, oceans and all other land forms that are so familiar to us. It deals with the sequence of rocks as they were formed on the earth, with the history of the earth as revealed by rock sequences and by the fossilized remains of life contained within the rocks. Finally, it is concerned with the history of life on the earth as shown by the study of fossils.

Thus, the inclusive science of geology is made up of varied separate sciences and these are often given distinct names, such as mineralogy for the study of minerals, petrology for the study of rocks, physiography or geomorphology for the study of land forms, structural geology for the study of earth structure, stratigraphy for the study of layered rocks, and paleontology for the study of ancient life on the earth.

The Department of Geology and Paleontology at The American Museum of Natural History is interested primarily with the two divisions of geology that are based mainly on Museum collections - paleontology and mineralogy - although other aspects of the sciences are given some attention. But since the work of the Museum is based to a large degree on specimens, it is in those fields of geology where specimens - fossils and minerals - are of particular importance that the work of the Department is concentrated.

The Museum has one of the great mineral collections of the world, and this collection is being studied and increased. The large fossil 
collections are subdivided into several categories, each under the care and direction of one or more authorities in his special field, assisted by technicians. Thus there is a collection of invertebrates, one of fishes, onc of amphibians and reptiles, and one of mammals. These collections form the core around which are built comprehensive programs of research, field studies, collecting activities, and exhibits. Thus, the exhibits are one of the end results of extended scientific work and it is only through active prosecution of basic studies upon collections and new matcrials that the exhibits are kept authoritative and up to date.

At the present time, the exhibits of this Department are being revised. Modern exhibits of geology and fossil invertebrates are planned for future installation.

\section{Scientific Work of the Department of Geology and Paleontology}

The scientific work of the Department is concentrated, at the present time, largely in the field of paleontology. Several programs of exploration and research are being carried forward, with the result that the collections of the Museum are being augmented and valuable new information is being published in technical papers. monographs, books and popular articles.

On death and burial, plant remains, and the shells and hard skeletons of mollusks, crustaceans and other invertebrates, are readily fossilized and preserved in the rocks. Indeed, many rock strata are largely composed of these fossil remains. Invertebrate remains are especially abundant in rocks that were formed as sediments in ancient seas which, at various times, covered almost all of the globe. Because of this abundance. mvertebrate fossils occupy a favored place in deciphering the history of the earth and in the practical service of man.

The fossil invertebrates of each geologic epoch are distinctive, so that, in general, they serve as the principal standards for the classification and dating of rock strata, especially those of marine origin. This is of great practical importance in mining, quarrying and in the search for petroleum. Happenings in the development of the earth are referred to a standard geologic time scale which was founded on the paleontological record, especially that of the invertebrate fossils. The evolutionar! historr of these animals goes back more than a half billion vears, to the Proterozoic cra, well before the adrent of the vertebrates and the land plants.

Verr small invertebrate fossils. such as the skeletons of protozoans. are ver commonly brought to the surface as oil wells are drilled, furnishing needed information on the relative position of each formation that is being penetrated, thus, in tact, guiding the drilling activity.

An active program of research in invertebrate paleontology, involving laboratory studies and field expeditions to various parts of the world. is being maintained. Sudies in recent years have emphasized the important contribution that fossil invertebrates make in understanding ecological conditions of past seas early in geologic time. Recent investi- 
The present research program on fossil amphibians and reptiles emphasizes the study of Triassic reptiles from various parts of the wortd. The purpose of this research schedule is to make known the animals that lived just before and during the early stages of the Age of Ininosaturs, a critical time in the evolution of reptiles. Extcosive explorations have been carriced on and collections made in the southwestern Enited States since the war, and much new material has been uncarthed. In addition, field studies have been made in certain foreign countries.

In the field of fossil mammals, work is directed especially toward the collection and study of the primitive mammals that lised during early Tertiary times and of the adranced mammals that inhabited North America during the final phases of the Cenomoic era. Active collecting programs are being followed in the southwestern part of the Lnited States for early Tertiary mammals, and in various sections of the west for the later mammals of the Cenozoic. Many fossils and new faunas have been found, to expand greatly our knowledge of the mammals that lived on the earth in former days. Much rescarch is also being donc on ancient South American mammals and on other problems of the evolution of this dominant group of animals.

All of this work on fossils reconstructs the history of life. It adds to our record of animals through time, and gives much new evidence for the interpretation of evolution. In addition, the research that is being carried on at this Museum is concerned with the former distribution ind association of animals in the world, and the bearing that such information has upon the past relationships of continents and the history of climates.

The history of life helps us to understand the origin, nature and destiny of man. Paleontology, as studied at this Museum, is concerned with concepts, and of these the concept of evolution is one of the most vital in our modern world. No single idea has revolutionized thought in modern times so much as the theory of organic evolution. And, in the study of evolution, the evidence and interpretation of fossils is of the utmost importance.

\section{MINERALS AND GEMS}

Minerals are nature's chemicals, and mineralogists have been able to recognize orer 1700 different species. THE MORG.AN HALL OF MINER ILS INI) GEMS is one of the outstanding collections of these minerals in America and, in fact, in the world today. Displayed here are many rare and unusual specimens, some of particular beatus. With few exceptions all of the known mincrals are represented in this collection. Some mincrals are so rare that only single examples exist, while many are so common that they are present almost everwhere in the carth s crust.

I study of the earth's crust shows that it consists of different kinds of rocks, a lew of which have familiar names such as granite, marble, sandstone and slate. We see these rocks around us every day; they 
OPALIZED WOOD. Opal is often found as the replacing material in fossil or petrified wood. Petrified wood is formed by ground water dissolving the woody matter from trees and simuitaneously depositing silica. The fine texture of the original material has been preserved in this specimen from Lincoln County, Idaho.

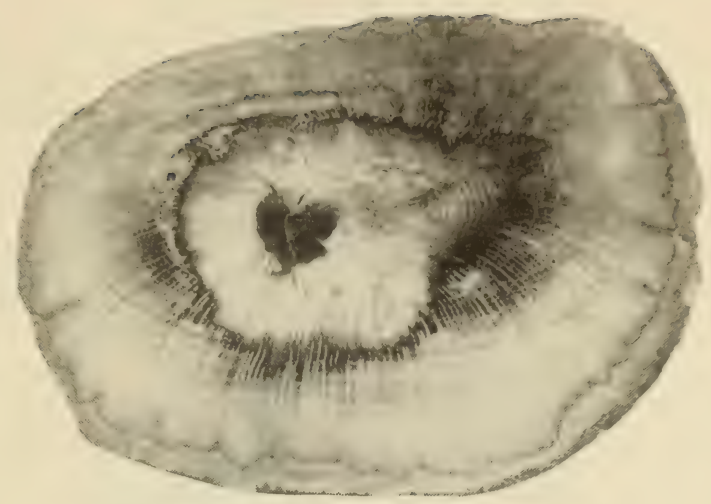

form our mountains and canyons, and many of our buildings. On closer examination it is found that each rock is composed of individual substances which we call minerals. For example. a handful of sand from the seashore can be scparated into various kinds of grains, and these grains frequently represent a variety of minerals. Each has definite properties of hardness, density, luster, color and transparency. These different kinds of substances, then, which nature has used to make up sand and the other materials of the earth's crust are called minerals. All of the various minerals may be classified on the basis of their chemical composition as shown in the accompanying table.

The primary task of the mineralogist is to understand the physical. chemical and historical aspects of the earth's crust. The science of mineralogy is, therefore, an integrated field of study related to geolog! on the one hand, and 10 physics and chemistry on the other. What does a professional mineralogist do? For example, if he wants to study a new mineral deposit. he first must have an understanding of the geologic setting in which the minerals are found, and he gains this by examining and mapping the rock formations in the field. Without this knowledge it would be impossible to speculate intelligently as to the origin of the deposit. Next, each mineral must be identified in the laboratory. Some minerals may be determined by inspection, whereas others vield their identity only through chemical tests or the measurement of optical constants by microscopic means, or in other ways. At times, the mineralogist may make x-ray diffraction patterns of his minerals, since a crystalline substance will give a regular pattern recorded on photographic film when subjected to x-rays. The intensity and positions of these lines are characteristic for each crystalline substance. He may, in addition, employ tools borrowed from the chemist and physicist, such as differential thermal analysis in which he subjects the mineral to a gradual rise in temperature, and observes the characteristic chemicai changes which take place. 
Or he may use spectrographic measurements which are useful in detecting minor clements which might be unnoticed by the usual qualitative chemical procedures. After all of the minerals of a deposit have been identified, the sequence of deposition can be worked out. Once this is known, the mineralogist can speculate as to the origin of the minerals and the nature of the conditions that gave rise to them.

All of the knowledge that the many mineralogists have gained after years of patient observation and study have been arranged in systematic form, and make up the science of mineralog! which may be outlined as follow's.

Crystallography -- An important branch of mineralogy which is concerned with the internal arrangement of atoms and the external geometric forms exhibited by minerals.

Physical mineralogy - This includes a consideration of the various physical properties such as hardness, cleavage, color, specific gravity, magnetism, electrical properties, tenacity, as well as optical properties.

Chemical mineralogy - The various chemical properties, and also the origin' and formation of minerals are considered. This includes chemical analysis, spectrographic techniques, x-ray fluorescence, and thermal analysis.

Descriptive mineralogy - This is a systematic listing of the various crystallographic, physical and chemical properties of minerals, and something of the environments in which they are found.

Determinatize mineralogy - A classification of minerals based on physical properties and chemical composition which facilitates identification.

Mineral substances and products are indispensable to the welfare, health and standard of living of modern man, and are among the most valued and jealously guarded of the natural resources of a nation. The outstanding characteristic of the industrial era in which we live is the wide application of machinery and the use of power. In the last analysis

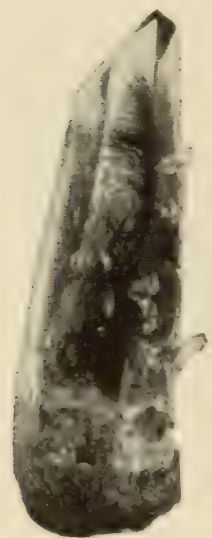

QUARTZ. This large crystal from St. Gotthard, Switzerland, has smaller crystals of quartz growing on its surface. Many minerals occur as inclusions in quartz, and in this case actinolite needles penetrate the quartz. 
STIBNITE. Stibnite is a sulfide of the semimetallic substance known as antimony. The slender orthorhombic prisms are made up of many crystals joined parallel to each other. The mineral is the chief source from which antimony is obtained. The specimen illustrated came from Inyo, Japan.

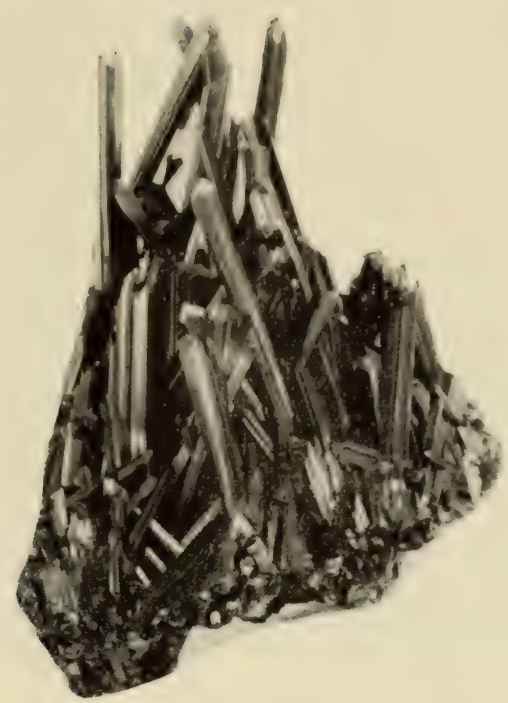

the significance of this civilization lies in the substitution of power machinery for animal muscle. This includes everything that has come to our generation through the steam engine. dynamo, automobile, airplane and telephone. The inventions have brought about the use of minerals in an ever-increasing quantity, and an ever-widening application. Thus, as industrial techniques have become more complex. minerals that contain metals with peculiarly distinctive properties such as aluminum. vanadium, tungsten, molybdenum, chromium, cobalt and nickel (previously of interest only in the laboratory) have assumed real economic importance. For example, platinum, in addition to its use in jewelry, is a necessary catalyst in sulphuric acid making, and acts as a key which unlocks a cheap process of chemical synthesis. Antimony is essential to the production of clear printing type metal, and mercury is a key metal in precise scientific instruments. All of the common materials used in modern building, such as steel. cement, brick, glass and plaster have their origin in minerals. The world demands more food, and as a result the phosphates, potash and nitrates bulk large in the commodities of commerce.

The methods of the mineralogist are used every day to solve practical problems such as the manufacture of abrasives, ceramics, refractories, synthetic crystals and steel. Mineralogy is an everyday tool with the mining geologist and should be for the prospector in order that he may identify properly the minerals which he finds. He must also know something of certain mineral associations, which are so characteristic that they may be important leads to the presence of others. Mineralogy has been of direct help in military operations.

Recently, the search for and study of radioactive minerals has become of great interest to mineralogists since these minerals form the basis for 
future atomic energy. Clays are being investigated as a possible guide for the location of mineral deposits. Surprisingly enough, mineralogists are being of help to medical science. Since many parts of our body contain crystalline substances similar to minerals, they are capable of being studied by mineralogical techniques.

THE MORGAN MEMORIAL HALL OF MINERALS AND GEMS is, in general, arranged according to the chemical classification of minerals shown on the accompanying table. Specimens from all these groups are exhibited. The wall panel assemblage is a key exhibit to the large and more detailed collection in the flat cases occupving the remainder of the room, with the exception of the center aisle, which contains particularly fine specimens of gem minerals. As one progresses around the room, beginning with Panel $A$ (at the left of the entrance) containing the native elements, it is evident that many of the minerals form regular solids with smooth faces which are characteristic of each mineral species. These regular forms are called crystals and are the external result of the unhampered growth and arrangement of the minute internal particles called atoms. The collection also has a number of fine wooden crystal models available for study. The recently acquired gold specimens from the William Boyce Thompson Collection are excellent examples of the crystallization of the native element gold. The sulphur crystals in Panel A are another good example of crystallization. Well developed crystals of the important iron mineral, hematite, are displaved in Panel M. There are several rare crvstals of barite, one of the sulfates, and a barium mineral, in Panel AA.

Certain minerals among the many hundreds of different species are of particular value and we call them gems, because they appeal to our sense of beauty. The qualifications which make minerals gems include beauty of color, a certain degree of transparency that permits the color qualities to be developed by cutting and polishing, and sufficient hardness to preserve them against wear. In addition, the value of gems is governed largely by their rarity, together with a fluctuating unknown dictated by fashion.

The Morgan Collection contains several outstanding gems, including the De Long Star Ruby, and the "Star of India," the largest star sapphire in the world. There are also notable diamond cristals, as well as glass models of the world's famous diamonds, both in the natural state and after cutting. Several fine specimens of chrysoberyl are in the collection. Occasionally, this aluminate of beryllium contains hair-like inclusions arranged in parallel bundles, and when cut and polished is known as "oriental cat's eve." The specimen from Kandy, Ceylon, is thought to be one of the world's finest.

Two cases illustrating the geology and minerals of New York State are exhibited on the first floor of the Roosevelt Memorial. The characteristic minerals together with the localities are indicated. 
KUNZITE. Kunzite is the clear lilac to pinkcolored variety of spodumene. Crystals of kunzite are usually prismatic and flat. The locality from which this crystal and many gems come is Pala, San Diego County, California.

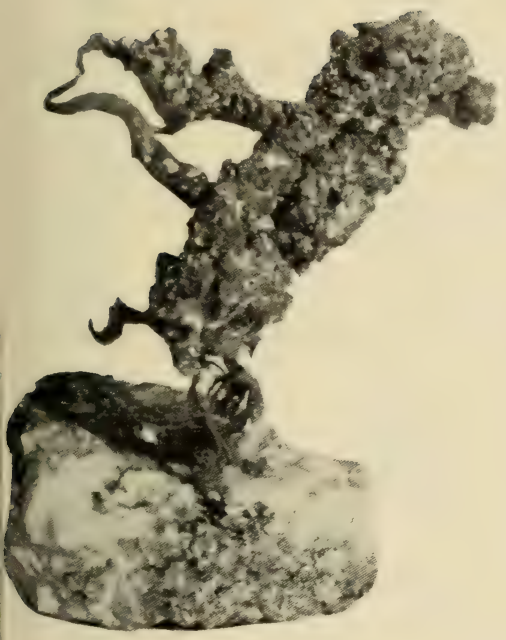

SILVER. This illustration shows a beautiful reticulated group of silver crystals from Kongsberg, Norway, a locality which has produced magnificent specimens of crystallized wire silver. Silver can be told from other silver-appearing minerals by its malleable nature, its silver-white color on a fresh surface, and its high specific gravity.
BARITE. These tabular crystals of barite on dolomite have come from Frizington, Cumberland, England. Barite, the chief source of barium, is used largely in the paint industry and to a lesser extent as a filler in saper and cloth, in cosmetics, and for sarium meais in medical radiology.

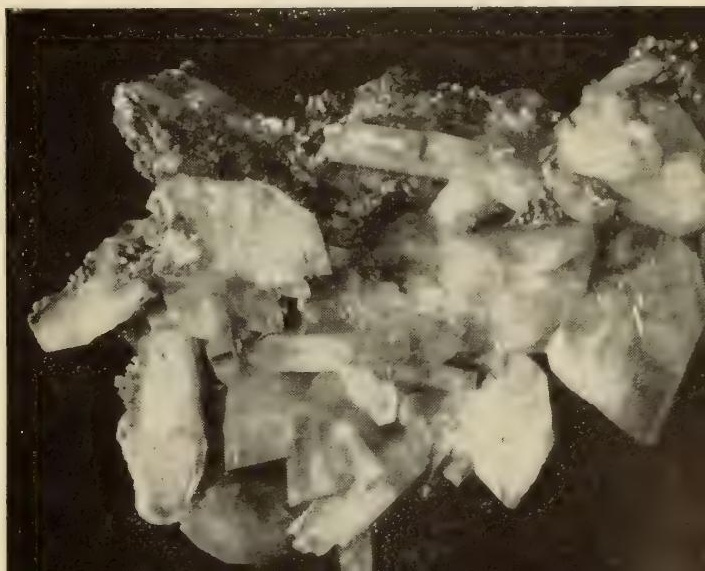




\section{Table of the Chemical Classification of Minerals}

Elements - 1bout 20 clements in an uncombincel form are found as minerals, and are said to occur in the native state.

Example, gold, Au

Sulfides - These minerals consist principally of combinations of the various metals such as copper and lead with sulfur, sclenium, or tellurium. The majority of the metallic ore minerals are in this class.

Example, galena, $\mathrm{PbS}$

Sulfosalls - Minerals composed of lead, copper, or silver combined with sulfur and antimony, arsenic, or bismuth are included in this class.

Example, enargite, $\mathrm{Cu}_{3} \mathrm{AsS}_{4}$

Oxides - a. Anhydrous oxides. The minerals of this rass contain a metal in combination with oxygen.

Example, hematite, $\mathrm{Fe}_{2} \mathrm{O}_{3}$

b. Hydrous oxides. The mineral oxides that contain water or the hydroxyl $(\mathrm{OH})$ as an important radical are included in this class.

Example, diaspore, $\mathrm{Al}_{2} \mathrm{O}_{3} \cdot \mathrm{H}_{2} \mathrm{O}$

Halides - This class includes the chlorides, fluorides, bromides, and iodides.

Example, fluorite, $\mathrm{CaF}_{2}$

Carbonates - The minerals whose formulas include the carbonate radical, $\mathrm{CO}_{3}$, are in this group.

Example, calcite, $\mathrm{CaCO}_{3}$

Nitrates - The mincrals in this class can be considered salts of nitric acid and contain the $\mathrm{NO}_{3}$ radical.

Example, niter, $\mathrm{KNO}_{3}$

Borates - The borates are salts of boric acid.

Example, borax, $\mathrm{Na}_{2} \mathrm{~B}_{4} \mathrm{O}_{7} \cdot 10 \mathrm{H}_{2} \mathrm{O}$

Phosphates - Minerals whose formulas include the phosphate radical, $\mathrm{PO}_{4}$, comprise this group.

Example, apatite, $\mathrm{Ca}_{5}(\mathrm{~F}, \mathrm{Cl})\left(\mathrm{PO}_{4}\right)_{3}$

Sulfates - Minerals whose formulas include the sulfate radical. SO $\mathrm{S}_{4}$ are in this class.

Example, barite, $\mathrm{BaSO}_{4}$

Tungstates - The few minerals whose formulas include the tungstate radical, $\mathrm{WO}_{4}$, comprise this group.

Example, scheelite, $\mathrm{CaWO}_{4}$

Silicales - The minerals included in this group form the largest class among minerals. They contain various elements, the most common of which are sodium, potassium, calcium, magnesium, aluminum, and iron. in combination with silicon and oxygen.

Example, quartz, $\mathrm{SiO}_{2}$ 
TIME SCALE OF EARTH HISTORY

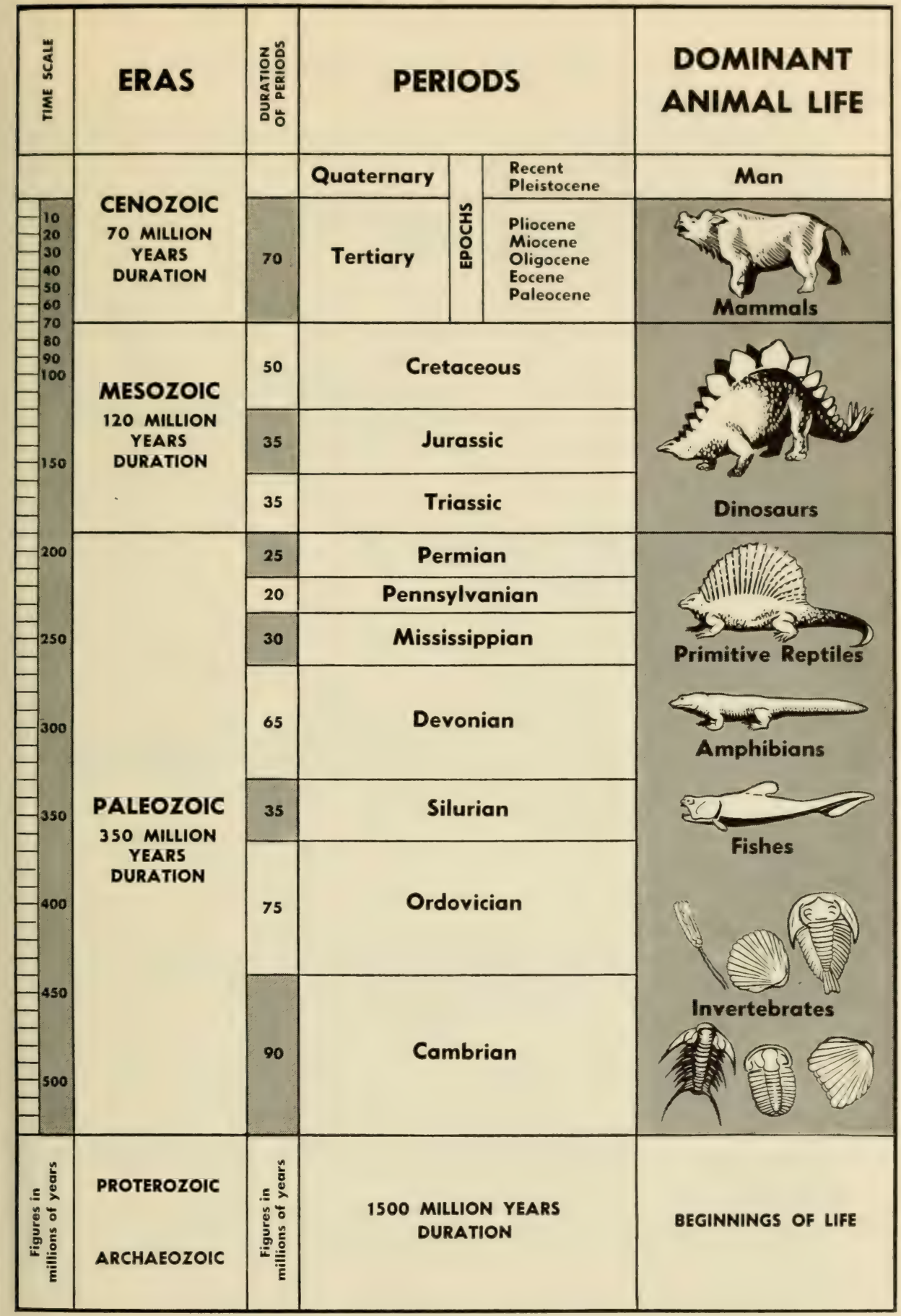

Only during the last $500,000,000$ years have plants and animals produced hard parts capable of being fossilized. Here is a simplified chart of that quarter of the earth's history. 


\section{Fossil Fish Alcove}

The known history of the fishes covers a time span of about 400 million vears. During this long interval four main groups or classes of fishes were evolved. The first group, called ostracoderms, were jawless and had well developed bony armor. They were the ancestors of the living lampreys and hagfishes. Some time during the Silurian period, the ostracoderms gave rise to the second major category, the placoderms, which were the first fishes with jaws. The placoderms evolved into a number of distinct types, most of them with heavy, bony armor and mobile, paired fins. They were the first rulers of the Devonian lakes and seas.

The sharks and their relatives comprise the next main group of fishes. They crolved from primitive placoderms, probably in the Silurian, although the earliest remains of sharks are found in Devonian deposits. Early sharks and sharklike forms were numerous and varied during the Carboniferous or Coal Age. The group declined in the Permian and Triassic periods, becoming more successful again in the Jurassic with the rise of the types living today.

The fourth class includes all the higher bony fishes. This large and varied assemblage likewise had a placoderm origin, probably during the Silurian period. At the time of their first appearance in the fossil record. the bony fishes were already separable into two subclasses; the ray-finned forms that evolved into the common fishes of today, and the fishes with internal nostrils. The ray-finned types separated into numerous cvolutionary lines before the Mesozoic era or Age of Dinosaurs. The fishes with internal nostrils included the crossopterygians and the dipnoans or lungfish. These earliest lung breathers were particularly numerous during the Devonian period. The crossopterygians are of great interest since they gave rise to the first land-living vertebrates. They are represented today by a single form, a fish called Latimeria, which lives in the coastal waters of South Africa. The lungfishes, once widely distributed. have persisted to the present time in South America, Africa and Australia.

The history of the fishes, as briefly summarized above, is illustrated in a series of simplified, synoptic exhibits in the Fossil Fish Alcove which is located at the west or far end of the First Fossil Hall. The visitor should walk in a counterclockwise direction within the Alcove when examining these exhibits, beginning with the family tree of the fishes which is to the right of the Alcove entrance.

Suspended above the entrance to the Alcove are the restored jaws of a Miocene fossil shark (Carcharodon megalodon). The plaster jaws are modeled after those of a living relative and they support the actual fossil teeth. This giant shark, which is closely related to the modern white-shark or man-eater, attained an estimated length of 46 feet. 


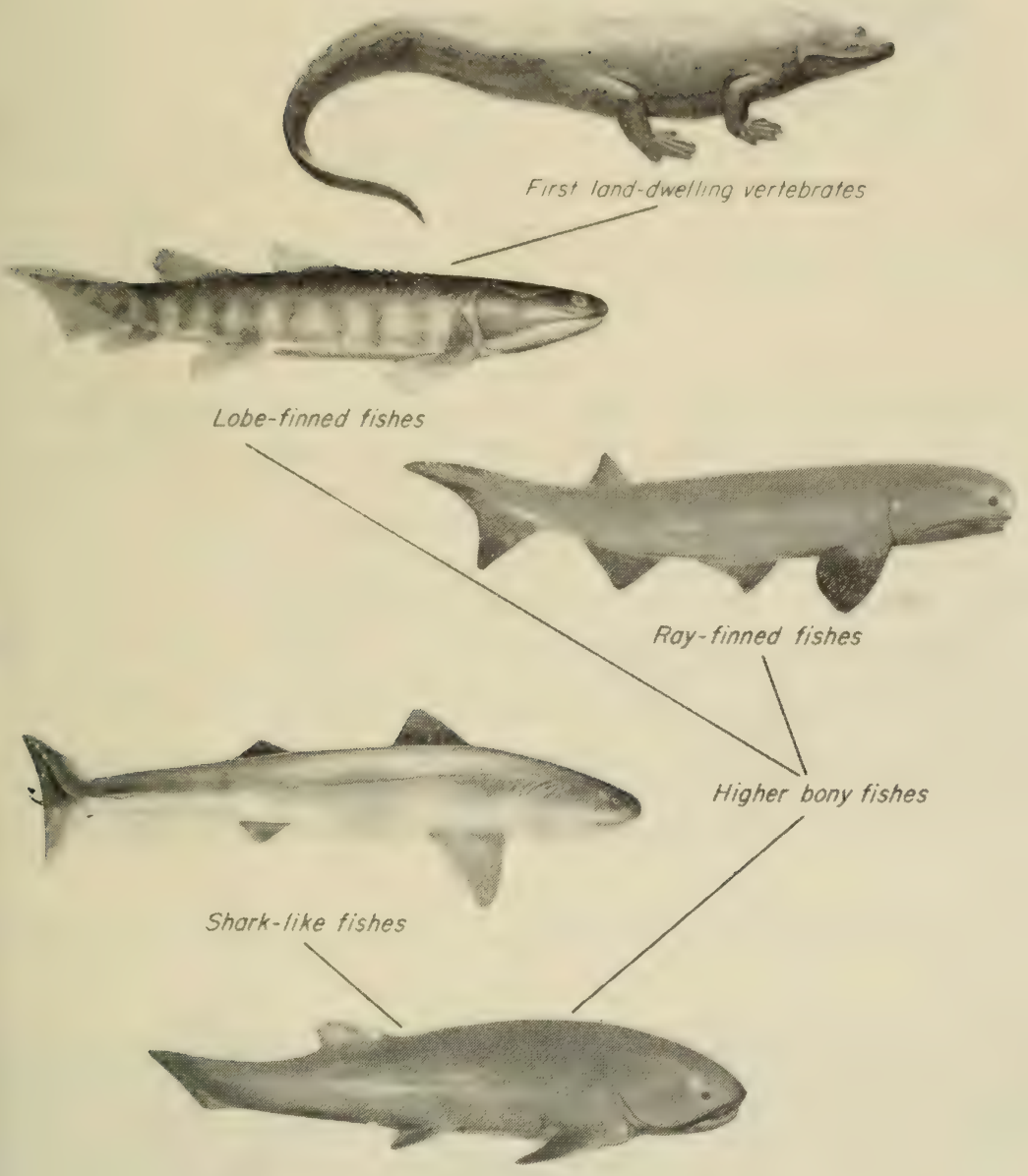

First fishes with jows

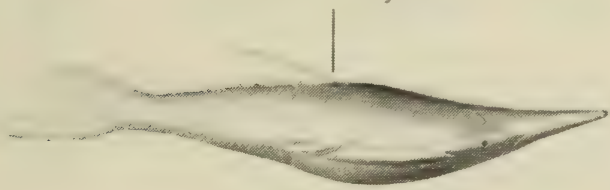

Primitive jowless fishes

FAMILY TREE OF THE MAJOR GROUPS OF FISHES. 
Inside the Alcove, is a simplified family tree of all the major groups of fishes discused in the introductory paragraphs. It illustrates in graphic form the complexity of fish evolution and points out the relationships and classification of the major groups. If the visitor is interested in the details of fish evolution, it may prove helpful to refer to this tree from time to time while examining the other exhibits in order to note the relationship of a particular group to the others.

Moving from right to left, the next exhil it is devoted to the oldest known vertebrates. the jawless fishes or ostracoderms. Typical examples of these ancient. armored forms are reconstructed in the models, while the cut-outs show some details of structure and variation in the form of the head armor. The ostracoderms include both bottom-dwellers and more active swimmers. In the left half of the same case are examples of the first jawed fi-hes, the placoderms. They existed in great variety during the Devonian period. The acanthodians were the most generalized types and they lasted into the Permian period. The others, which became extinct at the end of the Devonian, developed a variety of body shapes and claborations of the bony armor. Coccosteus and his larger relative Dimchthys were predators; Bothriolepis and such types as Lunaspis were bottom-feeders. An actual skull of Dinichthys from Deronian beds near Cleveland is exhibited in a separate case. On the wall above the fire exit is a model of Dinichthy's in the act of overtaking some primitive Devonian sharks (Cladoselache).

The next case on the left illustrates the long history of the sharks and their distant relatives the chimaeroids or ratfishes. Because the shark skeleton is made of cartilage, which disintegrates rapidly, it is

\section{A TRIASSIC RAY-FINNED FISH. Semionotus was a probable ancestor of the modern gars.}

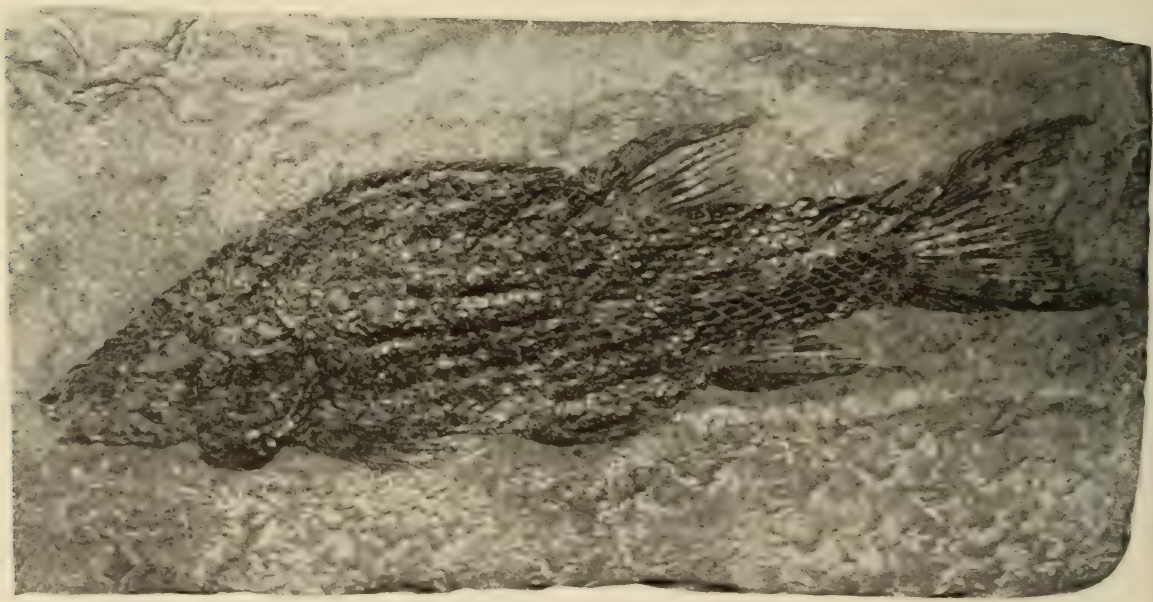




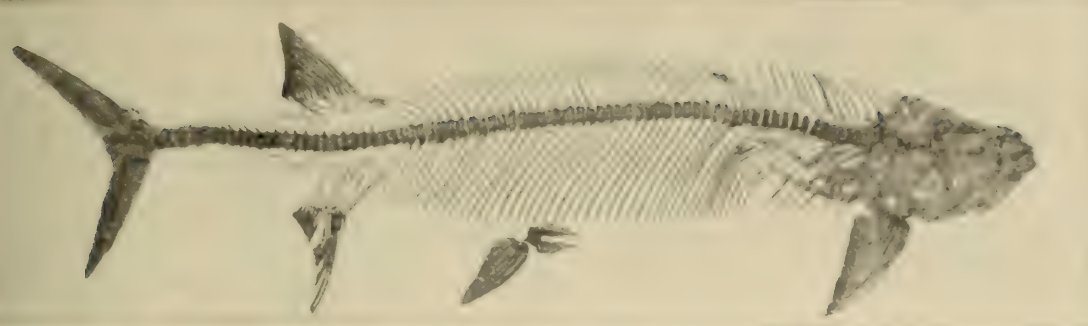

A GIANT CRETACeOUS TEleOSt FISH. Portheus lived in a large inland sea that covered much of central North America in late Cretaceous time. This specimen was discovered in the chalk beds of western Kansas.

rarely fossilized. Under exceptional conditions, however, shark skelctons were preserved, and in one Devonian form (Cladoselache) even some muscle and kidnev tissue was fossilized. Shark teeth, by contrast, are among the commonest of vertebrate fossils. Examples of the main types of teeth are displaved in this case. Fossil chimaeroids are known mostly from their teeth. The Paleozoic forms, called bradyodonts, had their teeth arranged as crushing plates and presumably they were mollusk eaters. The skull and some parts of the skeleton are preserved in the Carboniferous Helodus. The later chimaeroids, leading to the living marine Chimaera, are represented mostly by dental plates and spines.

The diorama represents a middle Deronian underwater lake scene about 300 million years ago. The fishes that swam in this lake are now preserved as fossils in the flagstones around Achanarras, Scotland, where they occur in considerable abundance. The models show the fishes as they appeared in life, although their coloring is, of course, hypothetical. The various types of fishes that lived together in this ancient lake placoderms, primitive ray-finned forms, crossoptervgians and lungfish -make up the fossil fish fauna of the Achanarras deposit. The vegetation, a simple aquatic plant or alga and submerged stems of the earliest land plants, also existed in middle Devonian time.

The exhibit to the right of the fire exit outlines the complex history of the bony ray-finned fishes or actinopterygians. This large and diverse group is usually divided into three subgroups which actually represent broad, succesive stages of specialization. These subgroups are termed the chondrostean, holostean and teleostean, typified by the sturgeon, the gar and the perch. The primitive chondrosteans, of which the Devonian Cheirolepis is a good example, developed a number of evolutionar lines that independently reached the holostean level. Thus, such holosteans as the modern gar and bowfin (Amia) had a separate ancestry beginning some time late in the Paleoroic era. The teleosts, including the great majority of living fishes (herring. catfish. perch, halibut, etc.) 
probably arose from a single ancestral stock in the Jurassic period. Since that time they have had an explosive evolution; there are more families of teleosts than in all the other major groups of fishes put together. On the wall alowe the shark exhibit is the fossil skeleton of a large Cretaceous teleost, Portheus molossus, from the chalk beds of Kansas.

The final exhibit, next to the Alcove entrance, considers the fishes with internal nostrils. The presence of internal nostrils indicates that these fishes came to the surface for air-breathing, and that they had true lungs in addition to gills. The central portion of the case shows the changes that occurred in the skull roof, the front or pectoral fin and the backbone during the transition from a primitive crossopterygian fish to an carly land-living vertebrate or amphibian. This great event in vertebrate cvolution took place in the Devonian period when seasonal droughts forced the crossopterygians to move over the dry stream beds in search of water and thus to explore the possibilities of land existence. The history of the coelacanth fishes, which arose from the Devonian crossopterygians, is illustrated on the right, ending in the living Latimeria. On'the left are the fresh-water lungfishes or dipnoans, likewise descended from the Devonian croscoptervians. Both the coelacanths and the dipnoans evolved slowly, the modern representatives showing a marked resemblance to their ancestors.

\section{Early Reptiles and Dinosaurs}

The First Fossil Hall is dominated by the skeletons of three upper Jurassic dinosaurs, placed on a large island in the middle of the hall. The largest of the three skeletons, that of Brontosaurus, is almost seventy feet in length and is some eighteen feet high at the hips. In life Brontosaurus must have weighed thirty or forty tons. The aggressive, meateating dinosaur, Allosanus, probably preyed upon the big, inoffensive plant-caters such as Brontosamrus, and in this group Allosamms is mounted as if feeding upon a brontosaur backbone. The third dinosaur in the group is the plated dinosaur, Stegosamms, another plant-eating form.

I truly dramatic exhibit in this hall is the series of original brontosaur tracks, set into the base of the central dinosaur island. This track-way was excarated near Glen Rose, Texas, and reassembled in the Museum. In it are to be seen six forefoot and six hindfoot impressions made by a gigantic brontosaur as it tramped through a limy mud millions of years ago. The three-toed tracks of an allosaur follow those of the brontosaur, and since two of the allosaur tracks are super-imposed upon two of the large brontosaur tracks, it is evident that the meat-eating dinosaur was actually following the big plant-eater. Here, preserved in stone, is a story from the ancient geologic past!

The walls of the First Fossil Hall are decorated with mural drawings illustrating some of the animals that lived during the late Paleozoic and Mesomoic eras, The Age of Reptiles. Several assemblages of animals - or 
faunas - are illustrated. These include the amphibians and reptiles that lived during the Permian times in what is now Texas, the Permian reptiles found in the Karroo descrt of South Africa, the Chinle fauna of Triassic age from the southwestern part of the United States, the Morrison fauna that spread over western North America in the late Jurassic times, the Belly River fauna of western Canada, and the Lance fauna, the last of all dinosaurian faunas in North America. Also are shown various marine reptiles that lived during the Age of Reptiles, when dinosaurs ruled the land.

The exhibits in the wall cases of this hall are arranged in a sequence that begins at the west end of the hall, near the entrance to the Alcove of Fossil Fishes. On the left side of the doorway is a case illustrating the origin and evolution of the first land-living vertebrates, the amphibians. This exhibit shows how the amphibians arose from fishes and how they developed along several evolutionary lines, the most important of which is that of the labyrinthodont amphibians. In the labyrinthodonts of Permian times, as represented by Eryops, shown here by skulls and a skeleton, the amphibians reached the culmination of their evolutionary development and for a brief time were in active competition with the reptiles for dominance of the land. The last of the labyrinthodonts lived in the Triassic period and are exemplified by the large, flattened form, Buettneria. With the close of Triassic times the labyrinthodonts became extinct, but before dying out they gave rise to the frogs and toads. Various other amphibians were contemporaneous with the labyrinthodonts, such as the bizarre animals represented in this exhibit by the genus Diplocaulus, a flat creature with an excessively broad skull, shaped rather like an arrowhead.

In this case are also to be seen the first reptiles, derived from aniphibian ancestors. The transition from the amphibians into the first reptiles was so gradual that it is difficult to draw a distinct line between the two classes of vertebrates. Seymouria is such a perfect intermediate form that the problem of whether it is properly an amphibian or a reptile is the subject of much scientific debate. A cast of the earliest known reptilian egg is seen as the central theme in this exhibit of the first reptiles; the original, in the Museum at Harvard University, was found in Permian sediments in north central Texas. Two primitive reptiles are exhibited in separate floor cases. One of these is Diadectes, from the Permian red beds of Texas; the other is Scutosaurus, from the Permian of northern Russia.

On the right side of the doorway leading to the Fossil Fish Alcove is an exhibit of mammal-like reptiles or therapsids from south Africa. These reptiles reached an advanced stage of evolution at an early date and some of them were directly ancestral to the mammals. In the center of the exhibit is a rare skeleton of one of the mammal-like reptiles, Lycaenops. Some therapsids developed along lines that were not directly ancestral to the mammals, but rather toward other areas of specialization. 
The dicynodonts werc large, plant-eating therapsids in which the teeth were suppressed except in the male animals, which had a pair of upper cusks in the skull. The dinocephalians were large therapsids, some of which were carnivorous and some herbivorous. A skeleton of Moschops, one of the plant-eating dinocephalians, is exhibited in a separate floor case.

Along the south wall of the hall, opposite the skeleton of Allosaurus, is a range of cases exhibiting pelycosaur reptiles from the Permian beds of Texas and Oklahoma. The pelycosaurs were related to the mammallike reptiles of South Africa. They were frequently specialized in rather strange wars. For instance, the predaceous form, Dimetrodon, had a large sail on its back formed by an elongation of the spine of the vertebrae. Edaphosaurus, a water-dwelling, mollusk-eating pelycosaur, also had a huge sail on the back, in this case complicated by numerous bony crossbars, like the yardarms on the mast of an old sailing vessel. The purpose of these sails is entirely a matter of conjecture. Cotylorhynchus was a large, heavy pelycosaur with a small skull.

Across the hall from the exhibit of Permian pelycosaurs is a series of cases in which are seen Triassic reptiles that lived during the early part of the Age of Dinosaurs. In the Triassic period reptiles other than dinosaurs were dominant, especially the large phytosaurs, of which a skeleton and some skulls are shown here. The phytosaurs, although they looked much like crocodiles, were not of crocodilian relationship. They preceded the crocodilians, and it was only after the phytosaurs became extinct, at the end of the Triassic period, that the crocodilians began their evolutionary development. The large slab of phytosaur bones exhibited in this case was found beneath the palisade cliffs of the Hudson River, about a half-mile south of the George Washington Bridge. Another fossil of local origin is the small skeleton of the primitive reptile Hypsognathus, discovered in a rock quarry between Clifton and Passaic New Jersey. Hypsognathus was the last of the cotylosaurian reptiles, and is related to some of the Permian cotylosaurs that are exhibited in the southwest corner of the hall.

A skeleton of a Triassic dinosaur, Plateosaurus, is displayed in a floor case near the wall cases just described. This specimen, from the upper Triassic sediments of Germany, represents a stage of evolution ancestral to the giant sauropod dinosaurs, such as Brontosaurus. Of particular importance in the study of dinosaurs are the skeletons of a primitive Triassic theropod. exhibited in the wall cases on the north wall and coward the east end of the hall. These skeletons, of the genus CoeIophysis, were excavated several years ago at Ghost Ranch in New Mexico, and they are among the most complete dinosaur remains ever discovered. Numerous skeletons, complete to the smallest bones and fully articulated, were found at Ghost Ranch. These represent animals in various stages of growth, and together they give us detailed information about the primitive dinosaurs. In this same case is a family tree of the dinosaurs, illustrated by scale models. 
Procheneosantus. Also there is a case showing the evolution of the skull in the duck-billed dinosaurs. Many of these reptiles developed large crests on the top of the skull, formed by an upgrowth of the premaxillary and nasal bones, and these contained extended loops of the nasal passages.

Related to the duck-billed dinosaurs were the peculiar troodonts or bone-headed dinosaturs, in which there was a great mass of bone above the brain. These animals reached the culmination of their evolution in Pachycephalosaurus, a skull of which is exhibited.

The horned dinosaurs, or ceratopsians, were plant-eaters, well adapted for defending themselves by fighting. They were something like rhinoccroses in the modern world. The skeleton of Triceratops show's the characteristic pose of a ceratopsian dinosaur, with the huge head lowered to present the three long, sharp horns at an adversary. These dinosaurs had a large frill on the back of the skull, which served in part as a protection for the neck and in part as an enlarged area of attachment for heary jaw and neck muscles. Various horned dinosaurs other

DINOSAURS AND THEIR EGGS. Protoceratops was a small, primitive horned dinosaur that lived in Mongolia during the Cretaceous period. The two skeletons are shown with a reconstructed nest of eggs.

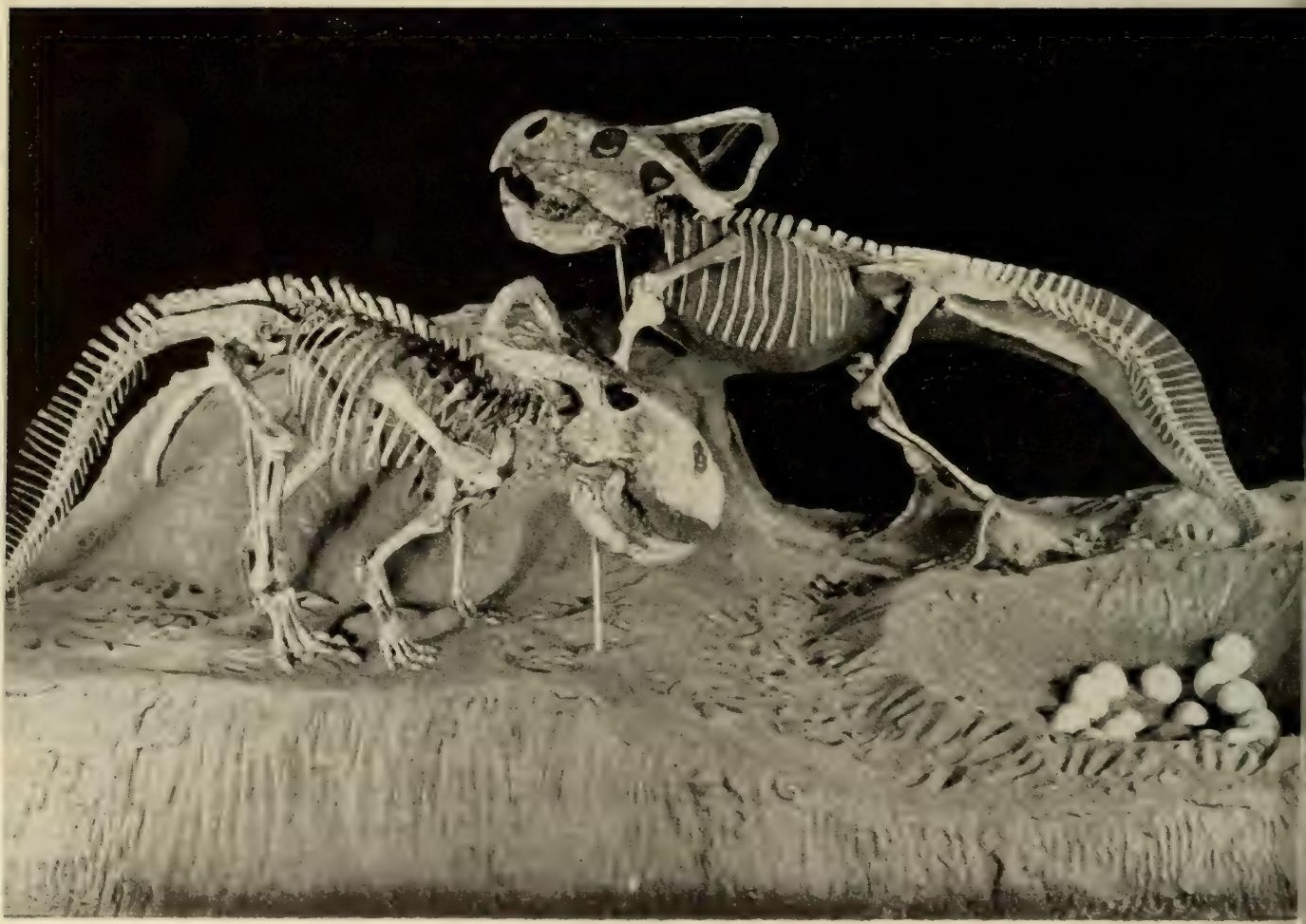




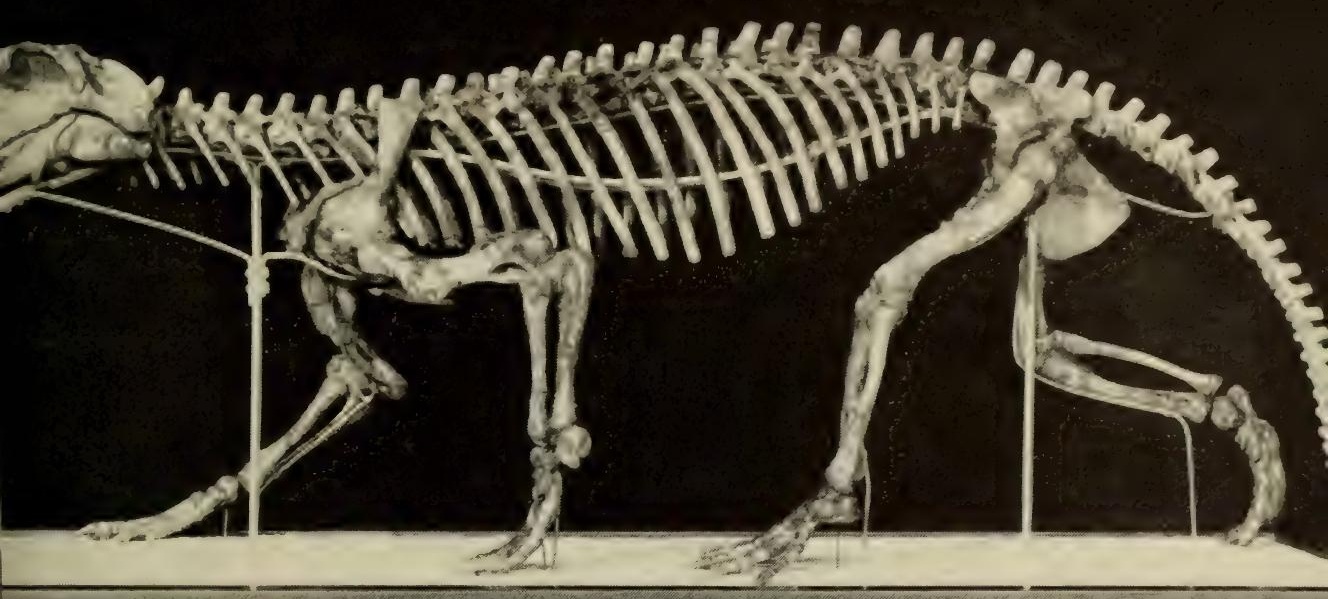

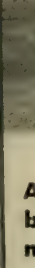
A MAMMAL-LIKE REPTILE FROM SOUTH AFRICA. Lyccenops was a Permian reptile,
belonging to the group of advanced reptiles that were ancestral to the first mam-
mals. It exhibits many mammal-like characters in the skeleton.

than Triceratops are on display, notably Monoclonius, with a single large horn on the nose and Styracosaurus, with spikes around the frill of the skull, in addition to the nasal horn. Of particular interest are the skeletons and eggs of Protoceratops, a small ceratopsian that was approximately ancestral to the larger types. The skeletons and eggs of Protoceratops were found at Djadochta in Outer Mongolia, by the Central Asiatic Expedition of this Museum. Several nests of eggs were discovered, and in some of the eggs are fossilized embryos of the dinosaur. These were the first dinosaur eggs to be discovered, and they confirmed previous speculations as to the method of reproduction in the dinosaurs. One other group of dinosaurs, the armored dinosaurs, is exhibited in this hall by a skeleton of Nodosaurus with the body armor in place. 
and by part of a skeleten of Palaeoscincus. These dinosaurs were completely covered on top by hear bony armor that protected them against attack from the large carnivorous dinosaurs of the time.

On the left side of the doorway at the north end of the hall is a display of the pterosaurs or flving reptiles. These reptiles arose in Jurassic times, at about the time the birds were first evolving. and for some time they shared the skies with the early birds. There were many forms of flying reptiles. some of them as small as sparrows, others, like the giant Plevanodon on the wall, with a wing spread of twenty feet or more. In these reptiles the fourth finger of the hand was elongated for a wing support, and the wing itsclf was formed by a large fold of skin.

On the other side of the doorway from the pterosaur exhibit is a display outlining the evolution of birds.

\section{THIRD FOSSIL HALL - Age of Mammals}

The beginning of the Age of Mammals was characterized by a radical change in the kinds of vertebrate animals that inhabited the earth. The dinosaurs had disappeared at the end of the Cretaceous period, and with them the great swimming reptiles and the bizarre pterodactvls or flving reptiles. Although the mammals had already evolved from their reptilian ancestors by the Jurassic period, they did not begin to dominate the land until the beginning of the Tertiary period.

The Third Fossil Hall, located in the southeast tower area, has been designed to illustrate a number of topics that may be logically considered with the first part of the Age of Mammals. As the visitor enters this hall from the Second Fossil Hall, he will notice ahead of him a large semicircular exhibition case. the right part of which is devoted to the important question of why and how animals became extinct in the geologic past. The left part introduces the history of the mammals with a family tree showing the relationships of the various mammalian orders.

The reptiles that survived the Age of Dinosaurs include the crocodilians, the lizards and snakes and the turtles. These groups are considered in a series of svnoptic exhibits along the corridor that leads from the Second to the Fourth Fossil Hall. Here are seen the skull of a late Cretaceous giant crocodile, Phobosuchus. from Texas and the shell and skeleton of a giant Pleistocene tortoise from India.

The stors of the rise of the mammals begins with an exhibit on the origin of the mammals which is located beside the entrance to the Late Dinosaur Hall. Here the visitor ma! compare the skeleton of a reptile and a mammal, and note the differences in the method of reproduction of these two Cilasses of vertebrates as well as the differences in growth patterns. I series of models demonstrates the transformation of the skull and skeleton from reptile to mammial.

The next exhibit illustrates the first true mammals. which lived together during the Age of Dinosaurs. They are known mostly from fragmentary skulls and teeth. Together with actual specimens of these 
first mammals, are enlarged models of lower jaws, skulls and reeth. These have been placed on a family wee to show how they were related to each other and to their later and more familiar descendants.

The marsupials are a well-defined group of mammals including the common opossum and the kangaroo. Their most distinctive chatrater is the usual presence of a pouch on the belly of the female, in which the young. born at a very immature stage, are carried for some time a!ter birth. There are also various characters in the skeleton that make it possible to distinguish the marsupials, fossil and living, from the great group of placental mammals to which man belongs. The exhibit on marsupials emphasizes the separate evolution of these animals into a variety of forms, many of which closely resemble various placental mammals. The marsupials were most successful in South Amcrica and particularly in Australia where they were for long periods not in direct competition with the placental mammals. In the adjoining case is a cast of the skeleton of Diprotodon, the largest known marsupial.

The placental mammals were not derived from the marsupials, although they and the marsupials had a common ancestor. The placentals multiplied and diversified rapidly in the Paleocene and particularly in the Eocene epochs. Quite distinctive assemblages existed in each of these periods along with characteristic plants and invertebrate animals, as shown by the exhibits that present cross-sections of early Tertiary life.

One such cross-section includes fishes of the early part of the Age of Mammals. Although little is known about the early evolution of the advanced bony fresh-water fishes, modern types are almost unknown in the fossil record until the Eocene period. Examples are exhibited of the various fossil fishes that occur in several large Eocene lake deposits in Wyoming, Colorado and Utah. In these lakes of 50 million years ago lived garfish, herrings, catfish and numerous other forms with close recent relatives.

Across the corridor is a series of skeletons of the first hoofed mammals or condylarths from the Paleocene and Eocene epochs. The long, low skull, short limbs and long tail were primitive characters shared for the most part with the earliest flesh-eating mammals. Meniscotherium was a small condylarth, about the size of a cat. Ectoconus, with its relatively small skull and heary limbs had the dimensions of a large dog Phenacodus, approaching the size of a tapir, represents the stock from which the odd-toed hoofed mammals (such as horses) probably arose.

SKELETON AND RESTORATION OF A PRIMITIVE HOOFED MAMMAL (Ectoconus). This ancient mammal, from the Paleocene period, was quite generalized and apparently ate a variety of foods.

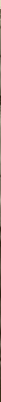


Skeletons of Comphodon and Uintatherium represent two different groups of archaic hoofed mammals, descended from the primitive condylarths, that lived during the first part of the Ige of Mammals. A family tree of these animals is displased around the corner from the Uintatherium skeleton. In the semicircular end case is a skeleton of a Pliocene "earth pig" or aardvark (Orycteropus). Aardrarks are living todas in Africa. The structure of the aardvark skeleton suggests that this curious animal may have evolved from the condvlarths, although the skull is highly specialized.

Across the alcove from the family tree of the archaic ungulates is an exhibit concerned with the important subject of historical zoogeography. Here are explained some of the factors that have influenced the distribution of animals, particularly land mammals, in the geologic past migration, the geographic isolation of groups of animals, their radiation from a point of origin and their sequence of arrival on a particular continent.

A general consideration of historical zoogeography naturally leads to an example of animal distribution and to the evolutionary effects of this distribution on the animals themselves. At the very beginning of the Age of Mammals, North and South America were connected by the Panama land bridge. At this time, three different groups of mammals crossed the bridge into South America: primitive marsupials, the ancestors of the armadillos and sloths, and one group of early hoofed mammals. Following this invasion, the land bridge sank beneath the sea and remained submerged until just before the beginning of the Ice Age, perhaps 3 million years ago. During this long period of isolation, the early immigrants into South America evolved along diverse lines. Across the corridor is a cast of the skeleton of Macrauchenia, a highly specialized descendant of the condylarth immigrants. This creature probably had a short elephant-like trunk which, together with its long neck and legs, must have presented a most bizarre appearance. In this section of the hall, the visitor can examine other mammals from South America. The notoungulates, evolved from the condilarths, were extremely varied, as the exhibits show. Toxodon lived in the Pliocene and Pleistocene epochs and, in build, must have resembled a short-legged rhinoceros. Scarrittia, from the Oligocene epoch, was a distant relative of Toxodon.

The edentates are a distinctive order of mostly South American mammals including the anteaters, armadillos and sloths. Grouped together in a dramatic manner in the tower alcove are some extinct descendants of the edentates that invaded South America during the Paleocene epoch. Included with them is the small Eocene Metacheiromys, a primitive edentate from North America. The ground sloths became common early in edentate history, and Hapalops is a typical OligoceneMiocene form. Megalocmus got to Cuba by the Pleistocene. Mylodon and Lestodon were the giants of their kind, the former reaching North America after the land bridge was reestablished in the Pleistocene. 
The armadillos were abundant and varied in Somb America We the Miocene. An early offshoot of the armadillo stock includes the gloptodons, which dereloped their protective ammor into an immosalste mass of solid, bony plates. By the Pliocene epoch thes berame rery large, and in the Pleistocene epoch they migrated into Texas and acrose (o) Florida. Glyptodon and Panochthus are representative examples.

In the corridor near the Fourth Fosil Hall is an exhibit of the first flesh-eating mammals, or carnivores, called creodonts. The creodonts lived during the first part of the Age of Mammals and their remains have been found on all the continents except South America and Australia. Most of them had long, low skulls with a small braincase. In such forms as Oxyaena, the dentition was of the shearing type characteristic of later carnirores. The teeth of Mesomy, on the other hand, had blunt, crushing cusps. The creodonts were the ancestors of all the later carnivores - the cats, hyaenas, civets, dogs, bears, racoons, mustelids, and also the seals and walruses.

The only placental mammals known from the Age of Dinosaurs belong to a group known as insectivores. These ancient placental mammals are exceedingly rare and of great value in evolutionary studies. Modern insectivores include the moles, shrews and hedgehogs. Certain Cretaceous members of this group, such as the tiny Deltatheridium from Mongolia, must be close to the ancestral stock from which all the other placental mammals arose. The skull of this form. which is the only part of the skeleton known, is exceedingly primitive and generalized for a placental mammal. A family tree of the insectivores is displayed in a case across the corridor from the creodont exhibit.

To the right of the insectivore exhibit are two unrelated groups of early mammals descended from the insectivores. The taeniodonts inhabited North America during the Paleocene and Eoccne epochs. They had high, peg-like teeth and short skulls with deep, powerful lower jaws. The limbs were short and stout. The tillodonts are known only from the Eocene epoch in North America. The skull had a small braincase and the molar teeth were low-crowned; the skeleton was rather bear-like in its proportions.

To the left of the insectivore exhibit is a large panel presenting a synoptic tree of the primates, the order of mammals to which man belongs. The primates evolved from the insectivore stock at the beginning of the Paleocene epoch. During the Paleocene and Eocene the early primates were numerous and divided into a number of separate evolutionary lines. Many of these then became extinct, but some continued on through the Age of Mammals to produce lemurs, Tarsius, the Ner: and Old World monkeys, the apes and, of course, man - all living today.

\section{FOURTH FOSSIL HALL - AGE OF MAMMALS}

\section{Osborn Memorial}

The fossil record for a few groups of mammals is unusually complete, and it is possible to follow evolutionary changes in the skeleton for 


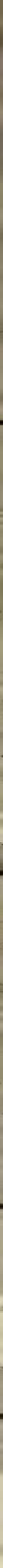

EVOLUTION OF THE HORSE. The important changes from the Eocene eohippus to the modern horse are illustrated here by the skull and feet. 


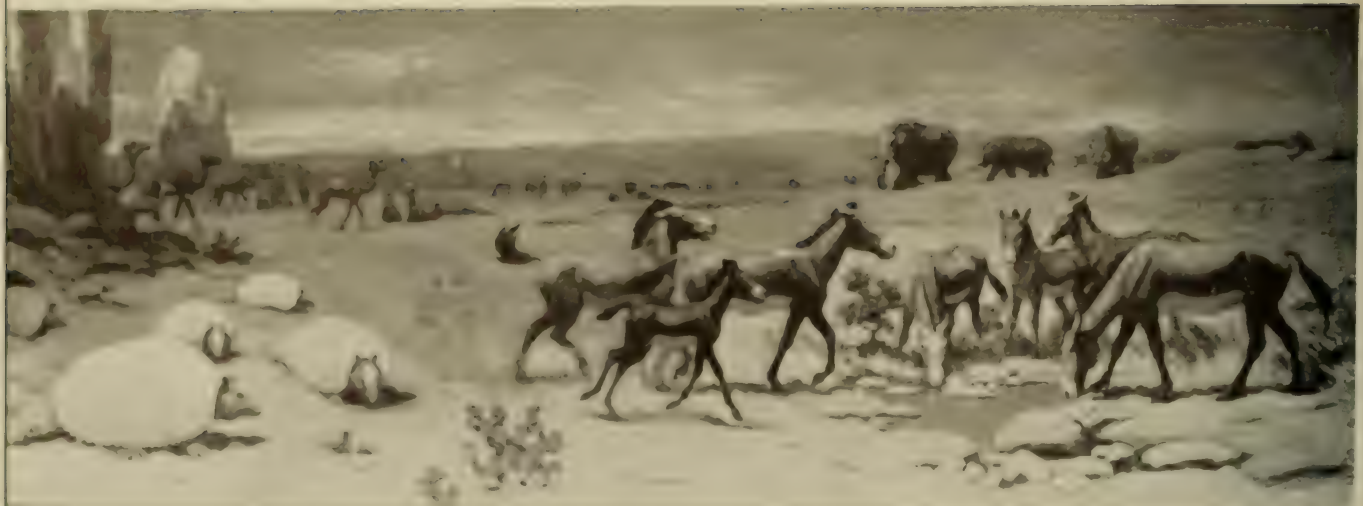

MAMMALS OF THE UPPER PLIOCENE IN ARIZONA. In the foreground (left) is the large armadillo-like Glypotherium and (right) the single-toed horse Plesippus. Merds of the camel Pliauchenia and the mastodon called Stegomastodon are seen in the distance.

A GROUP OF MIOCENE CAMEL SKELETONS (Stenomylus). Some of these are mounted in characteristic attitudes as if they were alive, others are lying on the rock matrix as their remains were actually found by a Museum expedition. These camels inhabited America at the beginning of the Miocene period.

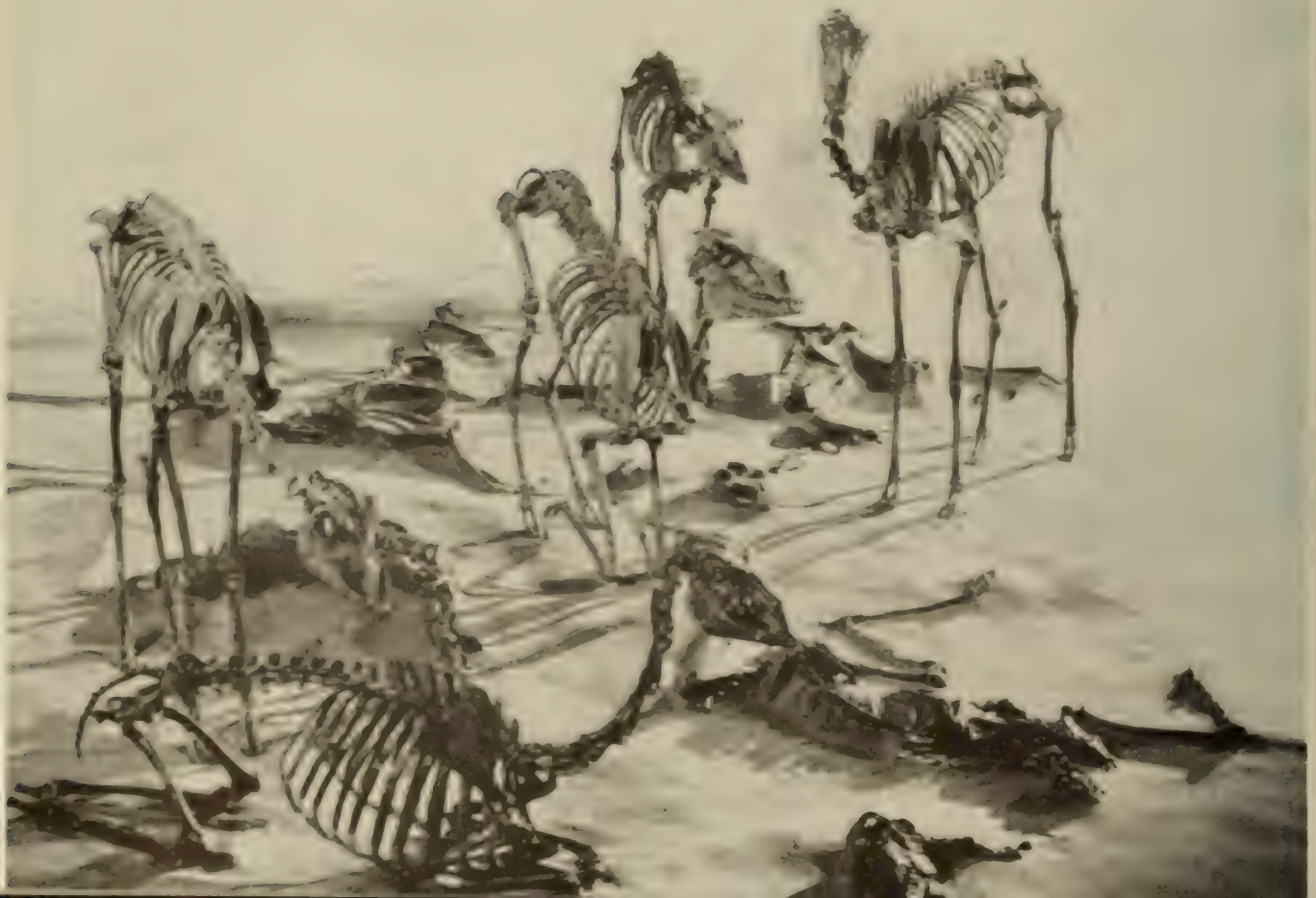


exactness because of the excellence of the horse fosil record. A series of progressively later horses demomblates the reduction in the number of toes to the single functional toe of the motern forms. The lenghtening of the limbs and the skull and the increase in general bods sise are well demonstrated.

Across the hall several alcoves are devoted to the many and varied even-toed ungulates or artiodacts.s. The family tree of the artiodacts shows the relationships of certain living members of the group) (which includes the pies, peccaries, hippopotami, camels, deer, girafles, antedopes and cattle), and a lew of the mam forsil families. The amtiodactsh, like the perissodactils, evolved from the condvlarths.

Perhaps the most successul artiodactyls of the Midclle Tertiary in North America were the oreodonts. These rather pig-like ruminamts were very abundant, particularly in the oligocene and Miocene periods. The agriochocrids, represented by the skeleton of forochoerus, resembled the oreodonts except that the leet bore claws rather than hoofs.

The pigs of the Old World and the living peccarics of the New World had a long separate history. Skulls of typical examples of each group are shown.

Stenomylus was a small Miocene camel that lived in North America. The group in the center aisle is made up of skeletons of this creature as they were preserved in the rock, and in various living poses. The early evolution of the camels occurred in North America, and they did not enter South America (llamas) or Asia until near the end of the Age of Mammals.

The display of flesh-eating mammals or carnivores includes fossil representatives of the various types of cats, including the saber-tooth forms, and also the mustelids, bears, raccoons and dogs.

The rodents - squirrels, beavers, rats and mice, porcupines and guinea pigs and a host of other living and extinct forms - are the most successful and numerous of living mammals. The various types of fossil rodents known from the Eocene and Oligocene periods indicate that this group was subdivided into many evolutionary lines early in the Age of Mammals. The rather squirrel-like Paramy's was a typical early rodent.

\section{FIFTH FOSSIL HALL - Ice Age Mammals}

The Pleistocene, or Ice-age, is one of the most interesting geological periods because it was during this comparatively short span of time that most of the evolution of man took place. The animals which lived then. sharing with early man the rigors of a glacial climate, were the most immediate ancestors of those we know today. In the Osborn Hall of the Age of Man are displayed many of the animals which are known to have been contemporaneous with early man. The murals on the walls, painted by Charles R. Knight, show groups of Pleistocene mammals of North and South America and Europe, and some of the early men associated with them. 


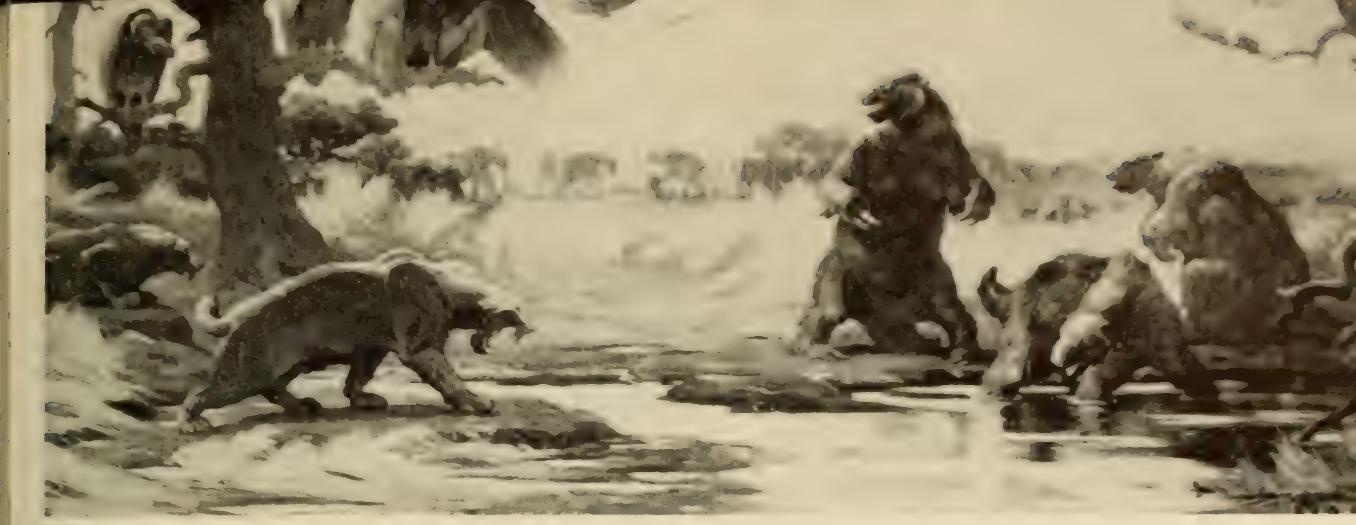

\begin{abstract}
RESTORATION OF RANCHO LA BREA TAR POOL SCENE. This painting includes the giant condor, saber-tooth cat, giant ground sloth, and in the distance, the Imperial Mammoth and the dire wolf.
\end{abstract}

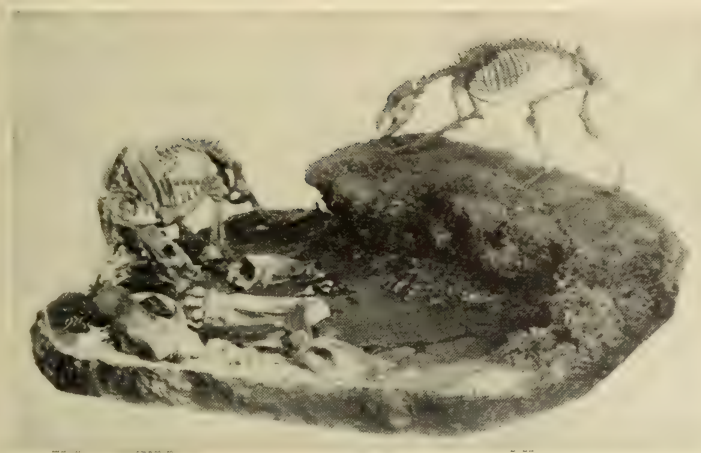

PLEISTOCENE MAMMALS. Skeletons of the saber-tooth cat (left), dire wolf (right) and giant sloth (foreground, mostly submerged in tar) from the Pleistocene tar pools of Rancho La Brea, Los Angeles, California.

it was purchased by Dr. John Collins Warren, a professor of anatomy at Harvard College, was mounted in 1846 and seen by thousands of visitors. In 1849 it was remounted and placed on exhibition in the Warren Museum in Boston, where it remained until 1906, when J. Pierpont Morgan presented it, with the entire Warren Collection, to this museum. In 1907 the skeleton was taken apart, cleaned and remounted as it stands today. The American mastodon was the most abundant of the Pleistocene proboscideans of North America, especially in the forested regions east of the Mississippi.

The tall Columbian mammoth skeleton, with its great incurved tusks, is a dramatic example of the group of true elephants which co-existed with the mastodons in Pleistocene times. Mammoth skulls and jaws from many parts of the world, and one of the largest known mammoth tusks, over 16 feet in length, are exhibited here, with skulls of the living Indian and African elephants for comparison. Many remains of Pleistocene mammals have been discovered in the frozen ground of the far 
north, often with flesh and hide well preserved. Examples of the dried flesh, wool and hair of a woolly mammoth found in Alaska may be seen here.

On the other side of the hall is a group showing how animals were trapped in natural asphalt pools at the famous Rancho la Brea tar pits in Los Angeles, California. Additional mounted skeletons of the sabertooth tiger and wolf are displayed nearby. Here also is the huge European cave-bear, mounted in a standing attitude of attack. Pleistocene artiodactyls, or "even-toed" ungulates, include a series of skulls of various kinds of wild cattle and a mounted skeleton of a bison from Folsom, New Mexico, showing the association of arrow-points with bones of this animal. The mounted skeleton of the Irish deer, Megaloceros, with its wide antlers, is historically interesting in being the first mounted fossil skeleton exhibited in this muscum. In contrast to this, is the skeleton of a pigmy hippopotamus which lived in Madagascar during Pleistocene times.

A small group showing one way in which fossil bones are preserved is the reproduction of part of the Conard Fissure locality in the Ozark Hills of northern Arkansas. During Pleistocene times, a fissure, or open crack caused by earth movements, was gradually filled with rocks, red clay and stalactites. Imbedded in this are found the bones of animals which inhabited the fissure, and of the prey they dragged into it. More than 60 different species of mammals, birds and reptiles have been found, mostly of a forest fauna such as bears, wild-cats, wolves, rodents, bats and snakes.

\section{MICROPALEONTOLOGY}

Micropaleontology is that phase of general paleontology that deals with very small animals and plants. The Department of Micropaleontology is wholly a research department and has no exhibits except for the models of Foraminifera displayed in the gallery of the Hall of Ocean Life.

The work of the Department includes research on the literature of the field, research on fossil material for clients, and independent work on microfossils. Studies are also carried on to determine the relationship of fossil and living forms to their past and present environments.

The results of these studies are largely contained in published material distributed to subscribing members of the Department. Among those subscribers are almost all of the larger universities and colleges, other museums and research institutions, and all the major oil companies of the world, whose principal output depends on a thorough knowledge of the tiny creatures that help us to find oil deposits. 


\section{INVERTEBRATES}

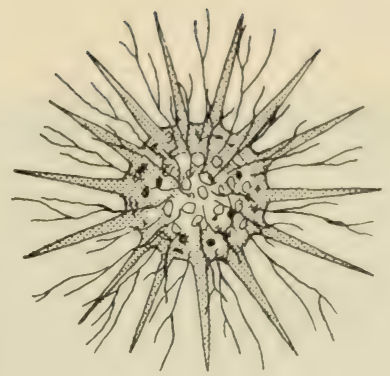

The exhibits include a number of habitat groups showing invertebrates in their natural surroundings and a synoptic series from the simplest single-cell animals to the most complex invertebrates.

\section{THE SYNOPTIC SERIES}

Because of the small size and fragile nature of many invertebrates, a large part of this exhibit consists of glass or wax models, often much enlarged. These include the famous jewel-like creations of Herman Mueller.

ONE-CELLED ANIMALS - Protozoa. These exhibits show the simplest form of animal life. Although in some forms the animals assemble into colonies, all are single-celled individuals. These exhibits are mainly models which represent protozoa enlarged hundreds of times.

SPONGES - Porifera. Sponges are made up of many cells but these are comparatively loosely organized and do not form definite and distinct tissues as in the higher animals. Sponges range in size from small incrustations on stones and shells to the gigantic Neptune Goblets of Eastem Seas.

STINGING ANIMALS - Coelenterates. These include the coral animals and their relatives, the hydroids, jellsfish, sea anemones, sea fans, sea plumes, stony corals and similar creatures. The stinging animals have their cells organized into definite tissues but these do not form real organ systems as in the higher forms.

COMB JELLIES - Ctenophora. While similar in appearance to the stinging animals, these lack the stinging cells characteristic of the last group. Although they do not have definite organ systems, their organiza- 
SETHOPHORMIS. This glass model shows the silica skeleton of a typical Radiolaria. These minute animals live in the deeper water of the seas.

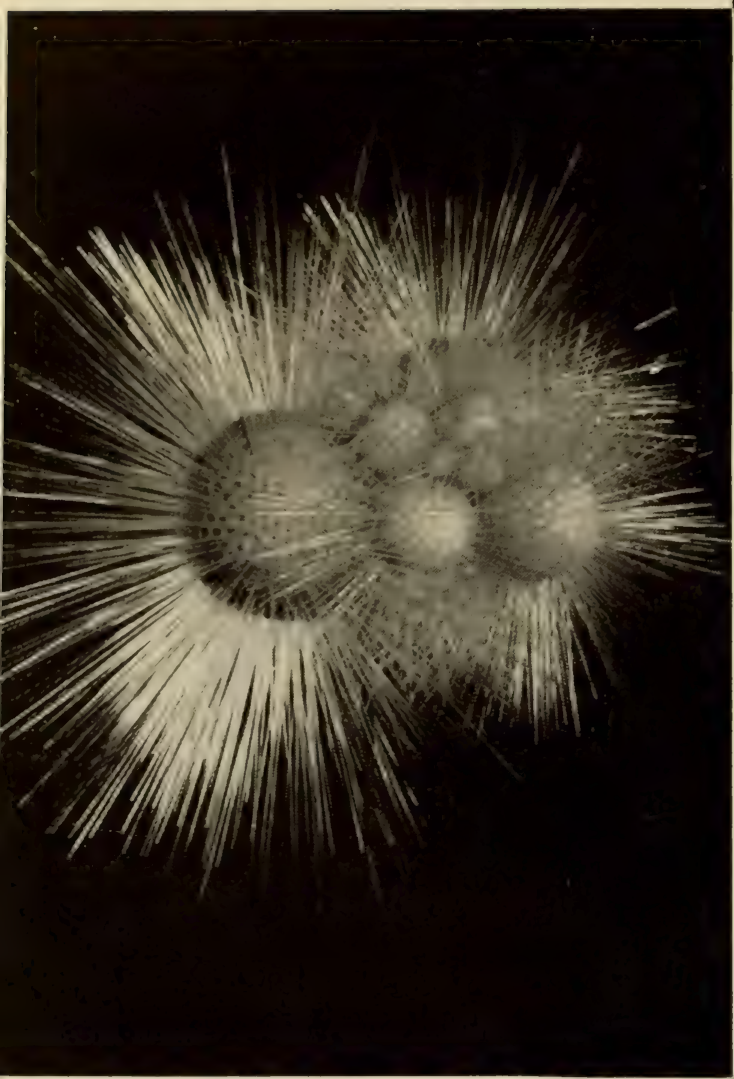

GLOBIGERINA. This is a minute sea animal belonging to the group called Foraminifera. The needles are a floating device. The lime shells of the dead animals fall to the ocean bottom where they form, in certain areas, a muck called the Globigerina ooza. The fossil shells of these animals as well as the Radiolaria are important to the oil industry because they are used to date the ages of rocks.

CHAMBERED NAUTILUS. Cross section showing chambers. The animal occupies the last chamber. 
tion is more complex than that of stinging animal. Transpancent with iridescent, vibrating, swimming hairs, in life they are often ofjects of great beauty.

FLAT WORMS - Platyhelminthes. There are many important parasitic species of flatworms, including the tapeworm, which are shown in a series of models. The enlarged wax models of free-living forms show mostly species from the Mediterranean, but beautifully colored flatworms are found in almost all seas; those living in fresh water are usually less brilliant. All of the important organ systems of the higher animals are present in these worms.

ROUNDWORMS - Nemathelminthes. The parasitic roundworms are very widespread; almost every other type of many-celled plants and animals harbour one or more species of nematodes. Several serious human diseases such as trichinosis and elephantiasis are caused by these animals. Less well-known are the vast numbers of free-living nematodes found nearly everywhere in the soil and in both fresh and salt water.

ROTIFERS - Rotifera. The minute wheel animals or rotifers include many exquisite or grotesque forms. A few are parasitic but most are free-living. Most of them live in fresh water where they are very widely distributed. In addition to the comparative series of models of enlarged rotifers in the wall case at the southwest end of the gallery, rotifers in their natural environment are shown in the Pond Life Group at the other side of the Bahama Reef Group.

SPINY ANIMALS - Echinodermata. These include the sea stars, brittle stars, sea urchins, sea cucumbers and sea lilies. In spite of their entirely different appearance, many zoologists believe that this group of invertebrates is that which is most closely related to the chordates, the group of animals to which man belongs. This conclusion is based upon a study of the body chemistry and of the early stages in their life history.

CHORDATES - Chordata. The phylum includes not only the vertebrates but a number of small, relatively primitive and unfamiliar animals as well. The three cases devoted to this phylum in the Gallery of Living Invertebrates show the hemichordata and the ascidians. Anatomical models of important members of these groups show the details of their internal anatomy while other exhibits show the external appearance of many other forms.

PROBOSCIS WORMS - Sipunculoidea and Echiuroidea. These small groups of worm-like animals have until recently been included either in the segmented worms or combined into one group, the Gephyrea. Their anatomical peculiarities are, however, sufficienty distinct to justify considering them as separate groups. They are all marine and for the most part live either in burrows or in natural fissures. 


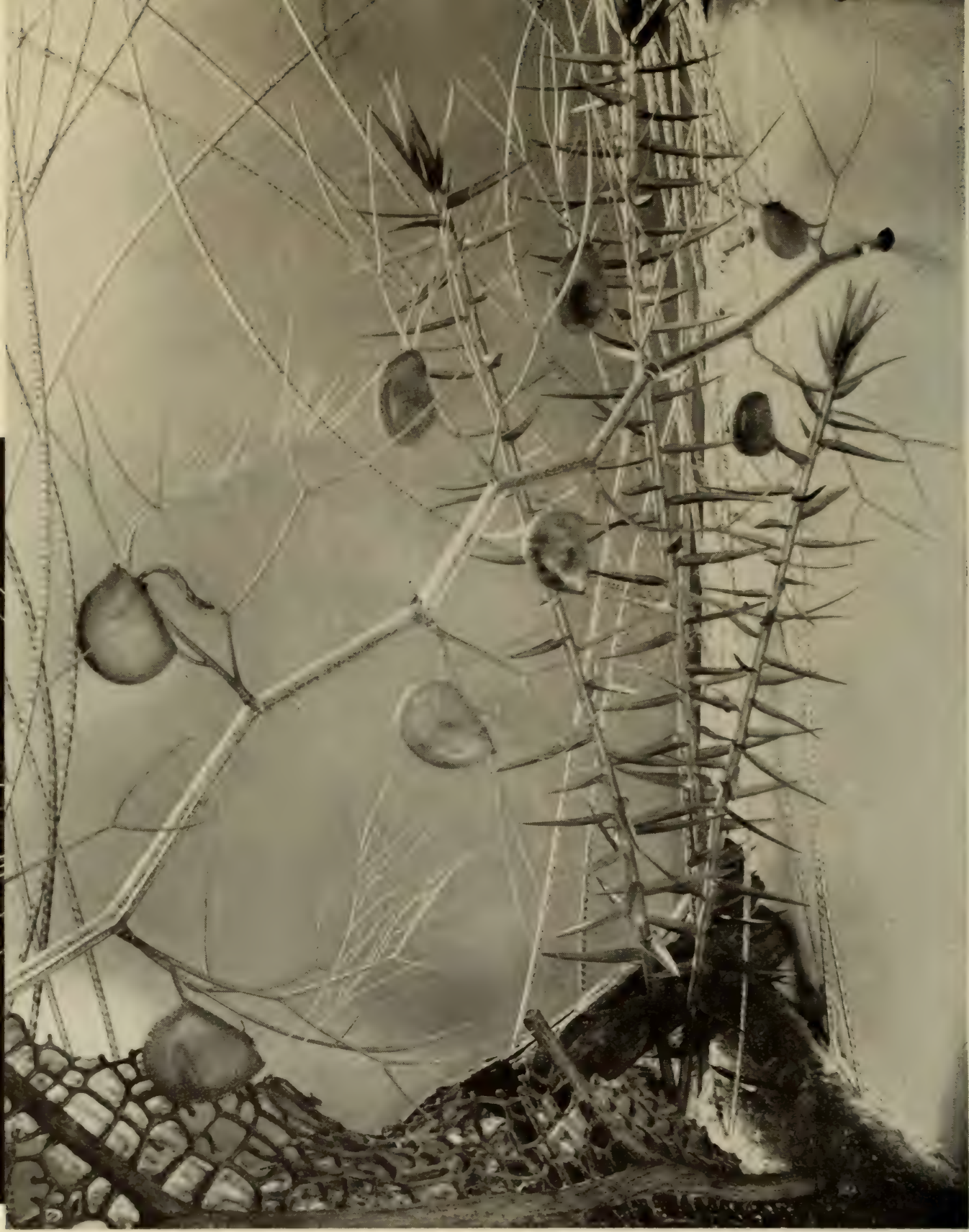

1,000,000 TIMES MAGNIFIED DROP OF POND WATER. This exhibit shows Spirogyra with its spiral band of chlorophyll. In the center is the common pond weed, bladderwart, which bears bladders that trap small animals. 


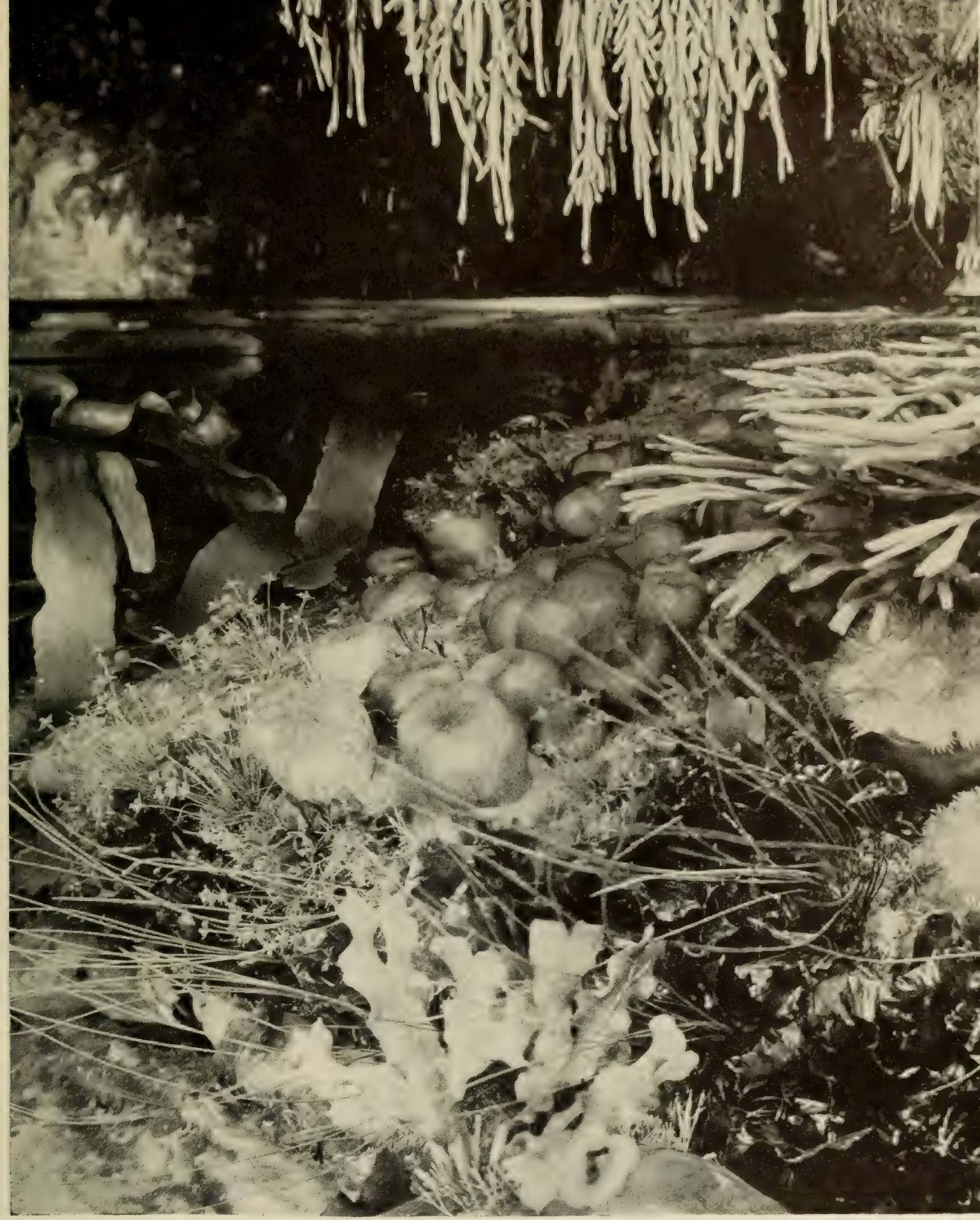

A PORTION OF THE ROCK POOL GROUP. On the rocky northern New England Coast are numerous basin-like crevices in the cliffs. At high tide, many of these are totally submerged, but as the water recedes they are left as stranded pools, richly populated with marine animals and plants. In this group, sea-anemones are disclosed among the rockweed, sea-lettuce and kelp. 
SEGMENTED WORMS - Anmulata. As typified by the common earthworm, these worms are made up of rings or segments. They include many remarkable and beautiful marine worms as well as the more familiar earthworms and leeches.

JOINT-LEGGED ANIMALS - Arthropoda. These include the crabs, lobsters, insects, spiders and their relatives. The number of living species in this group is greater than that of all the rest of the animal kingdom. The lobster exhibited here is one of the largest ever taken. The largest living arthropod is the Giant Japanese Spider Crab which is shown in the case at the north end of the gallery.

MOLLUSKS - Mollusca. The mollusca are next to the arthropods in the diversity and number of forms. They include clams, snails, slugs and limpets as well as squids and octopuses. All these animals have soft bodies but most of them secrete a hard exterior shell. The wall cases at the north end of the gallery contain a series of mollusk shells selected to show the range of size and form in each of the superfamilies. In the "A" case near the entrance to the hall are a group of large shells including a paper nautilus which is believed to be the largest perfect specimen.

Upon entering the hall, a large model of the GIANT SQUID, Architeuthis princeps is seen overhead. This model is based upon the studies made by Professor Verrill on specimens stranded in Newfoundland between 1872 and 1879. These large animals are attacked and eaten by the sperm whales. A fight between these two monsters of the sea is shown on the right in a mural painted by J. M. Guerry.

\section{HABITAT GROUPS}

On both sides of the hall at the far end of the gallery are displays showing invertebrates in their natural habitats. THE SALT MARSH GROUP is the first on the left. This group depicts the life in a salt marsh at Cold Spring Harbor, Long Island, and is typical of such marshes from Cape Cod to Cape Hatteras.

THE SOUND BOTTOM GROUP represents a sandy bottom with large granite boulders forming the reef known as the Devil's Bridge in Vineyard Sound, Massachusetts. The lobster and blue crab are among the animals shown.

THE WHARF PILE GROUP includes animals living in and among the submerged piles of an old wharf at Vinevard Haven, Massachusetts. The piles are covered with the flower-like colonies of sea anemones, hydroids and other stationary animals.

THE POND LIFE GROUP displays a cubic half inch of pond bottom enlarged one hundred diameters or cubically a million times, transforming a minute area into a forest peopled by rotifers and other strange creatures ordinarily invisible to the naked eye. 
On the other side of the upper part of the Bahamian Reef Group a companion exhibit to the Pond Life Group shows two square inches of sca bottom colarged to an area five feet square. Picces of sea weed are seen cncrusted with colonies of Bryoroa composed of thousands of small animals each of which has built a vase-like shell. Encrusting ascidians and their tadpole-like young. a sea spider and flower-like sea worms are among the other strange animals found here.

THE ROCK POOL GROUP contains the life which may be found in rock pools along our shores north of Cape Cod. In the scene, the falling ticle has left a pool in a rocky basin which shelters a community of sea anemones, sea stars and other invertebrates.

THE EELGR ASS GROUP shows a portion of the bottom of the harbor at Woods Hole, Marsachusetts. In addition to the animals living on or above the bottom, a cross-section of the bottom reveals animals which burrow into the mud and sand.

THE BAHAMIAN REEF GROUP is seen at the farther end as you enter the Hall of Ocean Life. The portion of the group above the gallery shows the coral island and quiet lagoon. On the distant horizon the low-lying Bahama Island of Andros is seen with its fringe of coconut palms. Here the finest barrier reef in the West Indies parallels the shore. The small island in the foreground below the gallery depicts the coral forest as seen from the bottom of the sea. Many colorful inhabitants of the reef are seen among the branches of the tree-like elkhorn coral which rise to the water surface sixteen feet above.

THE PEARL DIVERS GROUP to the right of the Bahamian Reef Group represents a scene on the ocean floor within the cnclosed lagoon of the coral atoll, Tongareva. This small, ring-shaped island, eleven miles in diameter, is in the South Pacific Ocean about 2000 miles south of Honolulu. This group show's the marked contrast between the brilliantly colored delicate ponds and finely divided clusters of coral found in the Pacific reef and the weird, branching species of the Atlantic exhibited in the adjoining Bahamian Reef Group. 


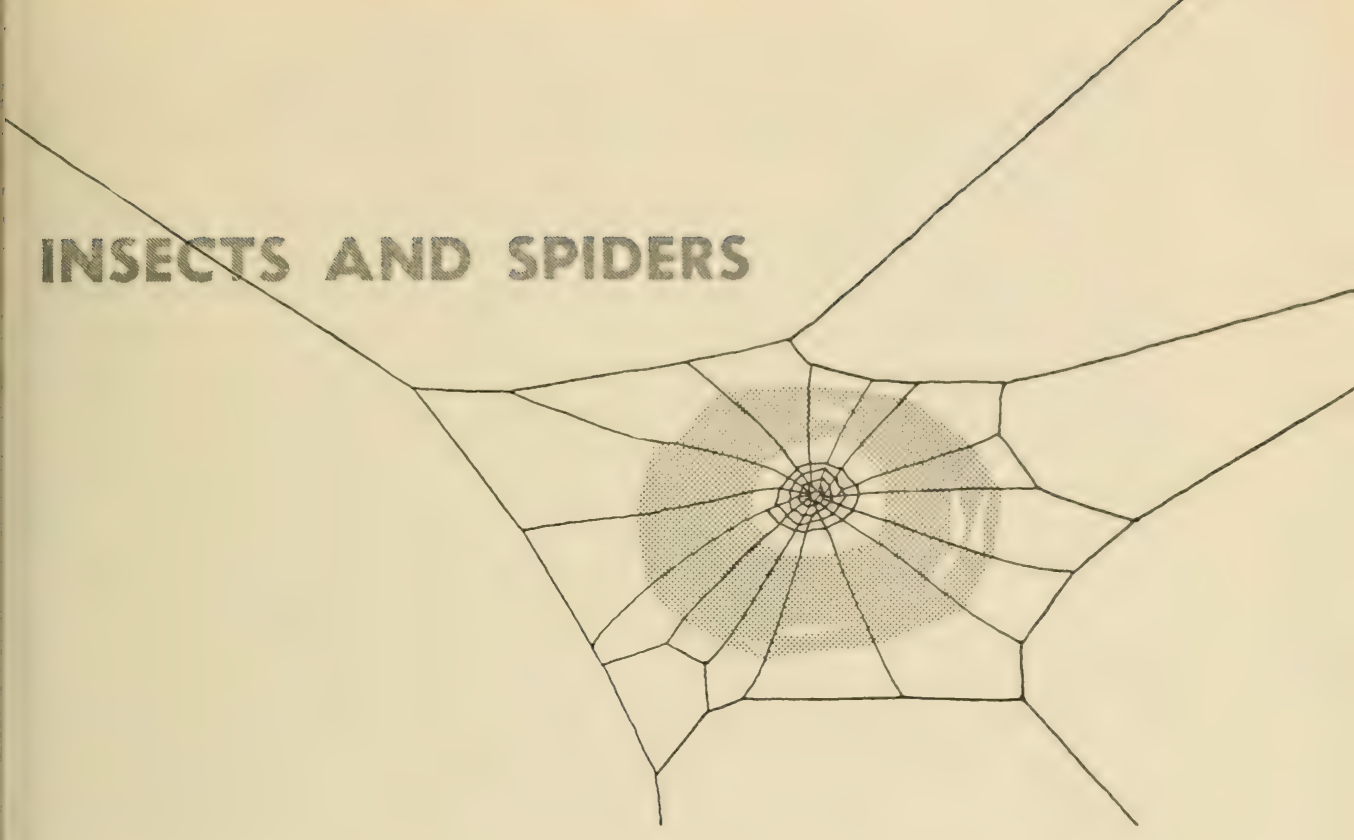

Insects and spiders play a very important part in man's every day life, a part which is too often ignored or about which too little is understood by the general public. About 80 ; of the total number of species in the Animal Kingdom belong in the phrlum Arthropoda which includes insects and spiders. At the present time approximately 850,000 species of insects and spiders have been described, and it is probable that there exists the almost unbelicrable $n$ mmber of $9,000,000$ additional species. Many insects and spiders have no direct bearing on man's economy or interests although ther mas be vers important in maintaining a balance in nature. Because of this large number of species, it is, therefore, impossible to display examples of each.

In the Insect and Spider Hall. which is the largest and most complete exhibit of its kind in this countrr, examples of some of the more interesting species, and ecological and biological phenomena are presented. Beneficial and destructive insects are displaved, along with beautiful and bizarre insects from all over the world. These exhibits have been accomplished through the efforts of the research staff of the Department of Insects and Spiders, which is constantly studying many phases of insect and spider life. Problems in biology and ecology are always attracting the staff to work aficld in many areas in this country and abroad where large and important collections are made.

Much of the work carried on in the laboratories at the Museum has to do with the classification or naming of the various species. The importance and necessity of this rescarch work to the public arises from the fact that each year we receive thousands of requests for identifications of insects and spiders that have come to the public's attention. We are 
constantly being asked to name a particular insect and to state whether or not it is dangerous, if it will destroy household furnishings, the home, personal belongings, or if it will affect the health of individuals coming in contact with it.

The visitor's interest in the Insect and Spider Hall will be affected by his own personal experience. The suburban dweller will perhaps be more interested in those insects affecting garden or ornamental plants, whereas the apartment house dweller who has no garden will probably le more interested in houschold insects. Exhibits of insects of interest 10 both groups are 10 be found in the Insect and Spider Hall.

Through the ages and even before the time of civilization, man has struggled with the insects for his existence. At the same time many insects contribute beneficially in supplying man with various commodities and many predaceous and parasitic species have aided in the control of destructive insects. The ways in which insects are beneficial to man are many and varied. Among these we might mention the silk worm in relation to true silk of commerce. Beeswax and honey are products of the honeybee which have long been used by man. Shellac is a secretion ol a scale insect of India. The cochincal scale insect is used as a dye for attificial coloring of foods, drinks and cosmetics. A number of extracts of medicinal value have been made from the bodies of insects, and spider silk is employed in the manufacture of certain optical instruments. These are but a few of the examples of direct ursage of insects. Probably the most important benefit derived from them is in their pollinizing of various fruits, seeds and vegetables which form a large portion of man's dict. Most of the animals used by man for his meat are dependent upon plants which would not exist if this pollinization were to cease. Even many of the fish products utilized by man would disappear were it not for the fact that aquatic insects are available as food for the fish. Many of our game birds are dependent almost entirely, or at least in large part, on insects for their food. In many parts of the world, from ancient times to the present day, insects have been eaten by human beings. Imong these we might mention grasshoppers, crickets, beetles, caterpillars of moths and butterflies, termites and aquatic flies and bugs. Insects have also been used extensively in scientific research on genetics. physiology, psychology and sociology.

The wass in which insects are injurious to man are many and often of a critical nature. They injure or kill all kinds of crops, forest trees and valuable plants by chewing the foliage, sucking the sap, boring or tumneling into roots, stems or leaves, by carring organisms such as fungi, bacteria, or protozoa which then attack the plant. It has been cstimated that the direct annual agricultural losses occasioned by insects in the United States are about $\$ 2,000,000,000$. Ther attack and annoy or kill living animals. Many species such as flies do direct damage by feeding on living tissue. others carry parasites of various diseases, some serve as intermediate hosts for organisms pathogenic to man and still others are venomous and are capable of causing bodily injury. 
The species most commomly observed he the public ane those which attack stored food products, clothing, books, lumniture and buildings. Termites are among the most destructive in this group) hut smoh imsen as powder post beetles and cigarette beetes do comsiderable damage to furnishings. The clothes moths and the carpet bectles do millioms of dollars in damage annually to clothing and similat mattrials. I he meal worms are often found in packaged cereats and other prepatred grain foods and make such products unfit for human consumption. Io this group can le added a host of species which attack field coops and upon which we are constantly required to apply expensive control meatures. Among these pests we might mention the colorado potato beete, the Mexican bean beetle, the cotton boll weevil and the corn ear worm. No part of a plant is immune to insect attack. The immature stages of many species feed on the roots, whereas both immature and adult insects attack the leaves, stems, fruits and flowers.

Some of the greatest scourges in the history of mankind have been transmitted by insects. Black Death or Plague, which is transmitted by a flea, has claimed millions of lives since the sixth century and continues to be a constant menace to modern society. Yellow fever transmitted by the mosquito has at times made portions of the world uninhabitable and nearly prevented the construction of the Panama Canal. Malaria, also transmitted by the mosquito, has been and is an important discase of man. It is widely distributed throughout the world and during the recent war a considerable number of men had to be employed in the control and prevention of this disease. Typhus, transmitted by the body louse, has always been a major problem in congested areas and many thousands of people in many parts of the world suffer from its depredations. Ticks and mites, which are not insects but are related, carry a number of diseases which are of great importance. Rocky Mountain spotted fever which has claimed the lives of many people is carriced by a tick. A number of species of mites are responsible for mange and almost everyone has come in contact with the red mites which make life miserable over extensive areas in the New World.

From the above account the reader will be impressed by the fact that very few organisms or habitats on the earth's surface are not frequented by insects. Indeed they have been more successful in adapting them-

THE HUMAN FLEA (Pulex irritans), relatives of which are responsible for the transmission of Bubonic Plague.

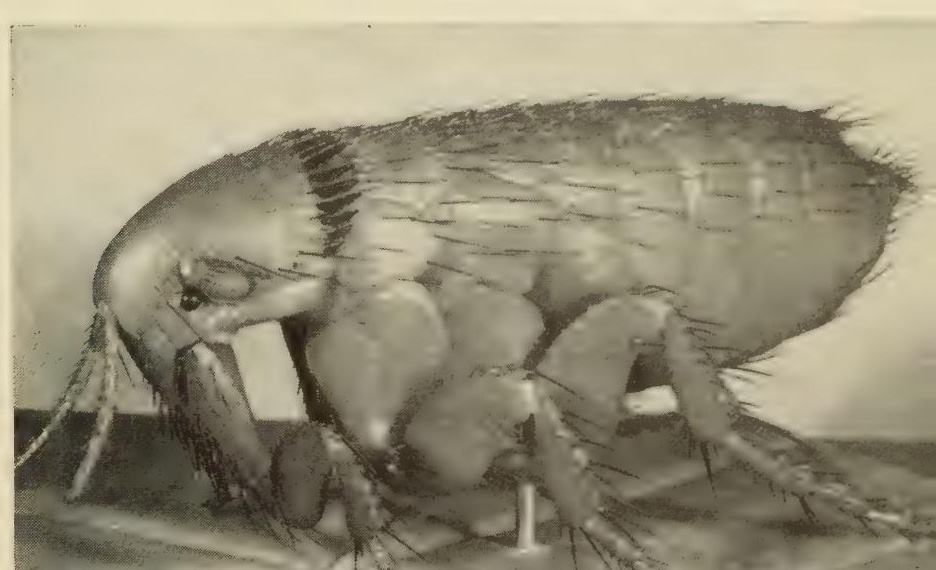


selves to life on this world of ours than any other organism. Proof of this adaptability can be seen when one comsiders that insects came into being some $300,000,000$ years ago and have out-lived such animals as the dinosaurs which might seem to have been better able to survive because of their size and strength.

\section{THE EXHIBITS}

The Museum visitor often wonders about the relationships between various groups of organisms. The Animal Kingdom is divided into a number of very large groups called Phyla. The insects, spiders and mites belong to the phylum Arthopoda. This phylum contains a number of classes including the Arachnida, or spiders and mites, and Insecta, or insects. In other words, the two groups belong to the same phylum but to two different classes within the phylum. The Insect and Spider Hall, therefore, covers members of two classes belonging to the phylum Arthropoda. Exhibits showing other classes in this phylum are presented in other halls in the Museum.

Because of the irregular architecture of the Insect and Spider Hall and the difficulty often experienced in locating particular exhibits, a map is presented to show the more important subjects and groups presented. It should be remembered, however, that there are many exhibits not indicated on the map and also that the cases are not numbered according to the map numbers. The numbers are referred to in the following text and the placement on the map is in the approximate location in the hall. Case 1 is to the left of the entrance from the Hall of Reptiles and Amphibia while Case 17 is to the left of the entrance coming from the Hall of Biology of Mammals.

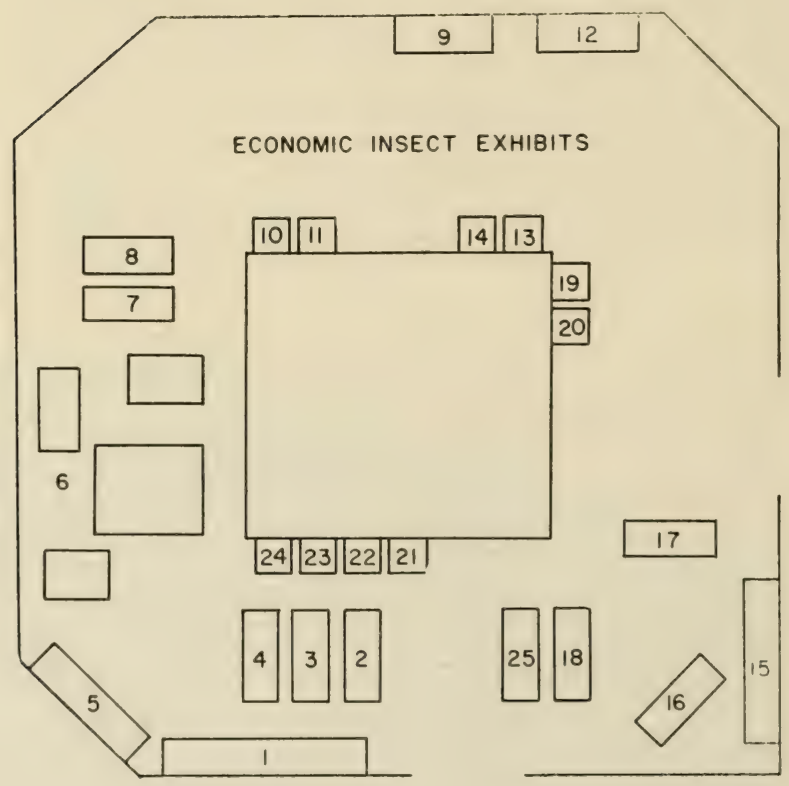

DIAGRAM OF THE HALL OF INSECT AND SPIDER LIFE showing the location of some of the more important and interesting exhibits referred to in the text. 
BENEFICIAL INSECTS. Many insects and insect products have been and are utilized directly or indirectly by man. In Case 9 examples of the swarming of honeybees as well as the various upes of cells contained in the hives are presented. Illustrations of the worker and yueen and drone bees are also shown. Included in this exhibit is an example of the bee moth whose larva feeds at night on the wax of the combs.

Many different kinds of insects are used for fish bait and others are used as models for the construction of fishermen's "flies." Case 24 contains a series of models showing how to tie a fly, together with models of well-known commercial flies now in use. Examples of both American and English fishing flies are shown.

In Case 2 various examples of fruits, vegetables and other products whose development is dependent upon insects for pollination are presented.

A very extensive exhibit on the progressive stages in silk culture is shown in wall cases. This traces the development from the larval stage of the silk moth through the various stages in the manufacture of silk to the finished product. Examples of the adult silk moths and related moths with their pupal cases are also given.

DESTRUCTIVE INSECTS. On the south side of the hall in a number of cases are a series of exhibits showing insects that attack various types of plants and food products that are of value to man. Actual specimens and examples of types of injury are included. Such household pests as clothes moths, carpet beetles, cockroaches, house ants and bedbugs are presented either as actual specimens, or, where the insects are very small, as enlarged models or illustrations. Pests of stored food products including the flour moths, meal worms and tobacco beetles are to be found in these groups. Other insects attacking cotton, truck crops, fruits, woody plants, shade trees, nut trees and coniferous plants are to be found in this series.

One of the most destructive and most commonly encountered of the household insects is the termite. In Case 25 the visitor will find enlarged models showing the differences between the termite and the ant and in Case 4 a diagrammatic chart of the life history of the termite. Also in this case the visitor will find a series of enlarged models showing the various castes in the termite's social organization.

INSECTS AND ART. In Cases 10 and 11 are examples of art work in which insects are employed as subjects, or in which actual insect specimens or portions of their bodies are used in various types of ornamentation. Examples of such work from Asia, Central and South America are presented.

INSECT BIOLOGY AND ECOLOGY. The life history, habits of ants and their relation with other insects are presented by a series of illustrations and photographs in Case 3.

In Case 12, by means of colored illustrations and actual specimens, the growth and development of the Io moth is shown. Also in this case the visitor will find the immature stages and adults of the 17-year locust. 


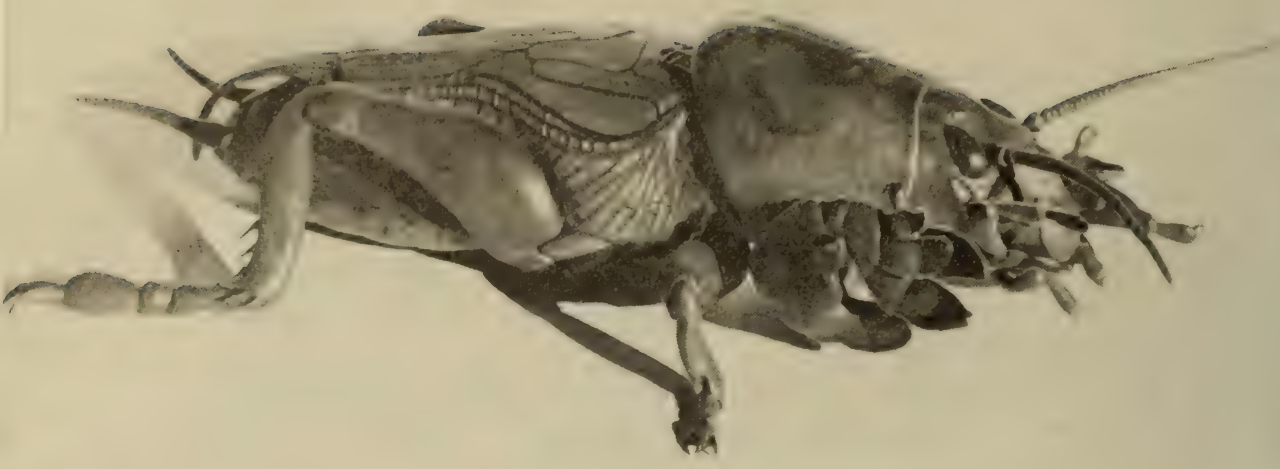

MODEL OF MOLE CRICKET (enlarged five diameters). An insect with forelegs especially adapted for digging.

Case 13 is a habitat group in which the Mole Cricket is shown in its natural environment in the ground.

Similarly in Case 14 a dragonfly nymph is shown in the act of catching a mosquito larva. Both of these exhibits depict the insects enlarged five times natural size.

Habitat group No. 21 shows a portion of a colony of Army ants with raiders bringing back insects they have captured and killed.

Case 22 is a similar exhibit showing leaf-cutting ants on branches, entering the nests, carrying the pieces of leaves that they have cut. These pieces of leaves are not eaten but are used in growing a special kind of fungus that is eaten as food.

Habitat group No. 23 shows a nest of the stingless bees with the entrance extending from a cavity in a tree. These bees are unable to sting and the honey of some species is pleasant to the human taste and is utilized by the inhabitants of many tropical countries.

An example of beetles in hibernation is presented in Case 20, showing the massing of Lady Bird beetles in a mountainous area.

The abundance of, and destruction caused by, the Japanese beetle is illustrated in Case 19.

INSECT AND SPIDER ARCHITECTURE. Case 5, although incomplete, contains a number of examples of the different types of nests constructed by various species of tropical wasps.

Various types of ant nests are shown in Case 3.

In wall case No. 1 are models showing the processes in the weaving of the spider web. Pictures of actual webs, with colored illustrations of the spiders, are also to be found in this group. 


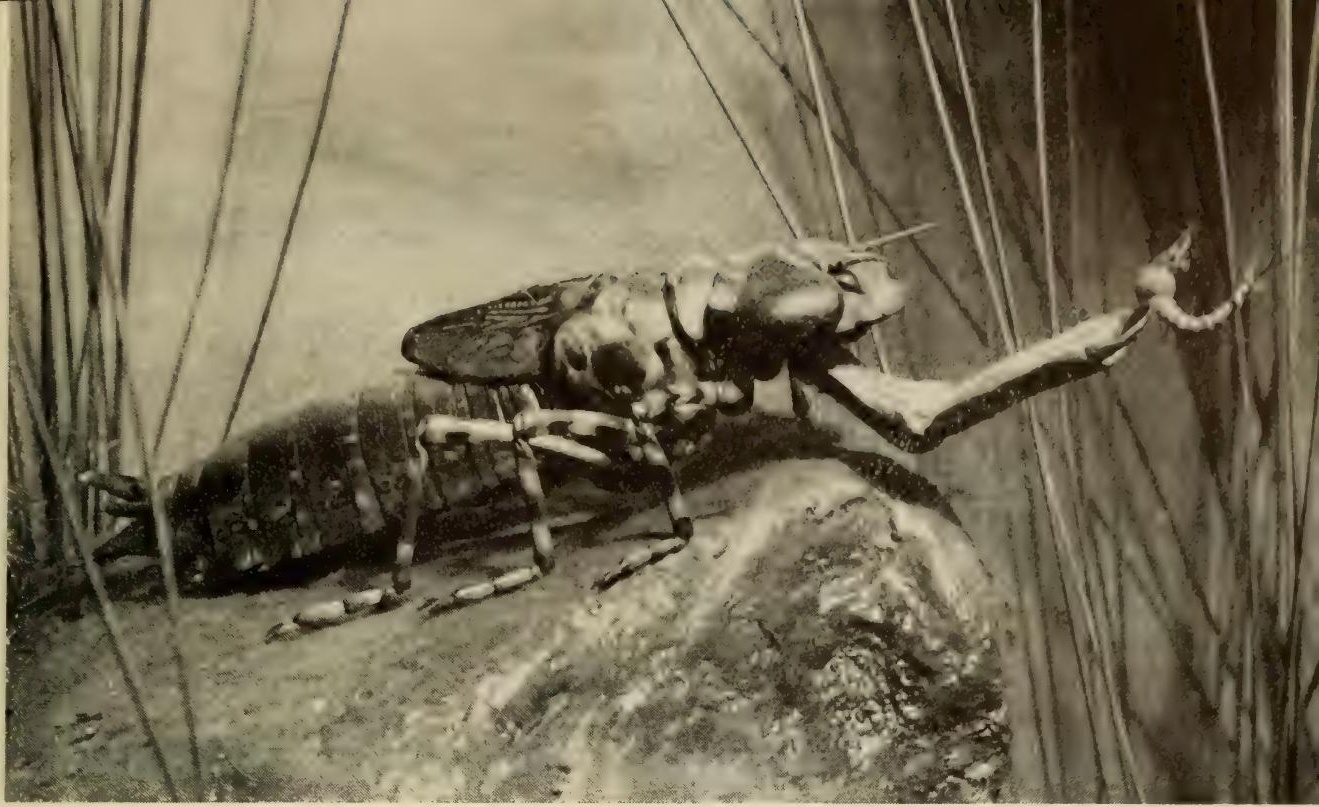

DRAGON-FLY NYMPH catching a mosquito larva by means of its curiously modified lower lip which is segmented and has a pair of pincers at its tip.

TROPICAL WASP NEST with side cut away to show the internal architecture.

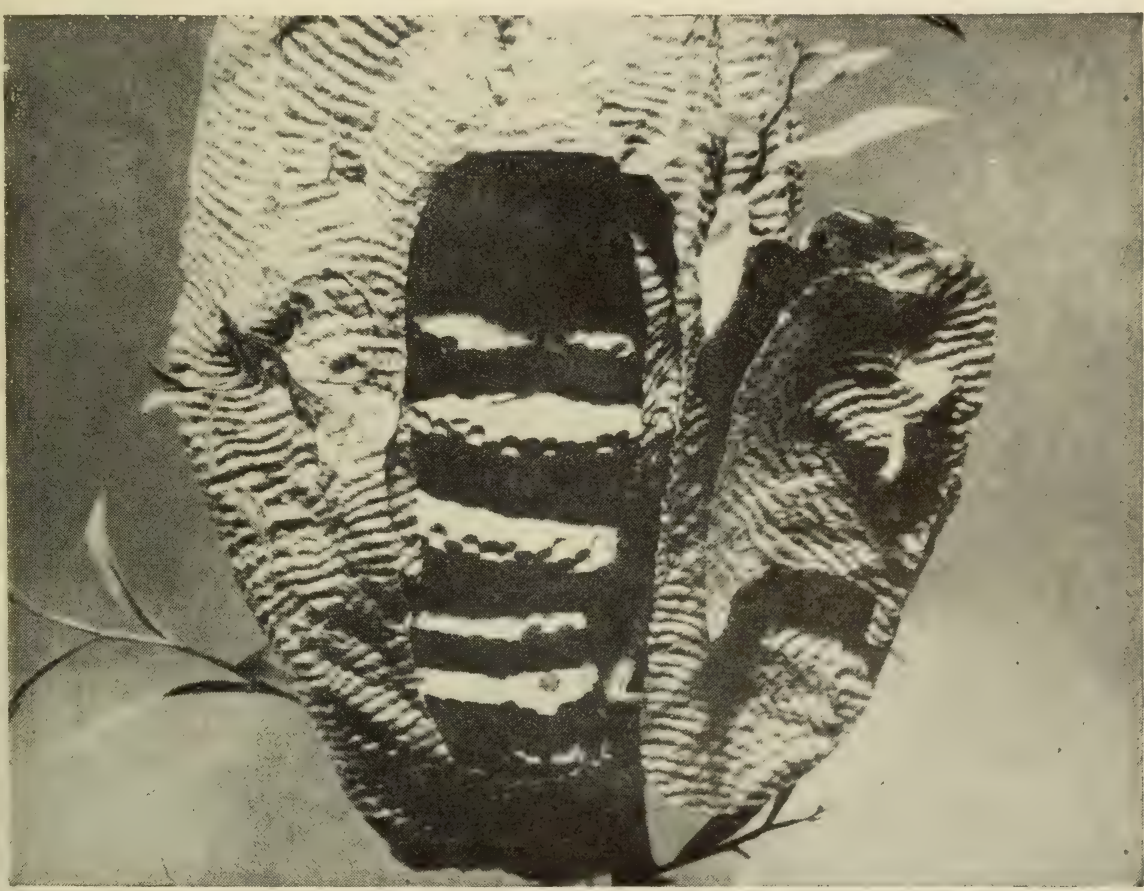


THE BODY LOUSE

(Pediculus humanus corporis), the carrier of Typhus fever.

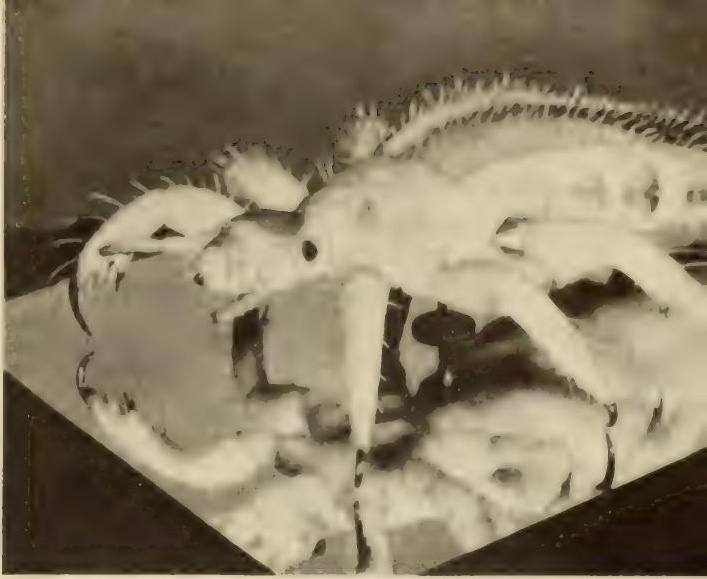

these insects in a portion of their actual enviromment. This exhibit also includes species that resemble dead twigs or leaves and others that look like fungus growths on tree trunks. A number of examples of mimion instances in which insects, commonly eaten by other organisms. rescmble species that are not eaten and are probably distasteful - are presented This case also includes a series of bizarre species. An example of a walking stick. one of the longest of all insects known, is on display with its wings extended. Various types of leg, antennal and mouthpart developments in beetles are shown by actual specimens.

INSECTS AND DISE.ASES OF MAN. It has been estimated that the annual vital loss to man and his domestic animals attributed to insects or diseases carried by insects is about $\$ 781,450,000$. One of the most important diseases in the Western Hemisphere is malaria carried b) the mosquito shown in exhibit No. 6. Shown are enlarged models of the egg, the egg raft, the larrae, the pupae and the adult and also a crosssection showing the internal anatomy of the adult. Iescriptions of the various stages and comparisons with other species are given on the labels and by means of various diagrams.

Another disease that has been the scourge of mankind is yellow ferer and the mosquito that is responsible for its transmission is shown in Case 7.

Typhus is a very important disease in congested areas and during

HOUSE-FLY (Musca domestica) showing four stages in its life cycle: eggs, larva, pupa and adult. This insect is responsible for the transmission of typhoid fever and filth diseases.
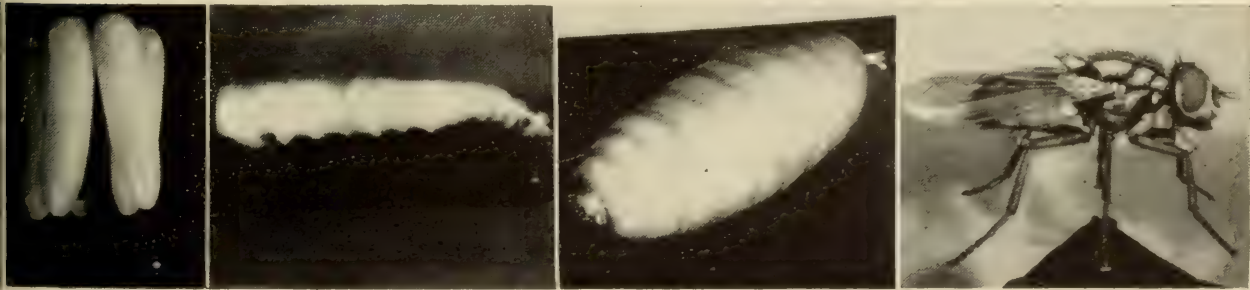
war time, and is transmitted by the body louse which is exhibited as an enlarged model in Case 7 . The carrier of Plague or Black Death, a flea, is also presented as a model in this same group. Everyone has come into contact at one time or another with the common house-fly. This insect, although primarily a food contaminator, is also a carrier of filth diseases and typhoid fever. Enlarged models in Case 7 show the eggs, larva, pupa and adult. Most of the models shown in Cases 6 and 7 are enlarged 74 diameters or 400,000 times the volume of the actual specimens.

Case 8 contains actual specimens and enlarged colored paintings of the tick which carries Rocky Mountain spotted fever, a bug that carries Chagas discase, and the flies that are responsible for African sleeping sickness, Tularaemia and Filariasis.

On the first floor Roosevelt entrance, in the section dealing with New York State exhibits, the visitor will find on the south wall in the corridor some examples of the butterflies and moths of New York State. These are actual specimens and bencath each is the correct name. Several of the species also have their immature stages illustrated in color. The viewer should remember that this is not a complete collection of the butterflies and moths of New York State although most of the common species are represented.

It is hoped that those individuals who have occasion to visit the insect and spider exhibits will find them stimulating and that they will be encouraged to make their own observations. Insects and spiders are so abundant in nature that it is not difficult for the average individual to find many interesting problems within his immediate surroundings. Many important observations on insect behavior and biology have yet to be made and important discoveries can be forthcoming from the careful amateur observer. We hope the insect hall serves as an introduction to many of the interesting phases of insect and spider life. 


\section{FISHES}

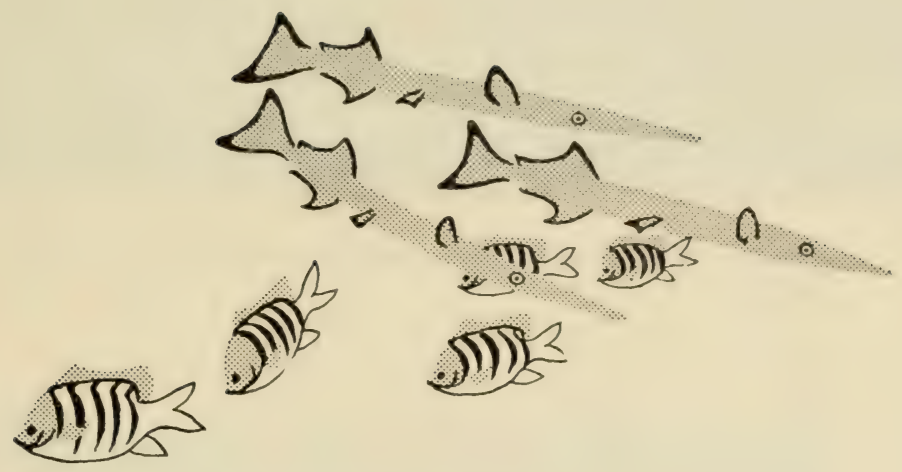

From earliest times, man has taken much of his food from the waters of the earth. The oceans, seas, lakes, ponds, rivers and streams abound in fishes and man has discorered many ingenious ways to catch them by hook, arrow, spear, net, trap and drug.

Today, we are still fishermen in the world's waters. Much of our food is taken from both salt and fresh water. We depend on fish for many raw materials as well. Much oil, fertilizer, medicine and leather are obtained from fishing. Millions of people fish for a living and millions more fish for sport and relaxation.

The scientist looks at fishes from a different viewpoint. He studies their physical structure, classifies them as to species, and finds out as much as he can about their distribution, migrations, feeding, choice of bottom, abundance, size and growth. Such information is of great value to other scientists, and at the same time is sought by educators, fishermen, industry and the general public.

\section{THE EXHIBITS}

On entering the Hall of Fishes from the Hall of North American Forests, one faces a group of sharks sweeping down upon a helpless logger-head turtle. The following sharks are represented in this group:

(1) WHITE SHARK or MAN-EATER. One of the largest sharks, growing to a length of 30 feet or more. This ferocious shark feeds on large fish and sea-turtles. It has been known to attack men and even small boats. Fortunately, it is apparently rare everywhere. 


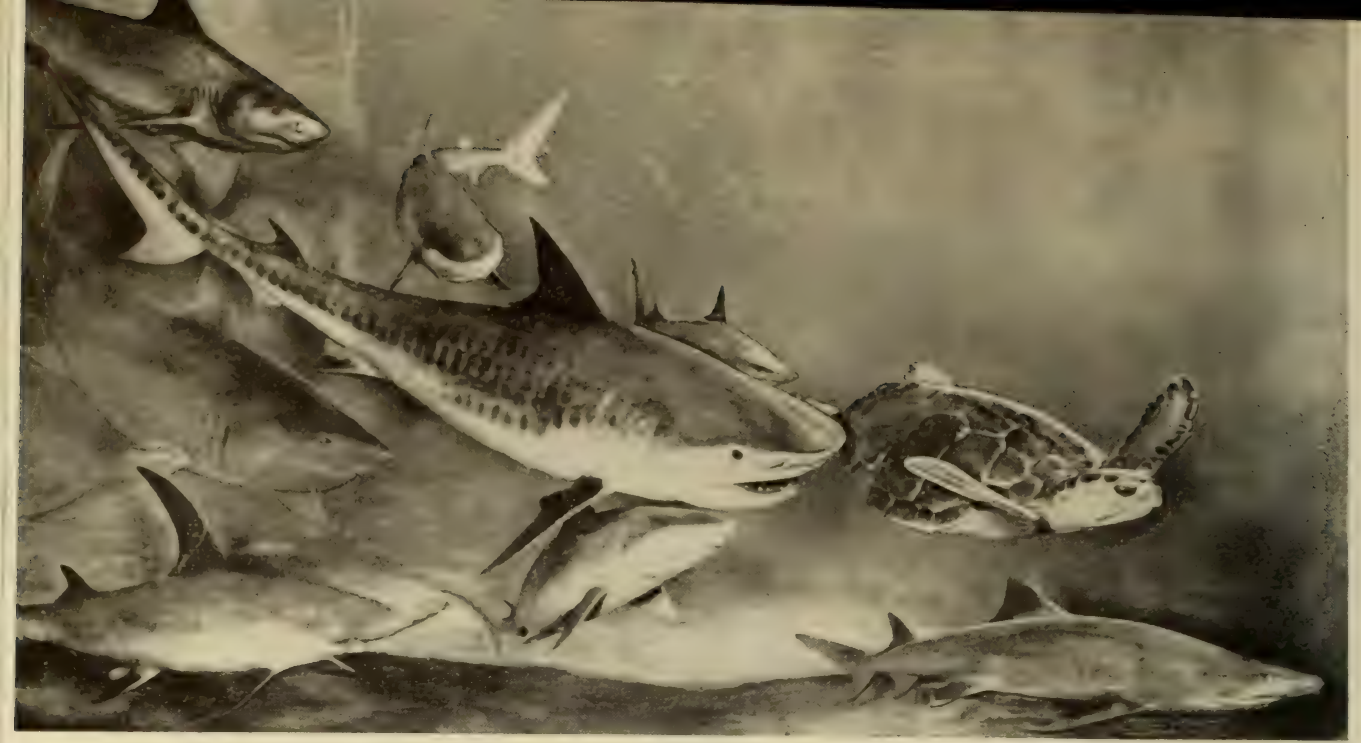

THE SEA ROVERS. An undersea scene showing a number of sharks attacking a sea turtle.

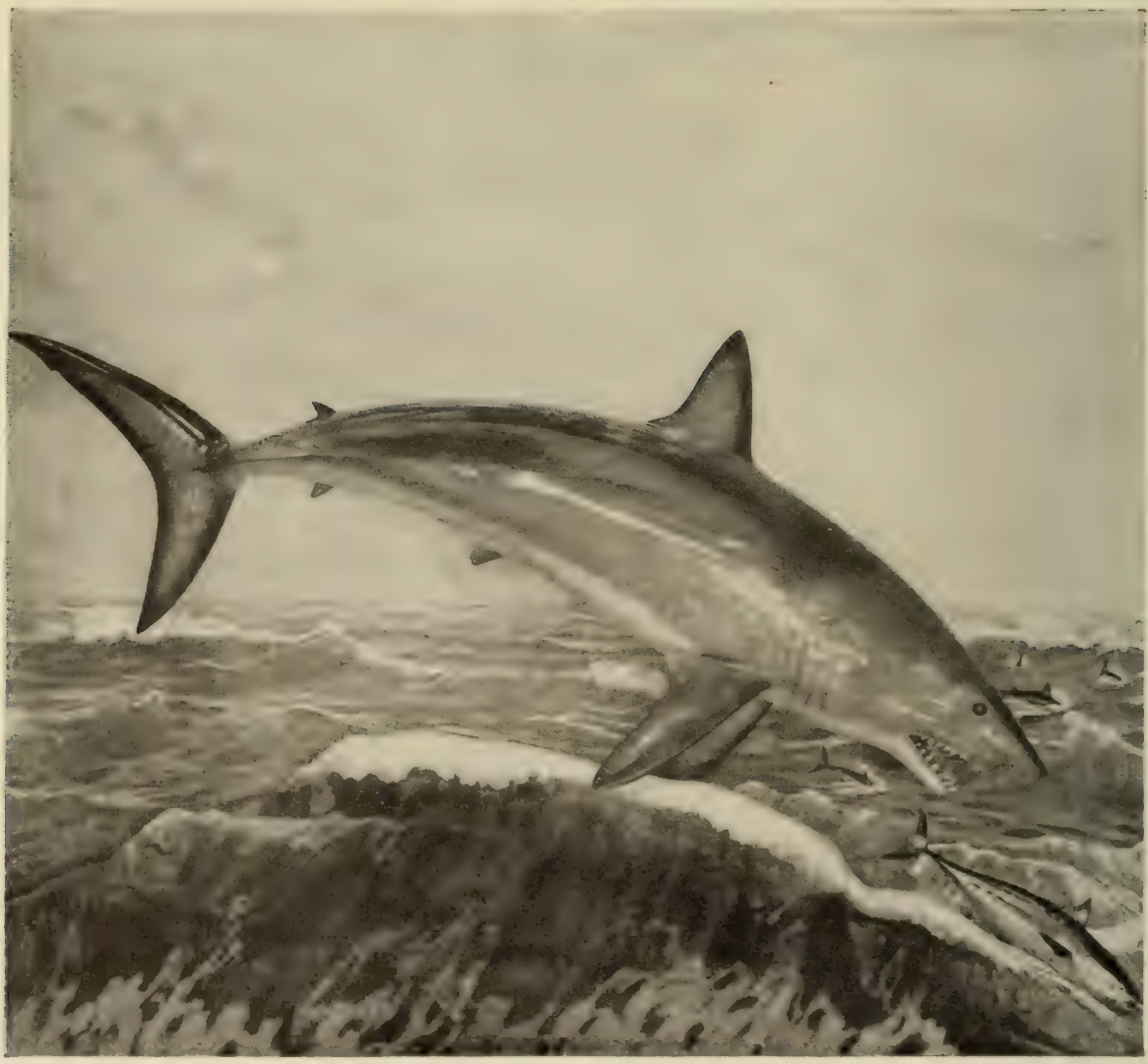




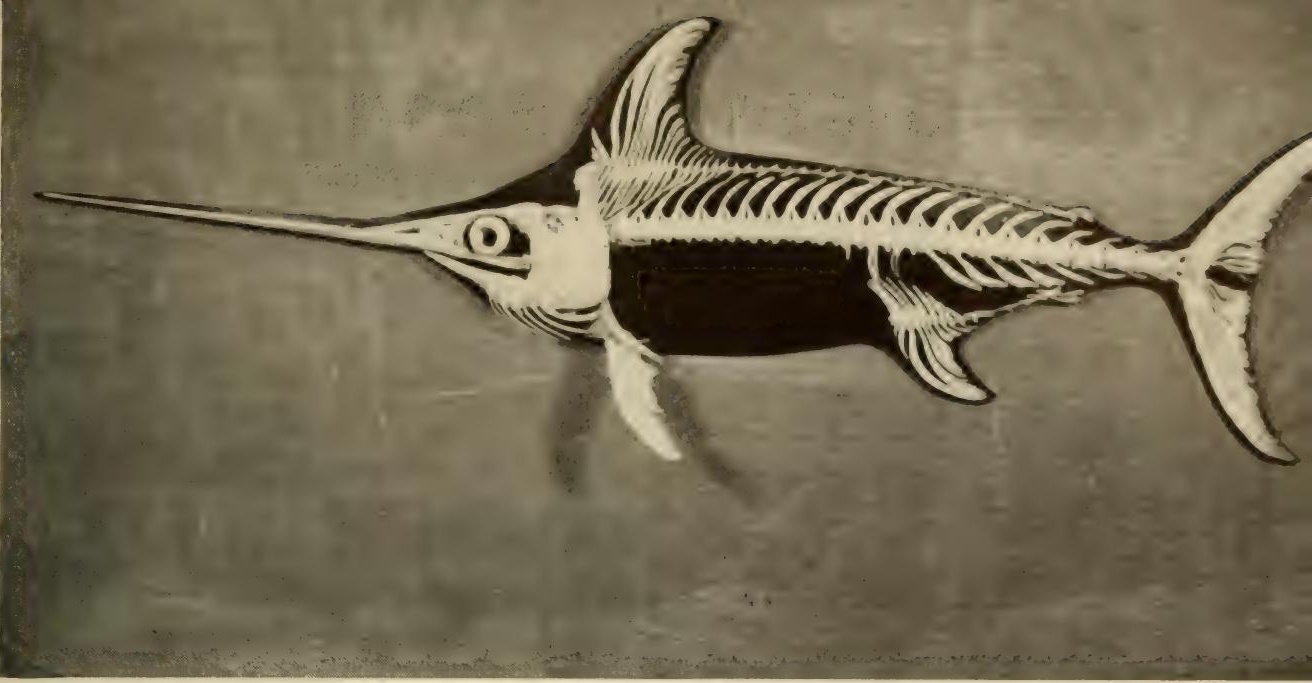

SKELETON OF A SWORDFISH.

(2) SPOT-FIN GROUND SHARK OR SHOVELNOSE. May be recognized by its small second dorsal fin and very long tapering pecorrais, in combination with a flattened, shovel-like nose. It produces living young, feeds chiefly on fishes and squid, and is harmless to man.

(3) SOUTHERN GROUND SHARK. Somewhat resembles the Tiger Shark but differs in its very blunt snout, stouter bods, very large pectoral fins and complete absence of spots. It lives in coastal waters and feeds on fishes. It is common about wharves, where it picks up refuse. It is not dangerous to man.

(4) TIGER SHARK. This fish sometimes reaches a length of 30 feet and is a very active predatory shark. It has wide jaws and powerful sickle-shaped teeth. It preys on large sea-turtles, other sharks, fishes and invertebrates. The Tiger Shark is much dreaded in the West Indies, but there are no authentic records of attacks on humans.

(5) HAMMER-HEAD SHARK. This shark is characlerized by a grotesque elongation of its eye stalks. It occasionally reaches a length of 12 feet.

(6) SAND SHARK. This shark lives chiefly on small fishes which it captures in great numbers.

THE SYSTEMATIC EXHIBIT includes a representative series of fishes, from the lowly "cartilege fishes," such as the sharks and rays. to the highest or most complexly constructed bony fishes. Noteworthy in this series are the mounted groups of "ganoids," including the sturgeons, spoonbills, bony gars and bowfins. In the alcoves and wall cases to the right, the visitor finds many curious forms, such as the giant catfishes. the handsome rooster fish, the brilliant parrot fish and butterfly fishes. 
On the left side of the SEA ROVERS group is the BIOLOGICAL EXHIBIT. This considers the fish as a machine - its streamlined form, its main principles of construction, its machinery for motion, and the mechanism of its jaws.

BIG G.MME FISHES. At the end of the Fish Hall, toward the Roosevelt Memorial, is the exhibit of Big Game Fishes, including many of great size taken with rod and line, chiefly by Michael Lerner and Zane Grey. The huge ocean sunfish, taken by Mr. Grey, weighed nearly a ton.

The central feature of the SAILFISH GROUP is the mounted skin of a fish caught off the rocky coast of Cape San Lucas, Lower California. It is shown in the act of leaping from the water in a desperate effort to shake the hook from its jaws.

Many other fishes well known to anglers and sportsmen hang in these cases, such as salmon, trout, perch, muskellunge, barracuda, yellowjack, bonefish, and the like.

Three fine specimens of the fishes caught and presented by Michael Lerner are exhibited in special cases as if rising through the water. One is the mounted skin of a tuna (Thunnus thynnus) which measured 8 feet. 3 inches in length and weighed 557 pounds. It was caught on rod and reel off Wedgeport, Nova Scotia. This is the common or BLUEFIN TUNA, also called Tunny and Horse Mackerel. It occurs in both the Atlantic and the Pacific, and huge specimens may reach a weight of over 1,000 pounds.

The second specimen, a BLUE MARLIN (Makaira nigricans ampla), weighed 305 pounds and measured 10 feet in length. It was caught on rod and reel off Bimini, Bahamas. A MAKO SHARK (Isurus oxyrhynchus), also caught off Bimini, is shown lunging above the surface of the water to catch an escaping albacore.

The tuna, the swordfish, the marlin, the sailfish and the mackerel are all related, belonging to the same suborder of fishes, the Scombroidei, a group which reaches the acme of streamlined form and speed.

On the right of the exit from the Fish Hall is a large exhibit, THE LIFE HISTORY OF THE SWORDFISH, tracing the development of the swordfish from a tiny egg to the adult. 


\section{AMPHIBIANS}

\section{AND REPTILES}

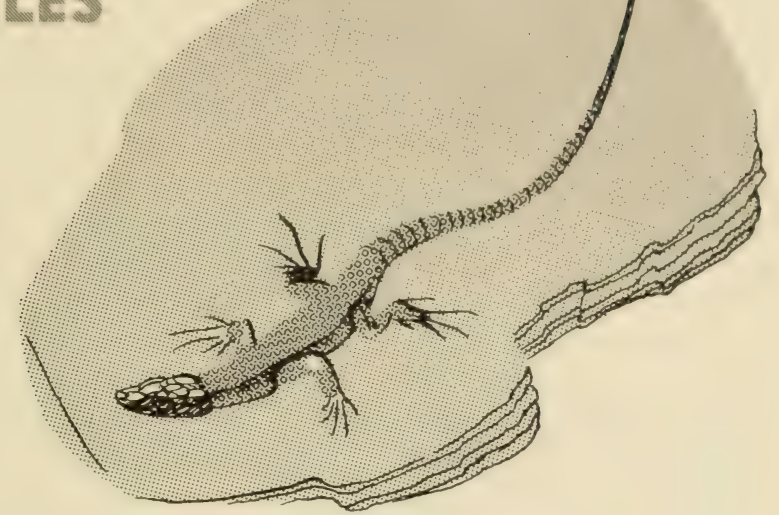

The branch of biology that deals with the amphibians and reptiles is known as herpetology. In its broadest sense herpetology is concerned with the origin, evolution, distribution and classification of the amphibians and reptiles, their relationships to their environment, their life histories, their habits and behavior, and their structures and their functions. Herpetology is also concerned with the economic importance of amphibians and reptiles, and their bearing on the activities of man. The study of extinct amphibians and reptiles is more often included under paleontology.

Amphibians are backboned animals with a moist glandular skin. If scales are present they are usually hidden in the skin, and amphibians lack the protective covering of feathers or hair seen in higher vertebrates. The eggs of amphibians are usually laid in water or at least in moist places, and most of them pass through a fish-like, water-dwelling stage before metamorphosing or changing to the adult form. There are three major groups of living Amphibia: (1) the caecilians (Apoda), superficially worm-like, limbless creatures, include burrowing as well as water-dwelling forms living in the tropics; (2) the salamanders (Urodela) or tailed amphibians, usually with four limbs, are largely confined to the northern hemisphere; (3) the frogs (Amura), many of them popularly called "toads," are the tailless amphibians, otherwise characterized by their relatively long hind limbs and their hopping or leaping mode of progression. The three groups of Amphibia comprise a total of approximately 2500 living species.

Amphibians were derived from lobe-finned fish ancestors well over three hundred million years ago. Some fifty million vears later one amphibian stock gave rise to the reptiles. Thus the amphibians are classed above the fishes, but below the reptiles. 
Reptiles are backboned animals with dry, scale-covered skins. Some reptiles give birth to their young, but most of them lay eggs, always on land. Upon emergence from the egg. the reptile is similar to its parents and equipped to obtain oxpgen from the air. The major groups of reptiles include: (1) the turtles (Testudinata): (2) the alligators and crocodiles (Crocodilia): (3) the "heak-heads" (Rhynchocephalia) represented by a single species, the relict Tuatara. Sphaenodom punctatum, of New Zealand; and (1) the lizards and smakes (Squamata), respectively included as subgroups of a single order owing to the existence of snakelike characters in several lizards and the retention of limb-girdles in some snakes.

Approximately 7000 kinds (species) of reptiles are still in existence. and many more passed into oblivion or are known only from their fossilized remains. The reptiles flourished at an early period of their crolution, which began well over two hundred million years ago. The original stock gave rise to such gigantic forms as some of the dinosaurs. Other stocks led independently to the warm-blooded mammals and birds. But several other stocks, including the larger "ruling reptiles," failed to survive. The modern reptiles include few species of great size: some marine turtles mav reach a ton in weight and crocodiles 24 feet in length mav weigh even more. The largest surviving lizard is scarcely ten feet long, but some snakes are believed to exceed thirty feet.

Unlike the birds and mammals, which produce heat internally, the amphibians and reptiles depend largely upon sources of heat outside the body. Some birds migrate to warmer climates in winter but others can remain abroad throughout the year, even in colder climates. Similarly, some mammals are continuously active, although others are forced to retire underground to avoid extremes of heat or cold. In this respect they are not unlike the reptiles, from which they differ in being heated internally while they are active.

One of the major research projects of the Department of Amphibians and Reptiles is concerned with the regulation of the body temperature in amphibians and reptiles. Investigations have disclosed the fact that many reptiles can maintain relatively high as well as fairly constant temperatures while they are abroad and active. They bask or seek out warm ground to raise the body temperature. When they become too hot they retire to shade or to shelter underground where their heat can be dissipated. Despite the fact that reptiles depend upon heat derived directly from the sun or from their surroundings, many species maintain body temperatures higher than those of man and other mammals. Thus, while reptiles are commonly termed "cold-blooded," it has become apparent that, when active, many reptiles are quite as warm as their more advanced relatives, the birds and mammals.

It is of fundamental importance, howerer, that the internal heating mechanism of birds and most mammals provides them with greater freedom in their activities than the amphibians and the reptiles possess. Nevertheless, it seems manifest that many elements of the highly complicated mechanism of heat production in the mammals had their origin 
in the reptiles. The same portion of the hain that is semsitide for tem perature changes in mammals is also heat semsitice in reptiles. I hus. by studying the origin and evolution of the meellanimm of heall regulat fion in reptiles and the more primitive mammals, it is possible 6 im prove our understanding of heat regulation in man, a matter of medical importance.

The Department of Amphibians and Reptiles has alse catricel ont research projects concerned with the venom and the wenom appatratus of cobras, their distributions and relationships, matters of particular im. portance in dealing with problems of snake bite and the therapeutic uses of renom. Similarly the Inepartment has comducted a thomough investigation of the one family comprised of renomous lizats. the cilat monster of the United States and its Mexican allies.

Other studies by the scientific staff include those made of snake locomotion, of methods of eradicating venomous snakes, of the semse organs employed by snakes in their recognition of enemies, of tooth and fang replacement in reptiles, of homing behavior in toads, and of moisture loss in relation to habitat selection in reptiles. Many investigations have dealt with the classification of individual groups of reptiles and amphibians, or with the fammas of individual areas. Few of these projects yield results of direct economic significance. Nan! of them are much more concerned with the elucidation of evolutionary or distributional principles. It is of value to learm how and where amphibians or reptiles live, how they reproduce, or how they are affected by their environment, but not only because this information is intrinsically interesting. Largely it is a matter of extending the scope of human knowledge and in part it is a matter of satisfying man's curiosity concerning the unknown. For a thorough understanding of our world depends upon the assemblage and interpretation of precise information concerning all living things that surround us, and that constitute our environment in its broadest sense. And only by disregarding immediate utility in our assemblage of information is the widest utility to be served in the end.

\section{THE EXHIBITS}

The exhibits in the Hall of Living Reptiles depict representatives of all the important groups of amphibians and reptiles now surviving. As a means of furthering the scientific study of amphibians and reptiles. the Museum maintains one of the largest collections in existence. It comprises approximately 150,000 specimens and a large percentage of the species. However, scarcely 700 specimens have been used in exhibits. which display nearly 400 species, or only one out of each twenty-four that are known to science. For the individual specimens on display have been carefully selected to illustrate some peculiarity, to show some interesting attribute of the species or to illustrate a biological principle.

Upon coming into the hall from the Insect Hall to the south, the exhibits one first sees are the floor cases. These display many of the larger reptiles, the relatively gigantic crocodilians, the large land- 
Continuing along the wall, this series of exhibits illustrates such biological principles as ADAPTATION, NATURAL SELECTION, AD.APTIVE R.IDIATION, ISOLATION and its erolutionary significance in the development of differences in form or habitat preference, the phenomena of PARALLEI EVOLUTION, and the selective importance of P.ARENT.AL C.ARE, and of ATTR.ACTING or FRIGHT ENING IOEVICES. Another exhibit along the same wall explains the nature of the venom apparatus and the methods used in treating snake bite.

The corridor enclosed by the wall containing the sunken panels provides access to a series of habitat groups. These portray American reptiles and amphibians engaged in their normal activities under natural conditions. The subjects in their order from the front of the corridor are: the I.E.ITHERBACK TURTLE: the GIANT S.ILA.MANIDER or Hellbender; the BULLFROG; a NEW ENGLAND MARSHLAND IN SPRING; WEST INDIAN TREE FROGS; REPTILES OF THE SOLTHWEST; the GAIÁPAGOS IGUANA; the RHINOCEROS

SURINAM TOAD. The female Surinam Toad (Pipa pipa) of northern South America carries her eggs in shallow pockets on the back until they hatch as fully formed froglets. After being fertilized internally, the female deposits eggs by extruding the cloaca over her back. The male, perched on her back, presses the eggs into the female's back; each egg separately sinks into a pocket that forms to receive it.

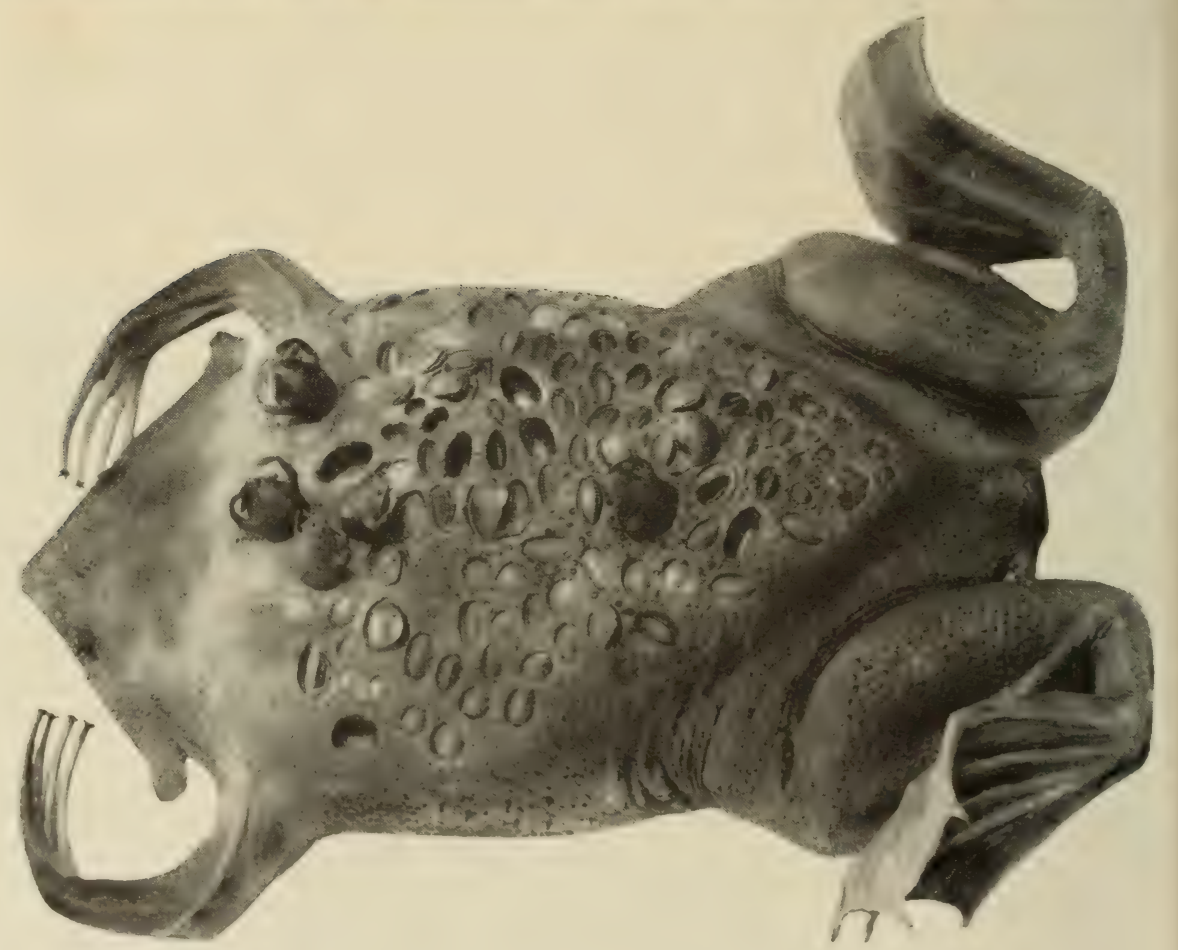


for it prevs upon a great varicty of smaller animals on land as well as in the pools. The breeding activities of frogs are exemplified in the New England marshland exhibit, which shows male frogs and toads calling to attract mates whose eggs will be laid and fertilized in the adjacent water. Next in order is the diorama showing the activities of trce frogs, and the small lizards called geckos as they would be observed by a naturalist abroad with his flashlight during the night on a West Indian island.

Reptiles, particularly the iguanas and their relatives in the New World, thrive in arid regions. The deserts of the southwestern portions of the United States extend into the peninsula of Baja California where such bizarre reptiles as the horned lizards share their habitat with the much larger herbivorous chuckawallas. Relatives of these desert dwellers have also reached many of the islands off the coast of the Americas. In the Galápagos Islands, off the coast of Ecuador, there are two large iguanas. One is confined to the land, but the other, the marine iguana more abundantly represented in the next group, lives on the rockv shores of these volcanic islands. Unlike any other lizard, it swims offshore to feed on marine plants.

Quite unlike this marine iguana, the rhinoceros iguana of the W'est Indian island of Santo Domingo inhabits the extremely arid portions of the island. The group illustrates the life history of the lizard, which is sufficiently powerful to dig its own burrows in the hard fossiliferous limestone. The eggs, buried in the sand, are deposited in July. W'hen they hatch, the young iguanas push their way to the surface, sometimes carrying portions of the egg shell with them.

Near the end of the corridor is the Gila monster group, showing the only venomous lizard in the United States in its desert surroundings. The desert tortoise and the Sonoran whipsnake, other reptiles inhabiting the same region, are not molested by the Gila monster although their eggs, as well as those of lizards, are dug from the earth and eaten. The Gila monster also devours the eggs of birds and their nestlings, and not infrequently preys on juvenile ground squirrels, and sometimes eats smaller lizards.

Exhibits outside the corridor at the end of the hall illustrate how species arise as the result of isolation on mountain tops. To the right of the exit are two groups illustrating various ways that reptiles deposit their eggs. A diagram in between explains the significant advances in reproduction represented by the reptile egg, which contains a large amount of rolk and is similar in many respects to that of the birds and the egg-laving mammals. The reptile egg allows the developing embryo to obtain its oxvgen directly from the air. Moreover, it contains other structures that eliminate the need for water so that reptiles are not so restricted in their habitats as their amphibian ancestors must have been.

On the outer side of the hall there are series of reptile skeletons exemplifying the various modifications in bony structure, venomous 


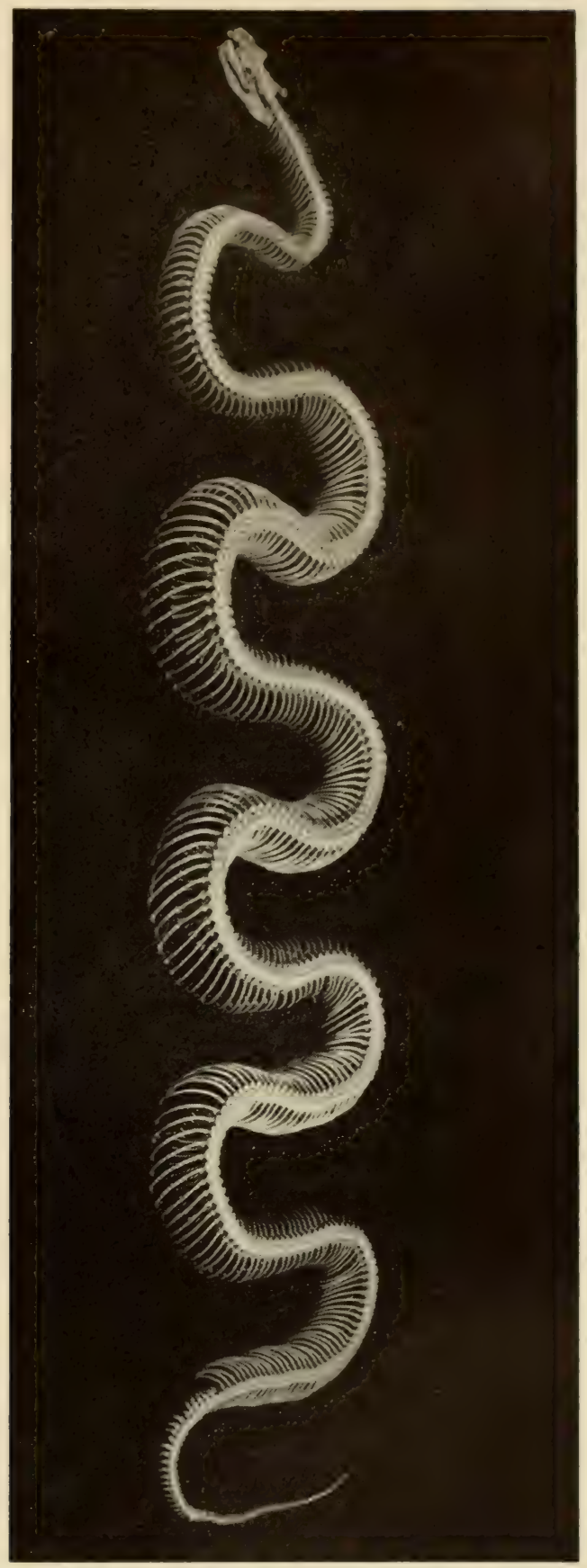

SKELETON OF A PYTHON. This reticulated python (python reficulatus) measured twenty-two feet and nine inches. The skeleton is made up of numerous vertebrae to which a pair of ribs is attached on each side. Snakes do not "walk on their ribs"; it is the muscles attached to these ribs, not the ribs, that enable the snake to move. 
snakes noteworthy because of their potential danger to man, and typical representatives of several main groups of amphibians and reptiles. Man! of the cases on this side of the hall answer such questions as "How do reptiles and amphibians feed?" or "How do they breed?" and "What is the economic value of reptiles and amphibians?"

The Department of Amphibians and Reptiles is, at one and the same time, a storehouse, a schoolroom, a bureau of information, a research center and a source of educational and artistic exhibits. It ('ncompasses the activities of a secondary school as well as those of a university, for it is not only searching out new facts and reaching new conclusions from them but also presenting this information in such a manner that it can be grasped by the elementary student or by the interested layman.

\section{Amphibians and Reptiles of the New York Region}

An exhibit showing the species found within a radius of fifty miles of New York City may be seen in the corridor of the Roosevelt Memorial Wing on the first floor. It is intended especially for the use of those who want to identify amphibians or reptiles encountered in their back yards. It is of general interest in showing the number of kinds of salamanders, frogs, turtles, lizards and snakes encountered within a limited region surrounding the metropolitan area. 


\section{BIRDS}
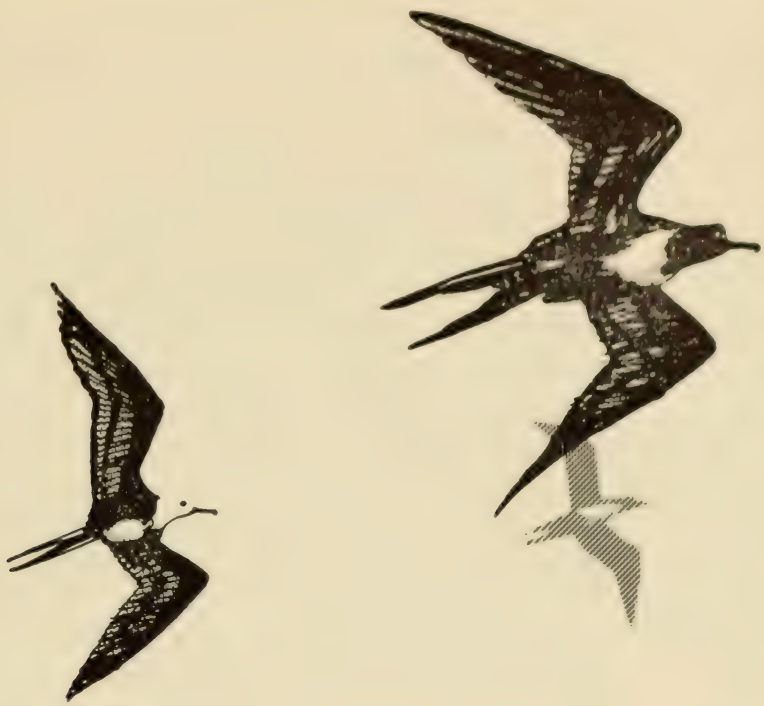

The science of bird study in all its aspects is known as ornithology. Like other branches of zoology, the study of animal life, ornithology began mainly as an attempt to determine the relationships, and to present a reasonable system of classification, of all birds, both living and extinct. In other words, the first challenge to an ornithologist was to describe and name the birds of the world and to divide them into species, genera, families, and higher categories of kinship. This end has now been attained, perhaps to a greater extent than in any other class of animals. Somewhat more than 27,000 forms of birds (species and subspecies) are known.

The curve of new discoveries has long passed its steep rise and has flattened out, owing to the fact that on an average only about two new species of birds are now found annually in all the world. Possibly fewer than 100 yet unknown species remain to be discovered. The situation contrasts strongly with that in the very much larger class of insects in which it is virtually certain that hundreds of thousands of species are yet to be found and described.

The foregoing statement does not mean that the day of systematic study in ornithology is past. There is still plenty to learn about the relationships of the higher groups (families and orders), besides which new methods in systematics, as applied to populations of closely related birds, are constantly leading to a better understanding of the processes of evolution.

It is true, neverthless, that about the beginning of the present century, when research in experimental zoology was coming to the fore. the contemporary interest in birds began to fall into a certain disrepute as a scientific subject. Professional careers for ornithologists were at that time limited in the United States chiefly to museums and to a few federal or state departments. 
Now, happily, all of that is changed for the better, and we mav confidently report that ornithology leads in several branches of biological investigation, such as those relating to speciation and the steps of crolution, to animal psychology (behavior), to the study of population dynamics, geographical distribution and ecology.

Migration, homing and direction-funding, the whole field of the bird's innate abilities, its "mind" and its instinctive, as distinguished from its learned, responses, its genetics and adaptations are today being widely studied by critical experimental methods. A quantitative and statistical approach has taken the place of the former aim of random observation coupled with the amassing of collections of skins, eggs and nests.

It is the living bird that has come to offer the most fruitful opportunity for research and that ties up most closely with the study of other animals, including man. As a result of all this change and growth, manv universities today seek trained ornithologists as regular members of their biological faculties, and the future of the discipline of ornithology has never seemed brighter or more comprehensive.

\section{THE WHITNEY WING}

The Whitney Wing of the Museum, newest section of our structure, was a joint gift of the late Harry Payne Whitney and the City of New York. It is wholly occupied by the Museum's Department of Birds. Three of its eight floors are devoted completely or in part to public exhibits.

\section{The Whitney Memorial Hall of South Pacific Birds}

The main entrance of this wing leads into Whitıey Memorial Hall from the New York State Theodore Roosevelt Memorial. The display represents bird life on islands in the Pacific Ocean, covering an expanse from Bering Strait southward beyond New Zealand and from the Galápagos Archipelago and small islets off the coast of Peru westward to the Australian barrier reef and New Guinea. Foyers at the ends of the hall contain maps and mural texts which describe both the purpose and plan of the exhibits. Here also are bronze busts of the late Messrs. William C. Whitney and Harry Payne Whitney, father and son, to whom the building and its contents are dedicated.

The design of this hall is intended to give the visitor the illusion that he is standing in the middle of the Pacific Ocean and viewing scenes in every direction throughout hundreds or even thousands of miles. In short, the hall represents the Pacific itself, reduced to extremely small compass. A common horizon crosses the background of all eightecn habitat groups and from these the sky appears to rise behind the fronts of the cases and to be continuous with the blue dome that forms the ceiling of the hall. Suspended by invisible wires in this vault are examples of oceanic birds which inhabit the Pacific from the tropical environment depicted near the northern end of the hall to the edge of the Antarctic toward the south end. It is through the latter that the visitor approaches from the Roosevelt Memorial building.

The eighteen habitat groups, beginning at the right of the entrance, are as follows: 
SHIP-FOILOWERS. The point of view is from the deck of an old fashioned sailing vessel in the open sea south and cast of New /ealand. in the zone of the westerly winds. In the backgromed is the Whitnes South Sea Expedition schooner, the "France," which served the American Museum during ten years in Polynesia. The expedition collected many of the specimens used throughout this hall.

Pelagic birds shown in the exhibit comprise a varicty of albatrosses and petrels, especially characteristic of the higher southern latitudes.

S.AMOA. A view from the hills of the island of Savaii toward the ocean. The site is at the point where forest meets more open slopes. The birds include those of both woodland and grassland, such as fruit pigeons. ducks, members of the parrot family and many smaller forms. Especially noteworthy is the Tooth-billed Pigeon (Didunculus), a very peculiar member of the pigeon family, confined entirely to a few islands of the Samoan group.

TUAMOTU. The island of Hao, an atoll, with the coral-grown lagoon at the left and the surf of the open ocean on the right. In the distant background, tree-and-shrub-covered segments of the island ring can be seen. Among the coconut palms and other typical beach vegetation of a coral island are man-o'-war birds, boobies, a nesting Red-tailed Tropicbird, several terns, including the white Fairy Tern which lays its egg on rough bark or in the crotch of a bush, and also a number of shore birds of both migratory and resident species. The example of the latter is the rare or nearly extinct Polynesian Sandpiper, one of the smallest members of its family, of which two stand in the left foreground.

The Tuamotu archipelago occupies a huge area in the central South Pacific and is one of the most extensive island groups on earth.

MARQUESAS. A scene in the volcanic island of Nukuhiva, showing a rugged shore line and ridges dissected by the sea, as viewed from a height of nearly 2,000 feet. On the right is the Valley of "Typee," famous as the locale of Herman Melville's romance of the same name.

The birds include the giant pigeon which exists only at the island of Nukuhiva, a smaller native fruit pigeon, swifts of the "edible-nest" group, warblers and Old World flycatchers peculiar to this island, a forest rail, a ground dove and a pair of wild chickens or jungle fowl, the ancestors of which were widely distributed in the Pacific by the original Polynesian immigrants.

PERUVIAN GUANO ISLANDS. Looking southward across the Bay of Pisco, Peru, from the southern island of the Chincha group. The scene shows the rainless coast of Peru where climatic conditions are responsible for the accumulation on such islands of sea bird manure, known as guano, which was the fertilizer of the Incas and other ancient farming peoples of the west coast of South America.

Despite the exhaustion of the old supplies of guano, it has again become an important commercial resource in Peru and the industry is now operated upon a scientific conservational basis.

The three principal species of guano-producing birds, all of which 
opposite or windward side of Katuai is extremely rainy and, on the tighe. fragments of storm clouds are shown whisking out orer the ballev, which, however, is not very humid because most of the rain falls farther (o) windward.

The Hawaiian archipelago, like that of the Galatpages, has been isolated from other land areas throughout mans ages, and some of the native birds and other animals show eren more peculiar and pronounced evolutionary changes. The Hawaiian honevereepers (I)repomididae). for example, are obviously members of a single family of small land birds, yet the specializations in the bills of several species range from shom. stout, almost parrot-like beaks to extremely long, pointed and sickleshaped organs. Feeding habits are, of course, correlated with such struc tures, for the stoutest-billed species can handle hard seeds and truics. whereas those with long slender bills must use them in taking nectar or small insects and spiders from inside flowers. Several examples of these honeveaters are shown, but it would be impossible to displas the whole range of variation in bills without drawing upon species inhabiting onler islands of the Hawaiian group.

At the right of the group three geese are shown in flight, the species being peculiar to Hawaii. In the air, down the valley, are two Whitetailed Tropic-birds, and the small land birds include one or more species having tufts of brightly-colored feathers which were used by the ancient Hawaiians in making the famous feather cloaks worn by chiefs of high rank.

LAYSAN. Albatrosses, of which there are some seventeen species in the world, resort during the nesting season to remote oceanic islands. There they carry on their remarkably elaborate courtship procedure. las the single egg, and rear their chick before they depart once more on the oceanic wanderings which continue until the return of the next breeding season.

Most albatrosses inhabit the higher latitudes of the southern oceans and no species regularly enters the North Atlantic. The North Pacific Ocean, however, is the home of three kinds of albatrosses, two of which are here shown on the nesting ground of Laysan Island, a leeward outlier of the Hawaiian archipelago.

The two species shown are the white-breasted Laysan Albatross and the all-dark, Black-footed Albatross. Both carry on an extraordinary ritual, commonly known as a courtship dance, although it really partakes of community behavior. The birds on the nesting ground salute, cross bills and bow not only to their own mates but to other albatrosses of both sexes.

A pair of the small native teal of Laysan, found nowhere else in the world, is also shown in this exhibit. Others displayed are nesting sea birds, such as boobies, man-o'-war birds and petrels (which occupy burrows in the sandy soil), and shore birds that make the island a resting place during their long migration from Alaskan breeding grounds to a winter home among islands of the south seas - Bristle-thighed Curlews, Golden Plovers, and others. 
NEW CALEDONIA. This large island, which is east of Australia, lies on one of the western Pacific arcs or submerged mountain ranges. It has had no connection with any other land area since it rose from the ocean in the early part of the Age of Mammals.

Because its life has been obtained by natural means from places across the sea, it is interesting to note that, among the 64 species of New Caledonian land birds, 6 belong 10 widespread Pacific species, 35 appear to have come from Australia, and 23 from the New Guinea region.

New Caledonia has five genera of birds found nowhere else, these comprising a pigeon, a parrot, a warbler, a honey-eater, and the strange flightless heron-like Kagu. The last is a very extraordinary bird which seems to have no near relatives anywhere else in the world.

The site of this exhibit is on the northeasterly coast of New Caledonia, at an altitude of slightly more than 1,000 feet. The birds, in addition to the Kagu (on the ground), include a fruit dove, kingfisher, cuckoo, warblers, flycatchers, whistlers, a wood-swallow, starling, honeveaters and a parrot finch.

SOLOMON ISLANDS. Since the United States armed forces made history at Guadalcanal Island, the savage Solomons no longer seem so far away as they formerly did. In this exhibit of bird life in a hot, humid and mountainous archipelago, the background shows Guadalcanal itself. The foreground represents a small islet off the southeastern end of Guadalcanal, with a cluster of native huts, and a garden in which coconut palms, bananas, papaya, cassava, breadfruit, taro and sweet potato are growing on the site of a recently-felled tropical jungle.

The Solomon Islands have a rich bird fauna, with 128 species of land birds alone. The 21 species shown in the exhibit can therefore be only a representative selection. They include the following: the Brahminy Kite, a bird of prey; the brush fowl, or megapode, which lays its eggs in mounds of rotting vegetation so that the heat of fermentation may hatch them; several species of doves, parrots, lories and cockatoos, including the King Parrot, of which the male is green and the female a vivid red; the Whiskered Tree Swift and various other colorful representatives of Old World families, such as rollers, cuckoo-shrikes, flycatchers, sunbirds and flower-peckers.

PHILIPPINES. This exhibit shows historic Bataan Peninsula on the island of Luzon, as viewed from nearly 3,000 feet above the sea at the summit of Mount Cayapo. In the middle of the background is Corregidor, famous island fortress, lying in the channel between Manila Bay and the China Sea. The scars of war have been rapidly overgrown by tropical vegetation and the forests and animal life of the region are relatively unspoiled.

The Philippines have about 325 species of native breeding birds. Of these, 47 are shown in the exhibit, a number not more than half those that might readily be seen at the site.

PAPUA. The great island of New Guinea is almost like a continent in the wealth of its plant and animal life. Lying in tropical latitudes, 
its vast mountain ranges nevertheless rise to the level of snow, as shown in the other New Guinea exhibit in this hall, the second beyond this.

The landscape of the Papuan group shows the Laloki Riser gorge behind Port Moreshy in the southern foothills of the (Owen stanley Mountains. Although the site is only $9^{\circ}$ south of the equator, the heat is never oppressive here. Rainfall averages 90 inche's anmually in the oak, tree-fern and beech forests of the mommtams, but onls about onethird of that in the eucalyptus-dotted grasslands behind the Pont. At the right is the spectacular Rouna waterfall, 1,00) leet alowe sea level. The area is an historic one because it was near here that Allied forces, in bitter jungle warlare, turned back the tide of the Japanese onslatught in the second World War. The area is now a tranquil wilderness inhabited by such species as the birds of paradise, crowned pigeons, (anso)waries, and bower birds shown in the group. More than 100 species of native birds were observed in the vicinity of the Rouna Falls. Thirtynine of these are displayed in the exhibit.

ISLANDS IN BERING SEA. Little Diomede and Big Diomede are two islands in Bering Sea, 50 miles south of the Arctic Circle and about midway between Alaska and Siberia.

The site of this exhibit is the foot of a 1,000-foot cliff at the south end of Little Diomede Island. Here, protected by isolation as well as

ARCTIC SEA BIRD LIFE. From a group in the Whitney Hall of Pacific Birds. The group depicts the lower part of a 1000-foot cliff on Little Diomede Island in Bering Sea. Here myriads of sea birds come each summer to lay their eggs and rear their young.

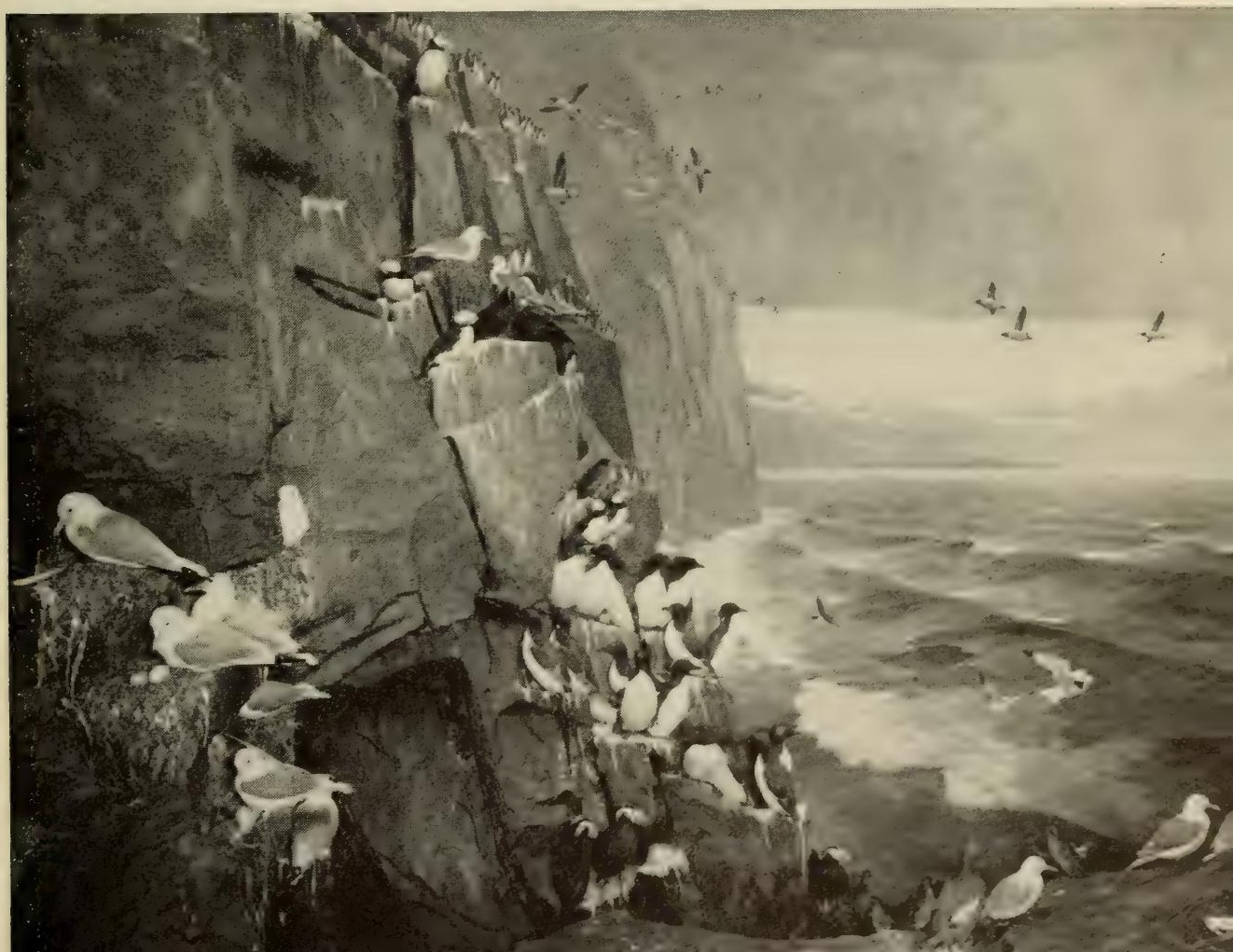




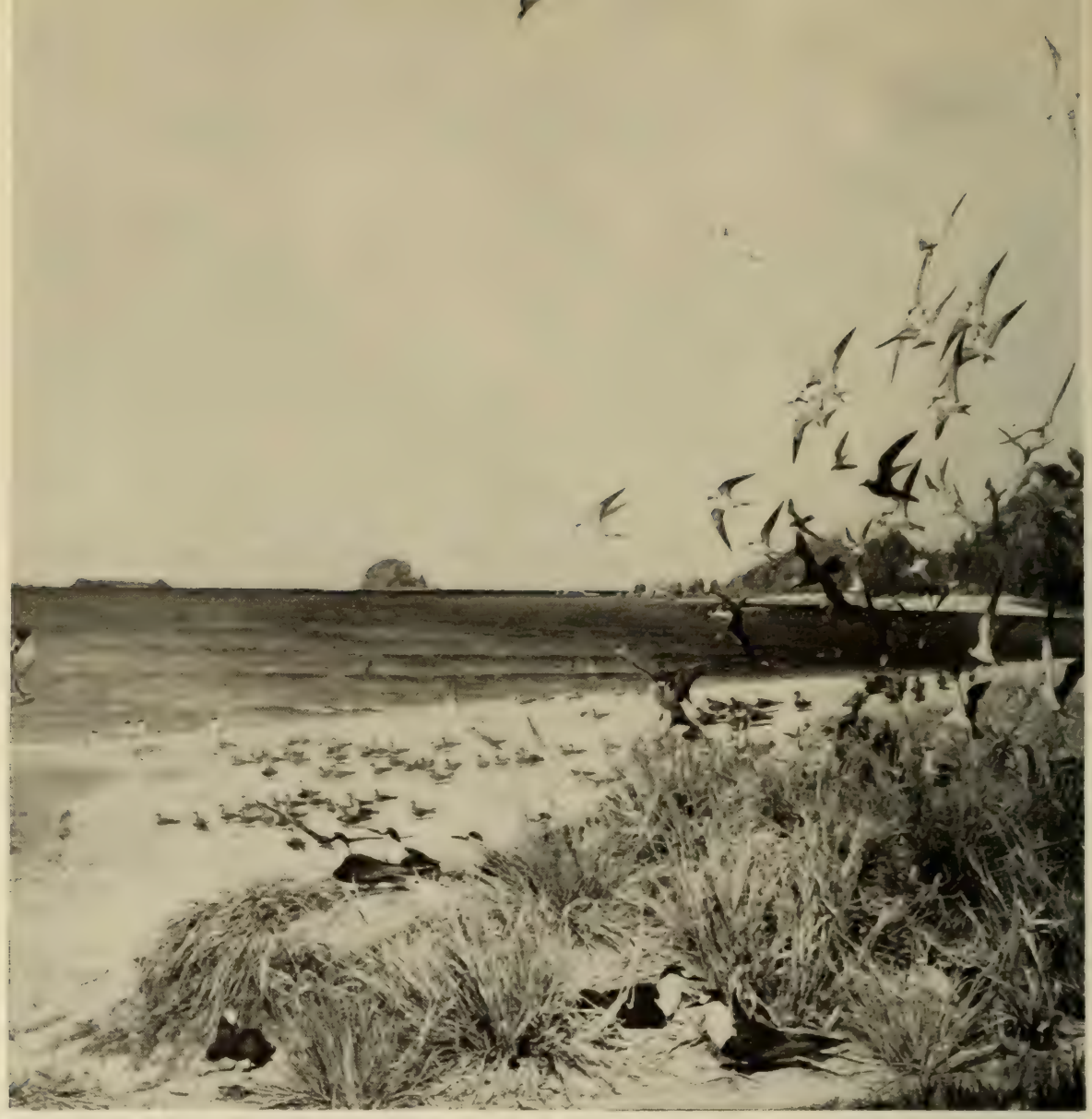

THE GREAT BARRIER REEF, AUSTRALIA. Most of the nying birds in this view are sooty terns. The darker ones are part of a colony of brown noddies.

by the inaccessible nature of their haunts, myriads of murres, guillemots, puffins, auklets, gulls and cormorants come each summer to lay their eggs and rear their young.

SNOW MOUNTAINS OF NEW GUINEA. Among its 650 species New Guinea has many birds not known in Australia, though the two land masses are only 100 miles apart at Torres Strait. A drop of 50 feet in the sea level would probably join them. On a map of the United States, New Guinea would reach from New York City to Colorado, and its interior offers some of the largest unexplored areas on earth. This exhibit depicts a scene on Lake Habbema, 11,000 feet above sea level, looking southward toward Mount Wilhelmina. Parrots, birds of paradise and sereral kinds of flower-visiting birds, as honey eaters and flowerpeckers, are among the most characteristic birds of the area. Every altitudinal level has its own bird life, and few, if any, of these mountain species can be found in the tropical lowlands. Many of the Snow Mountain birds are very rare in collections, since they occur nowhere else in the world. 


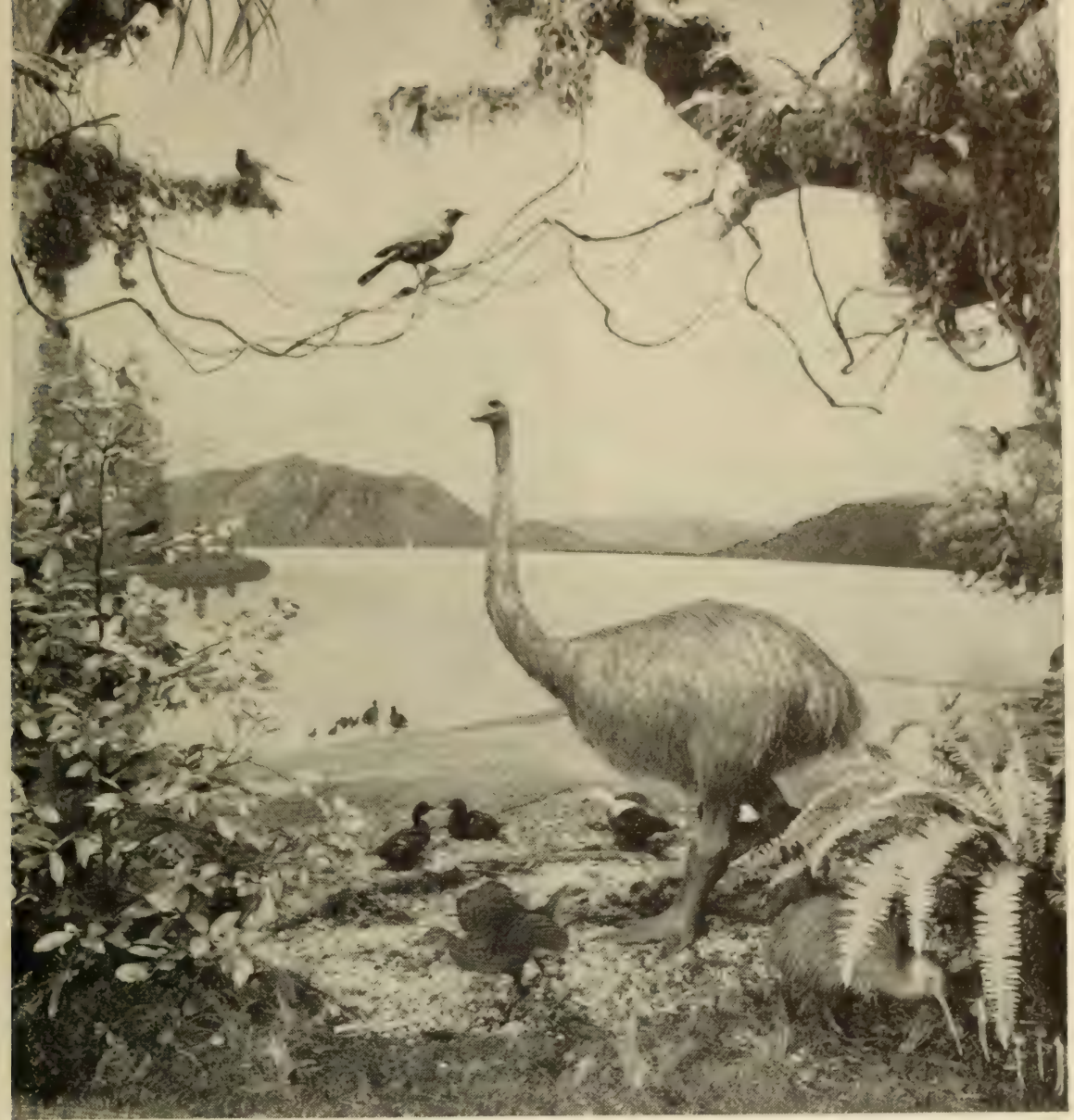

AN EXTINCT MOA OF NEW ZEALAND, reconstructed from a subfossil skeleton.

AUSTRALIAN BARRIER REEF. The Great Barrier Reef, which for more than 1,200 miles guards the east coast of Australia, is the largest coral reef in the world. In the extensive lagoon between the Barrier and the mainland are countless lesser reefs, islets of coral limestone and, near shore, higher islands which are detached fragments of the continental rock. Many of these have collected wind-blown soil and have acquired a luxuriant, even if limited, plant life. Others remain relatively bare, still far enough above the reach of the ocean to furnish breeding grounds for great colonies of sea fowl.

The birds of the Great Barrier are mostly of widespread types, as is characteristic of the avifaunas of beaches and small islands. They include a noisy colony of Brown Noodies and Sooty Terns, the fledgling young of the latter being the dark speckled birds which look so unlike their parents. Australian Silver Gulls, Crested Terns, Reef Herons in both gray and white phases, and man-o'-war birds complete the list of resident oceanic species. The sandpipers or tattlers in the beach pool are winter migrants from northern Asiatic nesting grounds. The white 
land birds painted in flight are Nutmeg Pigeons bound, perhaps, toward fruit trees growing on the islets.

FIfI forms part of one of the several great island arcs to the east of Australia and Vु(w Guinea and comprises more than 200 separate islands and islets. The larger members are mountainous, and many are surrounded by fringing reefs of coral.

Fiji has about 54 species of land birds, or only half as many as the Solomon Islands which are hundreds of miles nearer the ultimate source of supply in the Australasian region. The principal Fijian types are birds of families known to be able to make long colonizing flights across the ocean, such as parrots, pigeons, kingfishers, starlings and white-eyes.

In the Silky Dove and the Golden Dove, Fiji has two of the most spectacular of all birds. Both species are peculiar to this group of islands, and one of them only to Viti Levu Island, the site of the exhibit. The thirteen additional birds shown all belong to families found at other Pacific islands. but the species are mostly peculiar to Fiji. Most of the aboriginal Fijian birds are confined to mountain districts, while the common birds of town and village are more widespread or recently introduced kinds.

NEW ZEALAND. The view looks across Lake Brunner in the South Island Alps. The period is that of several centuries ago when many species of the heary and flightless moas lived as browsing and grazing birds in this isolated part of the temperate world. Both plants and birds shown belong to the older life of the islands, antedating the many kinds introduced by man that have since become very conspicuous in New Zealand. The landscape is on the western or rainy side of the mountains at the edge of tall forests of almost tropical luxuriance.

The flora and fauna of New Zealand are a product of marked isolation, the next large land area, Australia, being 1,200 miles away. Fourfooted mammals appear never to have reached New Zealand until they were transported there by man. In the absence of enemies and of competing grazing mammals, the peculiar and highly specialized moas took the place of antelopes, wild cattle, etc. that lived in so many of the world's continental areas. Euryapteryx, a moderate-sized moa reconstructed from a subfossil skeleton, is centered in the exhibit. In the extreme left is a large flightless rail, the Takahe or Notornis, long thought to be extinct in New Zealand but recently rediscovered. Other birds shown include several native ducks, together with a pigeon. a falcon, an owl, three species of parrots and several kinds of honev-eaters and other song birds known only from New Zealand.

SNARES ISLAND. To the south of New Zealand, in the west wind zone. lies a small and rarely visited subantarctic group of islets which are called the Snares because they were regarded as a navigational hazard. Since they have never been inhabited by man or such of his domestic associates as rats, goats, pigs and weeds, the conditions today are much as they were in primitive times. 
The climate is blustery, chilly and rains, although neser extrenely cold. There are about 25 kinds of higher plants, including terns, the most conspicuous elements being coarse, tall tussoxk grass and the "diatsy tree" (Olearia) which forms an ecrie lorest. The large orange blossom clusters belong to a groundsel shrub.

Seals of several kinds are the onls mammals. The birds number a little over a score of species. They include Crested Penguins, altatrosses. petrels, gulls, terns and skuas. There are only two land birds, a tomtit peculiar to the Snares, and a fernbird. A nearly flightless grass snipe is, however, more of a land than a water bird.

In December, the southern "June," the sea fowl are nesting, and the multitudinous Sooty Shearwaters or "muttonbirds" fill the sky towal sunset before dropping each to its own soggy burrow.

BIRDS OF PARADISE. The first case consists of two exhibits, onc of the Plume-Birds of Paradise, and one of the South Sca Lories, a group of parrots. The second case contains an exhibit of the Rifle Birds (Birds of Paradise) and one of various birds of the Malay Archipelago.

\section{Leonard C. Sanford Hall}

The Sanford Memorial Hall of Biology of Birds is located in The Whitney Wing and is deroted mainly to diagrammatic exhibits illustrating the bird's place in nature and many aspects of the structure, descent, relationships and behavior of birds and their relation to man. The exhibits are in part technical, and they deal with fundamental scientific problems.

They are intended to be instructive rather than picturesque, although a large exhibit of tropical marsh birds in flight against a sunset sky faces the entrance of the Hall, and a number of other habitat exhibits show beautiful and spectacular birds, extinct species, and certain extraordinary aspects of reproductive behavior. At the left of the Hall is the synoptic collection of birds of the world designed to show in sistematic sequence examples of virtually all of the families of birds and a large proportion of the more important genera.

\section{EXHIBIT EXPLAINING THE PRINCIPLES OF FLIGHT.}

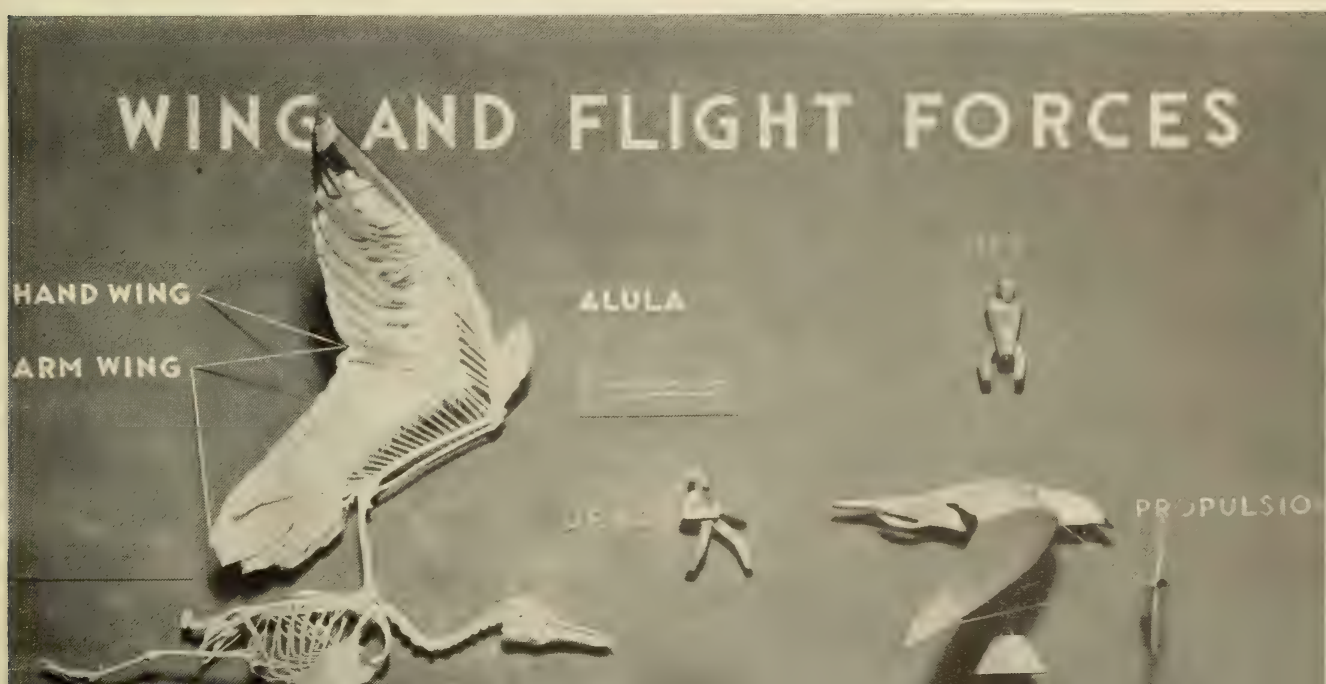


HIGH ANDES GROUP. The Paramo 7one of Somb Imericat is fommd at sea level at the southern end of the continent but occupies increasingls high elevations in the Andes, below the snow line, as the equaten is approached. In the neighborhood of Mt. Aconcagua, Chile, shown in the background, this zone is reached at 10,000 leet elevation, but the birds are still closely related to those of the lowlands of Patagoniat and southern Chile. The Andean Condor is a characteristic species.

AMERICAN TROPICAI ZONE. Barro Colorado Island, in the Canal Zone, was once a hilltop and part of the unbroken humid tropical forest of the Panamanian lowlands, but it was cut off from the surrounding forest when the valley of the Chagres River was flooded by the closing of the Gatun Dam. It is now preserved as a natural laboratory under the care of the Institute for Research in Tropical America. It has becn made known through the writings of Dr. Frank M. Chapman, particularly by his books "My Tropical Air Castle" and "Life in an Air Ciastle."

SOUTH GEORGIA GROUP. The bird-life of the Antarctic regions is not as rich in species as that of the tropics but possesses certain very interesting forms, among which the penguins are outstanding. The group shows an assemblage of King Penguins on the island of South Georgia, 1,200 miles east of Cape Horn. Among the other characteristic species are the Wilson's Petrel (one of the birds known to sailors as "Mother Carey's Chickens"), the Kelp Gull, Giant Fulmar, the curious Sheathbill, and (painted) the Wandering Albatross.

EAST AFRICAN PLAINS. The easterly third of Africa is largely a grassy country dotted with thorny bushes and trees. The Kidong Valley, scene of the group, lies some 40 miles northwest of Nairobi, Kenya Colony, in the Great Rift Valley that extends from northern Tanganyika to the Red Sea and southern Palestine. The Ostrich, Marabou, Bustard, Courser, Secretary Bird, Hoopoe, Coly and Lark shown in the group are typical of the plains region, though some of the other birds shown have close relatives in the forests.

CONGO FOREST GROUP. The equatorial forests along the Congo River in western Africa are rich in bird-life. As in other tropical forests, many species of birds often band together in loosely mixed flocks that roam the woods for insects and other food, searching from the ground to the tops of the trees. The exhibit shows such an assemblage of antchasers together with other inhabitants of the region. The scene is at Lukolela, about 500 miles upstream from the mouth of the Congo River. AUSTRALIA. This is a scene in the Blue Mountains of New South Wales, about 100 miles west of Sydney, at the edge of the forest looking out over the eucalyptus-dotted savanna. Two Lvre Birds (male and female) have come to the forest margin. A flock of Crimson Rosclla Parrots has settled on the ground and in the trees, and two Eastern Rosellas are nearby. Several Black-backed Magpies are on the ground or (painted) flying, and a Laughing Jackass is perched in a tree overhead. Various characteristic birds of eastern Australia are shown, such as the Peaceful Dove, Satin Flycatcher, Broad-billed Roller, Gang-gang 
local names may differ. Occasionally the same name is applied to quite different species as in the case of the European and American robins. The group shows the famous "Roosevelt Walk" in the New Forest, in the Valley of the Itchen, in Hampshire, where Lord (then Sir Edward) Grey and Theodore Roosevelt watched the birds together in 1910.

TUNDRA GROUP. Churchill, Manitoba, on the western side of Hudson Bay, lies in what the Indian called the "land of little sticks." Here the Canadian forests to the southward are giving way to the treeless tundra that reaches northward to the Arctic Ocean. In summer the tundra is dotted with inumerable insect-filled ponds. Here to nest come myriads of migratory water birds - sandpipers, plovers, gulls, ducks and geese - that have wintered in warmer lands to the southward. A few land birds also nest on the tundra. One of these, the Arctic grouse or Ptarmigan, is able to endure the long Arctic winter and, unlike most of the tundra birds, does not migrate. A number of forest- or bushdwelling birds reach the northern limit of their distribution near Churchill. Some of these may be seen in the group.

\section{HALL OF NORTH AMERICAN BIRD GROUPS}

The backgrounds of the Hall of North American Bird Groups are reproductions of specific localities, painted from sketches made by the artist who usually went with the naturalists when the field studies for the groups were made. Practically all sections of the country are shown; thus the series shows characteristic North American scenery as well as bird-life.

ORIZABA GROUP. The distribution of birds, in spite of their power of flight, is limited in great measure by climate. Thus in traveling from Panama north to Greenland there are zones of bird-life corresponding to the zones of temperature. This condition is illustrated on the mountain of Orizaba in Mexico where, in traveling from the tropical jungle at its base to its snow-clad peak, the naturalist finds zones of life conparable with those to be found in going north on the continent.

COBB'S ISLAND GROUP. Among our most beautiful and graceful shore-birds are the terns and gulls, which were once ceaselessly hunted and killed for their plumage. Thanks to protection, they have now greatly increased in numbers. The group represents a section of an island off the Virginia coast where the birds are now protected by law.

DUCK HAWK GROUP. The Duck Hawk may be found nesting on the Palisades of the Hudson River almost within the limits of New York City. It nests on the ledges of the high cliffs. This hawk is the Peregrine Falcon, much used for hunting in the Middle Ages. It often comes into the city for pigeons.

HACKENSACK MEADOW GROUP. In August and September the meadows and marshlands bordering the Hackensack River, New Jersey, formerly teemed with bird-life. In the group are swallows preparing to migrate southward, Bobolinks or "Rice Birds" in autumn plumage, Red- 
winged Blackbirds, Rails, Wood Ducks, and Long-billed Marsh Wrens. Industry and settlement have driven many of the birds to quieter haunts. WILD TURKEY GROUP. The Wild Turkey is a native of America and was once abundant in the wooded regions of the eastern part of the United States. It differs slightly in color from the Mexican bird, the ancestor of our common barnyard turkey that was introduced from Mexico into Europe in 1502 and was brought by the colonists to America. The scene is reproduced from studies near Slaty Forks, West Virginia.

FLORIDA GREAT BLUE HERON GROUP. The Great Blue Heron usually nests in trees. The bird flies with its neck curved back on its body, and because of this habit it can be easily distinguished from cranes. Locale is near St. Lucie, Florida.

WATER TURKEY OR “SNAKE-BIRD" GROUP. In the vellow pondlily swamps near St. Lucie, Florida, grown with cypresses and cabbage palmettos, the shy Water Turkey builds its nest. It gets the name "turkey" from its turkey-like tail, and the title "snake-bird" from its habit of swimming with only the long slender neck and head above water.

SANDHILL CRANE GROUP. Unlike the Herons, the Sandhill Crane builds its nest of reeds in the water. It differs also in its manner of flight, always fully extending its neck when on the wing. The scene is the Kissimmee Prairies of Florida.

BROWN PELICAN GROUP. Pelican Island, on the Indian River of Florida, has been made a reservation by the United States government to protect these grotesque birds. The view shows a section of the island at the height of the nesting season.

AMERICAN EGRET GROUP. This beautiful bird was once almost wiped out through the use of its "aigrette plumes" for hats. It is now found again throughout much of its former range, owing to effective protection. The birds have these plumes only during the nesting season, at which time the death of the parent means the starvation of the young. This group represents a rookery in South Carolina.

TURKEY VULTURE GROUP. The Turkey Vulture or "Buzzard" is one of the best-known birds of the South, where it is a valuable scavenger. It is protected by law and by sentiment and has become both abundant and tame. The scene is on Plummer's Island, above Washington, in the Potomac River.

CALIFORNIA CONDOR GROUP. The California Condor is the largest and one of the rarest birds of North America. In the group the visitor stands in the interior of the condor's cave, looking down on the river of the Piru Cañon, California.

BRANDT'S CORMORANT GROUP. The foreground of the group shows a detail of the island that is painted in the background. The young birds are feeding and it may be noted that one fledgling is reaching down the mother's throat after the predigested food. 
SAN JOAQUIN VALLEY GROUP. This area was once an arid place with a characteristic desert bird latumat. Since ramchers hate integled the land, aquatic bird-life is plemtiful. This group) is a gond illustration of the influence of man on the bird-life of a region.

FLAMINGO GROUP. There were estimated to be two thounand nests in this colony in the Bahama Islands. The Flamingos make their nests by scooping up mud with their bills and packing it down with bill and feet. The nests are raised to a height of twelve or fourteen inches, protecting the eggs and young from high water. Only one egg is laid, and the down-covered young is fed by the mother on predigested food.

BOOBY AND MAN-O'-WAR BIRD) GROUP. Part of a coral islet in the Bahamas shows three thousand boobies nesting on the ground and four hundred Man-o'-War birds nesting in the sea grape bushes.

FLORIDA ROOKERY GROUP. This Florida Everglades group shows Roseate Spoonbills, Snowy Egrets, American Egrets, Little Blue Herons, Louisiana Herons, Ibises, Cormorants and Water I Irkeys. Because of the isolation of this island it was one of the last places to be visited by the plume-hunter.

WHISTLING SWAN GROUP. A Whistling Swan on the nest is seen far across the arctic tundra, the summer home of this species. The nest is of moss, etc., and in it are two to five white eggs, four and a quarter inches long. Both male and female share the labor of nest-building, incubation, and caring for the young.

AMERICAN EGRET GROUP, in the Hall of North American Birds.

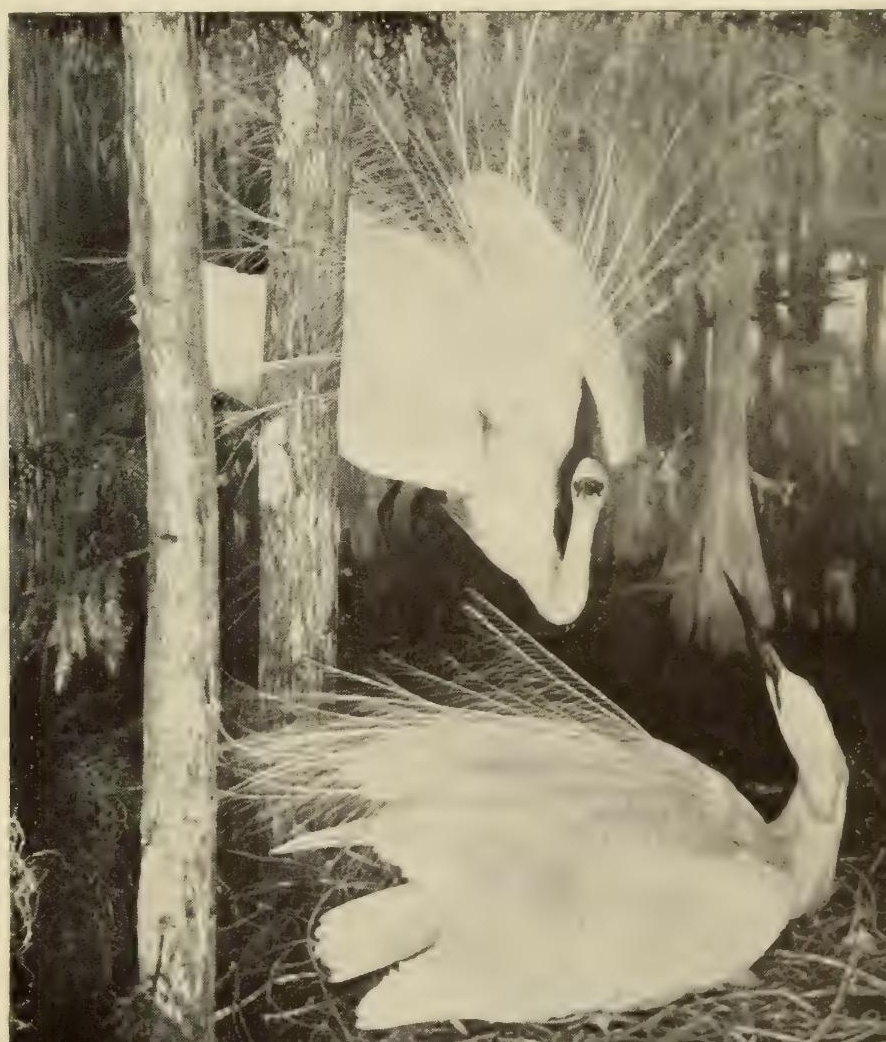


GOLIDEN EAGIE GROUP. The Golden Eagle is one of the most widely distributed of birds. In North America it is common from the Rockies to the Pacific, and as far east as Maine. Its food consists of rabbits, squirrels, woodchucks and occasionally lambs.

KL IM ITH I. IKE GROUP. The bird-life here show's how normal nesting habits may be changed by birds being forced to live in a new place. White Pelicans that usually make a nest of pebbles. Caspian Terns that commonly build their nests on sand, and Cormorants that nest on rocks are all nesting together here on the islets of the lake.

ARCITIC-ILPINE BIRI)-IIFE GROUP. The scene in this group is above the timberline on a crest of the Canadian Rockies, 8,000 feet above the sea. Although those mountains are in the temperate region, the altitude gives climatic conditions that would be found in the far North. and the bird-life is arctic in character. White-tailed Ptarmigans, Rosy Finches and Pipits are nesting here.

SAGE GROUSE GROUP. The male Sage Grouse is shown, strutting and wooing a mate in the sage brush of a western plateau near Medicine Bow, Wyoming.

PRAIRIE CHICKEN GROUP. The Prairie Chickens are the common grouse of the western grasslands. The group show's a typical scene during the mating season. The male birds go through most surprising antics in their efforts to attract the females. They blow up the orange-colored sacs on the sides of their necks, dancing and strutting about, and uttering a loud, resonant, booming note.

CANADA GOOSE GROUP. The Canada Goose is one of the first birds to migrate north in the spring. It nests among the lakes of Canada even before the ice is melted. The Scene is at Crane Lake, Saskatchewan, Canada.

GREBE GROUP. The Grebes are aquatic birds, building their nests in the water. During incubation the parent usually covers the eggs with grass and reeds when leaving the nest. Nesting at the same lake with the Grebes was the Redhead Duck.

LOON GROLP. The Loon is justly famed for its skill as a diver and can swim with great speed under water. Its "laugh" and other calls are familiar sounds on the northern New England lakes. Many Loons pass the winter at sea fifty miles or more from land.

BIRD ROCK GROUP. This rocks island thirts miles from shore in the Gulf of St. Lawrence gives protection to the sea birds that still nest in considerable numbers on its cliffs. Seven species are shown nesting in the group - the Razorbilled Auk, Leach's Petrel. Gannet, Puffin, Kittiwake Gull, Common Murre and Brunnich's Murre. 


\section{MAMMALS}

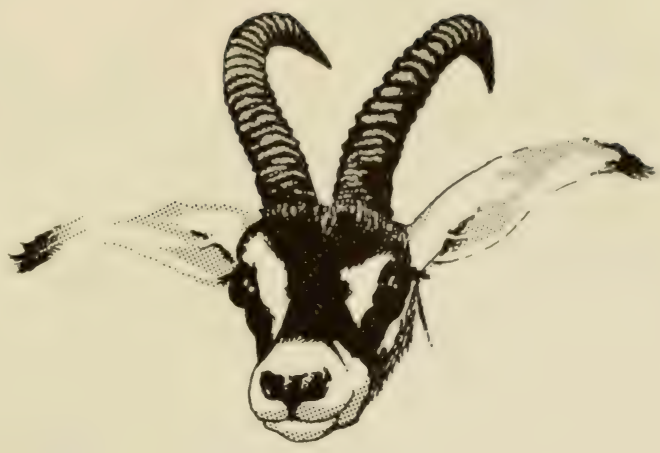

A mammal is a warm-blooded backboned animal, clothed with fur or hair. The young are fed with milk by the mother. Mice, cats, dogs, horses, elephants, whales, monkeys and men are mammals. Birds, snakes, frogs, turtles and fishes all have backbones but they are not mammals. They have neither fur nor hair nor do they nurse their young with milk.

The Department of Mammals is devoted to their study-classification, physical structure, developments, including growth and size, distribution, adaptation to environment, abundance and many other avenues of research. Ficld and laboratory investigation results are presented in both scientific and popular publications.

The Department also is responsible for the splendid natural habitat groups to be seen in the various halls. Here the visitor will see representative mammals from all parts of the world, together with the kind of environment in which they live. There is a multiple purpose in such exhibition. The visitor sees the animal at home, he appreciates the relationship between the environment and the kind of creature that can live in it, and he is brought to realize the necessity of preserving such environments if the animals themselves are not to be driven out of existence. Thus, both the aims of education and of conservation are served.

\section{THE HALL OF NORTH AMERICAN MAMMALS}

The Hall of North American Mammals is approached from the Hall of New York State Mammal exhibits. It was opened to the public on April 8, 1942. A few of the groups are still under construction.

At the west end of the hall, opposite the entrance, is the AL.ASKA BROWN BEAR GROUP. These great carnivores are shown against the background of the Pinnacles, steep mountains of the Alaska Peninsula. 


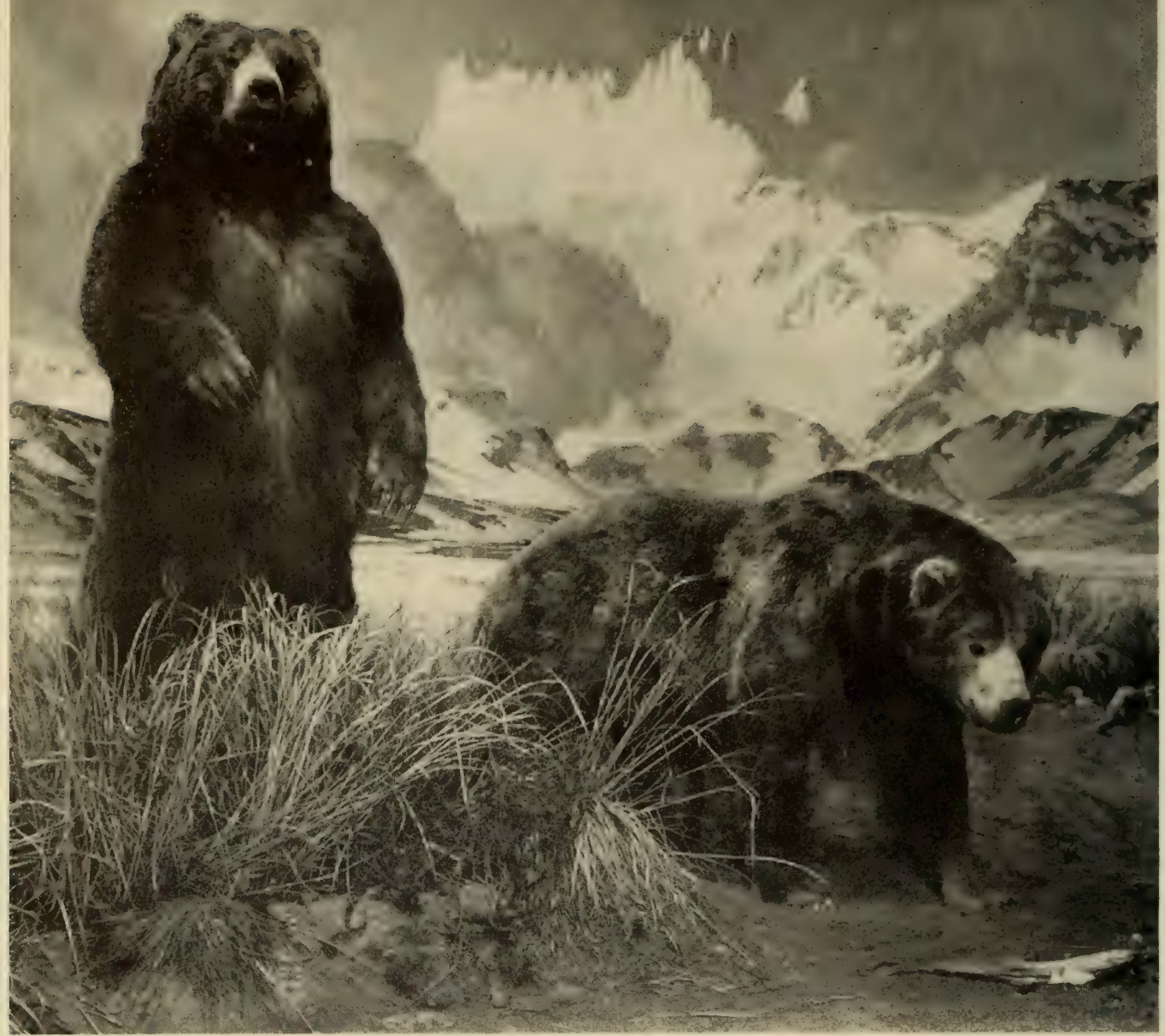

ALASKA BROWN BEAR, the world's largest carnivore. It goes into hibernation on the mountain slopes in the fall and emerges in April or May.

A salmon lies on the shore of a small creek. The Otter that caught the salmon is being frightened awav by the approach of the bears.

On either side of the entrance to the hall are small-scale groups, showing the mammals of North America and their environments during the Ice Age. These animals are now extinct here, although their close relatives exist in other parts of the world. Some of our living mammals could have been found in company with extinct ones. The group to the right shows the mammals found in Alaska. The group on the left depicts those that occurred in southern California.

The GRANT CARIBOU in their home on the Alaska Peninsula appear in the first large group to the right of the entrance. 


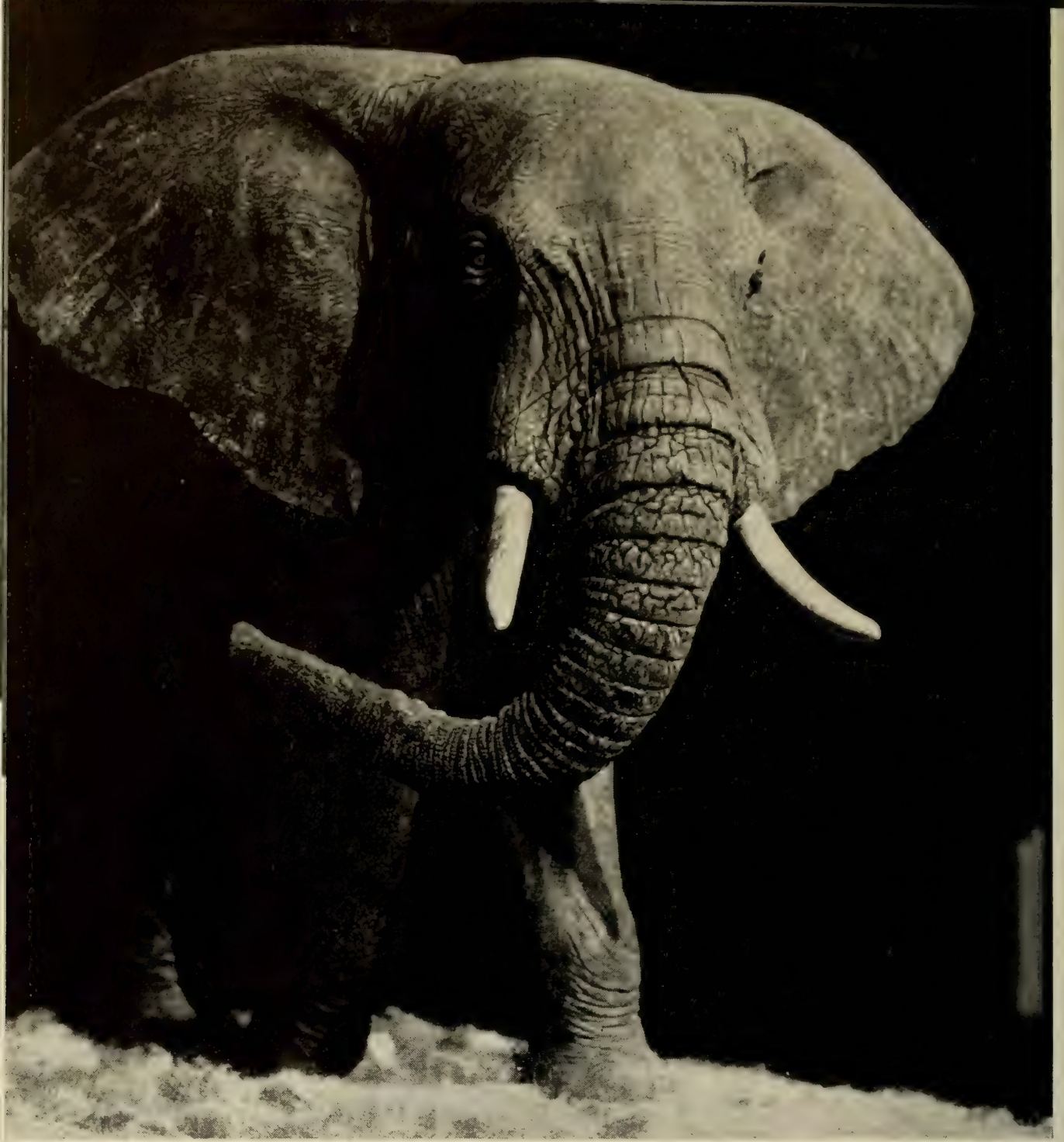

THE REAR GUARD. Detail from the great elephant group in the Akeley African Hall. In every herd of elephants, in the wild condition at least, one animal takes the responsibility of wheeling about at frequent intervals to see that all is well behind. The young male shown above is mounted in this position in the elephant herd. It was collected by John T. McCutcheon in 1910 when he was in the field with Carl Akeley.

\section{AKELEY MEMORIAL HALL OF AFRICAN MAMMALS}

The main floor of this hall, entered from the Theodore Roosevelt Memorial Building, was opened to the public in the Spring of 1936 . Here are exhibited mammals typical of Africa, in their natural surroundings.

At each side of the door are sculptured representations of African natives by Malvina Hoffman. At the opposite end are a very large pair of elephant tusks. 


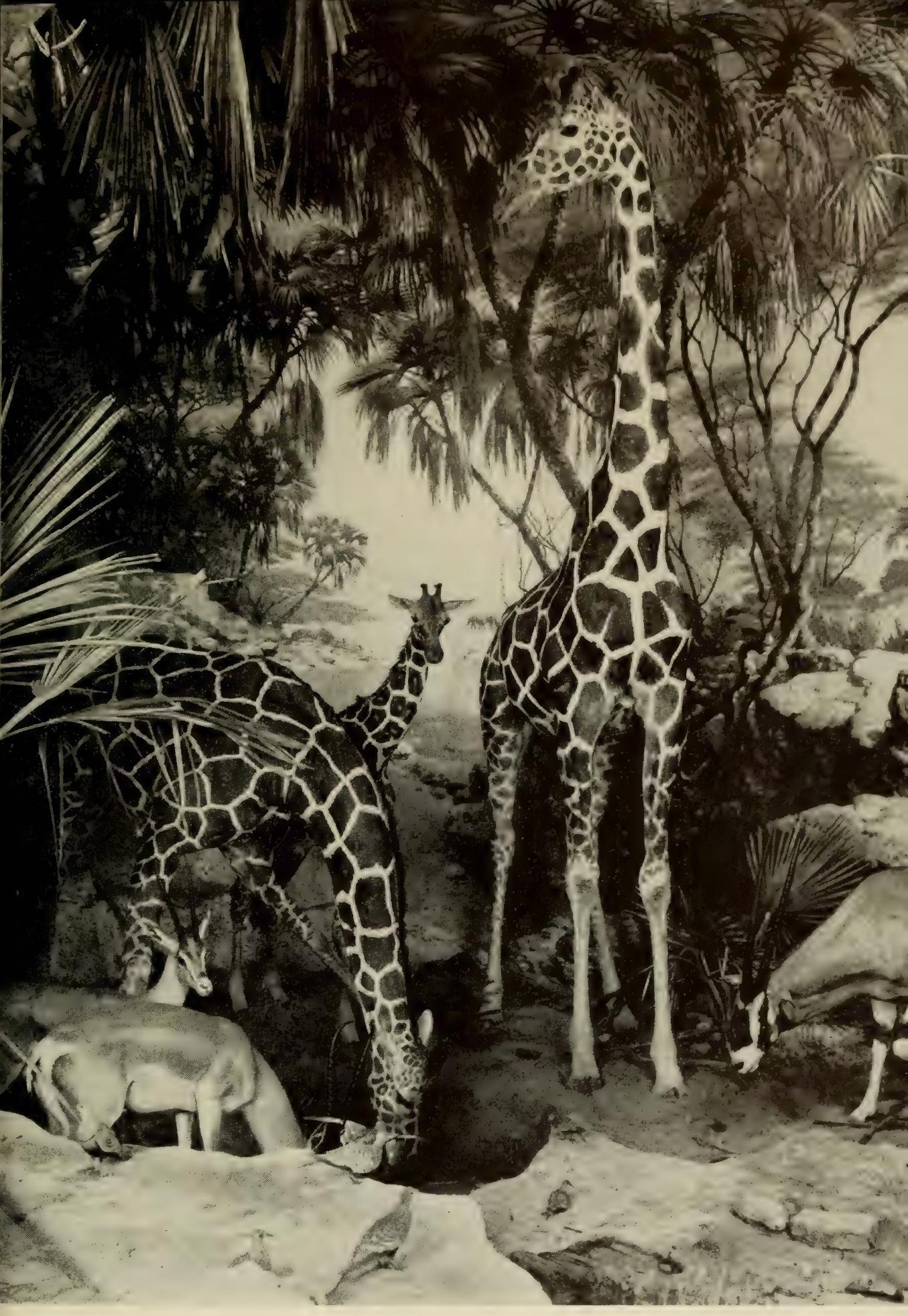


In the center, dominating the hall, stands a herd of AFRICAN ELEPHANTS in characteristic formation when alarmed. The great bull's trunk is raised to test the air for scent, while a younger bull wheels about to cover the rear of the herd from possible attack.

Immediately to the right of the entrance is the WATER HOLE GROUP. The animals of the plains must come, during the dry season, to such seepage holes to drink. Drawn together by their common thirst are Reticulated Giraffes, Grant Gazelles, Orvxes with long straight horns. and Grevy Zebras. Other typical mammals of Kenya are seen in the background.

Next are the MOUNTAIN NYALA, handsome antelopes, on the heather-covered uplands of Abyssinia.

A herd of AFRICAN BUFFALO emerges from the marshes along the Tana River, Kenya, in late afternoon.

A FAMILY GROUP OF LIONS rests in the shade of a tree, their tawny hides dappled with sunshine. In the background a herd of antelopes and zebras feeds unconcernedly.

The BONGO GROUP show a pair of these boldly striped antelopes in their native bamboo forest high on the Aberdare Mountains, Kenya. They have disturbed another typical forest-dweller, the Giant Forest Hog.

The GIANT ELAND, in the southern Sudan, is the largest of the antelopes.

The UPPER NILE REGION GROUP. Waterbuck, Kob, Nile Lechwe, Tiang Antelope, Situanga, Roan Antelope and Hippopotamus are found together in this exhibit. A tributary of the Nile, showing sunning crocodiles, forms the background.

At the end of a short hallway, there is a large-scale map of Africa, showing localities from which the various animals and their settings were taken.

To the left of the Upper Nile Region Group is the PLAINS GROUP. Here is the teeming mammalian life of the East African plains. The several kinds of antelope and zebra in this group are typical of this part of Africa.

The GREATER KOODOO, the most prized of the twisted-horn antelopes, bears the longest horns of any. An old male, a female and a young male stand in a setting duplicating the rough, scrub-covered hills where these animals were collected.

The GIANT SABLE is noted for its elegant form. deep rich color and long saber-like horns. It is found in a limited area of the dry, park-like country of central Angola and is rapidly becoming extinct.

The GEMSBOK is a larger relative of the Oryx seen in the Water Hole Group. Although once widely distributed in South Africa, the Gemsbok is now common only in dry parts of the Kalahari Desert.

The OKAPI is forest-dwelling and is the only living relative of the Giraffe.

The LIBYAN DESERT shelters such animals as the Addax, with 


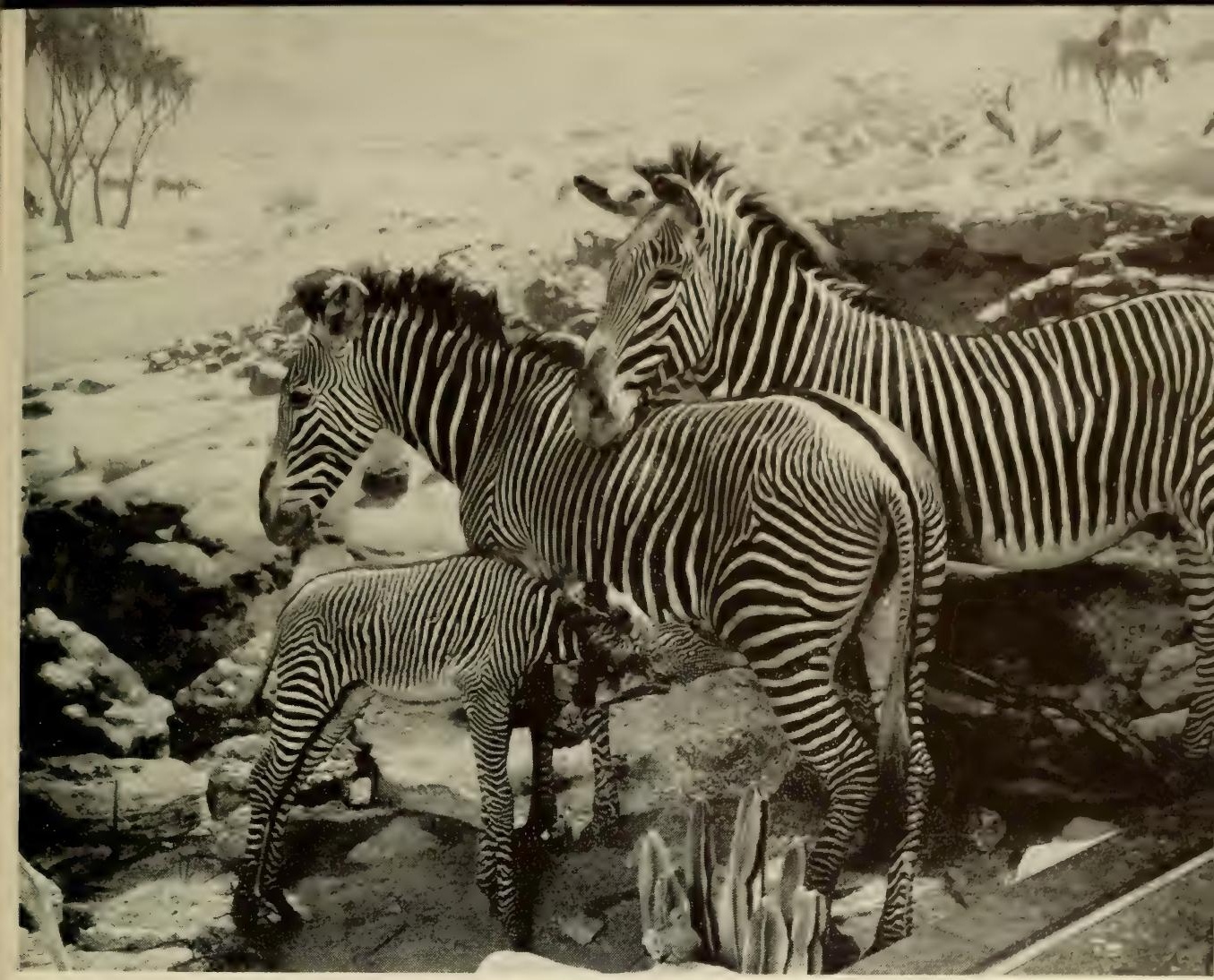

GREVY ZEBRAS FROM WATER HOLE GROUP IN AKELEY AFRICAN HALL.

AFRICAN BUfFalo. Detail of the group in Akeley African Hall.

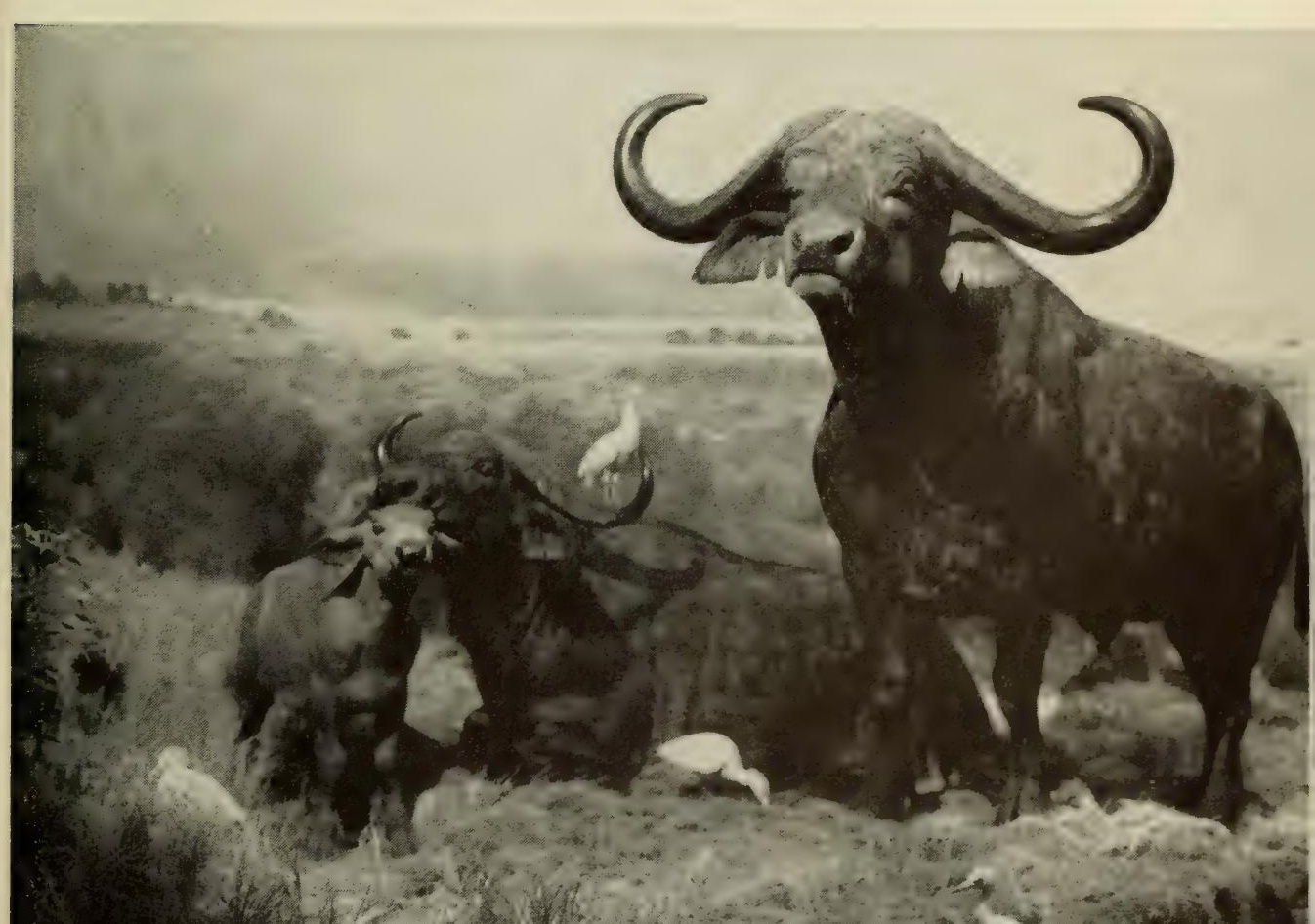




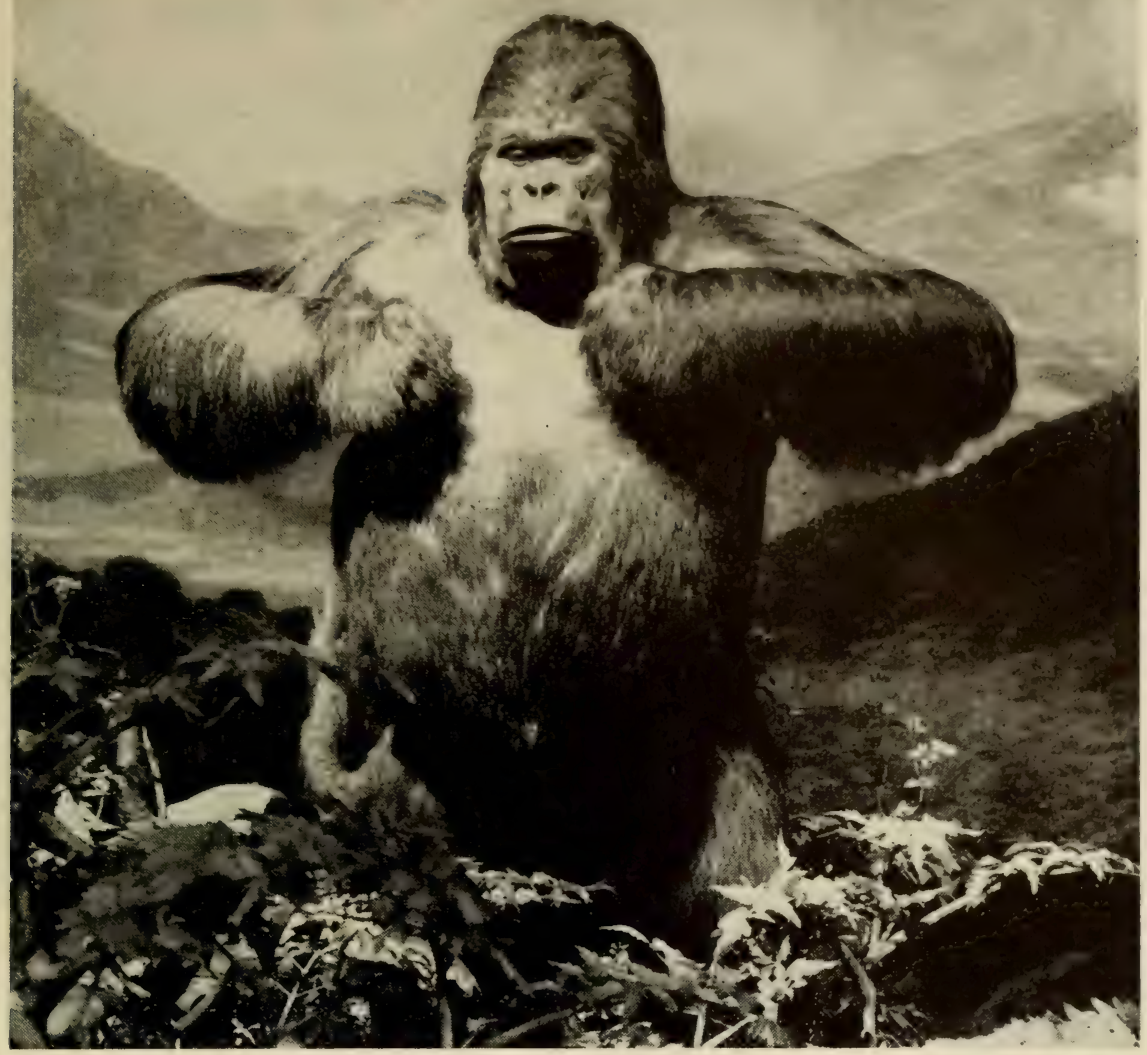

MOUNTAIN GORILLA. Of all living animals, the gorilla appears to be most nearly like man. The adult males may reach a weight of 500 pounds. Their strength is tremendous and they are dangerous when enraged. They are found in the rain forests in the highlands of the eastern Belgian Congo. Terrestrial in habit, they feed on fruits and herbage. Details of group in Akeley African Hall.

their spirally twisted horns, the White Oryx, with the scimiter-shaped horns, and the Addra Gazelles.

The GORILLA family is of particular significance because these great apes are among the most man-like of all the living animals. They are shown here in a clearing in the dense rain forest of the Kivu Mountains, an exact replica of their natural habitat.

\section{Gallery of Akeley African Hall}

The first group on the right shows the KLIPSPRINGER, the small, rock-climbing antelope in the background. East African Baboons are in the right foreground and a pair of Mountain Reedbuck appears on the left. Among the rocks in the left foreground is a Hyrax or Cony.

A pair of CHEETAH, fast-running cats, closely watches two Nyalas which have just come out of the forest. This setting is in the country near the lower Zambesi River in Mozambique.

A party of CHIMPANZEES is in their tree habitat overlooking the 


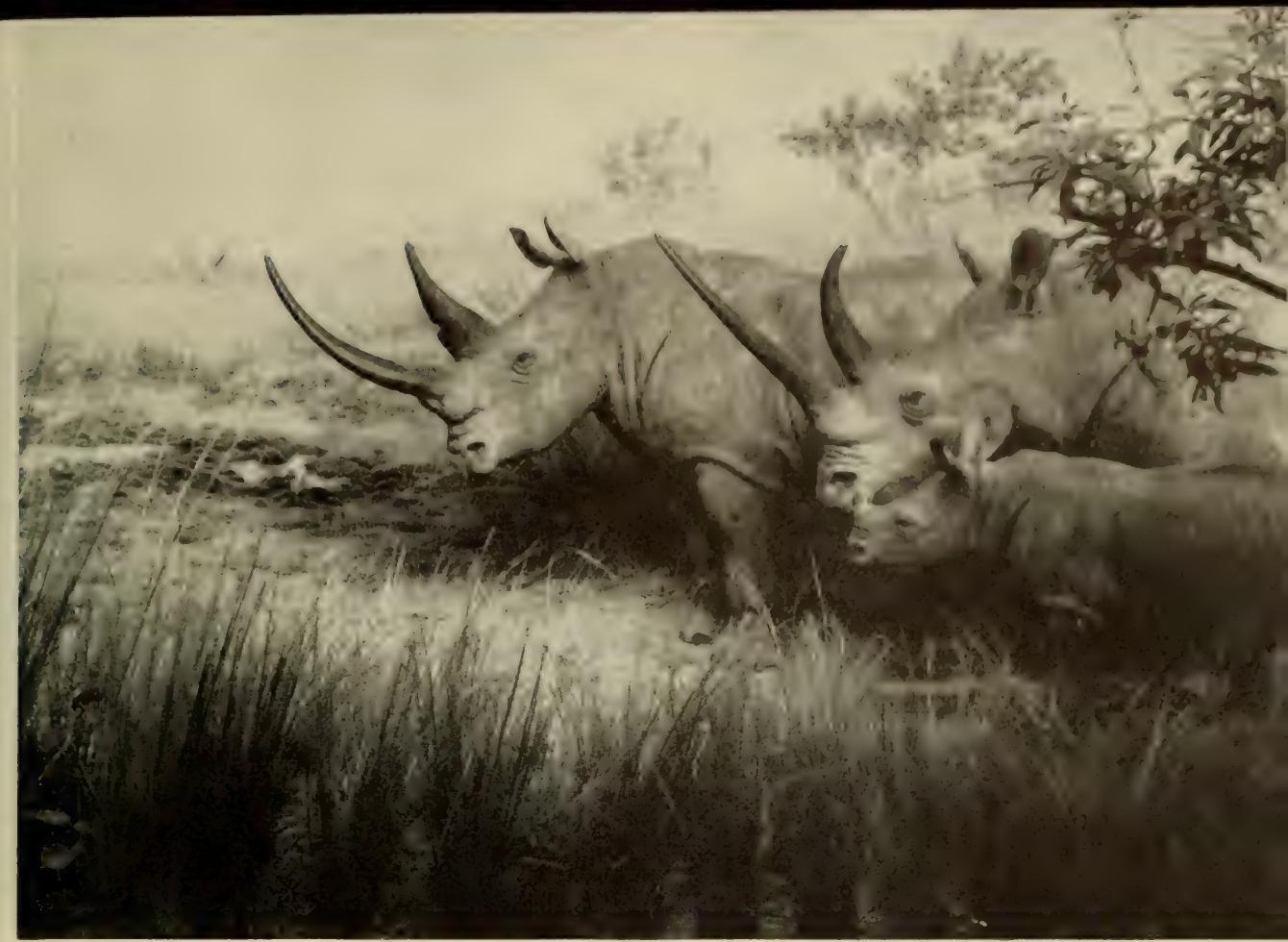

WHITE RHINOCEROS GROUP.

COLOBUS MONKEY. Its long, handsome black-and-white coat suggests a bishop's robe. Actually, if blends with the hanging, light-colored lichens and dark shadows of its forest habitat.

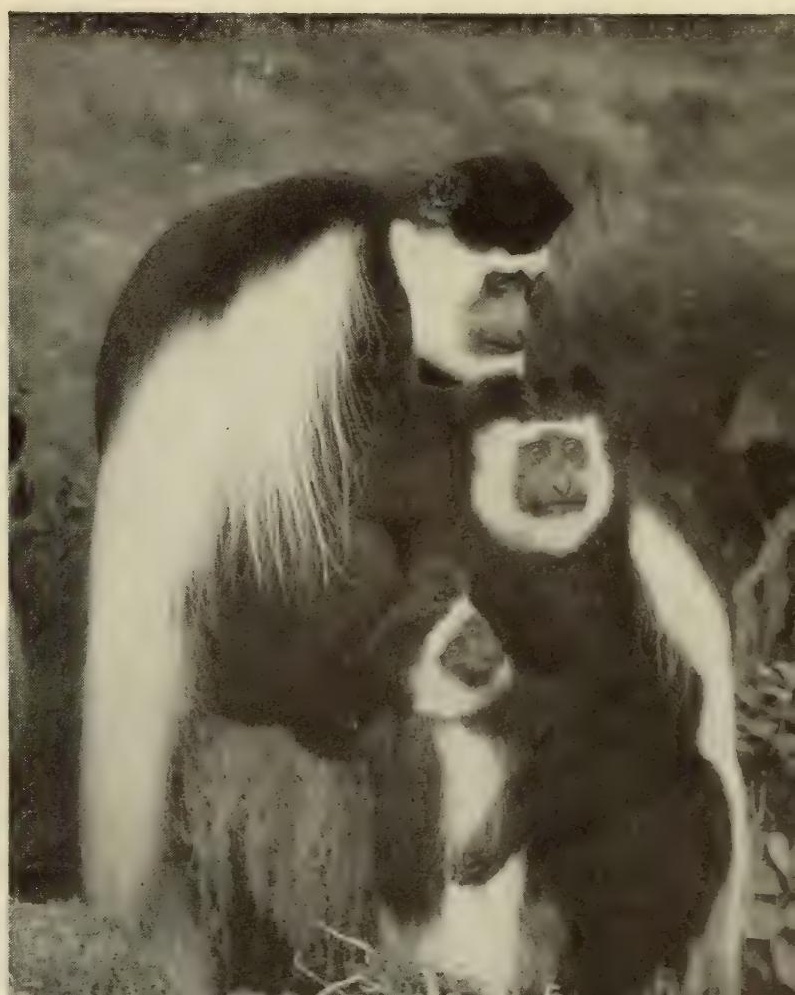




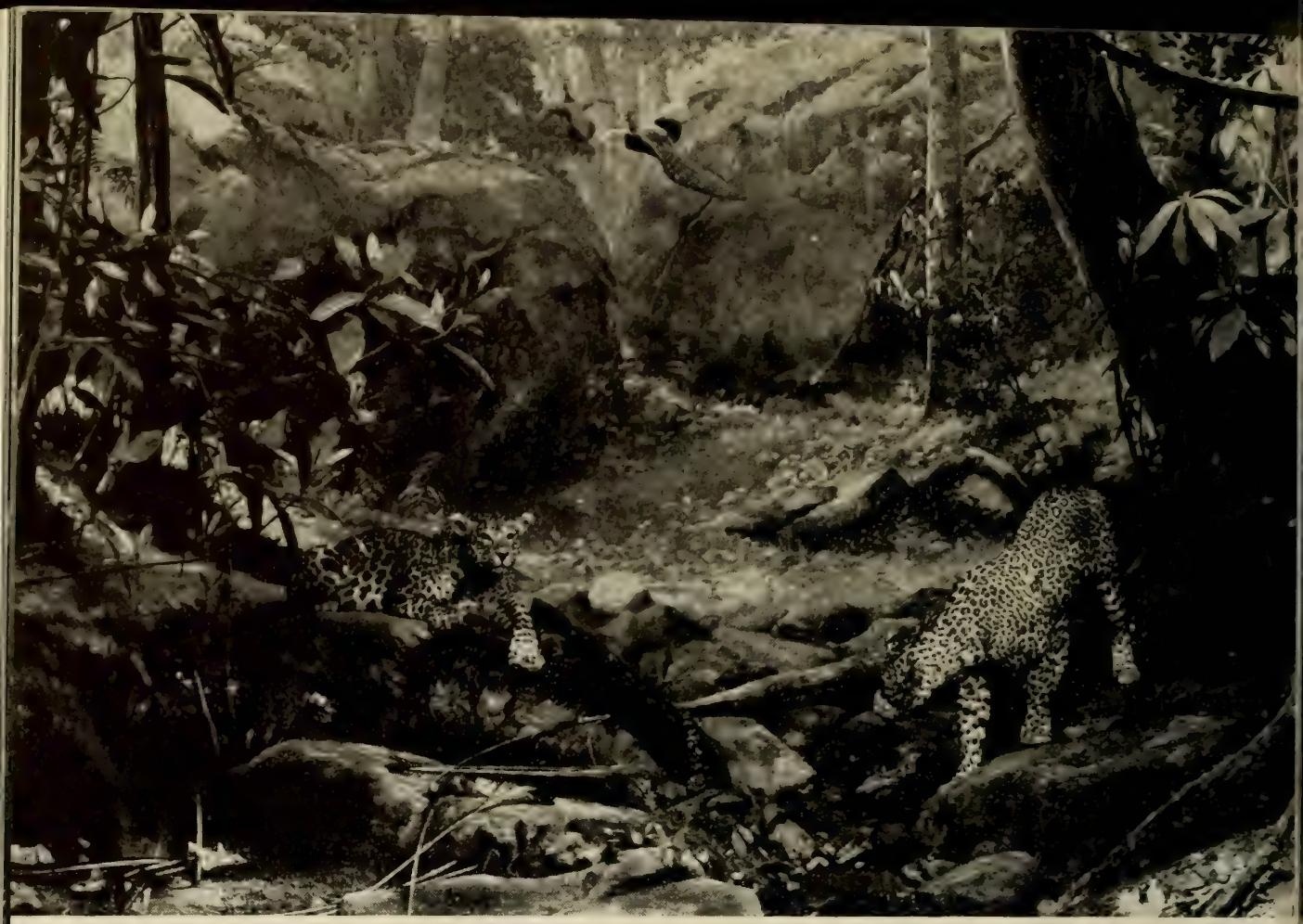

THE LEOPARD GROUP IN THE SOUTH ASIATIC HALL.

SAMBAR ATTACKED BY WILD DOGS.

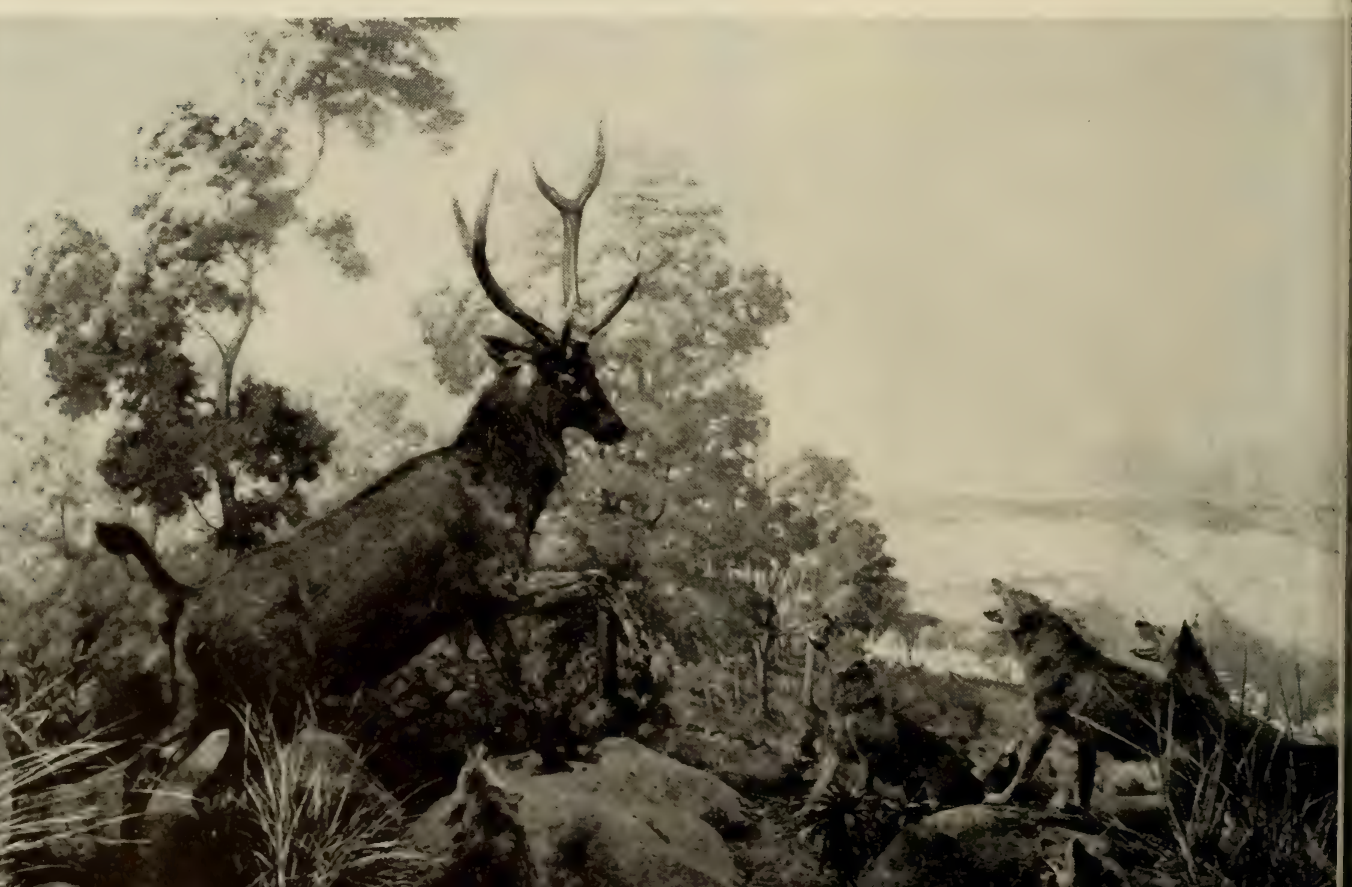


attack these larger species. Gatrelles, Impala, and smaller animals are their usual prey.

The HYENA-JACKAL-VULTIRE GROUP. Out on the Sorengeti Plains, Tanganvika, a pair of lions have killed a zebra. As they with. draw after completing their feast, the scavengers arrive for their shate of the spoils. The animals and birds included in this group are a Spotted Hyena, two Black-backed Jackals, White-backed Griffon V'ultures, a Ruppell's Griffon Vulture, two Eared Vultures, a Hood Vulture, a Marabou Stork and a White-collared Raven.

LEOPARDS about to spring upon an unsuspecting BUSH PIG is the subject of the next group. The scene is on the edge of a small swamp) in the Aberdare Mountains, Kenya.

The COLOBUS MONKEY GROUP shows a troop of these showy black and white monkeys among the branches of a tree overlooking a section of the Aberdare Mountain Forest, Kenya.

The SOUTH AFRICAN GROUP depicts typical mammals of the high veldt as they were when white men first came there. Springlok are now greatly reduced in number and Blesbok and Black Wildebeest have survived only on a few farms where they are protected.

The OSTRICH GROUP includes a pair of these large birds with young ones just hatched from the eggs. The Wart Hogs would relish the young ostriches but the parents stand guard belligerently.

\section{VERNAY-FAUNTHORPE HALL OF SOUTH ASIATIC MAMMALS}

This hall is entered from the left or southern end of the Roosevelt Memorial Hall.

From 1922 to 1928, Mr. Arthur S. Vernay of Great Britain made six expeditions to India, Burma and Siam to collect and give to the Museum this collection. It is considered the finest and most complete exhibit of the larger South Asiatic Mammals in existence.

Two fine examples of the INDIAN ELEPHANT stand in the center of the hall. giving due prominence to the largest and perhaps most characteristic mammal of southern Asia. This species differs from the African Elephant in its smaller ears, higher forehead, and arched back. It also has different teeth and trunk with only one "finger."

The INDIAN LEOPARD differs only slightly from those found in Africa. Both are forest animals but occur in the dry bush country also. They feed on deer. pig, and larger birds such as the peafowl, an example of which has been captured by the Leopard in this group.

The SAMBAR is the largest of the Indian deer, found throughout the wooded part of southern Asia. Its size makes it an important source of food for the larger meat-eaters, but it is powerful and may be dangerous when brought to bay. The Red Wild Dog or Dhole of India hunts in packs, sometimes as many as forty strong. These packs are able to kill animals as large as the Sambar.

The BLACK BUCK is found in the high plains country. The adult male alone is blackish, the females and even young males are yellowish- 


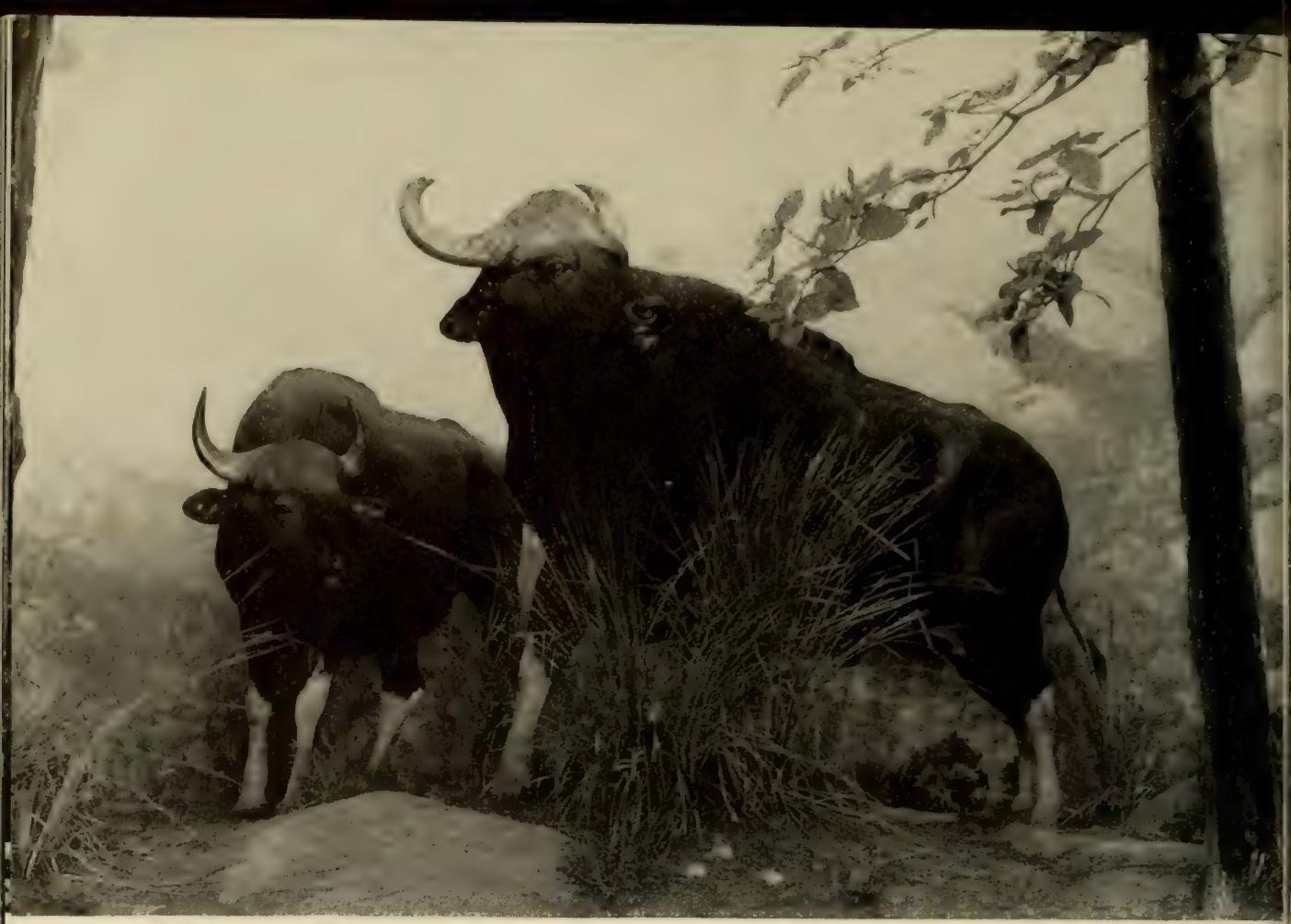

THE GAUR. The Gaur is an imposing animal of India, Burma and the Malay Peninsula. It is found in the forests, but sometimes feeds in grassy areas on the high hills. It is not found in the lowlands.

ASIATIC WATER BUFFALO. These buffaloes are the cattle of the grassy plains of India. They are widely domesticated as draft animals and furnish milk to the natives. 


\section{THE HALL OF OCEAN LIFE}

I.eading from the Hall of Fishes is the Hall of Ocean Life. In it are dieplayed whales, porpoises, marine mammals, the great CORAI, REEF GROUP and marine invertebrates.

"Oscar," the whale embryo, is shown in the vestibule of the hall, opposite the shell of a great clam.

Immediately upon entering the hall, the visitor will note the large skeletons and models of whales and porpoises suspended from the ceiling. In the corner, at the left of the entrance, is a model of the WHITE WHALE, a large northern porpoise. Just in front of the entrance to the hall is the striking full-size morlel of the KILLER WHALE, with contrasting black and white markings. The Killer Whale is a fierce hunting animal, capable of swallowing a fur seal or small porpoise at a gulp. Near the Killer and facing it hangs the model of a BLACKFISH, which, like the Killer, is a species of giant porpoise, although milder in disposition. Skeletons of these animals are below the models.

Above the balcony in front of the entrance is suspended a life-like model of a GIANT SQUID, a great backboneless sea animal upon which the sperm Whale prevs. The large skeleton to the right is that of a SPERM WHALE, the largest of the living toothed whales. The Sperm Whale was formerly most sought by whalers as the source of spermaceti, a white, brittle, fatty substance found in the sperm-oil in the head of the whale. It was used in making candles and in salves and ointments. Beyond the Sperm Whale, on the same side. hangs a skeleton of the FINBACK WHALE.

Just above these two large skeletons are found skeletons of the NARWAHL and species of toothed whales, including several rare types. At the near end of this row is a sperm Whale model, and at the far end a small model of the SULPHUR-BOTTOM WHALE, the largest animal in the world.

Along the left side of the hall, three skeletons of whales are hung. The one nearest the entrance is a RIGHT WHALE, the middle one a

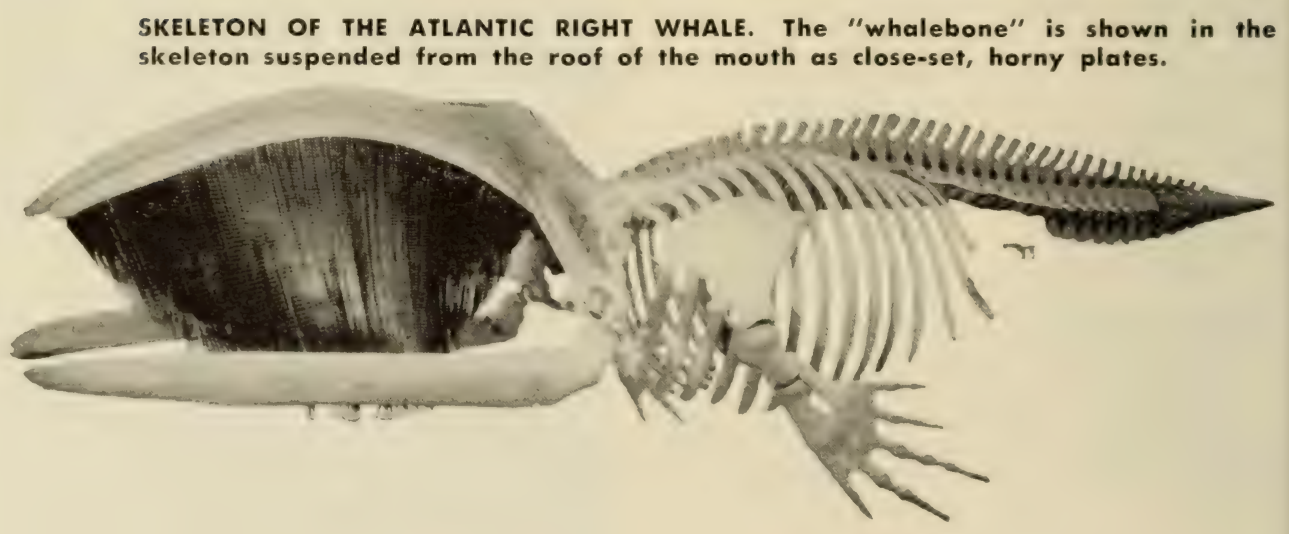




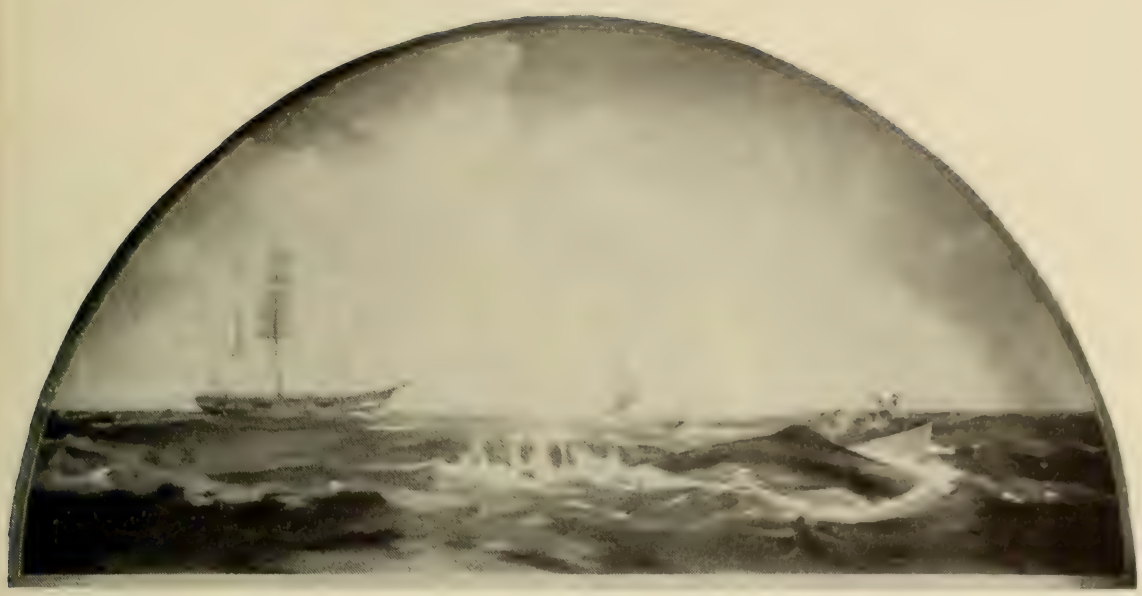

HARPOONING THE SPERM WHALE DURING THE DAYS OF SAILING SHIPS. ONE Of a series of murals in the Hall of Ocean Life depicting whaling in olden times when sailing vessels were used and the whales were captured with a harpoon thrown by hand.

PYGMY RIGHT WHALE, and the third a CALIFORNIA GRAY WHALE. Above them is a long row of life-like models of whales and porpoises, ranging in species from the Right Whale and the Common Dolphin to the rare River and Lake Dolphins.

About the center of the row is a model of the PYGMY SPERM WHALE. At the far end are two large models, one of the spectacular NARWHAL with long ivory tusk (at the right), the other the FALSE KILLER, formerly a very rare species, but in recent years appearing unexpectedly off the British Isles and the coast of South Africa, where a large number were stranded in shallow water.

Around the walls of the balcony are eleven murals. Along the right side are four great paintings showing scenes typical of AMERICAN SPERM WHALING and titled respectively "The Chase," "The Attack," "Towing the Carcass." and "Trying Out." On the left wall are three canvases portraying the life of TYPICAL SPECIES OF WHALES, including "Bowhead Whale," "Finback Whale," and "Killer Whales Attacking a Gray Whale." These seven murals are the work of Mr. John P. Benson, the noted marine painter.

The walls to the right and left of the entrance bear murals by J. M. Guerry: left, the Sulphur-bottom Whale; right, Sperm Whale with its favorite food, the Giant Squid.

Below the level of the balcony and hanging just beyond reach from the rail at the head of the stairway is a cast of a YOUNG SPERM WHALE which came into New York Harbor and was eventually made captive in the Gowanus Canal in Brooklyn. It was brought entire to the Museum.

On the main floor of the Hall of Ocean Life and under the balcony are the habitat groups of marine mammals. Beginning at the near right 
A toy-size antelope, Swayne's dik-dik is a close relative of the Giant Eland which weighs 1200 pounds: one of the many interesting exhibits in the Synoptic Mall.

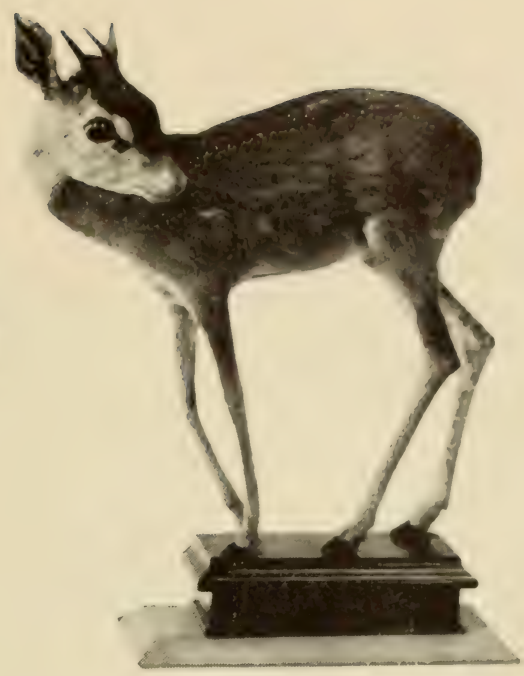

corner, the first of these is the group of NORTHERN ELEPHANT SEALS, huge, ponderous animals that have hauled themselves out on the rocky beach of Guadaloupe Island, Lower California. The fullgrown male of this species has a long, hanging proboscis suggestive of an elephant's trunk. Next is the exhibit of the FLORIDA MANATEE, a thick-set beast, well-adapted to its life in the water.

The PACIFIC WALRUS, one of the largest groups in the Museum, shows these Arctic sea mammals at home on an ice floe in the Bering Sea.

In the first left corner is a large group of STELLER SEA LIONS on St. George Island, one of the Pribilofs. The male Sea Lions are huge, powerful seals with massive necks and shoulders.

Many details of the home life of the beautiful ALASKA FUR SEALS. on Kitovi Rookery, St. Paul's Island, may be noted. Each vigorous, dominant bull has his harem of sleek, slender cows, while nearby are the bachelor bulls and the playful pups.

On the floor of the hall are several cases with special exhibits. One of these is the TOWNSEND FUR SEAL, a species almost extinct and only recently rediscovered after it was believed by many to have disappeared completely. Another case displays several types of diving gear with full equipment of pump, telephone, etc.

\section{SYNOPTIC HALL OF MAMMALS}

This hall, entered from the Insect Hall, chiefly illustrates various interesting differences in the habits and structures of mammals. It also shows their principal orders and the main subdivisions of these, known as families. Each family is, as far as possible, represented by a mounted specimen and a skeleton.

Starting from the farther or western end and walking around the room from left to right. one passes from the egg-laving Platypus to 
Man, represented by the figure of an Australian native, armed with a boomerang.

Certain exhibits demonstrate modifications of form and structure for various ways of locomotion, and the superiority of the brain of mammals over that of other backboned animals. Others show albinism (white varicties) and melanism (black varieties). Still others point out that animals outwardly similar may be only very distantly related. How the coat of the hare changes from brown to white and how plants and animals adapt to a desert habitat are also illustrated.

Of special note is the SKELETON OF JUMBO, the largest elephant ever brought to this country alive.

The FRUIT BATS, often known as FLYING FOXES, the largest member of the bat family, and found only in the warmer parts of the Old World, are represented by a small portion of a colony from Calapan, Philippine Islands. Such a colony may be very destructive to bananas and other fruits.

The most striking object in the hall is the suspended life-size model of a SULPHUR-BOTTOM WHALE, seventy-six feet long. The original of this specimen was captured in Newfoundland and the model is accurately reproduced from careful measurements. This species of whale is not only the largest of living animals, but, as far as we know, the largest animal that has ever lived. A specimen of this size would weigh from sixty to seventy tons, twice as much as the extinct reptile BRONTOSAURUS. Although whales and porpoises live in the water, they are not fishes but true mammals, since they are warm-blooded, breathe by means of lungs, not gills, and nurse their young with milk.

\section{MAMMALS OF NEW YORK STATE}

A complete series of the living mammals which have been known to exist within the limits of New York State is presented in the corridor on the first floor of the Roosevelt Memorial in the neighborhood of the elevators. This exhibit includes skins and skulls of all mammals of moderate size, models of the larger species, and cutout figures of the whales and other large sea-animals recorded from the water around New York. 


\section{ANIMAL BEHAVIOR}

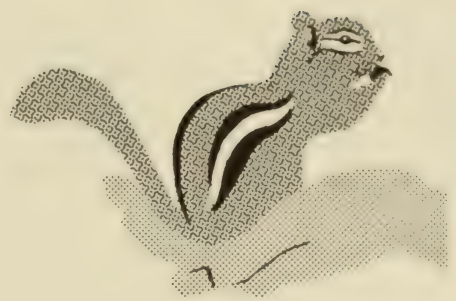

Most visitors are unaware that the Museum also houses a large laboratory devoted entirely to the study of LIVING animals. This is the Department of Animal Behavior which is located on the sixth and seventh floors of the African Wing. Although this area of the Muscum is not open to the general public, special science groups are takin through the laboratory when advance arrangements are made. In this way hundreds of advanced students from New York City High Schools as well as college classes have visited the laboratory in recent years and for many, this was their first opportunity to see a research laboratory in operation. The staff of the Department is also available for consultation when important problems concerning animal behavior arise.

About two decades ago, Museum authorities in their deliberations concerning Museum policy decided that while a major function of this institution continues to be the census, classification and structure of animals, attention should also be paid to the relationship of the various animals to each other and to their surroundings. Museum scientists should investigate and exhibit not only what animals do, but also how and why they behave as they do. Thus the Department of Animal Behavior was established so that specialists in the psychology and physi. ology of animals could study these aspects of natural history. and could be available for consultation particularly in the planning of new exhibits.

Much can be learned by the scientist when he obscrves how animals behave in their natural surroundings. However, this approach to animal study has very definite limitations. It is generally difficult in a ficld study 


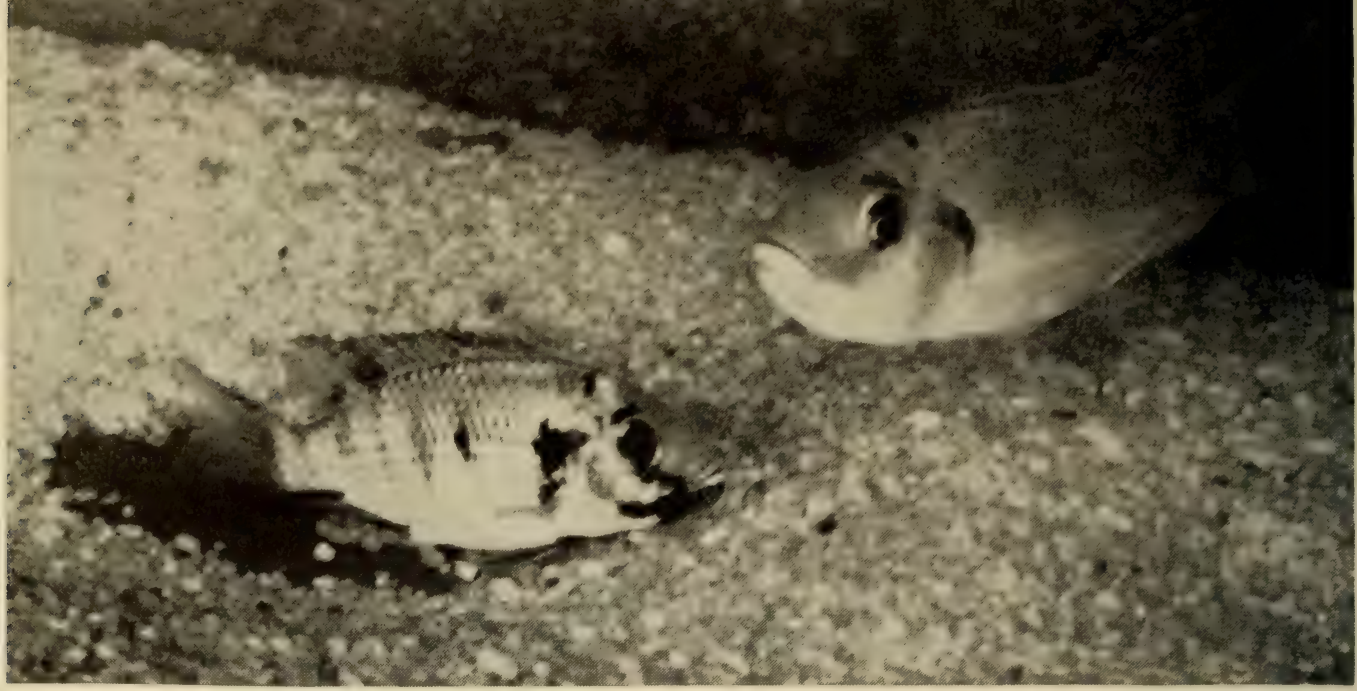

AFRICAN MOUTHBREEDING FISH SPAWNING IN LABORATORY AQUARIUM. ThE female is laying eggs in the "nest," as the male stands by ready to fertilize them. Within a minute after the last egg is laid and fertilized, the male will pick up these eggs and carry them in his mouth until they develop into young fry.

A CIRCULAR COLUMN OF WORKER ARMY ANTS IN A LABORATORY NEST. Under natural conditions, these ants carry out their daily pillaging raids on complex systems of branching chemical trails. Excited by the presence of active larvae, the workers in the laboratory enclosure also move incessantly, but now in a circle. Once such an endless column is formed, the workers may run in it more or less continuously for several days, until all are dead from dryness.

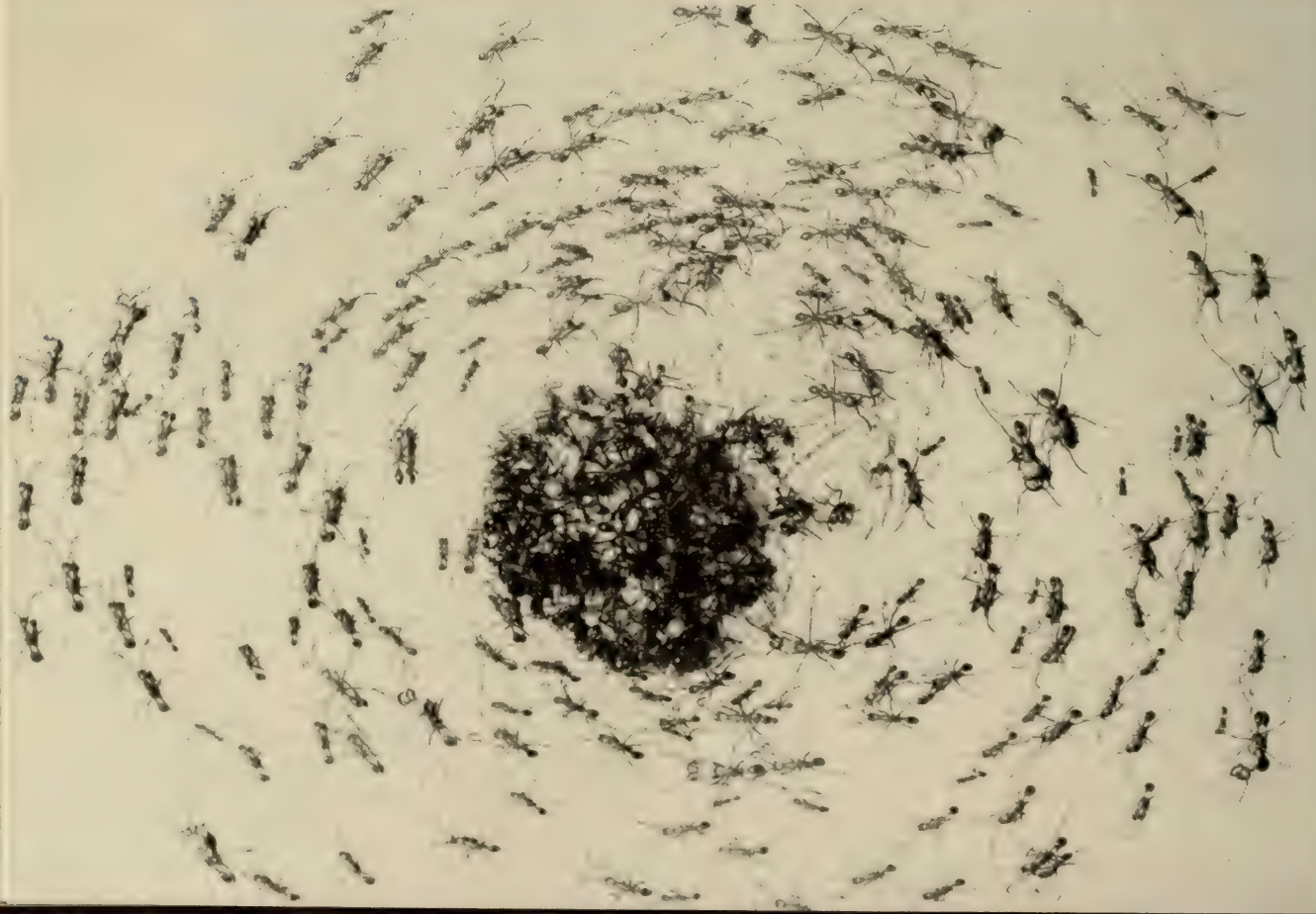




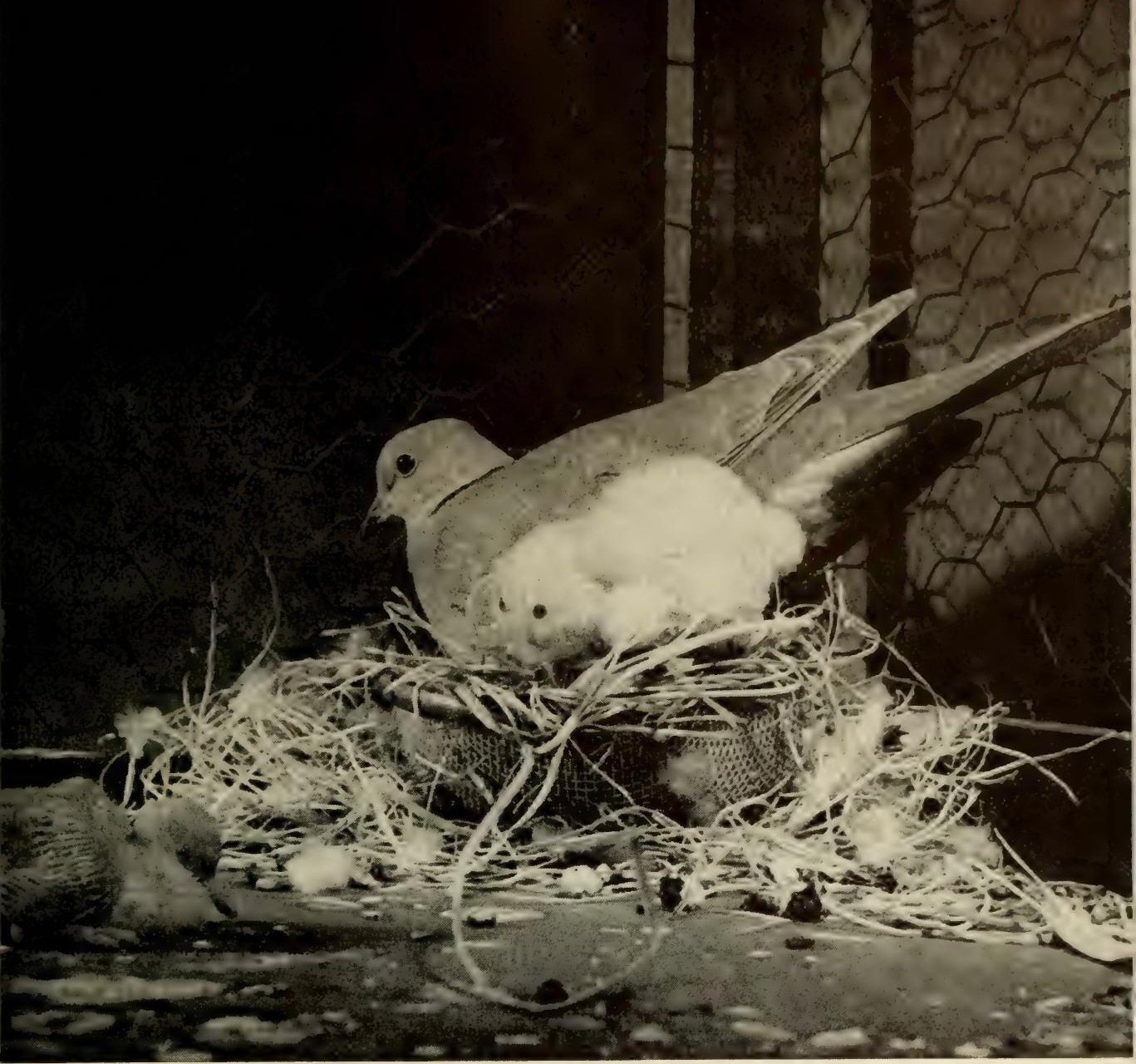

A SIMPLE TEST OF PARENTAL BEHAVIOR IN THE RING DOVE. For a considerable part of the incubation and nesting period in this bird, the nest locality and the nest itself are attractive to the parents, whereas eggs or young alone are not. In this test the parent bird, removed from the nest, was presented with the young on one side and the nest on the other. Brushing past the young without pause, the adult returned directly to the nest and proceeded to sit in it.

to rearrange the surroundings so that a given aspect of behavior can be studied reliably. Laboratory study offers an opportunity to follow "Ip), to supplement or to correct ideas developed in the ficld. Also many important problems must be brought into the laboratory if they are 10 be studied at all. For example, some species of fish live in water so muddy that they can be seen only when the seine brings them to the surface. They can be collected in the field, but their way of life remains hidden except to laboratory study. For reasons such as these, the Department of Animal Behavior has a laboratory designed to keep animals alive and in good health, so that their behavior can be observed and analyzed under suitable conditions. A large greenhouse situated on the 
roof has aquaria for warm water fishes and facilities for other tropical animals. There are flight cages and nest quarters for birds. There are rooms with controlled lighting so that animals (an be placed in reversed daylight cycles and thus nocturnal species can be studied during the davtime. There are special air-conditioned and heat-controlled rooms and other means of regulating laboratory surroundings to meet the conditions needed for each type of animal and problem.

The Departmental program is focused upon the important problem of behavior development in the individual and species and upon those types of hehavior commonly referred to as "instinctive." Physiological mechanisms involving brain, nerves, glands, and hormones are studied along with social factors. previous experience and finally the general influence of an animal's surroundings upon its behavior pattern. All of these affect the animal's behavior to some extent, and the question is "how." Somewhat as the evolution of animals is reflected in changes from simple to more complex structures, we find among animals an evolution of behavior from the forced movements characteristic of onecelled forms to the elaborate behavior patterns characteristic of mammals and man. For a proper understanding of the evolution of behavior it is necessary to study a variety of behavior patterns in very different animals. Thus as the Departmental program progresses, living quarters are provided for many types of animals under study, usually including insects, fish, amphibia, birds and various species of mammals. 


\section{ANTHROPOLOGY}

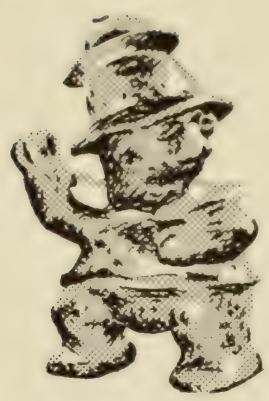

\section{MAN AND HIS ORIGINS}

Anthropology is both a natural and a social science dealing with the complex subject of man as a physical being and also with man's culture what he does and thinks.

That branch of the science concerned with man as an organism is known in this country as physical anthropology. This includes the evolution of man, the classification of the varieties and races of man as he exists today and has in the past, and various aspects of human biology.

Anthropology, as a social science, has been concerned chiefly with the development and meaning of culture. There are two principal branches: archaeology and ethnology.

The archaeologist works with the tools, buildings, and other objects left by ancient peoples and attempts to reconstruct the history of human culture from the time of its origin through the many thousands of vears preceding the periods for which we have written records.

The ethnologist studies and compares the varieties of customs and beliefs of the existing peoples of the world. Both are primarily interested in understanding the nature of human culture - that which can be defined as the body of knowledge, beliefs, customs or ways of doing things which are passed along from generation to generation by the informal or formal processes of education.

Only by knowing the varied forms that the cultures of man have attained and something of their changes throughout time can we fully understand the unique creature which is man.

\section{HALL OF PRIMATES}

The Systemic Series of Primates, intended to give some idea of the types of animals included in this order, and their range in size, form, and color, begins on the left with examples of gorillas and chimpanzees and is 


\section{HE SKELETON FROM FISH TO M}

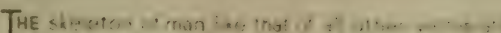

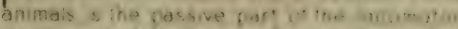

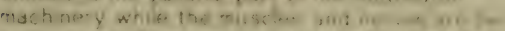

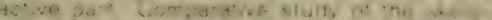

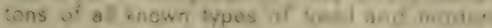
arimis kas made : : ... : : ne. the

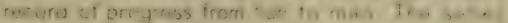

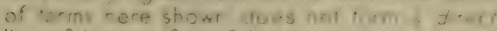
line of descent from fish 10 man bui edch stage shown is the nearest to the direct line so far discovered

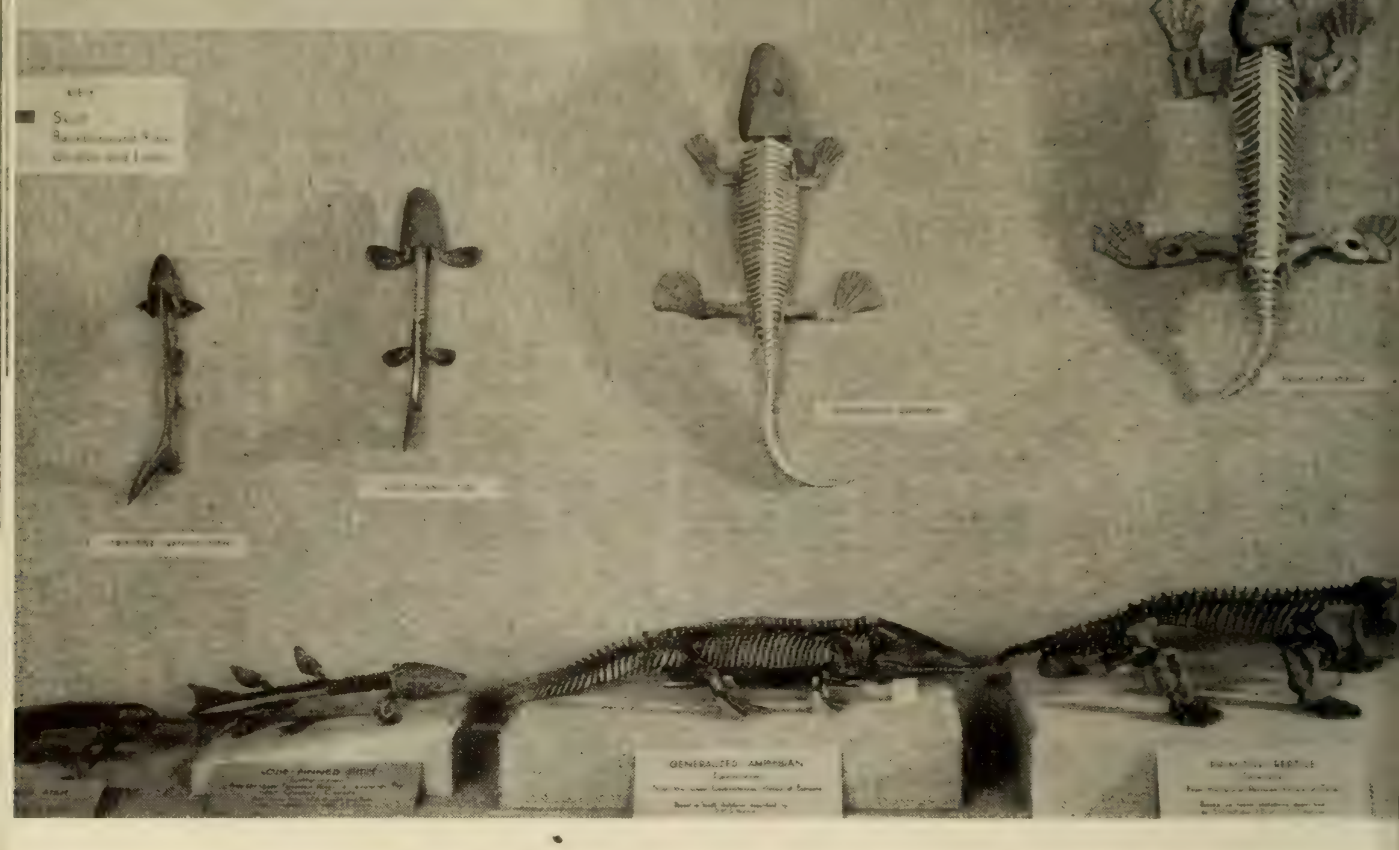

THE FIRST FOUR STAGES FROM FISH TO MAN. (From water-living to land-living)

Stage 1

Primitive Ganoid Fish (Cheirolepis)
Stage 2

Lobe-Finned Fish

(Eusthenopteron)
Stage 3

Generalized Amphibian

(Diplovertebron)
Stage 4

Primitive Repti (Seymouria)

continued in the wall cases around the room, ending with the lemurs. Noteworthy among the primates is the gorilla, largest and most powerful of apes; the curious "proboscis" monkey from Borneo; and the aye-aye of Madagascar.

The center corridor contains groups of primates characteristic of various parts of the world - Mfrica. Asia, South America and Madagascar, and a group of human pygmies living in the forest of central Africa.

Outside of the central corridor, on the left side of the hall. is a group of orangutans from Borneo.

At the farther end of the hall, a series of skeletons demonstrates the comparative structure of the primates and the changes that take place in passing from lemurs to man.

156 


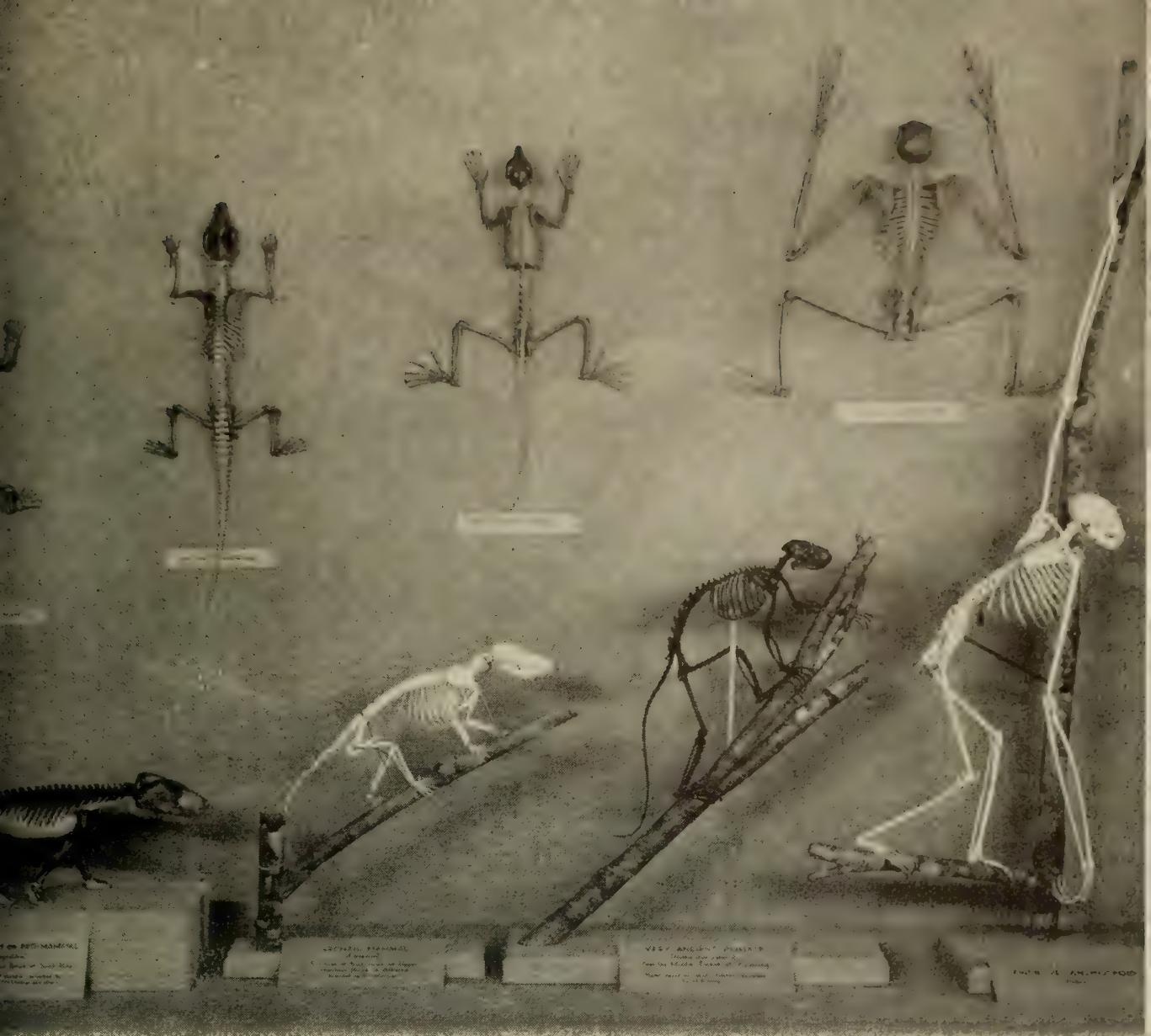

THE SECOND FOUR STAGES FROM FISH TO MAN. (From ground-dwelling to tree-dwelling)

5

odont Reptile or

Mammal (Cynognathus)

\section{Stage 6 \\ Oppossum}

Archaic Mammal Very Ancient Primate

\section{Stage 7 \\ (Notharctus)}

\section{Stage 8 \\ Primitive Anthropoid Gibbon}

\section{HALL OF THE NATURAL HISTORY OF MAN}

The Hall of the Natural History of Man consists of two parts Introduction to Human and Comparative Anatomy, and the second part dealing with the physical characteristics of the Races of Man, Development, Growth, and related topics.

The first part begins by showing MAN IN HIS COSMIC ASPEC:T, with man conceived as a living engine which derives its working capital of energy directly or indirectly from the encrgy of the sun stored up in plant and animal tissue. This energy is appropriated by man in food substances and distributed through the various anatomical systems.

In another exhibit the ELEMENTS OF THE LOCOMIOTOR APPARATUS in backboned animals are set forth. It is shown how red 


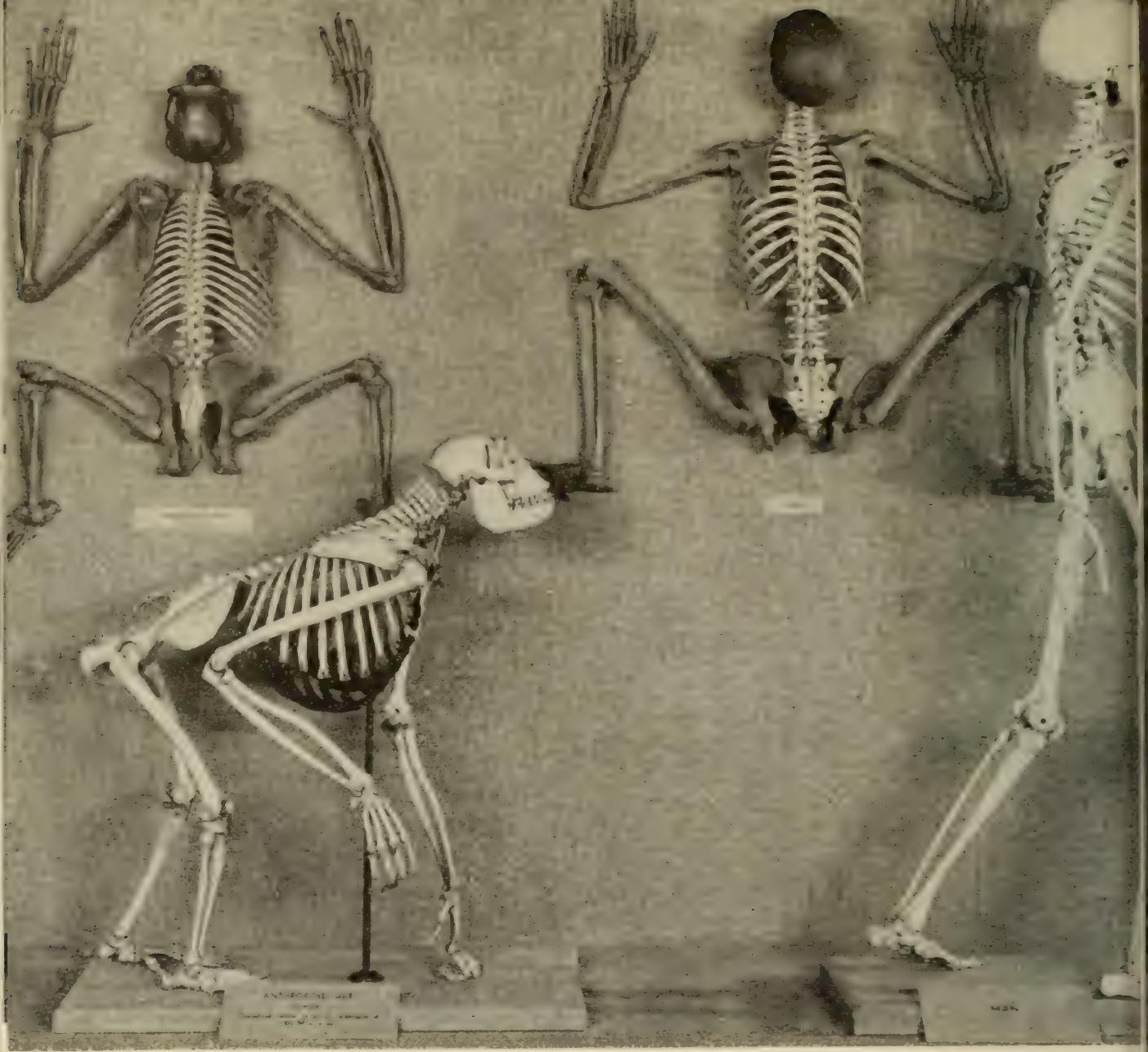

THE TWO FINAL STAGES FROM FISH TO MAN. (On the ground again, and attainment erect posture)

Stage 9

Stage 10

Anthropoid Ape (Chimpanzee, above; Gorilla, below)

muscle fibers of the fish are combined into 11 -shaped muscle segments or myomeres and how the muscles of man are constructed.

Other exhibits deal with the anatomy of man as compared with lower backboned animals. following the chief organ sistems of the body and the parts concerned with locomotion.

The POSITION OF MAN AMONG THE VERTEBRATES and the eridences of his evolution from lower backboned types are shown by (omparisons of skeletal structure in living and in fossil types. and by comparisons of his muscle ssstem with lower forms, as well as by comparative embryology. An analysis of the nervous system, and the evolution of the human brain are dealt with. and the functions of the lsain are demonstrated. 
The second part of the exhibit. on the right side of this hall, is

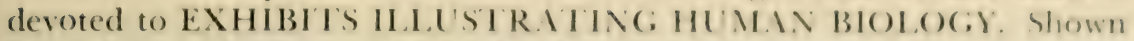
are exhibits of the growth and development of a human embers, sketetal growth in the head, and the variety of phesical ypes of man as modifued by glandular secretions. A series of full-sie figures showing some of the major racial types of man has been placed in the central alcose.

Two charts are also displayed in this alcose. One illustlates the natural habitats of the various racial types exhibited. The other depiets the major population movements throughout the world since 1.192.

At the far end of this side of the hall will be found an exhibit on some of the more important endocrine functions.

\section{The Skeleton from Fish to Man}

The judgment of science is that our pre-human ancestors only reached the grade of humanity after many millions of years of evolution from lower to higher grades of life.

Owing to the enormous number and variety of organisms in nearly all geologic ages, and to the wholesale destruction of their skcletons loy natural agencies, only a small number of the fossil forms which we have discovered to date happen to lie in or near the direct line of ascent from fish to man. Nevertheless, the story of the evolution of the skeleton from fish to man is clear in its main outlines as shown in this exhibit.

The FIRST STAGE represents the earliest true fishes by a model of a fish in the early stage of evolution of higher bony fishes. This fish, which breathed by gills in the normal fish way and which perhaps had a simple air-sac or lung, must have looked something like a trout, but its tail was more like that of a shark. The body moved forward in the water by a wriggling movement caused by the contraction of the regularly arranged muscle segments along either side of the bodv. The axis of the body was an elastic rod called the notochord, similar to that which appears in the embryonic stages of all higher backboned animals, including man. The fins were composed of rays serving as kecls and rudders.

The SECOND ST AGE represents a long step in advance. It is based on a fossil fish named Eusthenopteron, from the Upper Inevonian of Canada. This fish still had gills but there is some evidence that it also possessed an air-sac or lung. It had two pairs of paddles, corresponding to the fore and hind limbs respectively of four-footed land animals.

The THIRD STAGE, from the Carboniferous Age, represents the oldest known type of four-footed animals. The skeleton of the hands, feet and limbs is much more developed than in the previous stages. There are five digits on each of the hands and feet.

The FOURTH STAGE represents the primitive reptilian or lizardlike stage from the Lower Permian of Texas. The skeleton on the whole is not greatly different from the preceding stage, except in detail, but the limbs are better developed.

The FIFTH STAGE represents an advanced mammal-like reptile (Cynognathus) from the Upper Triassic of South Africa. In this form the 
limbs are better adapted for rumning, and there are many features of the skull, backbone, and limbs that approach the condition in mammals.

For the SIXTH STAGE the skeleton of a modern opossum is used. It retains in the main the leading characters of the skeleton of the older fossil mammals. This form has five-toed grasping hands and feet, by means of which it climbs about in the trees. It has kept a relatively low type of skull, teeth, and brain.

In the SEVENTH STAGE we come to Notharctus, a form that lies near the lower limits of the order of primates to which man belongs. These animals were thoroughly adapted to life in the trees but they had much larger eyes and bigger brains than any of the preceding stages.

The EIGHTH STAGE is represented by the skeleton of the gibbon, an East Asiatic ape which is a tree-living descendant of the first family of the tailless or man-like apes. When on the ground it is the only existing man-like ape which normally walks on its hind legs. Its skeleton begins to be almost human in many ways but the arms are excessively long.

The NINTH STAGE is represented by our distant cousins, the gorilla (below) and the chimpanzee (above). These apes retain the essential characters of fossil apes from India and South Africa, some of which approached quite near to the oldest known fossil men. The ape brain is much more developed than the brains of lower animals, and ape intelligence at times is almost human.

In the TENTH STAGE, we see that the human skeleton is built on the same general plan as that of the chimpanzee, gorilla, and gibbon, but that in man the backbone, pelvis, and limbs are modified to enable him to walk on his hind legs and to use his forelegs as arms and hands rather than as supports. His brain is much larger and more highly developed than in the apes.

\section{OSBORN HALL OF THE AGE OF MAN}

This hall is devoted to early man and his contemporaries, the mammoths and mastodons, and the giant ground sloths of South America. The visitor learns what is known of the early history of our own race as shown by the remains of early man and the implements he used. As fossil remains of man are rare and usually very fragmentary, these are represented mainly by casts, but they include examples of all of the more perfect and noteworthy specimens that have been found, from Pithecanthropus and Sinanthropus to NEANDERTHAL and CRO-MAGNON.

In the surrounding cases are some of the principal skeletons and skulls of animals mostly of the Pleistocene Age (see Time Chart on p. 51) known to have been associated with man especially in North and South America. Skeletons and skulls on the right side of the hall show the evolution of the Proboscidea. They fall naturally into two groups: first, the mastodons; and sccond, the mammoths and elephants. In the former division, beginning near the entrance of the hall, are the most primitive mastodons, with two upper and two lower tusks, and a very 


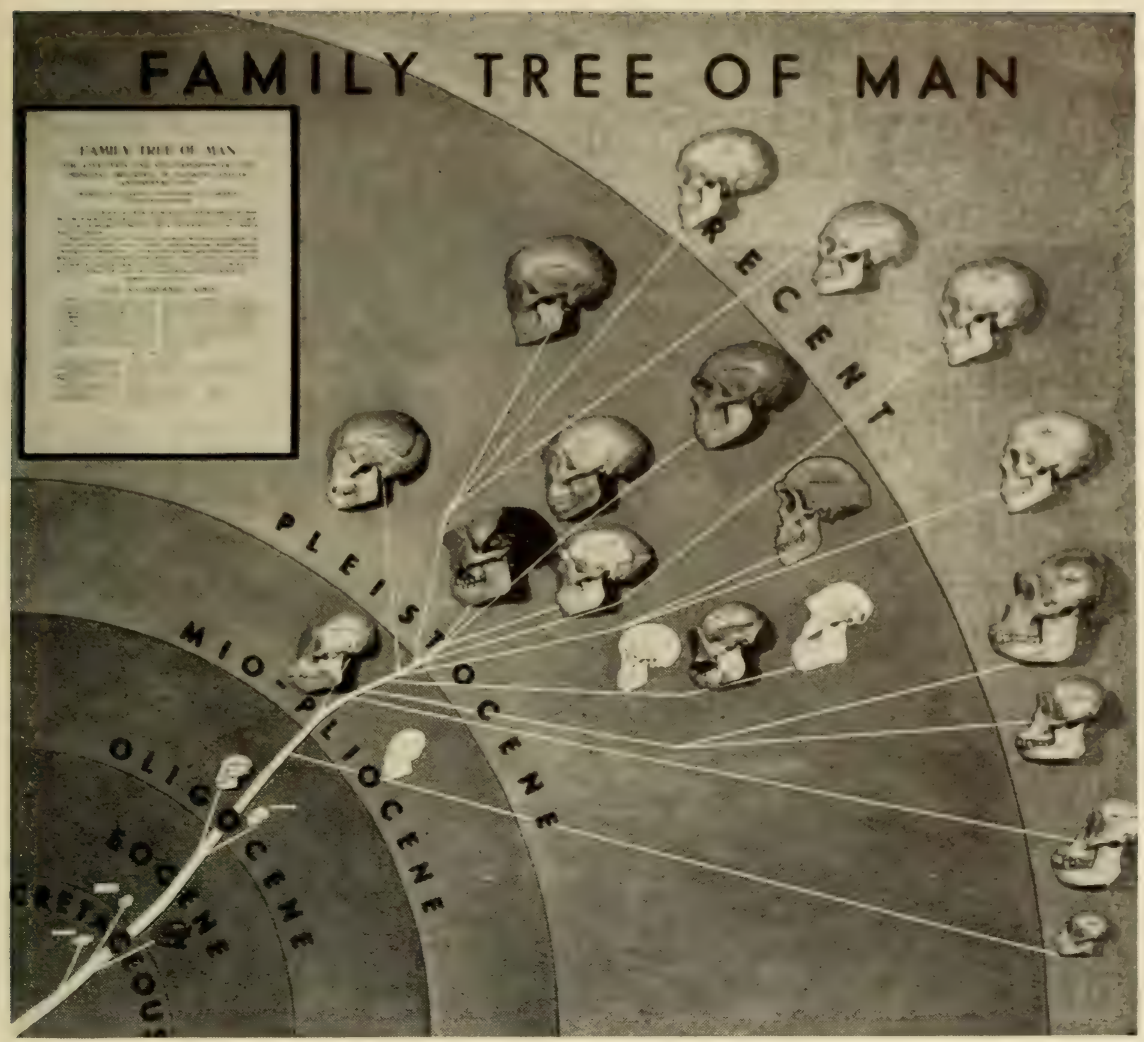

THE FAMILY TREE OF MAN. The evolution and relationships of the principal branches of mankind and of anthropoid apes.

short proboscis. The succeeding cases show the gradual reduction of the number of teeth and the shortening of the front part of the skull for the accommodation of the longer proboscis found in all of the later stages of mastodons and mammoths.

On the left is a group illustrating the famous asphalt trap of Rancho la Brea at Los Angeles, California, and fossils from South America, the most striking of which is the group of giant ground sloths. There are also good examples of gigantic relatives of the armadillo. the glyptodonts or "carved-toothed" animals.

Among other strange extinct animals are the camel-like MACRAUCHENIA, and the rhinoceros-like TOXODON. These evolved in South America during the Age of Mammals when it was an island continent as Australia is today.

On the walls are mural decorations painted by Charles R. Knight, showing the typical groups of Pleistocene animals of North and South America and Europe that were associated with early man. 
In the HALL OF THE NATURAL HISTORY OF MAN we see models of various skulls, ranging from the earliest Primates of the Eocene Period, through the monkeys and apes of the Miocene and Pliocene, to the subhuman and human races of the Pleistocene and Recent ages.

The exhibits in the central aisle of the HALL OF THE AGE OF MAN deal mainly with the older races of mankind as shown by their fossil remains and by preserved fragments of their handiwork.

MEN OF THE STONE AGE. Here we see a representation of the newly discovered Australopithecus of South Africa, a skull cast of Trinil. or Java "ape-man," and skeletal remains or cases representing Peking Man, Piltdown Man, Heidelberg Man, Neanderthal Man, and CroMagnon Man. An excellent series of sculptured restorations of these types, four of which are illustrated below, have been made and are generally considered as embodying the most recent scientific deductions as to the general appearance of these primitive races of mankind. The earliest of them takes man back at least to the lower Pleistocene, estimated at 1,000,000 years ago.

Weapons and implements of rough and polished stone and of bone are exhibited as evidence of the gradual building-up of human culture through the "rough stone" and "polished stone" ages of Man's prehistoric period. Reproductions of the cave paintings of Cro-Magnon man in France and Spain show the artistic ability of the early stock which first represents modern man in Europe.

A series of mural paintings by Charles R. Knight over the doorways of the Hall of the Age of Man gives a vivid idea of the various races of early man as seen by the artist in harmony with our best scientific knowledge.

The HALL OF PREHISTORIC CULTURES on the second floor also exhibits the early arts and industries of the European Cave Men and Lake Dwellers, as well as North American prehistoric men.

RESTORATIONS OF HEAD AND SHOULDERS OF EARLY MAN. These restorations were made by Professor J. M. McGregor following scientific principles and utilizing the skull-remains of the various types as a starting point. They are as follows:

1. Trinil Ape-Man (Pithecanthropus erectus)
2. Piltdown Man (Eoanthropus dawsoni)
3. Neanderthal Man (Homo neanderthalensis)
4. Cro-Magnon Man (Homo sapiens cromagnonensis)

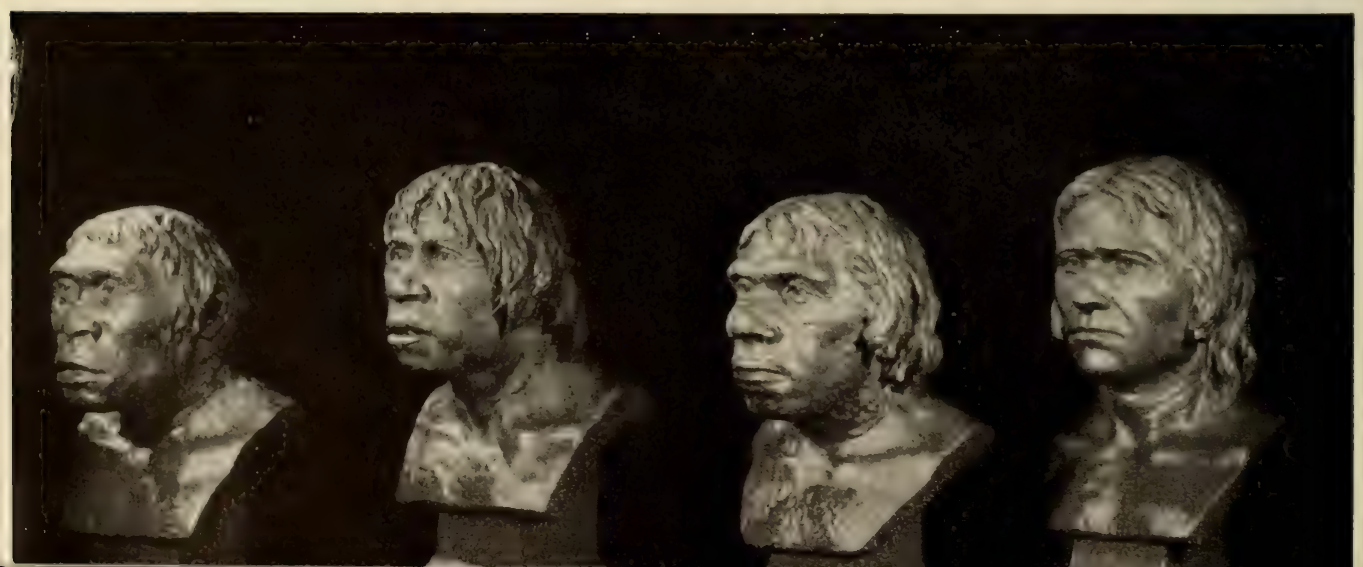




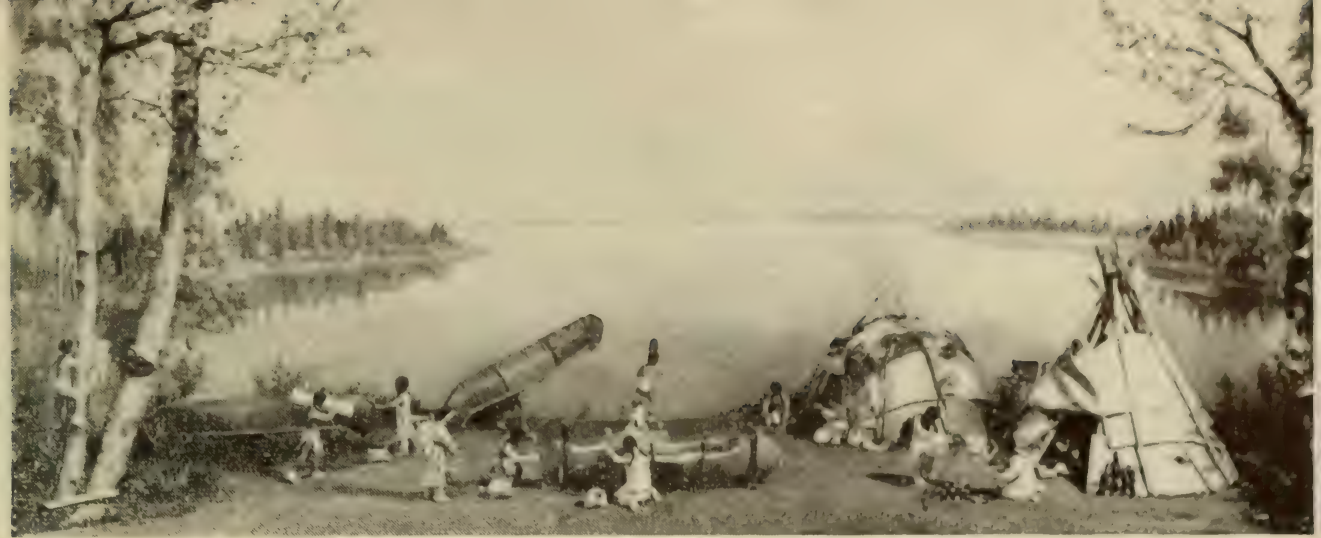

USES OF BIRCHBARK AMONG THE EASTERN WOODLANDS INDIANS. (From a miniature diorama in the Woodlands Indians Hall)

\section{LIVING RACES OF MAN}

\section{The Woodlands Indians}

Walking to the left on entering the Museum from 77 th Street, we meet first the Indians of New York and New England. The successive exhibits are so arranged that the visitor can imagine himself traveling across the United States from east to west.

Although called the Eastern Woodlands Indians Hall (northeastern United States and Canada), the exhibits in this hall include the Southeastern and Mackenzic culture areas, the former joining the Eastern Woodlands on the south, the latter on the northwest. The whole Eastern Woodlands area was in forest and reached westward from the Atlantic coast to the Mississippi River. Objects on display show that these Indians lived in the forest. The materials they used came from the forest, and this fact influenced their houses, tools, weapons, clothing, and ornaments, so that they are readily distinguished from those of other areas.

These forest Indians were primarily hunters and fishermen but they also ate wild rice and maple sugar. They grew corn. beans, squash, tobacco and other plants where the climate allowed. (See miniature dioramas at north side of hall.) Their woodland environment led to simple industries dependent upon the raw materials that were at hand and adaptable to their daily needs.

Wood was used for canoes, mortars, spoons, bowls, dishes, houses and wood splint baskets. Bark of various kinds was a farorite material. For example, the birchbark industry is illustrated not only by a diorama but by containers and ornaments in many of the cases. Bark like that of the basswood tree was also shredded to make the fiber for weaving bags.

Skins were originally used for costumes, but, since the $11^{\text {roodlands }}$ area was one of the first regions of North America to be influenced by European contact, cloth was often bought from white traders. Many wild plants and trees furnished fiber from which these Indians made good string and cord for making fish-nets and for weaving bags. Every well-equipped house required mats for the floor and for sleeping. 
Climate influences the ways of life. In this hall, the tribes represent a range from near-Arctic Canada to sub-tropical Florida. Their clothing varies from fur garments among the Dene and the Cree, to thin dresces of commercial cloth among the Seminole.

A number of miniature groups along the side walls and in the rases show tribal costumes, housing and industries. Especially interesting subjects are rock shelters, the making of rabbit skin clothing. weaving with basswood fiber, making a false face, and the stages by which corn is made into bread.

Travel was on foot. Dugout or bark canoes were used in summer where streams or lakes were accessible. Snowshoes were used in wintcr. and in the north the toboggan was common.

The dwellings of this area are of several forms. Among these are the long rectangular houses of the Iroquois covered with oak bark, the dome-shaped huts of Long Island and vicinity which were covered with mats and bundles of grass, and the familiar cone-shaped wigwam of the Ojibway covered with birchbark. The utensils are of pottery, wood or birchbark. Pottery was made by most of the Eastern tribes and scems to be associated with farming. The designs are cut in, cord-marked. or paddle-stamped, but never painted.

Bowls, trays and spoons are made of wood and are often decorated with animal carvings. The use of birchbark in making light household vessels is one of the particular traits of our Eastern Indians.

These Indians invented canoes, maple sugar, tobacco pipes, cornhusk weaving, splint baskets, tump-lines or devices for carrying heavy loads. wampum, the game of la crosse, netted snowshoes, the toboggan and the water-drum.

The Indians' history begins with the landing of white men. Many of the objects shown in the cases are historic, but others, such as the stone, bone and shell objects found in the ground, are usually prehistoric. In the exhibits dealing with Manhattan and Staten Island, from which the Indians were driven by the first settlers, we can show nothing but pottery, stone, bone and shell objects. These local relics will be found near the entrance to the hall. On the left are some pottery vessels and many small objects made of stone and bone from Manhattan Island. Staten Island, Long Island, and Westchester County. Nearby, on the same side of the hall, are collections obtained from living Indians of the coast region north and south of New York. These are the Penobscot and Passamaquoddy of Maine, the Micmac and Malecite of the lower provinces of Canada, and a few rare objects from the Delaware who once occupied the vicinity of New York City and the State of New Jersey. The age and historical relations of these cultures are shown in a large label at the left of the entrance.

A family group of Micmac Indians, in a birchbark cone-shaped house, is shown half way down the hall.

On the opposite side are the Iroquois, whose league included the Mohawk, Seneca, Oneida, Onondaga, Cayuga, and later the Tuscarora. 
They dominated New York and much adjoining territory. The exhibits represent particularly the agriculture of the East, which was carricd on with rude tools by the women.

In the farther end of the hall, on the left, are the collections from the Ojibway, who lived mainly north of the Great Lakes. They had but little agriculture, living chiefly by hunting and fishing and the gathering of wild rice. Beyond the Ojibway are the Cree, who lived farther north.

Opposite the Ojibway are the great Central Algonkin tribes, the Menomini and Sauk and Fox, as well as the Siouan Winnebago, who lived south and west of the Great Lakes. They too gathered wild rice and hunted and fished and also did some farming.

In the southeastern portion of the United States, agriculture was highly developed. These tribes are represented by the Cherokee and Yuchi, who made pottery, and by the Choctaw and Chitimacha, who made fine baskets of cane as well. The Seminole of Florida, though long influenced by the white man, have maintained an independent existence in the Everglades for nearly a hundred years. Their prehistoric arts are illustrated in the table case. They excelled in polishing stones and working shell. (See the diorama on the north wall.)

\section{The Plains Indians}

When we think of Plains Indian life, we think of such terms as "tipi," "buffalo," "horse," and large decorated "pipes." The tipi and the pipe are especially conspicuous in the center of the hall.

The art of these Indians is highly original and popular. Painting on skin is the usual method, but many designs in beadwork and quills are shown.

Artists look upon the feather headdress of these Indians as the most beautiful type of headdress to be found anywhere in the world. With this and his highly decorated costume, the Plains Indian is a colorful figure.

Indians of the Plains made up the tribes living west of the Mississippi and east of the Rocky Mountains as far south as the vallev of the Rio Grande and as far north as the Saskatchewan.

Beginning on the left, the buffalo-hunting tribes: the Plains-Cree. Dakota, Crow, Blackfoot. Gros Ventre, Arapaho and Chevenne, occupy the greater part of the hall. These tribes did not farm but depended almost entirely on the buffalo. They ate the buffalo and used its skin to make their clothing. Sometimes a buffalo paunch was used for cooking, and horns were made into various tools and weapons. The spirit of the buffalo was thought to be a powerful ally and was called upon to cure sickness, to ward off evil, and to give aid in the hunt. Wherever the buffalo herds led the way, the more nomadic Plains tribes moved their tipis and followed. When most of the buffalo were wiped out, the entire life of the Plains Indians was revolutionized.

On the right, near the entrance, are the village tribes of the Plains: the Mandan, with whom Lewis and Clark passed the winter of 1804-1805; 


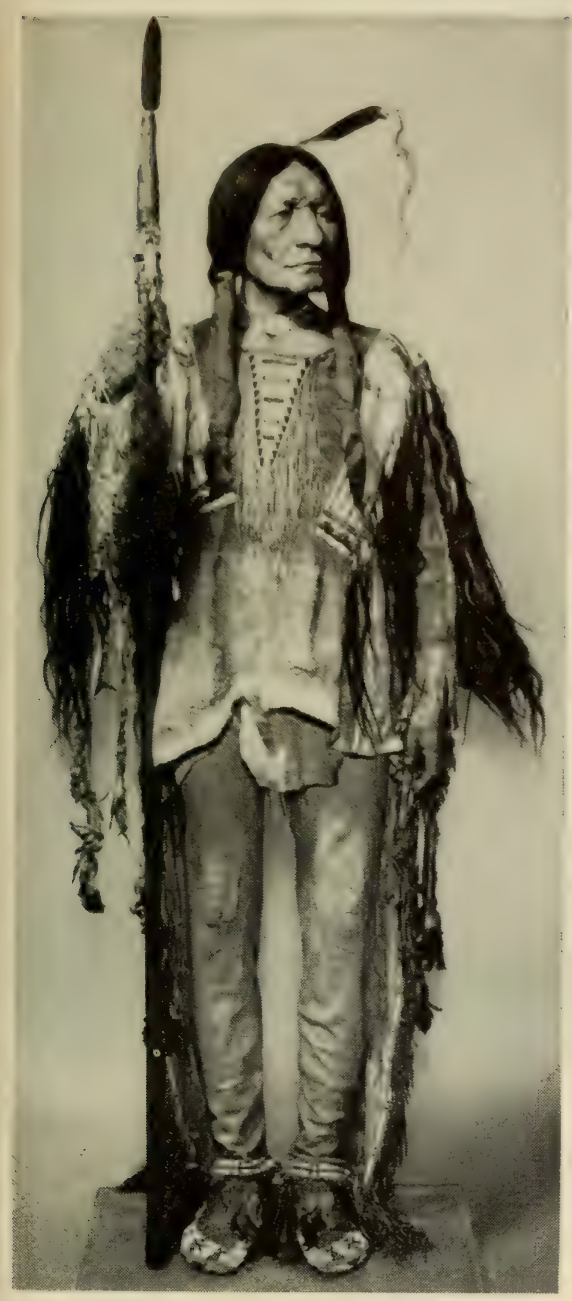

\section{A DAKOTA WARRIOR.} (Model in Plains Indians Hall)

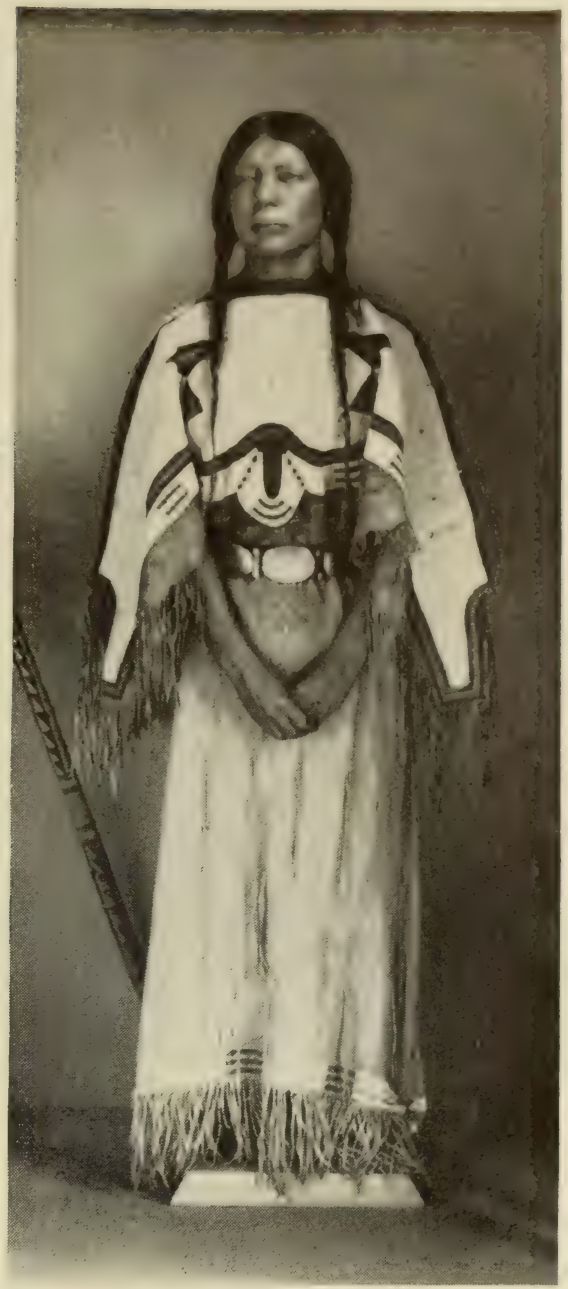

A DAKOTA WOMAN.

(Model in Plains Indians Hall)

the Hidasta, who now live with them; and the Omaha. Kansa, Iowa, and Pawnee. All these tribes raised corn and lived in large earth-covered houses. A small model of one of these houses stands near the exhibits.

In the center of this hall is a Blackfoot Indian tipi with paintings of otters on the sides, representing a vision of the owner. This tipi has been fitted up to show the home life of a typical buffalo-hunting Indian.

There were numerous soldier societies among the Plains Indians which included practically all the adult males. Each society had a special dance and special costumes. (See the Arapaho cases for costumes of dancers.) There were other dances connected with tribal religious ceremonials, the best known and most important of which is the Sun Dance, shown by a model at the left of the tipi. The Sun Dance was held yearly 
in the early summer to keep a vow made the winter before by some member of the tribe who wished a sick relative to recover. The dance involved self-torture, great physical endurance and a fast lasting three days.

In the center of the hall is a medicine pipe, held in awe by the Indians and dearly parted with; also the contents of a medicine bundle. The contents of another medicine bundle, belonging to a leading medicine man of the Blackfoot tribe, together with the headdress which he wore in ceremonies, are in a case near the tower. Other remarkable bundles, particularly the skull bundle, are in the Pawnee case on the north wall.

The Plains Indians are noted for their painted buffalo robes and for their quillwork. which was superseded by beadwork when glass beads became available in historical times. They have a highly developed decorative art in which simple geometric designs are the elements of composition. This is one of the most interesting features of their art. (See Dakota case.)

\section{Indians of the Southwest}

This region is famous for two reasons: its picturesque living Indian tribes, and the large number of ruins built by prehistoric Indians. Since many of the latter are placed upon high rocks or in the walls of canyons. they are spoken of as Cliff Dwellings.

This hall presents collections from both the prehistoric and the living Indians of the Southwest. On the right are the nomadic or wandering tribes: the Apache, Navajo, Pima, Papago, and Havasupai. A life-size exhibit, the first of a series along the right-hand wall, shows the home life of the San Carlos Apache. Next is a larger group showing a Navajo hogan in Canyon de Chelly, and the Night Chant ceremony. The painted background of this group gives a view of the canyon, and in a cave of its walls one may see the famous White House ruins.

Navajo silverwork and blankets are shown in nearby cases. The Navajo are the modern blanket makers. They card, spin and weave the wool of the sheep they raise with simple implements and looms. This art has arisen since the coming of the Spaniards and it is known to have passed through several stages in the last sixty years. Some of the older types of blankets shown here contain yarn which was gotten by cutting or raveling from imported flannels, called in Spanish "bayeta," from which these blankets get their name. These are either bright red or old rose in color, resulting from cochineal dye. Several blankets are made of yarn bought ready-dyed from traders and are called Germantowns. The greater number, however, are made of yarn of native spinning, dyed with native vegetable and mineral dyes.

The Navajo are a large and widely scattered tribe. During the winter they live in log houses, but in milder weather they camp in the slight shelter of a cliff or windbreak and shade made of brush. They live by raising corn in the moist valleys, and on the flesh of their many flocks of sheep. 
The Western Apache live along the upper portion of the Gila and Salt Rivers, where they farm, gather natural products and hunt. Indians related to these, under Geronimo, raided the settlements of southern Arizona and northern Mexico and evaded our troops for years. They live in grass-thatched houses or in the open under the shade of flat-topped opened-sided shelters.

The Eastern Apache lived in buffalo skin tipis. They went far out on the plains in search of the herds, avoiding, if possible, the Plains tribes, but fighting them with vigor when necessary. In dress and outward life they resemble the Plains Indians, but in their legends and ceremonies they are like their Southwestern relatives and neighbors.

In the first alcove to the right of the entrance is a basketry exhibit showing the types of baskets and the materials, tools, and techniques used by the Southwestern tribes. This exhibit is in contrast with the corresponding case of pottery on the opposite side. Not the environment, but social habits, caused one people to develop pottery and the other to make the easily carried and not easily breakable baskets.

At the left of the hall, as we enter, are exhibits for the modern village Indians - first types of pottery from San Ildefonso, Laguna, Santo Domingo, Zuni, and Hopi.

A NAVAJO MEDICINE LODGE. For the celebration of the Navajo Night Chant a special house is erected. The medicine man is laying down an elaborate ceremonial sand-painting. Group in Southwest Indian Hall.

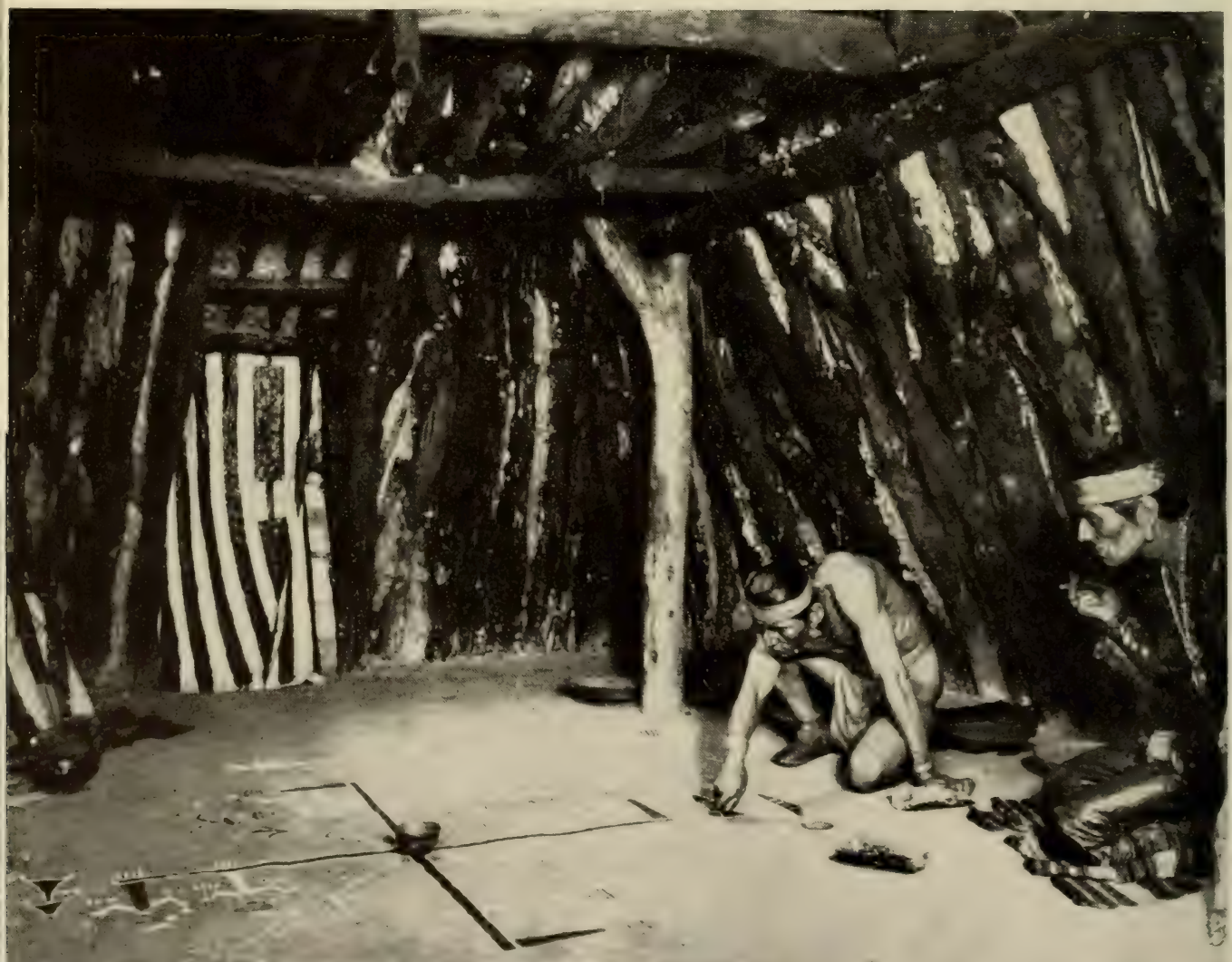




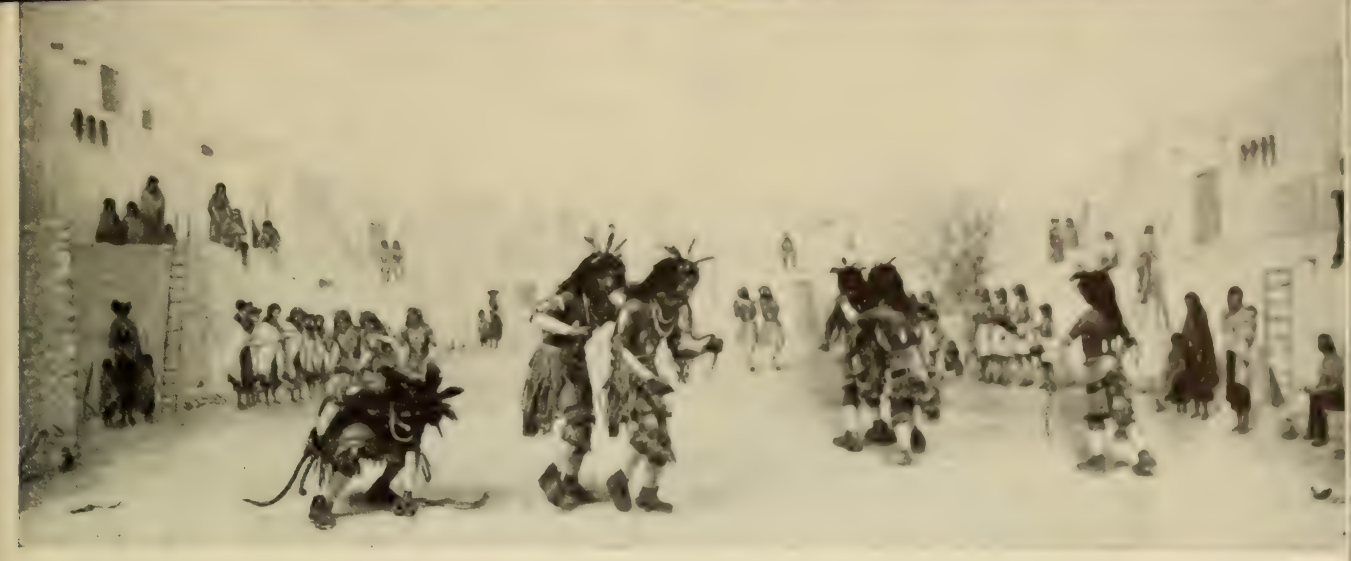

HOPI SNAKE DANCE. This is given on alternate years by the Snake and Antelope priests in all but two of the Hopi villages to insure the rain needed for the crops. (From a miniature diorama in the Southwest Indian Hall)

The Pueblo Indians live in large community houses, built of stone or adobe, often with several stepped-back stories. They depend chiefly on farming for their food, make a great variety of pottery, and have many claborate religious ceremonies. The nomadic peoples live in tipis or small brush and thatched houses which are moved or deserted when they are forced to seek the wild game and wild vegetable products which furnish much of their food. They make baskets for houschold purposes which are more easily carried than vessels of clay. In the hall are models of the pueblos of Taos and Acoma, of prehistoric cliff-dwellings, and of the houses used by the Navajo.

The inhabitants of Zuni are believed to be the descendants of the first people seen by the Spaniards in 1540. Their former villages, many of which are now in ruins, were probably the "Seven Cities of Cibola," for which Coronado was looking at that time. Although there were missionaries among them for about three hundred vears, they have kept many of their own religious ceremonies. Many ceremonial objects, as well as those of everyday life, are shown in this alcove.

In the Hopi section are costumes, masks, images, and basketry plaques used in their ceremonies. Their best known ceremony is the Snake Dance, supposed to increase rainfall and the crops. Some of the regalia worn for the Snake Dance are shown, as well as a small model of a single phase of the ceremony. In the center of the hall a table case shows a Hopi altar, of the type that figures in nearly all Hopi ceremonies.

In the center of the hall, as well as in the farther half of the left side. are special exhibits for the prehistoric Indians of the Southwest. Near the center is an exhibit showing how many prehistoric ruins have been dated by the tree-ring method. A chart at the entrance to the hall gives the successive culture periods for the Southwest, beginning with early Basket Makers and ending with the modern Pueblo villages. Typical objects made by the Basket Makers are shown in small cases in the center of the hall and in upright cases to the left. 
Two of the most famous prehistoric Southwestern ruins are Bonito and Aztec. A model of the latter stands in the center, and near the entrance is an exhibit of turquoise from Pueblo Bonito. Other collections from these $t w 0$ ruins are shown in cases at the left of the hall. One contains a remarkable collection of pottery from Pueblo Bonito. Similar black-on-white wares with very elaborate and splendidly executed designs, shown in adjacent cases, are from Rio Tularosa, and in part from cliffdwellings. In another case is found material gathered by the Museum expedition which explored the Galisteo Valley, New Mexico.

Other exhibits in this area illustrate the culture of the living Indians of California. Most outstanding of the achievements of these tribes was their basketry, some examples of which are among the finest produced in the world.

\section{Indians of the North Pacific Coast}

The Jesup North Pacific Hall is devoted to the Indians living in the heavily forested and mountainous coastal belt extending from the Columbia River in Washington to Mt. St. Elias in southern Alaska, as well as on the offshore islands. They are the most skillful wood workers on the American continent, as shown by the models of their houses; their intricately carved and painted totem, house, and grave posts; their ceremonial masks, boxes, implements, and tools. They depended on their forest environment for housing, clothing, and utensils and they depended on the products of the sea for food. Travel and transportation were mainly by water and they skillfully hollowed out giant cedar logs for canoes like the large Haida war canoe in the center of the hall.

MODEL OF A KWAKIUTL VILLAGE, VANCOUVER ISLAND, showing plank houses facing the sea with canoes drawn up on the shore. Crests of the owners are painted on the walls of houses and carved on the house posts in front.

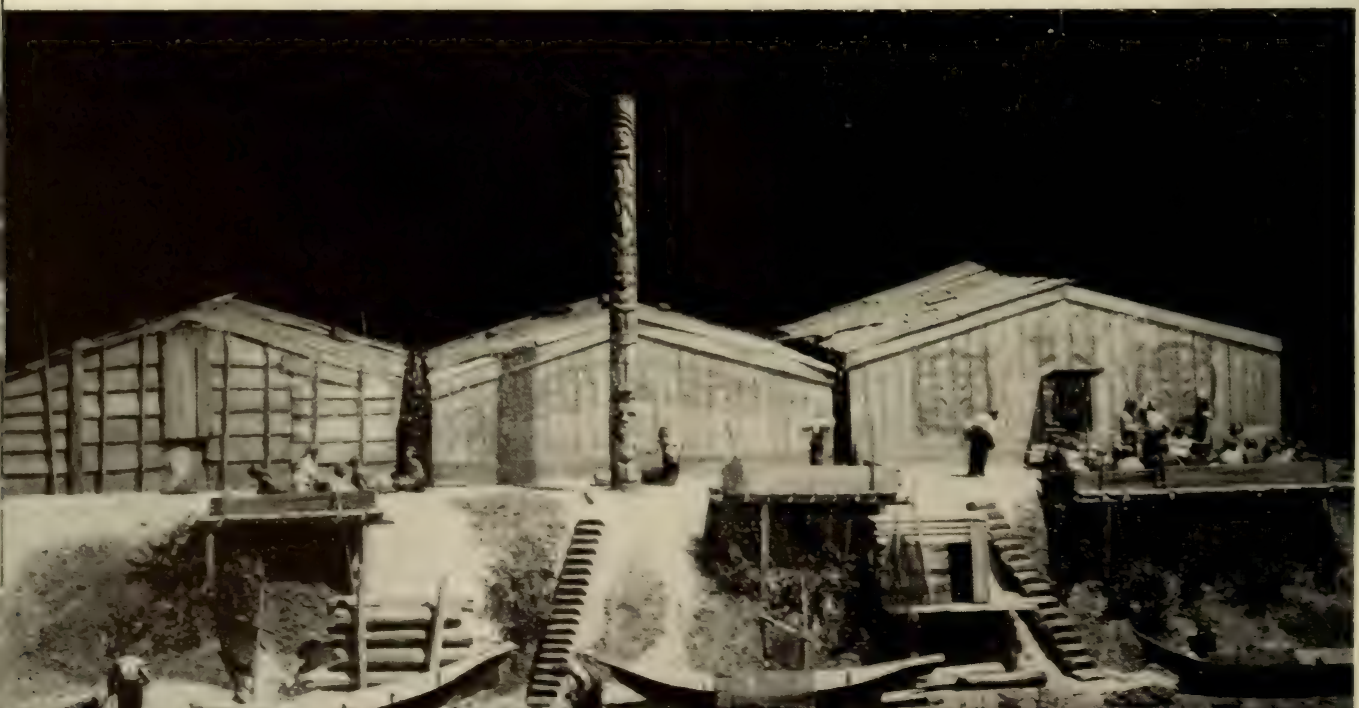




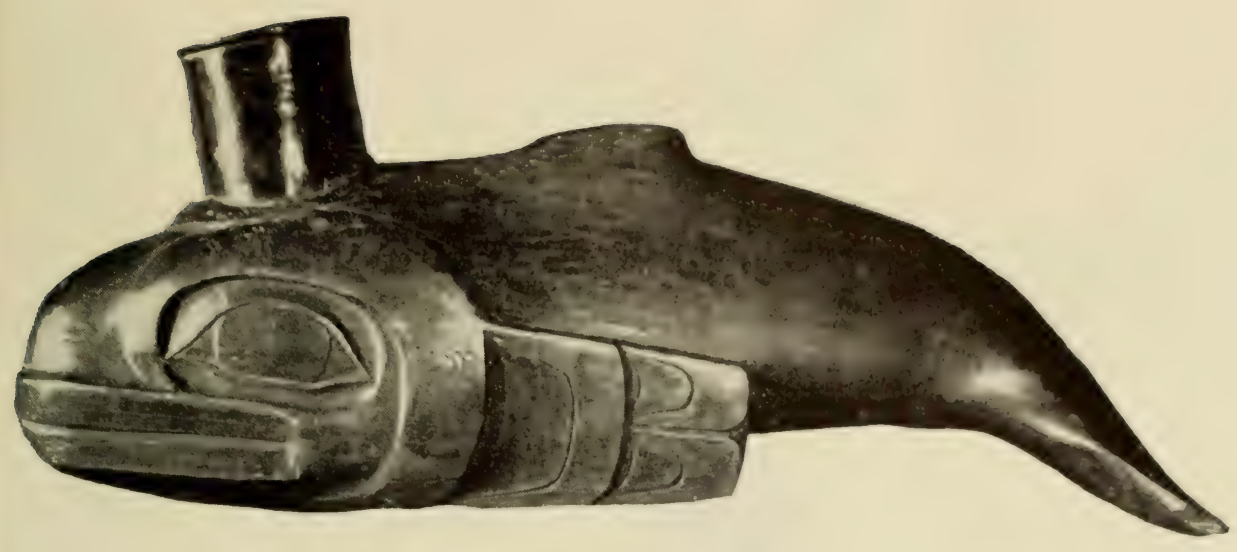

A PIPE

carved in the form of

a whale by the

rlingit Indians

of Alaska.

Except for two tribes, the Shuswap and Thompson, who live in the interior of British Columbia, the exhibits are arranged in the order in which the various tribes are encountered in going from south to north along the coast of Washington, British Columbia, and Alaska. On the right side of the hall are the Bella Coola, Tsimshian, Haida; on the left, the Nootka, Kwakiutl, Tlingit.

The murals of Will S. Taylor depict not only the industries, religious and social life of these Indians, but also their heavily forested and fogand-rain-drenched environment. The murals on the right side show ceremonials and religious life. On the left they show daily life and industries. Games are illustrated over the entrance and at the farther end of the hall, the return of a victorious war party.

They were also skilled in weaving with mountain goat wool and shredded bark and in making baskets. Notice the Chilkat ceremonial blankets a little over halfway along the hall, on the left, and the Tlingit baskets at the end. These Indians have likewise distinguished themselves in the carving of stone, bone, and ivory, examples of which are shown for the various tribal groups.

Outstanding perhaps is the wealth of decoration seen on all their products. The typical grotesque art motifs, based on the distortion of animal forms, are found in equal abundance on useful and ceremonial objects. 


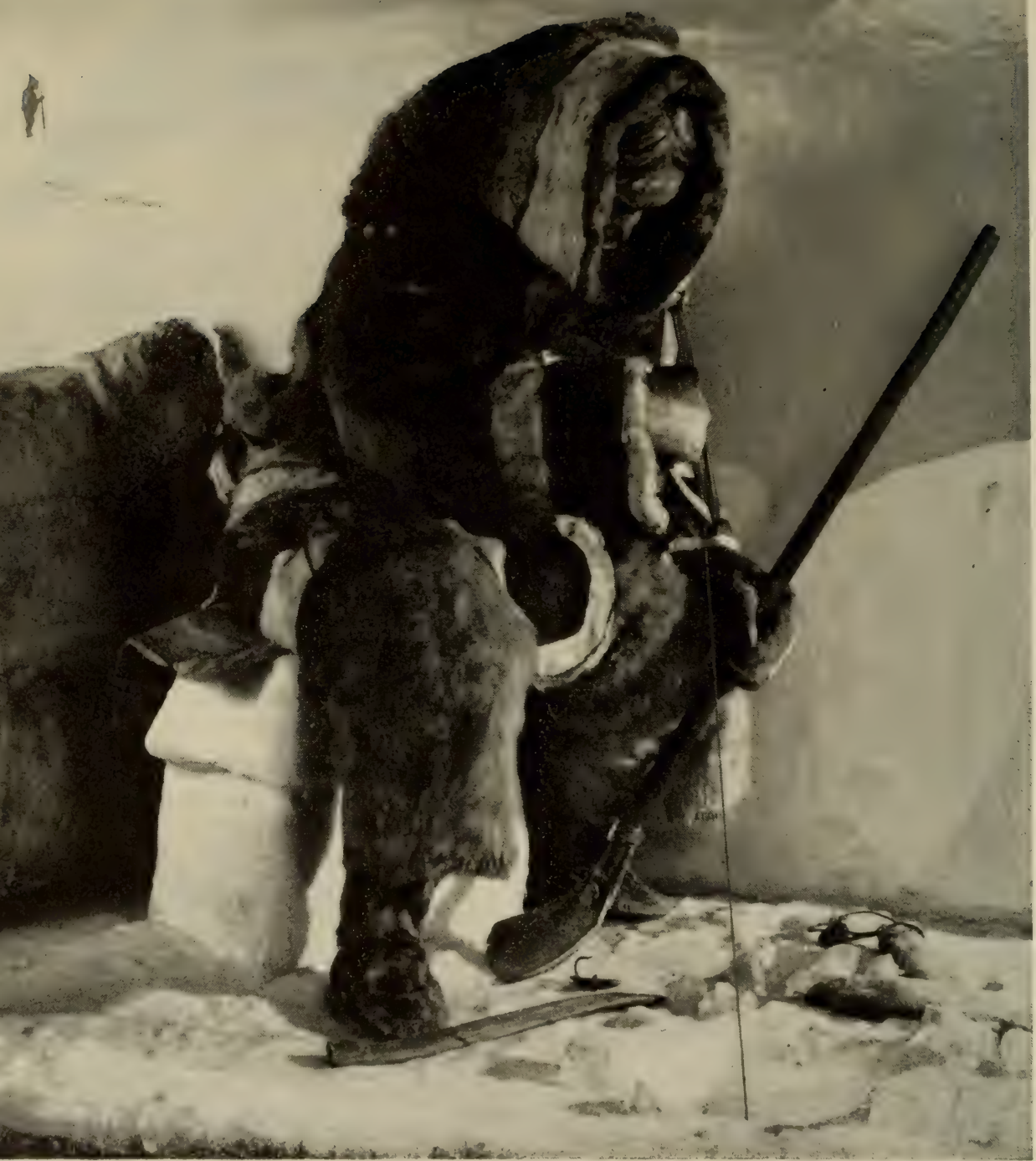

ESKIMO WOMAN FISHING THROUGH THE ICE. (Group in the Eskimo Hall) 


\section{Indians of Mexico and Central America}

At the west stairway on the second floor, we enter an alcove and a hall devoted to the ancient civilizations of Mexico and Central America. The alcove contains a series of small dioramas showing the varieties of climate and landscape in Middle America, a large series of gold and jade objects, and pottery vessels typical of several of the culture areas into which Middle America can be divided.

Entering the central part of the main hall, one faces a cast of a gigantic stone head of the Olmec culture. Along the sides of the central portion are reproductions of some of the great carved monuments of the Maya sites of Copan and Quirigua, and a series of cases containing a number of the more beautiful objects in the Museum's collections.

Four of the alcoves along the right side of the hall are given over to each of the four major cultural periods in the history of the Valley of Mexico, the others to the Central Vera Cruz area, the Huastec area, the Maya, and the cultures of El Salvador and Costa Rica.

The left side of the hall deals with Western and Northern Mexico, with the cultures of Oaxaca and with a number of the major sculptured monuments of the Aztec of Central Mexico. The far end of the hall is Mayan, with several models of Maya buildings and two large cases

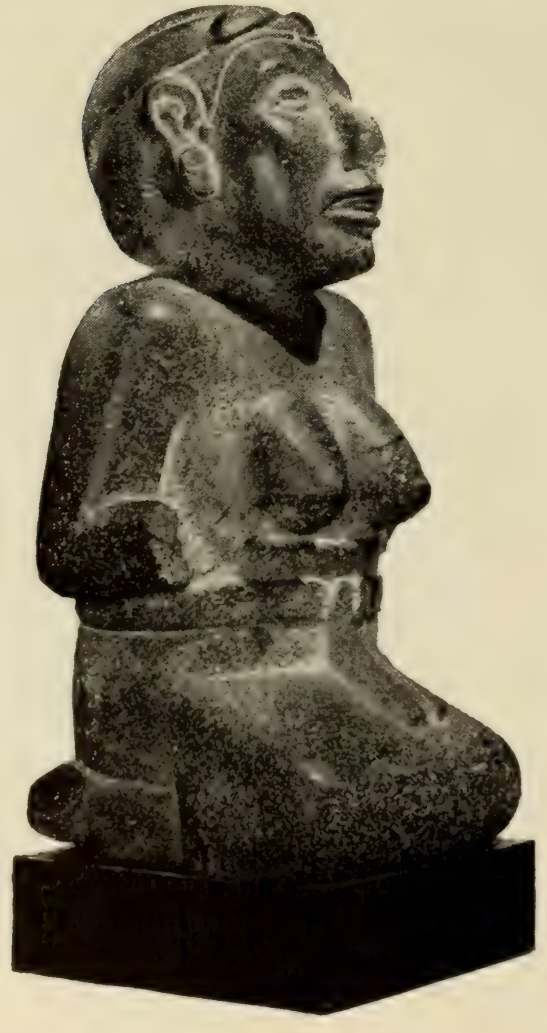

AZTEC CORN GODDESS. This outstanding example of Axtec stone sculpture is notable for its simple naturalistic presentation. It was found in Ixtapalapa, a town near Mexico City. 
OLMEC STYLE CEREMONIAL AXE IN GREEN JADE. One of the largest and finest Olmec jades known, this is one of the great treasures of the Middle American collection.

containing examples of Maya sculptures. These original pieces are from Copan and from Northern Yucatan, the latter being all that remain from a collection made by John Lloyd Stephens, the "discoverer" of the Maya civilization early in the last century.

The walls and landings of the west stairway between the first and third floors exhibit reproductions of various Maya and Central American sculptures.

CULTURES REPRESENTED: The material represented in this hall shows the history and cultural accomplishments of some of the more civilized peoples of the New World, sometimes referred 10 as those of Middle America or Mesoamerica. Within this area there were many local cultures, but all of them had characteristics in common which set them off as a unit distinct from the somewhat less highly developed cultures of North America, and both the lesser and higher cultures of South America. Several distinctive features of the Middle American cultures are the use of lime mortar in building and the existence of complex calendar systems and hieroglyphic or picture writing.

The higher Middle American cultures lasted for a period of nearly 3,000 years, so time is an important factor in any consideration of them. The following basic time schedule is generally applied:

15,000 B.C.-1,000 B.C. - Period of Early Man. Only meager remains of this earliest period have yet been discovered in Middle America, most important being the skeleton of Tepexpan Man, estimated to date from 10,000 B.C. No materials from this period are on exhibit. 1,000 B.C.-1 A.D. - Pre-Classic Period. Variously known as the 
Archaic or Middle Culture Period, this is represented by peoples living in permanent villages depending on farming, but without the great ceremonial buildings of later periods. Pottery-making and sculpture in clay were important.

1 A.I.-900 A.D. - Classic Period. This is the great period of Middle Amcrican civilisation, taking in the so-called Old Empire of the Maya and the Teotihuacan, Zapotec, and Totonac cultures of Mexico proper. It is the period of the great cities and many of the sculptured monuments shown in the hall.

900 A.D.-1520 A.D. - Post-Classic Period. With the close of the Cilassic Period, new and seemingly more militaristic orders were established, represented by the New Empire or Mexican Period in Yucatan and by the succeeding Toltec and Aztec dominations of Central Mexico. The period ends with Cortez's conquest of Mexico and the almost complete destruction of the native cultures.

SCALE MODEL OF MAYA TEMPLE. The temple on top of a high pyramid at Tikal, Guatemala, is shown here in miniature. This is one of a number of architectural models on display.

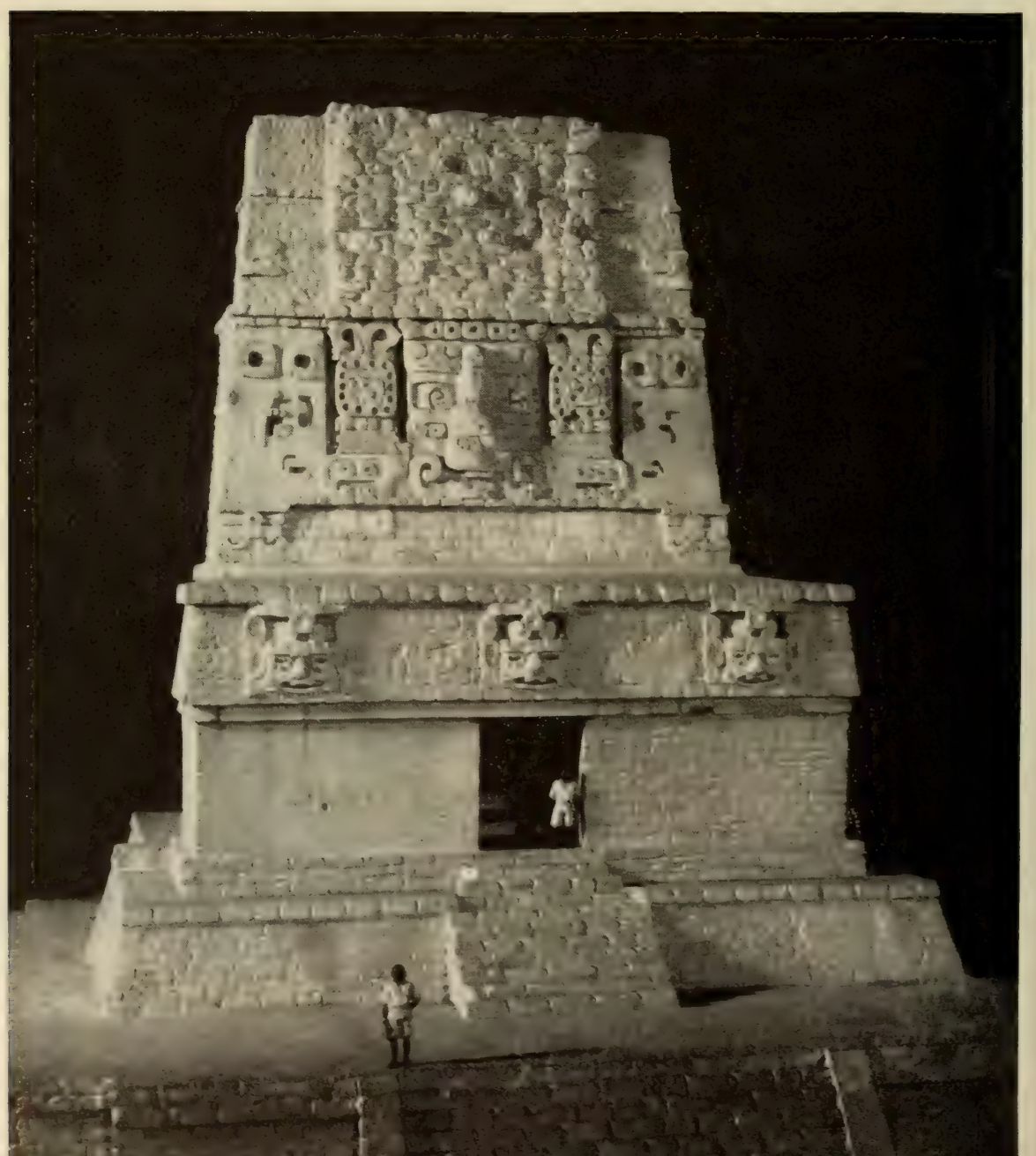


GOLD LIP PLUG. This extraordinarily fine ornament is attributed to the Mixtec culture of Oaxaca in southern Mexico.

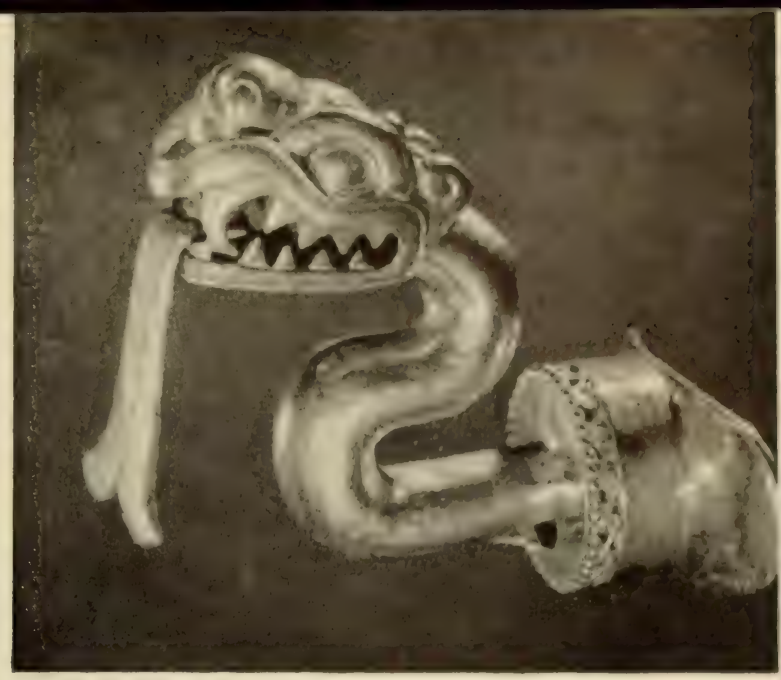

NATURE OF OBJECTS. It is impossible to present a well-rounded picture of the ancient Middle American civilizations, for, with rare exceptions, it is only the more lasting objects of pottery, stone, bone, shell and metal that have survived the destructive action of time and weather. Such things as the wooden drums of the Aztec are thereforc great treasures. However, in our attempt to understand the life of ancient Middle America, we can rely heavily on the small number of native manuscripts in picture-writing that have been preserved and on the remarkably full accounts of native life written by the early Spaniards.

ARCHITECTURE. The varied and imposing architecture of Middle America may be seen in the models and illustrations distributed around the hall. The buildings preserved are either temple structures builı on pyramid-like platforms or are thought to be housing for the priests or persons concerned with the elaborate religious ceremonies. Ornate tombs are also important, the full-sized reproduction of one at Monte Alban being a good example of this architectural form. Little remains, and nothing is shown, of the ordinary living quarters, as these were apparently of wood or thatch, similar to those in use at the present time and just as impermanent.

SCULPTURE. It is in sculpture that we may best measure the tremendous attainments of the ancient peoples of Middle America. Their religions with their many gods required many images shown in a great variety of human and animal forms. These are often grotesque and hard for us to appreciate, but they are usually conceived according to universally accepted standards of beauty and high artistic quality. An early and important style is that seen in the Olmec sculptures, which range from the most delicate of jade carvings to the colossal stone head from southern Vera Cruz, mounted in the center of the hall. In the Olmec style, the human figure is presented with a suggestion of Negroid features, often in combination with those of the jaguar, an animal that 
played an important role in the symbolism of the early cultures. It is curious that the Olmec carvers. who seem to represent one of the earliest of the high cultures of Middle America, were the greatest masters in the carving of jade and produced sculptural forms most readily appreciated by us.

Mava sculpture is more complex and appears to reflect an involved religious belief and ritual. The great skill of the native sculptors is apparent in the Copan and Quirigua stelae or tall stone slabs, where intricate detail is combined with the handling of erormous masses. Our respect for these ancient peoples is further increased when we realize that these great works were done without the benefit of metal tools.

Many and varied figures in baked clay also show a great technical and artistic ability. Especially interesting is the historical series of figurines from the Pre-Classic and Teotihuacan horizons of the Valley of Mexico. The succession of styles has been used by the archaeologist as a sensitive marker of culture change.

WRITING AND THE CALENDAR. The highest developments of the art of writing in the New World were attained by the Maya. A number

THE GOD XIPE-TOTEC. This life-sized image of terra cotta shows the wearing of the skin of a sacrificial victim. From near Texcoco, across the lake from Mexico City, the figure dates from the Toltec period.

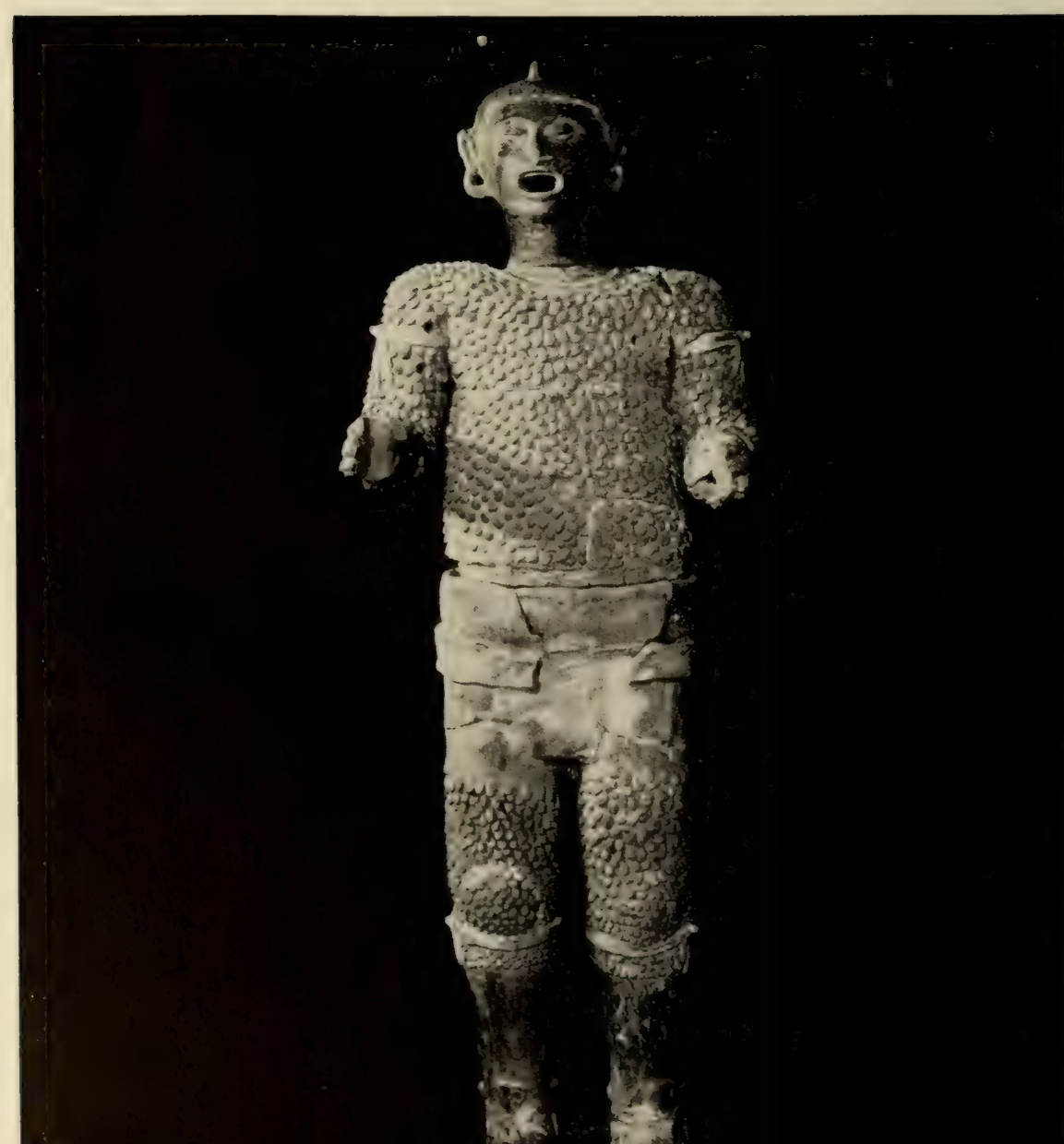




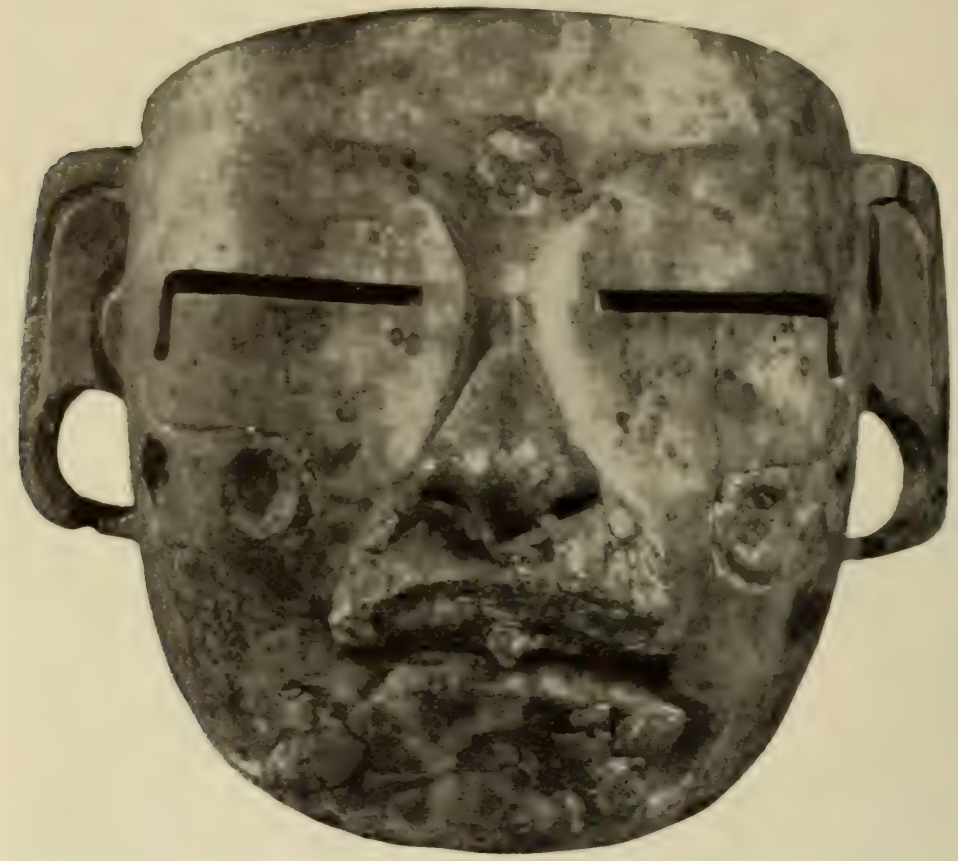

OLMEC WOODEN MASK. This is a unique specimen, being the only wooden object known from the Olmec culture. The sensitive sculpturing of the mouth portion is partly hidden by several remaining pieces of a jade mosaic and by a gummy substance used to hold the mosaic in place.

area. The modern archaeologist relies to a large extent on the broken pottery found in the kitchen middens or refuse heaps of living sites. Bv carefully excavating and analyzing the changes in pottery types from the lower to the higher levels in these refuse heaps, he is able to estimate the changes of styles and of peoples through time and from area to area. An example of this method of reading history by examination of pottery lavers is shown in the Huastec alcove on the right side of the hall.

METALS. The use of metals appeared late in Middle American history - at the beginning of the Post-Classic Period. The techniques of metalworking occur much earlier in South America and it is assumed that these arts were diffused northward into Middle America. Nevertheless. the gold-work of Mexico is considered to be of higher technical and artistic quality than any other in the New World.

JADE. Various kinds of semi-precious stones were used in Middle America for ornament or insignia, but jade was the substance most highly prized. The Middle American jades are classified as jadeite, but are distinct from the Asiatic types. Several styles of jade carving are recognized, the finest being those of the Olmec and the Mava, of which outstanding examples are to be seen in the alcove to the left of the entrance to the main hall. 
CAST OF OLMEC STONE HEAD. The original of this gigantic stone head lies in the jungle in southern Vera Cruz at the Olmec site of San Lorenzo. It is nine feet in height and weighs an estimated 15 tons.

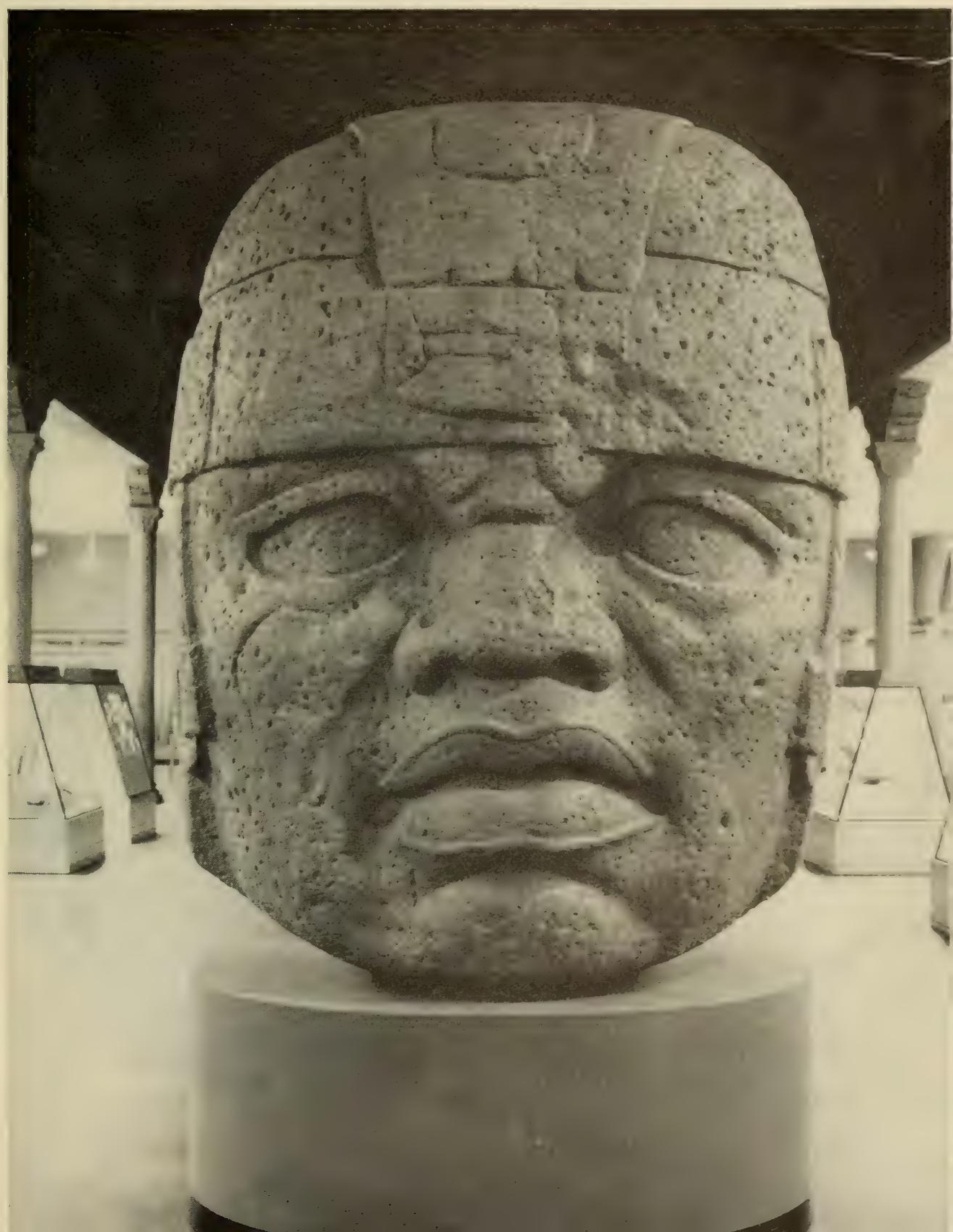




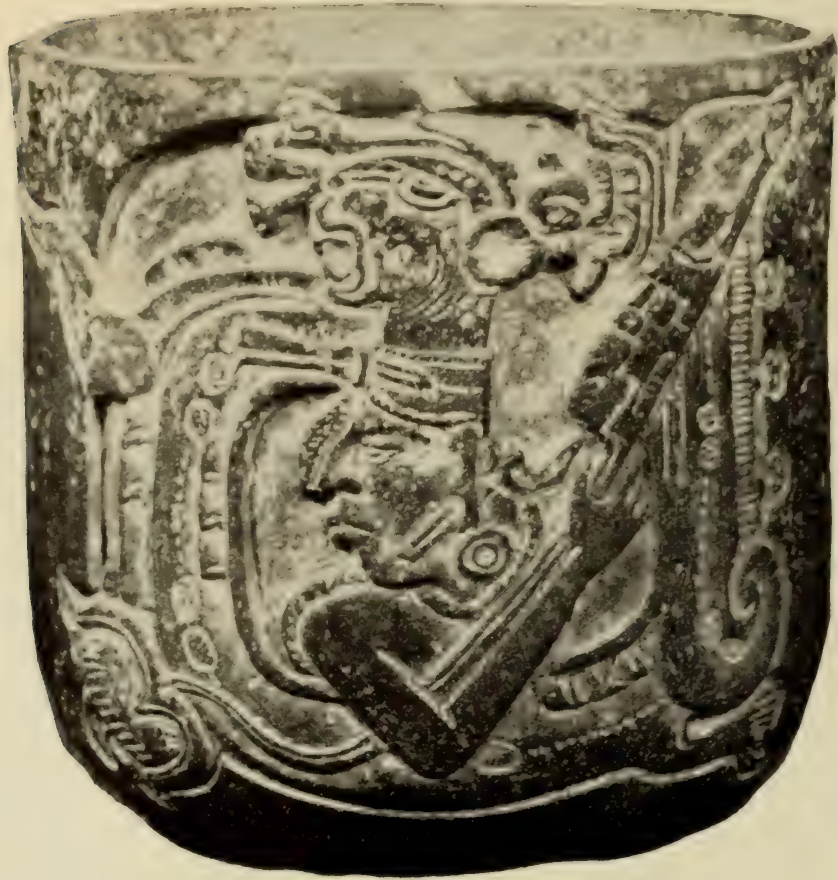

MAYA POTTERY BOWL

WITH CARVED DECORATION.

$A$ fine vessel from

northern Yucatan dating

from late in the

Classic Period.

CARVED SLATE MIRROR BACK.

The elegant design and the curvilinear motifs around the edge of the disc place this piece

in the so-called Tajin culture of central Vera Cruz. It is probably late Classic in date.

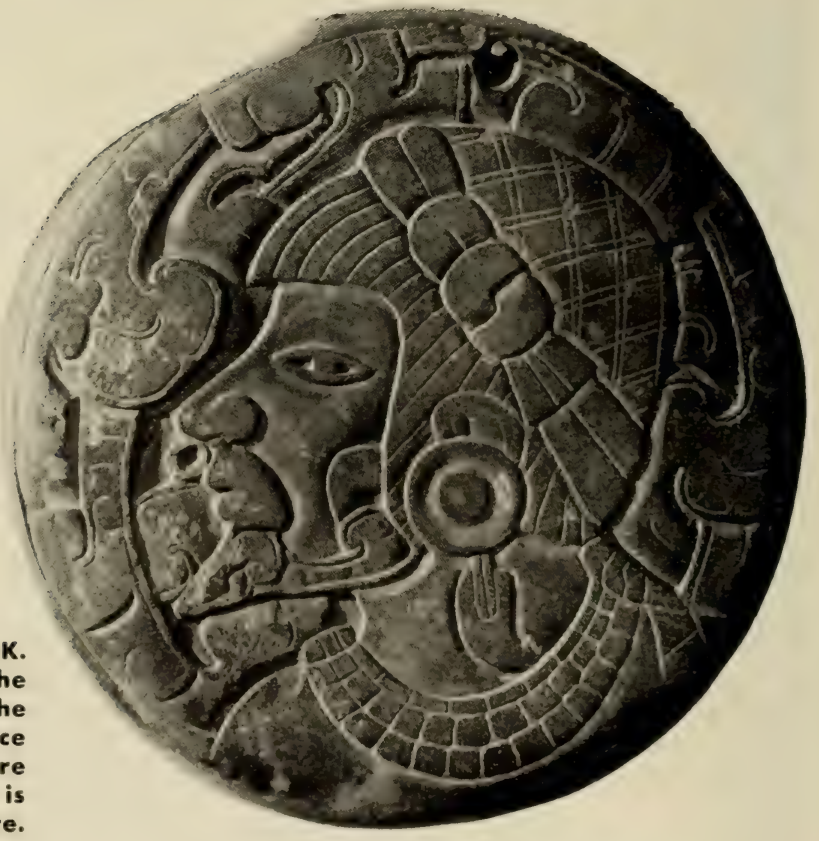


the present day. The matcrials used were cotton and the wool of the llama, alpaca and vicuma. In the cases near the entrance are examples of these textiles and the fibers, spindles, threads, looms and other equipment used in their manufacture. At the center of the hall are beautiful examples of fabrics decorated with feathers. Some of the costumes in use at the time of the Conquest are displayed at the right of the entrance hall. To the left are complex embroideries made by the people of Paracas before the beginning of the Christian era.

On the right side of the hall are collections from important localities in Peru, followed by exhibits from Ecuador, Colombia, Venezuela, Brazil and Panama. In Case 57, near the center of the hall, selected pieces of pottery show the different forms and decorations which distinguish the various important cultures of Peru and Bolivia. As far as our present knowledge permits, the changes which occurred in the course of time are also indicated. Each of these cultures is shown in greater detail in individual cases.

Outstanding is the beautiful work of the Nazca people who excelled among all American potters in their use of color. This display is arranged to show the wide representation of mythological creatures, birds and animals, with one section devoted to the differences which distinguished two separate traditions in their motifs.

POTTERY OF THE MOCHICA OR EARLY CHIMU PERIOD. A warrior in full regalia is depicted on the vessel at the left. In his right hand he holds a mace; in his left, a shield, spear thrower, and javelins. The central piece is a "portrait" jar. The vessel at the right shows a hand to hand combat between mythical beings.
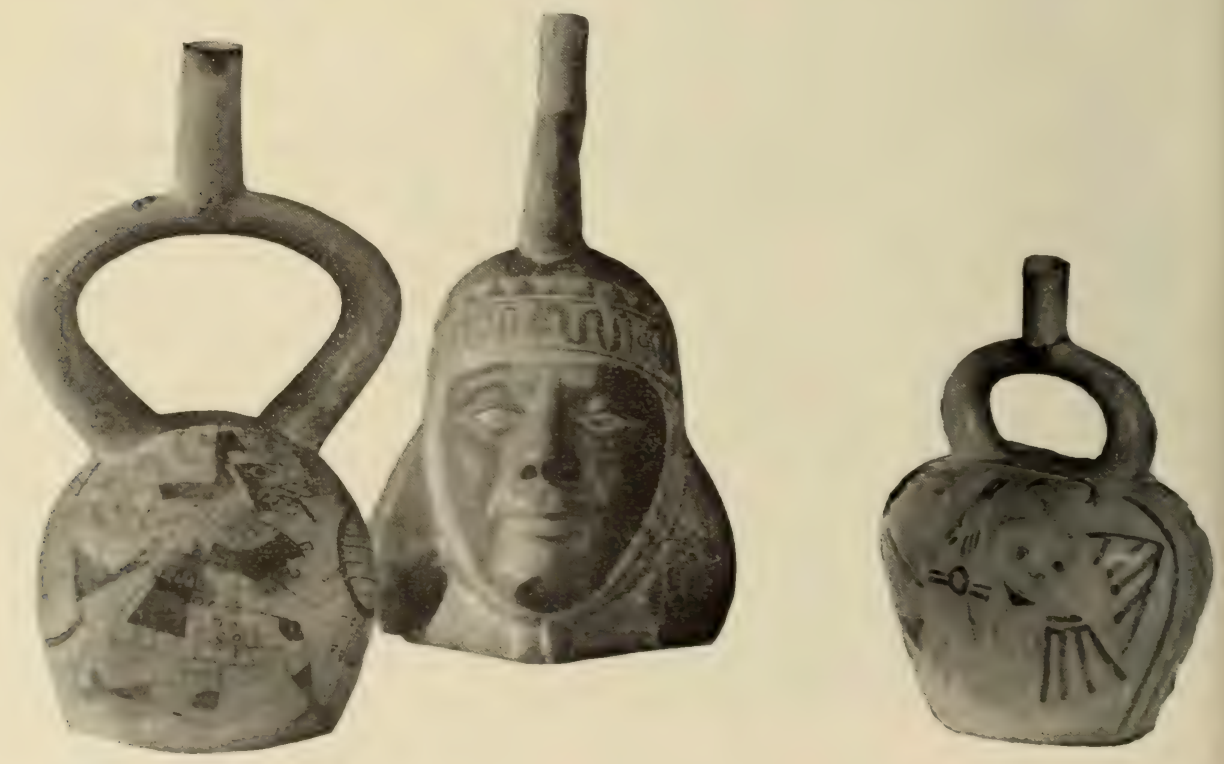

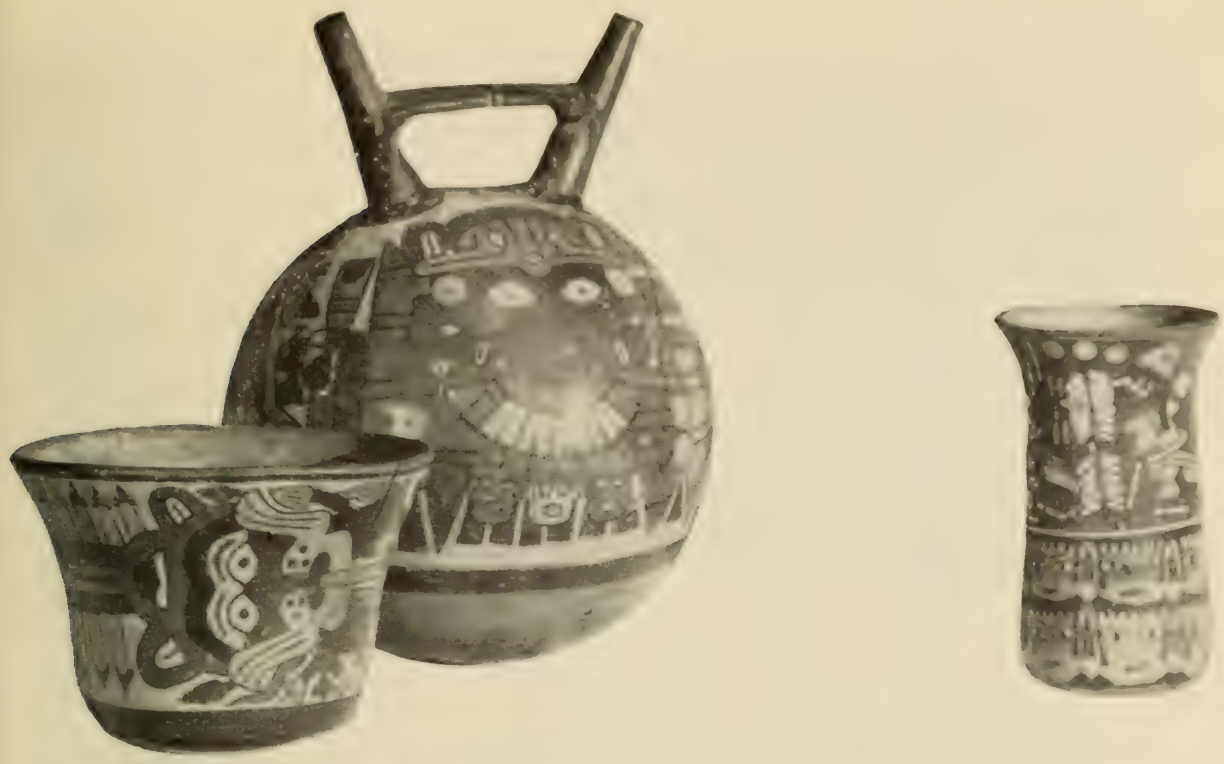

NAZCA POTTERY. By far the most skillful use of color in Peruvian ceramics is seen on such specimens as these. As some of the mythological beings depicted also appear on earlier Paracas embroideries a cultural continuity of the two periods is indicated.

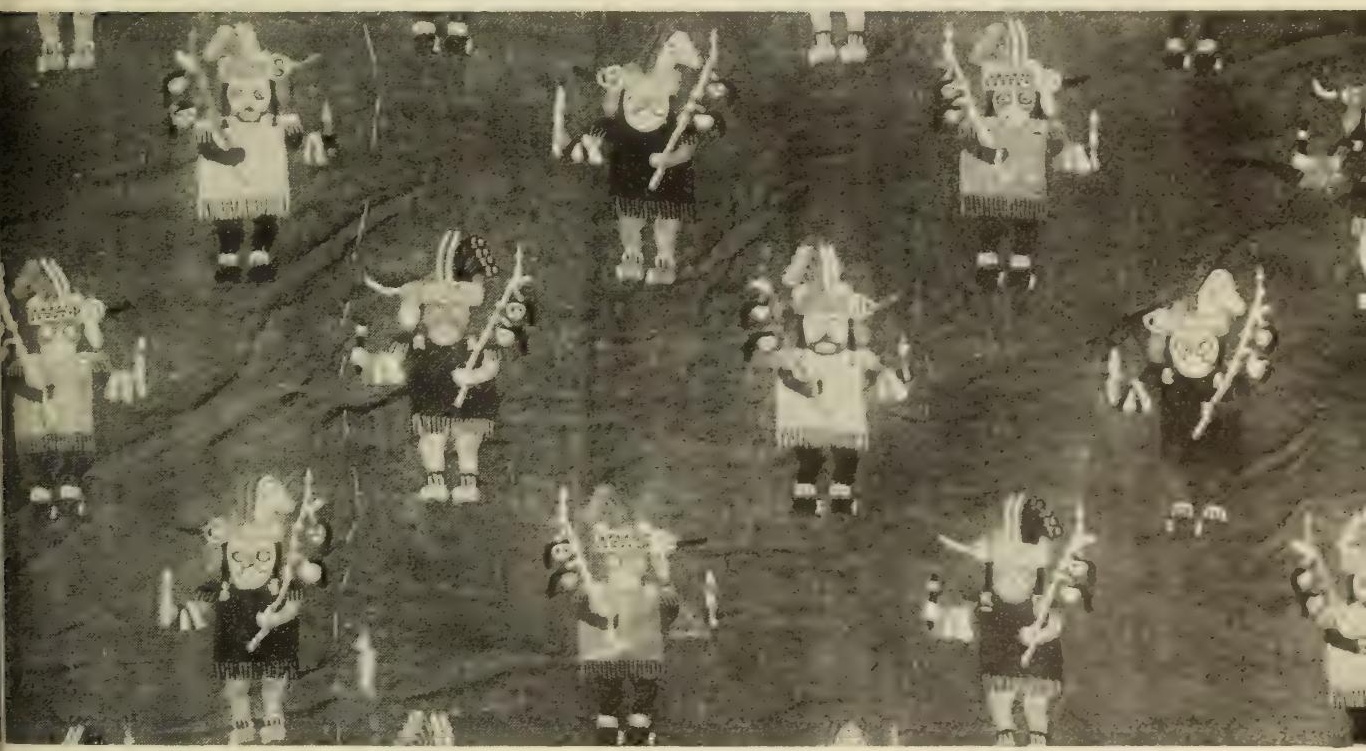

A SECTION OF EMBROIDERED MANTLE, PARACAS PERIOD, PERU. Possibly 2000 years old, Paracas embroideries are famous for the intricate use of rich colors in strange designs and figures. Trophy heads, frequently portrayed, are seen here pendant on the staffs held over the shoulder. 


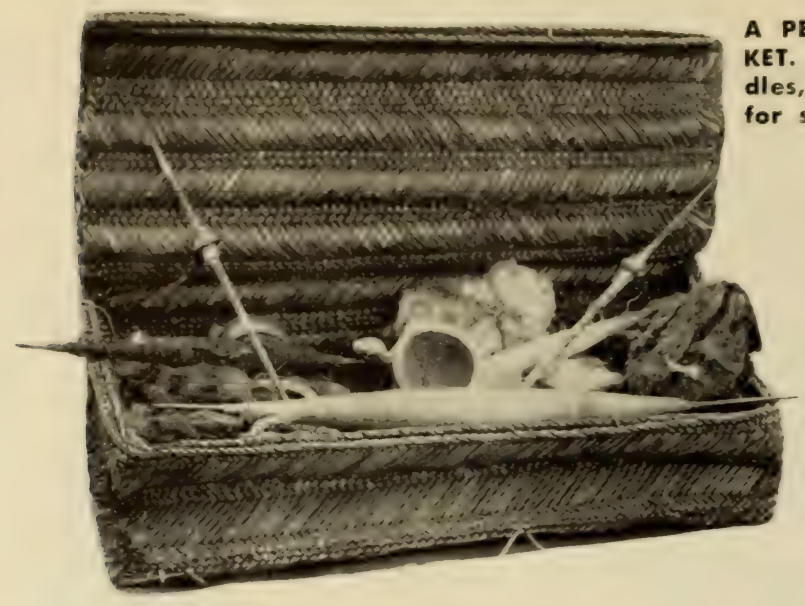

A PERUVIAN WOMAN'S WORK BASKET. Containing carded fiber, spindles, bobbins, and other equipment for spinning and weaving.

PARACAS EMBROIDERY. A fine example of highly conventionalized treatment of a cat figure.

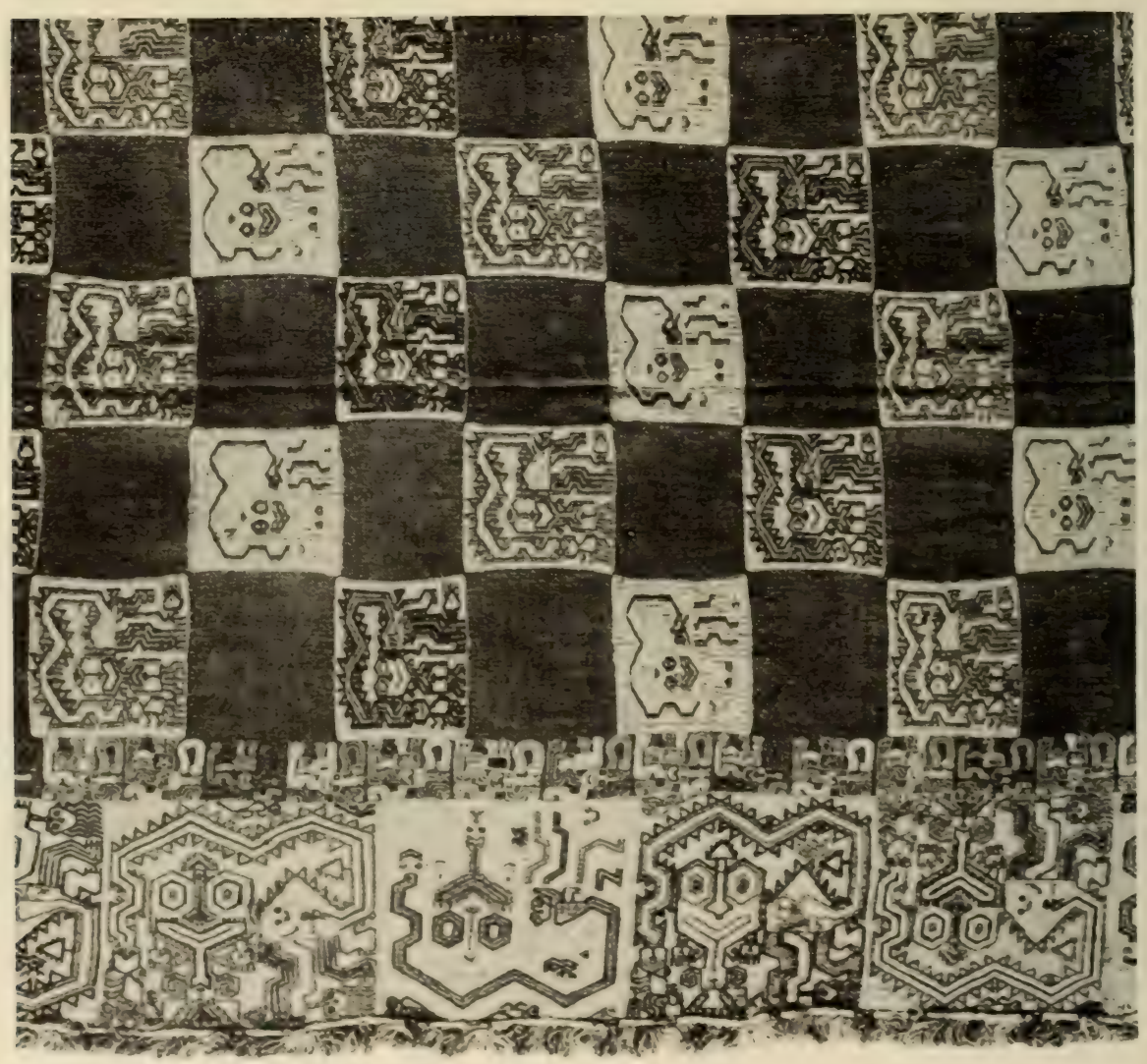



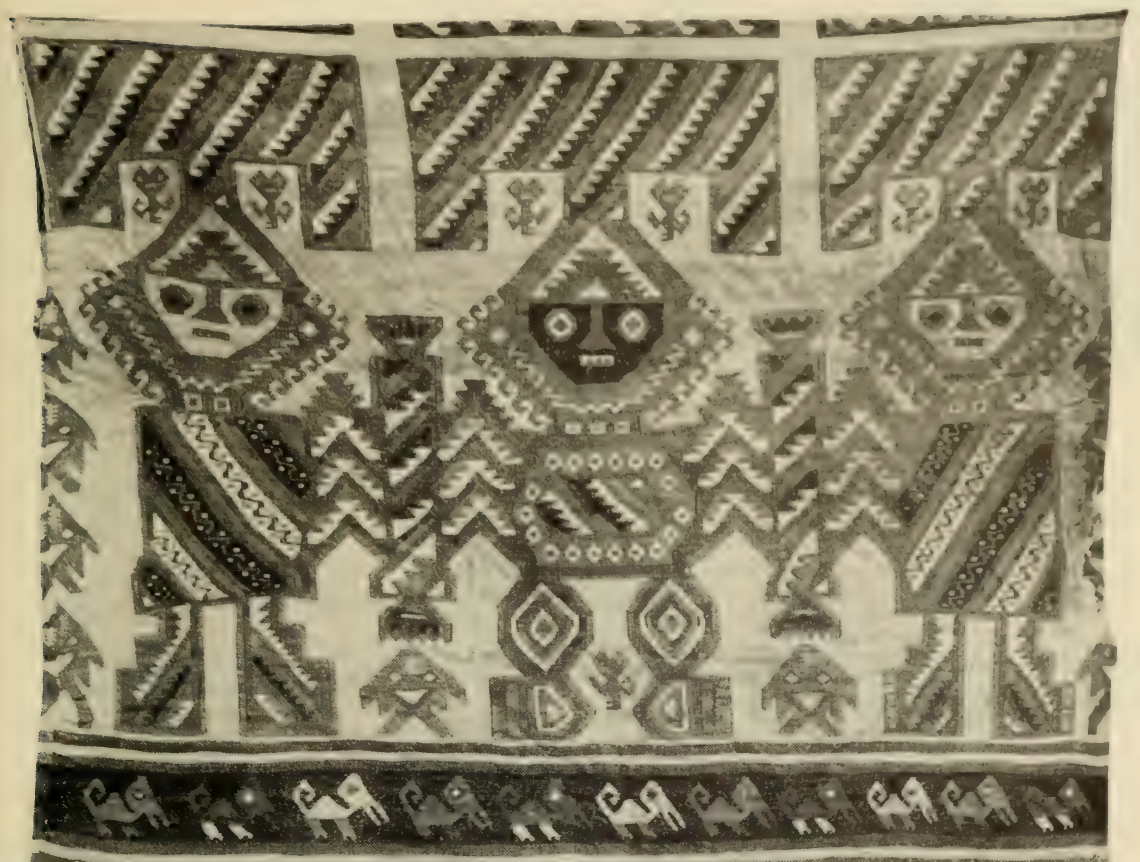

.

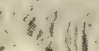

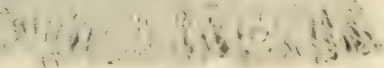

A PERUVian tapestry. An excellent tapestry from Pachacamac, Peru, with slits left open between color areas as part of the design.

In special exhibits are grouped such things as musical instruments, whistling water jars, examples of intentionally deformed human heads and trephined skulls showing the successful practice of a delicate surgical operation by the ancient Peruvians.

Much of our knowledge of their daily life we owe to a fortunate combination of climatic conditions and tribal customs. Along the coast of Peru, where the extreme dryness of the climate has preserved perishable materials for centuries, are more extensive burial places than anvwhere else in America. Countless thousands of bodies were buried with such things as had been most useful and prized during life or were considered to be most serviceable in a future life. Examples of these mummy bundles are displayed, and it was from such as these that many objects in the hall were obtained.

The mummy in the case at the west side of the room was found in a copper mine at Chuquicamata, Chile. The body is that of an Indian miner who was killed by the falling of rocks and earth while he was getting out the copper ore (atacamite) used by the Indians in making implements and ornaments in prehistoric times. The tissues of the body 
MODEL OF ALACALUF HUT. Used by nomadic fishermen in southern Chile, this type of shelter is well suited to the cool, rainy environment. The floor plan of these huts is oval, about 13 by 8 feet, with a fireplace in the center between the two entrances. Sea lion skins serve as covering.

have been preserved by copper salts with which they are impregnated. The tools he was using at the time of his death are lying beside him in the case.

Much more primitive than any of the prehistoric people just mentioned were the nomadic hunters and fishermen who lived in the southern end of the continent and the neighboring islands. Their story trom the time when they hunted the extinct native American horses and ground sloths, about nine to ten thousand years ago, was recovered from caves and shell mounds. The simple tools and weapons they used are arranged in time-order in a case in the rear of the hall. Near by are examples of the equipment of the various tribes still living in the same region at the present time.

In neighboring cases are exhibits for other living Indians of South America. As there are a great many distinct tribes. sometimes living in widely different geographical areas, the collection is far from complete. An example of native life in the tropical rain forest of northeastern Peru is shown in a miniature group of the Montana Indians. They raise plantains and cassava and hunt small game. so their equipment is naturaliy specialized for these occupations. This latter exhibit is temporarily on display in the MEN OF MONTAN.A H.ALL: a temporary exhibit hall.

\section{The Pacific}

Two halls are devoted to the peoples of the Pacific Islands and of Australia. The first, SOUTH PACIFIC HALL, contains collections from Polynesia, Micronesia, Melanesia, New Guinea and Australia. l'olynesia, as represented by the Maori of New Zealand, extends into the second hall, which is principally devoted to exhibits from the Philippine Islands, small special exhibits from New Guinea, and special collections from Java, Sumatra and Borneo.

The most conspicuous objects in these halls are the Easter Island statue, the models of Tahitian and Philippine life, including a Philippine tree house, the collection of tattooed heads from New Zealand, and the collection of masks from New Ireland. 


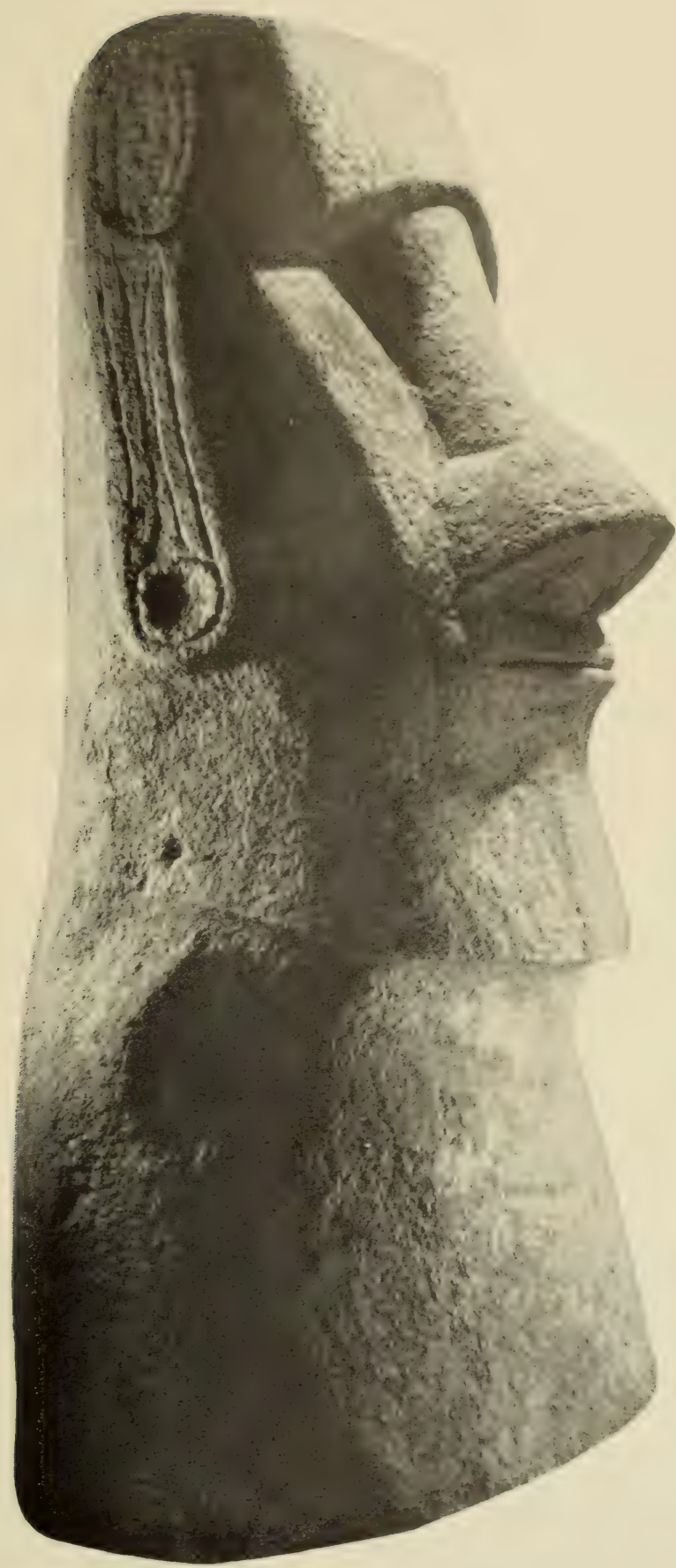

EASTER ISLAND STATUE. Easter Island, in the South Pacific, is famous for the immense stone statues found there, from one of which a Museum expedition made the cast here illustrated. 
On entering the South Pacific Hall, beyond the Hall of Minerals, the visitor sees a huge stone face, a cast of one of the famous Easter Island statues. This was brought back in 1935 by the Templeton Crocker Expedition. These statues are unique to Easter Island. They were found set on stone platforms all around the island. Their origin and exact meaning are unknown.

Directly in the center of the hall is a Tahitian priest taking part in the fire-walking ceremony, in which the participants walk over heated lava boulders. On each side is a group showing natives engaged in typical activities - grating coconut, preparing kava or plaiting pandanus.

Just behind the Easter Island statue is a fine Hawaiian feather cape, such as was formerly worn by the highest ranks of the Hawaiian society. Red and vellow honeysucker feathers, which were collected as taxes, were fastened on a netted twine foundation. The value of these garments depended on the enormous labor spent on their making.

The hall is roughly divided into two main sections. In the first half are shown the collections from Polynesia and Micronesia, while the second half is given over to New Guinea, Melanesia and Australia. How ever, it proved impossible to be wholly consistent and to separate Melanesian Fiji from Samoa and Tonga.

In the POLYNESIAN section, the examples of decorated native bark cloth (tapa) are especially noteworthy, and a number of canoe models remind us that these people are daring seafarers. A series of ceremonial adzes from the Cook Islands in the farther quarter of the hall shows aboriginal carving at its best.

In the section on the right, the elaborately carved sacred masks, about 14 feet back of the Tahitian fire-walker, illustrate the type of carving characteristic of the Melanesians of New Ireland as do the two delicately carved poles against the west wall.

Another beautiful and distinctive style is found in the carvings of

POLYNESIAN BARK CLOTH OR TAPA. This cloth was made from the inner bark of the paper-mulberry tree which is steeped in water; thinned out with a shell scraper, and pounded on a board with a mallet. Designs may be painted on the cloth free-hand, but more frequently they are printed from wooden stamps.

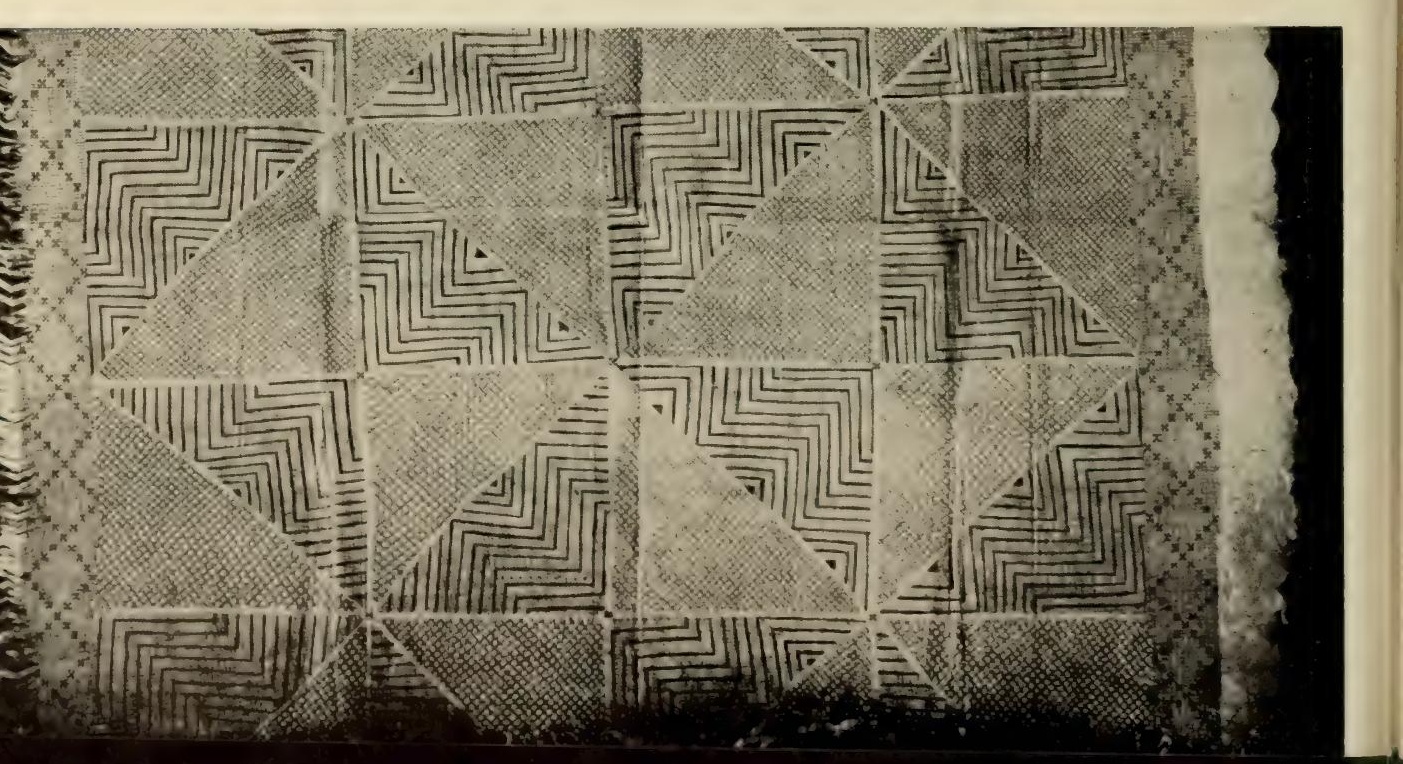




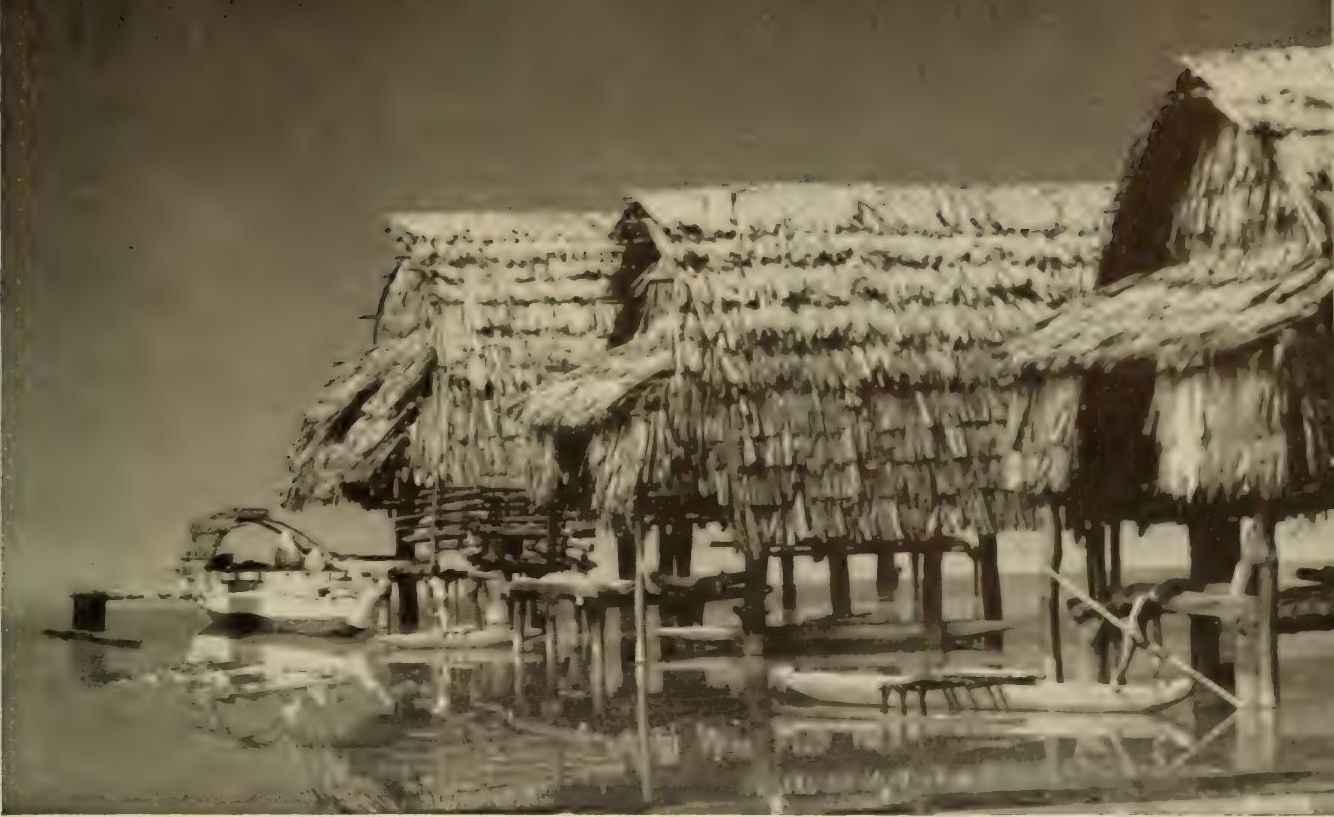

A SECTION OF A MANUS (ADMIRALTY ISLANDS) VILLAGE, reconstructed with scientific accuracy in every detail; one of many miniature models in the American Museum showing native home life and activities.

the Maori of New Zealand. where a spiral motif is dominant. The series of dried and tattooed heads forms one of the most remarkable exhibits in the Museum.

Near the boundary between the two main sections are the AUSTR.ALIAN cases with numerous boomerangs and very crude stone tools, which should be compared with those in the archaeological hall. The farther corner contains a collection from the Admiralty Islands, including a model of a village of the Manus tribe, a lagoon-dwelling, fishing people who build their houses on piles far from land. In the right corner of the hall are shields, clubs, carvings and household utensils from New Guinea.

The islands of the Pacific Ocean may be divided into two types: the high islands which represent remnants of sunken land masses or else the result of volcanic action, and the second variety consisting of low coral atolls rising not much more than 20 or 25 feet above the sea. The environments that these islands provide for their inhabitants are strikingly different and have affected the kind of life they are able to lead.

The high islands are, for the most part, fertile and well covered with a variety of vegetation. The coral atolls have little or no soil and support a very thin plant life. Although both high and low islands occur in various parts of the Pacific, there are two principal areas where the coral atolls are specially concentrated: one is in Micronesia and the other in the Tuamotu chain of Eastern Polynesia.

The people who live in these various islands belong to a number of different stocks. The Polynesians occupy the easternmost islands and 


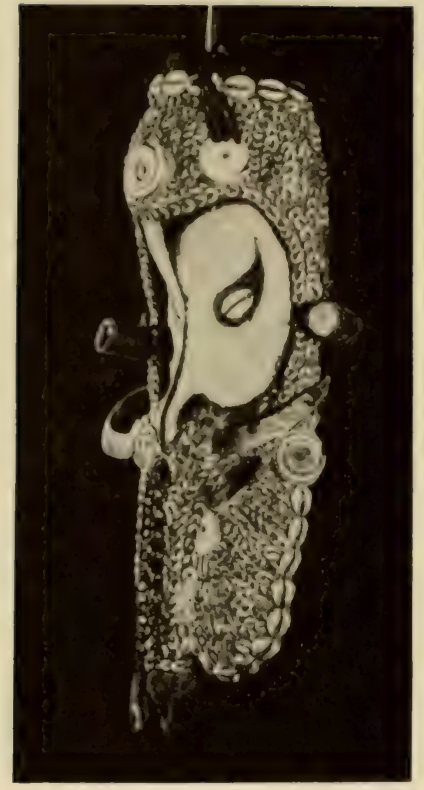

MASK. TCHAMBULI, SEPIK DISTRICT, NEW GUINEA.

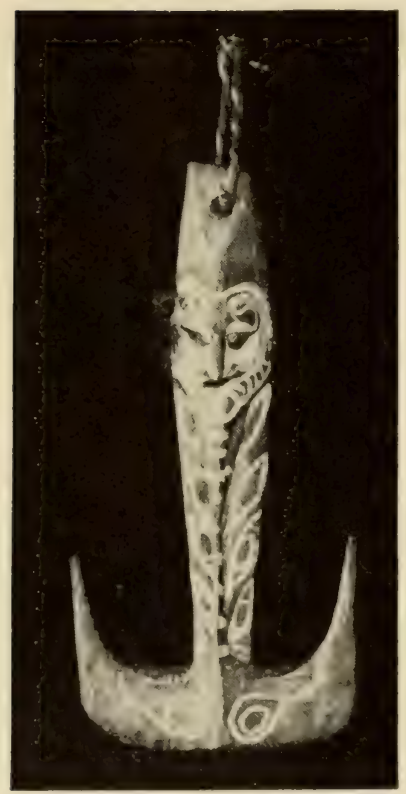

CARVED WOODEN HOOK USED IN DECORATING MEN'S HOUSES IN TCHAMBULI, NEW GUINEA.

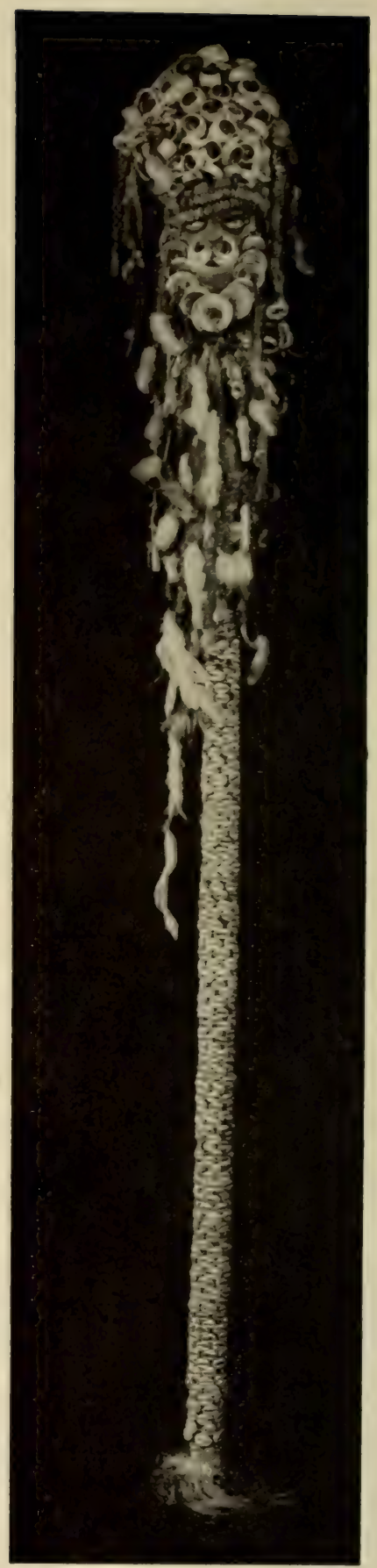

SACRED FLUTE, MUNDUGUMOR, NEW GUINEA. These nutes, known as crocodile spirit children, are so heavily encrusted with shells that they are non-functional. 

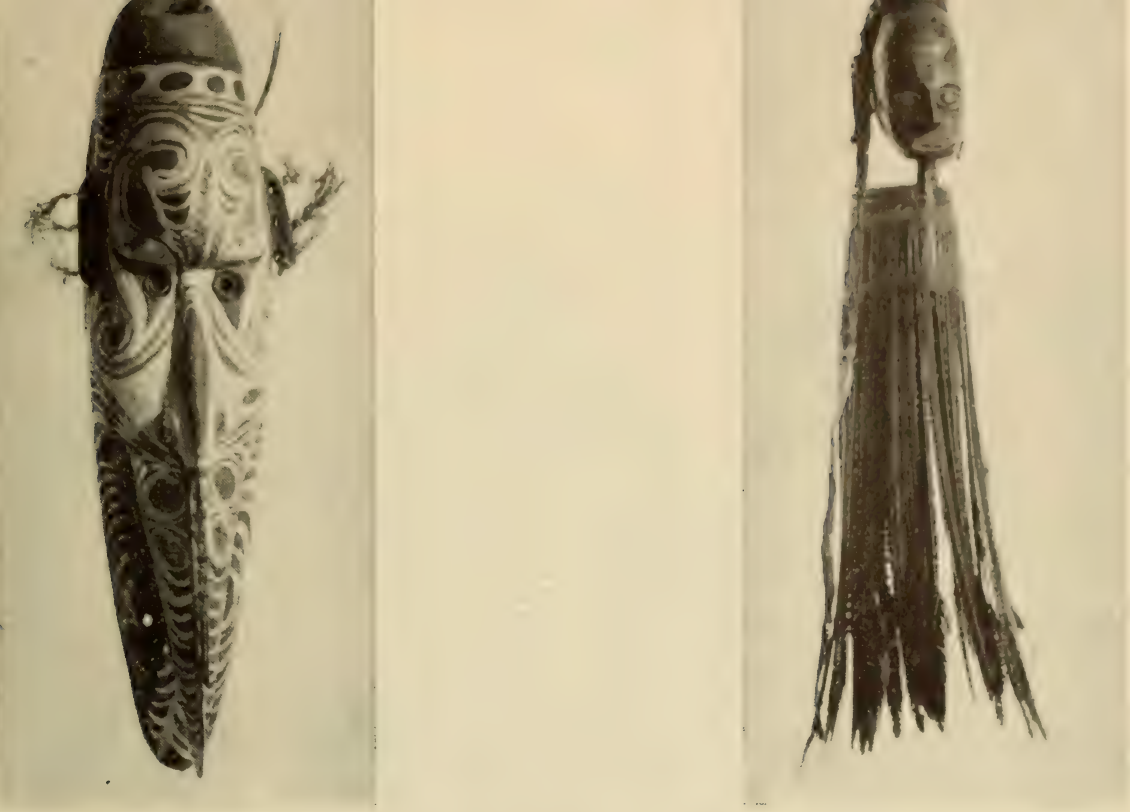

Left, CARVED HOOK, TCHAMBULI, NEW GUINEA. Right, WAR CHARM, made by the people of Pak in the Admiralty Islands. It is worn on the back, and it is believed that when a man is slow in going into battle the charm scratches his back and urges him on.

differ significantly from the dark-skinned, frizzly-haired people of Melanesia on the one hand and from the short, more Mongoloid type found in the Micronesian islands.

Culturally, these three major island groupings also show differences that suggest, to a large extent, independent histories. The Polynesians manufacture bark cloth and matting, have no pottery, drink kava, fight with clubs, and are skilled navigators. They are governed by chiefs who trace their ancestry back many generations. The Melanesians make some pottery, do grotesque carvings, use bows and arrows and spears for hunting and fishing. They have men's cults into which boys are initiated and from which women are rigidly excluded.

The Micronesians live on the chain of small islands extending south from Japan to Melanesia. They are characterized by a complex political organization, great skill as navigators, and a simple food economy based on the sea.

The peoples of the New Guinea mainland and the interior of some of the larger islands of Melanesia can be grouped together as land peoples, speaking complex or non-Melanesian languages.

The aboriginal inhabitants of Australia had one of the simplest technologies to be found in the contemporary world. A hunting and foodgathering people, their tools and weapons had to be carried with them, and almost all the elaborations of their culture were expressed in songs, dances and complicated marriage patterns which cannot be shown in Museum cases. 
PHILIPPINE TREE HOUSE.

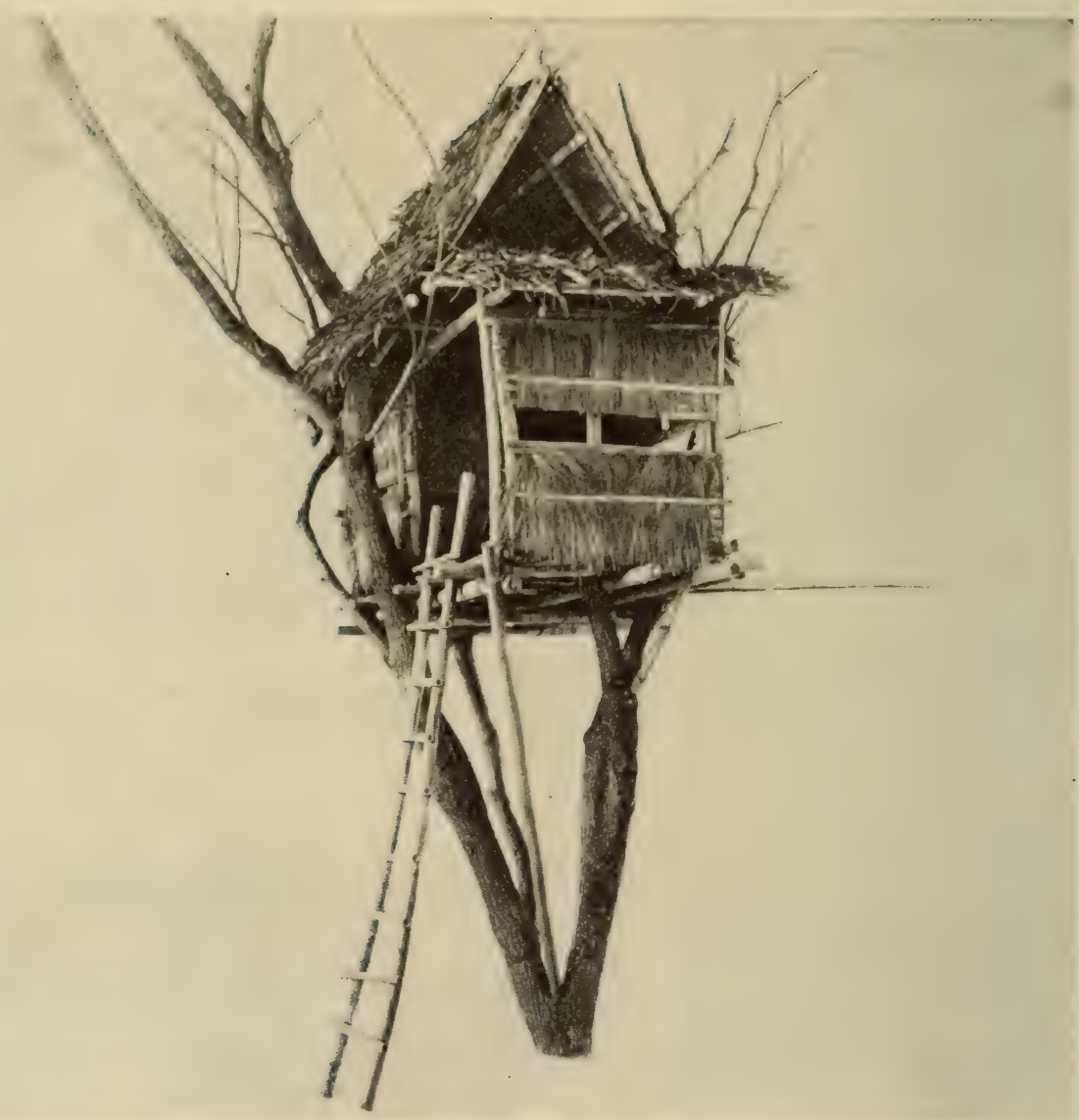

\section{Collections from the Philippines and Malaysia}

This hall is reached by turning to the right in the South Sea Island Hall.

The side aisles display Philippine Island objects. The farther section of the hall contains exhibits from other parts of Malaysia with an interesting series of marionettes from Java.

At the right of the entrance is a case containing life casts of faces, noses and hair from the different races represented in this hall, also charts of stature and head form, with distribution maps.

In the center is a model of a Filipino bamboo-walled and thatchroofed house. At the far end, a native tree house dominates the scene, and on the left may be seen the model of a woman weaving a garment on a native loom.

The visitor should note that, like the African Negroes, the Malayan tribes represented in this hall use iron tools. The numerous iron weapons 
- spears, battle-axes, and krises (daggers with serpentine blades)-are especially remarkable.

On the left side of the hall are found a number of exhibits of native krises, shields, fabrics, basketry and pottery. Pottery is not highls. developed in this area, but the textile arts flourish to a remarkable degree. The industrial life of the Bagobo of Mindanao is particularly well-illustrated in the collections.

Much more primitive in their culture than the other Malaysians are the Negritos, a dark-skinned and frizzly-haired pygmy stock lorming, with like groups in other parts of the world, a distinct division of the Negro race. They are everywhere hunters, using the bow and arrow, and ignorant of agriculture. Their simple tools are shown in a table case in the farther section of the hall.

The islands lying close to the coast of Asia have been subjected to several migrations and to varying cultural contacts. The present population is predominantly Malay in origin, members of the great Mongolian race. Their cultural arts include pottery, metal work and textile. The metal work is especially fine in the weapon-making of Java and among the Mohammedan inhabitants of the Philippines. Among the textiles are exhibited the batik work of Java, the tie-dyeing of the Bagobo in the Philippines, and fine textiles of Luzon.

They possess fowls and pigs, grow rice, and use the carabao, or water buffalo, as a domestic aid in farming and transportation. Their form of the widespread Pacific canoe type usually has a double outrigger. Their weapons are blow-guns, bows and arrows, spears, and knives. In parts of Melanesia, head hunting was formerly practiced and formed a striking cultural feature in this area.

Although the Malay culture has deeply influenced all the peoples of the area, influences from India and China have also been felt here; the former affecting thought and philosophy, and the latter furnishing, through commerce, cherished objects of art and use. Nore recently. Mohammedanism has entered the islands and has become the prevailing religion in some of them. About 300 years ago, Christianity and European culture were first introduced by the Dutch and the Spaniards.

\section{Asiatic Ethnology}

At the entrance to this hall to the right is a section given to a bricf exposition of the prehistory and early historic periods of Japan. The exhibits on the left side illustrate in the main the life of the Chinese at the turn of the century when the bulk of the collections was made, so that many of the objects shown here no longer have a function in Chinese life. Bamboo, porcelain, basketry, inlaid work, cloisonne enamel. lacquer, farming implements, carvings in wood, ivory and stone, costumes. and embroidery are shown to advantage. Several technological processes are shown in detail, such as cloisonne and the history of printing. 


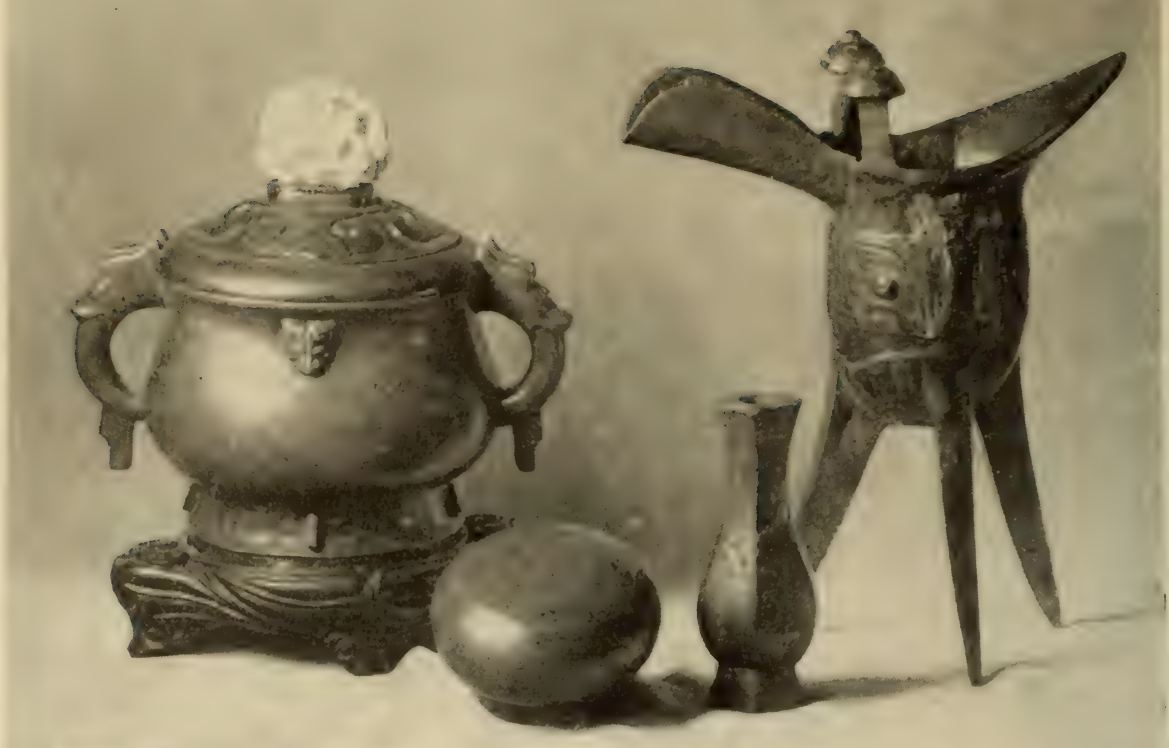

CHINESE BRONZES. A set of three bronze ornaments inlaid with silver from the Sung Dynasty, 960-1279 A.D. To the right is a bronze libation cup, probably used in religious ceremonies, from the Shang Dynasty, 1766-1122 B.C.

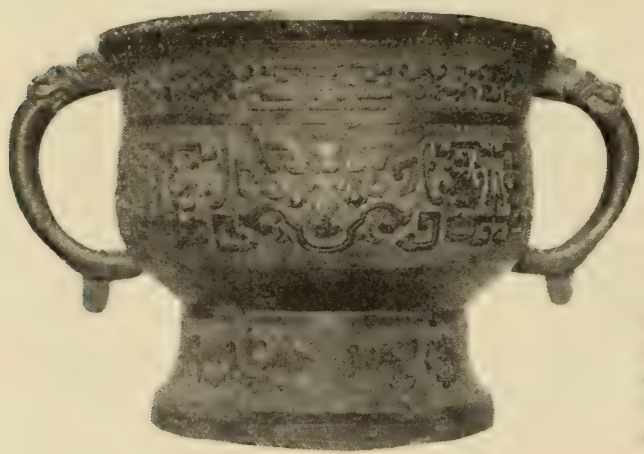

CHINESE BRONZE BOWL. This large bronze bowl has the original scroll design characteristic of the Chou Dynasty. Attributed to the Sung or Ming Dynasty.

A PAIR OF CHINESE BRONZE HORSES. They may have represented the horses of a chariot which has been lost. Ts In Dynasty.

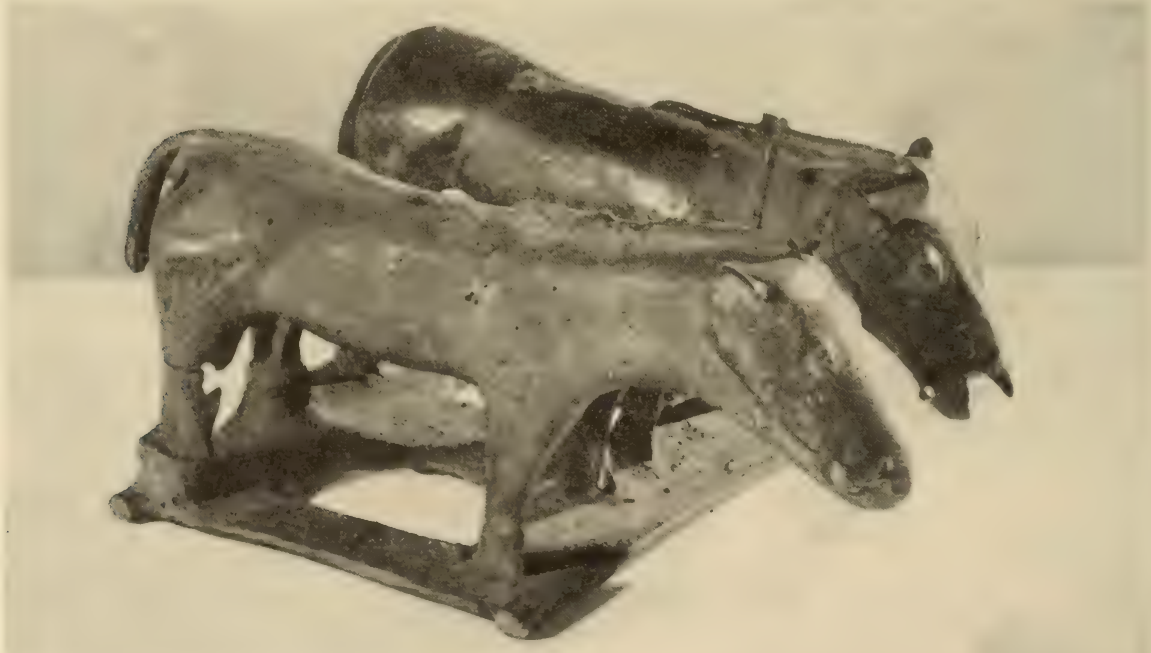




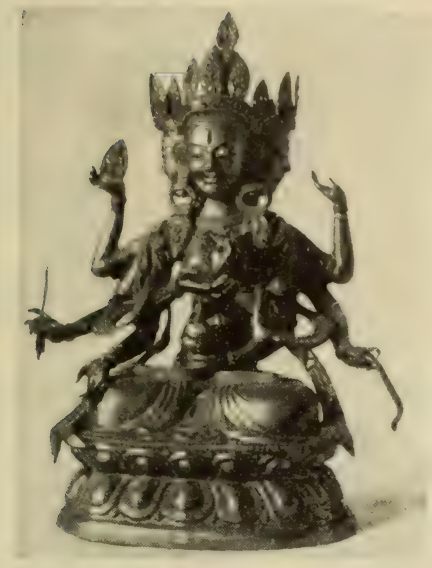

A Religious imAGe, TIBET. The Victorious Goddess of the Ushnisha, a feminine divinity, known in Sanskrit as Ushnishavijaya and in Tibetan as gtsug-tor-rnam-par rgyal-ma.

In the wall cases to the left of the entrance is a collection of ancient Chinese bronzes, and adjacent to the tower at the left is the Whitney collection of Lamaistic ritual objects from Tibet, supplemented by costumes and household utensils used in daily life by the Tibetans.

Next to these is a series of the Vedic and Puranic gods of India.

The way of life of the island Asiatic peoples - Japan, Ainu, and Korea - is shown in the west end of the hall. Of particular interest are the two models of Japanese dwellings, an example of Japanese armor and No drama masks.

Other peoples represented are some of the tribal groups such as the Meiteis and Maring of the Assam-Burma region and the Chin and Kachin of the Upper Chindwin River, Burma.

The right side of the hall is occupied by the Chukchi. Koryak. Tungus, Yakut, Lamut, Yukaghir and Gold, all of whom live in Northeastern Siberia including the Kamchatka Peninsula. The Koryak, for example. are related in language to the Chukchi and Kamchadal, with whom they share many cultural attributes. Like the Chukchi, thes are divided into a Reindeer and a Maritime branch, but differ from their neighbors in the almost exactly equal size of these divisions. The Reindeer Koryak live mainly on the flesh of their herds. The Maritime group depend largely on fishing, while the hunting of sea mammals is also important but relatively less so than among the Maritime Chuchi. The Reindeer people live in movable tents. The stationary, partly underground house of the Maritime division is illustrated by a model. Both divisions of the Koryak wear clothing made of reindeer skins. 


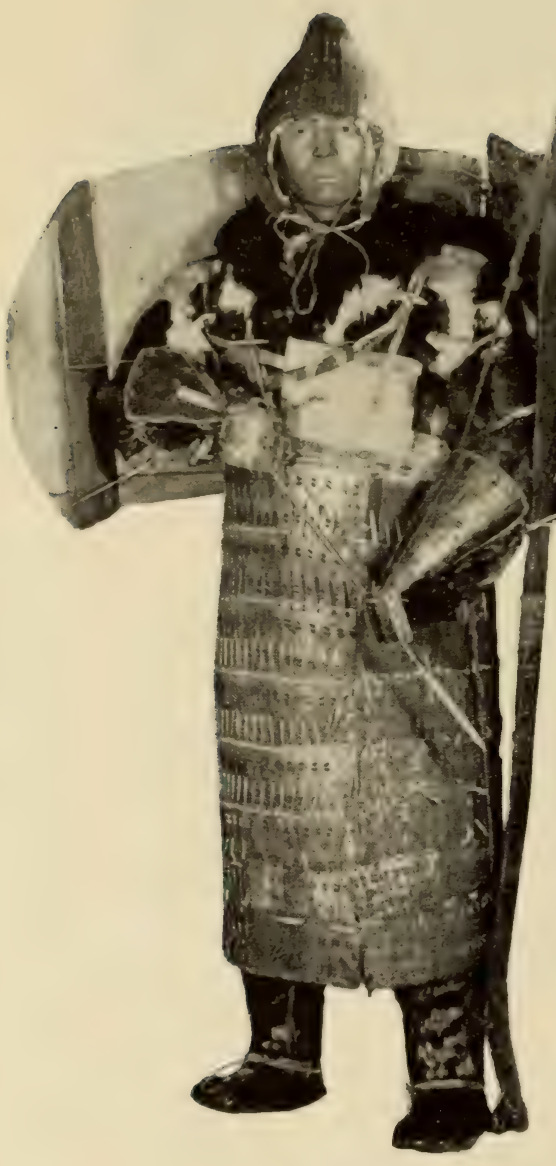

KORYAK MAN IN ARMOR.

Before contact with other peoples, the Koryak had no metal and made all their implements by chipping stone. Several settlements were noted for their iron technique, which may antedate the coming of the Russians. since the Tungus and Yakut were both familiar with the blacksmith's art.

The dressing of skins and the weaving of baskets by the coiled and twined methods are important industries. Remains brought to light by excarations of old dwellings show that the ancient Korvak knew how to manufacture pottery. The Koryak have attained a high degree of perfection as carvers in wood, antler and ivory, and in the skillful handling of furs in the manufacture of their cloth. 


\section{Drummond Collection of Jade}

The famous DRUMMONI COLLECION of carsed (hinese jade, amber, Japanese irory, and sword-guards is in the southwest Tower on the fourth floor, opening out of the South Seat Island Hall. This magnificent collection gathered by the late Dr. I. Wiman Drummond and presented to the Museum in his memory, is installed as a unit, largely according to Dr. Drummond's original arrangement.

It is really a group of collections, each one of the greatest importance and beauty. The JADE COLLECIION alone is a rich and well balanced series. representative of all periods and covering a cultural range of more than thirty centuries. The left half of the room is devoted to jade arranged by periods, while the right half is given over to AMBER, IVORY, LACQUER, and BRONZE SWORD-GUARIDS. The oriental amber displayed is the finest of its kind in the world.

A unique composite piece of white jade, occupving the center of the room, was a birthday gift to the Emperor Kien Lung from the officials of his court. This assemblage of jade carvings consists of thirteen pieces fashioned from purest white jade and fitted together. Surrounding the central piece are twelve segments fitted together, each of which is carved with a representation of one of the twelve terrestrial branches corresponding to the signs of the zodiac.

A very fine piece of white jade of the Kien Lung period of renaissance in glyptic art is in the form of a "Scepter of Good Luck" (Joo-i scepter). ()n the long handle of this piece are carred in high relief the figures of the Eight Immortals, the half-mythical, half-historical personages so often represented in Taoist art. Each of these carries some characteristic object, such as the flute of Han Hsiang-tzu, whose marvelous tone caused flowers to grow and blossom instantly.

AN EMPEROR'S BIRTHDAY GIFT. An assemblage of elaborate carvings fashioned from purest white jade and fitted together. 


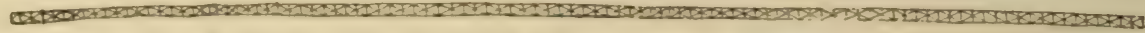

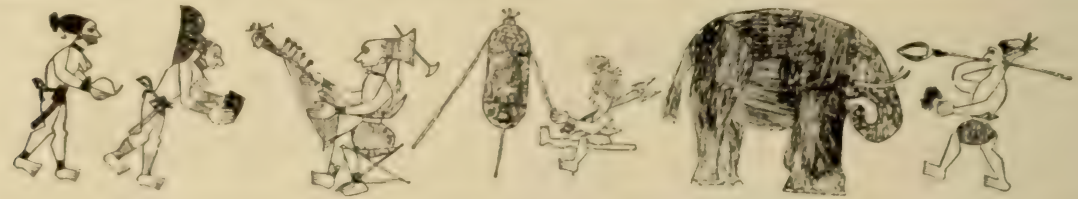

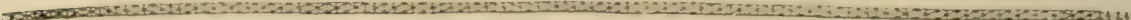

PICTOGRAPHS from Mangbettu carved camwood and ivory boxes.

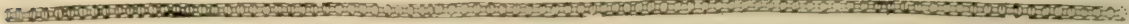

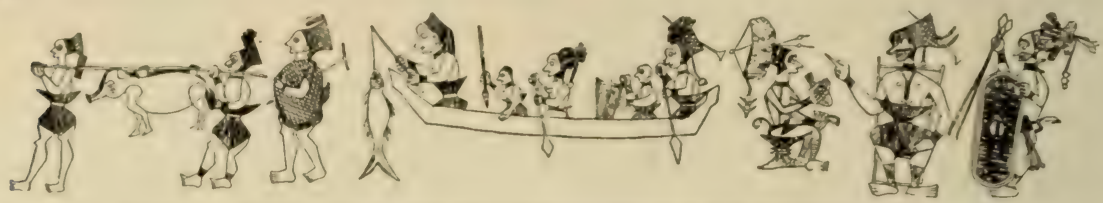

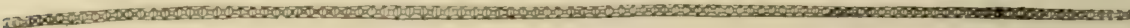

IVORY HANDLED IRON WEAPONS OF THE MANGBETTU. The great sickle-shaped knives were worn over the shoulder by the king and other prominent men when they were sitting in council, partly as proof of the wearer's readiness to strike. At other times the knives were pushed under the belt.

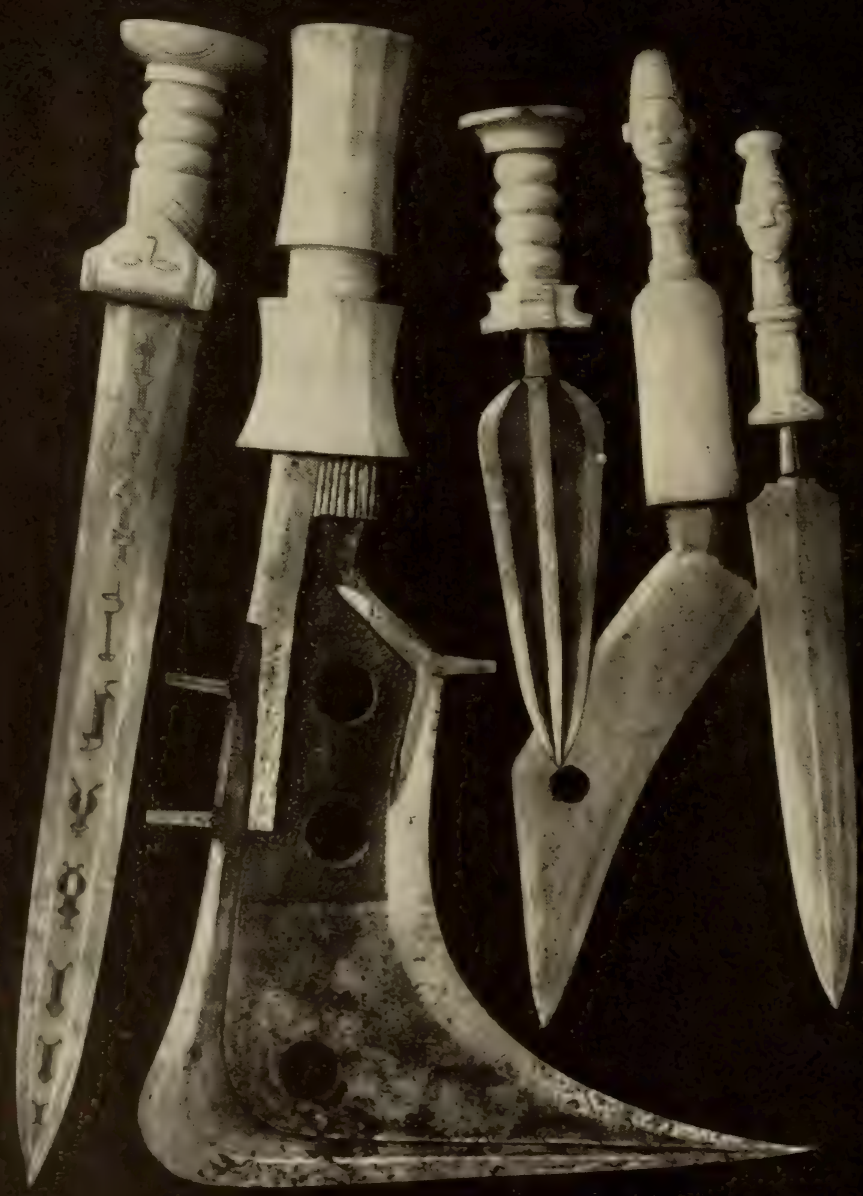




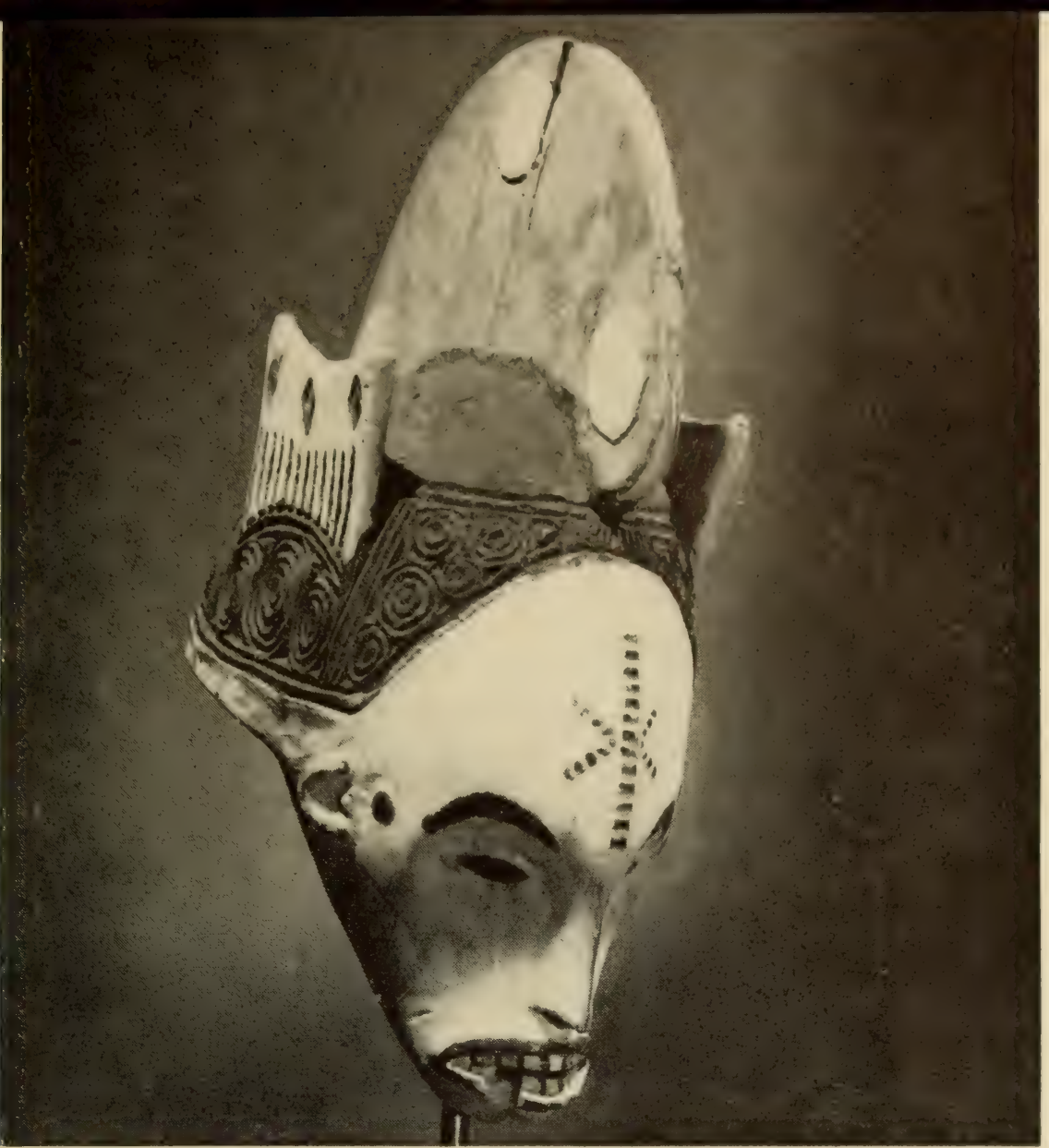

MASK. IBO, NIGERIA.

\section{African Ethnology}

The order in this hall is roughly geographical. Thus, as the visitor proceeds through the hall, he meets the tribes that would be found in passing from south to north in Africa. The West African peoples are represented along the left hand wall, the East African along the right hand wall, and the tribes of the Congo around the central rectangle.

Nothing is more characteristic of the Negro culture than the art of smelting iron and making iron tools. The process used by the African blacksmith is shown in a group on the left at the entrance and the finished products, such as knives, axes and spears, are amply displayed throughout the hall. The knowledge of the iron technique distinguished the Negro culturally from the American Indian, the Oceanian and the Australian.

A pictorial map indicates the various culture areas distinguished on the continent. Clothing is either of skin, bark cloth, or loom-woven plant fiber. The manufacture of a skin cloak is illustrated by one of the figures 
in the group to the left of the entrance. Bark cloths from Uganda are shown in the farthest right-hand section of the hall, while looms and the completed garments are on view in the large central rectangle given over to Congo ethnology. The most beautiful of the last-mentioned products are the "pile cloths" of the Bakuba, woven by the men and supplied with decorative patterns by the women. Very fine wooden goblets, fetish figures, masks, and especially a series of ivories from the Congo, bear witness to the high artistic sense and craftsmanship of the African natives. The importance of musical accompaniment to their ritualistic dances is demonstrated by the great variety of musical instruments.

A unique art is illustrated in the Benin case in the farther section of the hall where the visitor will see bronze and brass castings made by a process similar to that used in Europe in the Renaissance period.

The religious beliefs of the natives are shown by numerous fetishes and charms, believed to give security in battle or to avert evils. Ceremonial masks are shown, which were worn in native rituals. 


\section{CONSERVATION AND}

\section{GENERAL ECOLOGY}

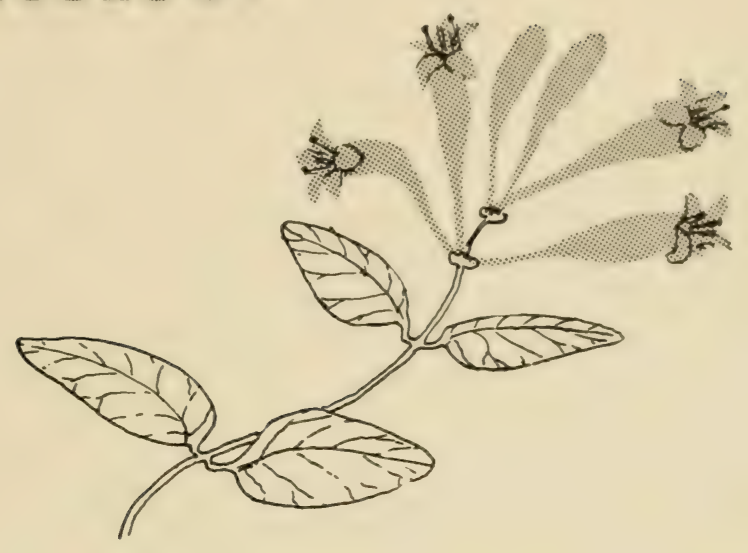

Wherever you go on land or water you will find living things. Usually both plants and animals will be present, although the kinds will vary greatly from place to place. These natural assemblages of plants and animals that live together in the same area are spoken of as wildlife communities. Ecology is the branch of natural history that concerns itself with these wildlife communities. It seeks an understanding of (1) why they vary from region to region, (2) how they function, (3) how each species present has become specifically adapted to life in such a community, (4) what the relation of each is to the other members of the community, and (5) what contribution each makes to the welfare of the whole.

In any region local differences in slope, elevation and drainage, the character of the underlying rock or glacial deposit, and the varying impact of natural or man-induced "disasters", produce a series of different wildlife communities. However, the basic structure and organization of a wildlife community is everywhere the same. It must have, first of all, plants capable of locking up and storing some of the sun energy that falls on the area it occupies.

To perform this task plants borrow from their environment carbon dioxide and water molecules, and, using these as raw materials, they 
build sugar molecules in which some of the sun energy is locked up. This energy is then used by plants to build other more complex plant substances in which are incorporated additional elements such as nitrogen, phosphorous, sulphur, calcium and potassium. In time these become the tissue of some part of the plant's structure or of its seeds.

These plant substances are the base which supports a community's animal life. as well as its parasitic and saprophytic plants. Saprophytic plants are those that feed on rotting wood and other dead organic matter. Buds, leaves, fruits, sap and the many other forms into which these plant materials are finally converted, serve as food for a host of different plant-cating - herbivorous - animals. As most herbivorous animals are rather specialized in their diet, the average community has places - or, as an cologist would say, niches - for many such species. Through the process of digestion the various plant materials are absorbed into the bodies of animals, where they provide the organic building blocks from which animals fashion the tissues of their own bodies. Equally important is the energy that these plant substances make available to animals. All an animal has to do is to oxidize them, and the locked up sun energy is released. It is this energy that makes an active life possible for an animal and keeps it warm if it is warm-blooded.

Few natural communities stop here. They have, in addition, a lesser number of flesh-eating-carnivorous - animals that differ from herbivores in that they obtain their food supply of plant-originated organic materials second-hand; in other words, rearranged into meat or lat. In fact, those carnivores that prey largely on other carnivores may te said to obtain their supply of sun energy and organic building blocks thirdhand. In many of the more complex wildlife communities the steps are carried still further, and food chains with five. six or more links are not uncommon. However, it takes a lot of plant material in support one large animal at the end of a long food chain and a communit! never has many individuals of such a species.

Man lives either by exploiting natural plant-animal communities for products he can use or by destroving them and substituting artificial communities that are more productive in terms of his specialized needs. The latter we call farming, and we either directly harvest the plants for human use or utilize tame herbivores like cows and chickens to harvest them and turn them into products we can use. Farmers regard most plant-eating wild animals as potential competitors. To keep their numbers down to a minimum, wise farmers encourage predators like the insect-eating songbirds, moles and skunks. and the rodent-eating weasels. hawks and owls. If conflicts arise because chickens and other domestic animals are also attacked, it is often wiser to give such livestock better protection than to kill the offending carnivore and lose its help in holding down crop-eating wild animals.

Conservation is often called applied ecology, because we must first understand how plant-animal communities live and function if we are 
to manage them wisely. It is therefore one of the chicf tasks of the Museum's Department of Conservation and General Ecologs (1) make better known the natural laws to which man must conform it he wishes to exploit land or a natural community without impairing its future productivity.

As students of natural history we are also interested in the preensa. tion of samples of every wild plant-animal community that is native to this continent. Only if we are successful in this, will coming generations of naturalists have an opportunity to study and enjor all the forms of wildlife now native to North America.

There are some plants and animals that cannot tolerate any disturbance by man of the community of which they are a part, so we seek to have communities set aside as nature reserves, free from human interference or management of any sort. Such areas have a very special value to students of natural history, as a wild plant or animal is only truls and wholly understandable in terms of its role as a functional unit or $\operatorname{cog}$ in the community of which it is an integral part. Its evolution through the centuries to its present form, possessed of certain specific habits and other attributes, took place in the setting provided by such a community. Here it is continually subjected to the normal impact of competition, predation. and the many other forces that operate within a community on every one of its members - influences that are essential to the continuing health of a species.

\section{FELIX M. WARBURG MEMORIAL HALL}

Here is dissected for you a typical rural area near New York City. We show you something of both its geological and glacial history and its more recent history under the impact of man. We show you its wildlile communities and some of the artificial ones with which man replaces them. Here you can see the history of man's attempt to exploit more fully the land and how nature re-establishes wildlife communities when man. because of his failure to maintain soil fertility. abandons further attempts at cultivation. Here are samples of the area's soils, its bodies of water and woodland, and the cycles of lite and decay within the communities that occupy them. You can see how differences in rocks and soils tend to produce different wildlife communities. In short, we help you to explore and understand the ecology of a typical landscape.

AN OCTOBER AFTERNOON NEAR STISSING MOUNTAIN. Stissing Mountain, a hard mass of gneiss, is the most commanding topographical feature in the Pine Plains' landscape. Here we see it in the glowing colors that are one of the outstanding characteristics of the deciduous - leaf-shedding - forest of Northeastern United States. Here, too, are a few of the animals that form an integral part of the community - the blue jay, red fox and dragon fly. 
BIRD'S-EYE VIEW OF STISSING MOUNTAIN AND VILLAGE OF PINE PLAINS. This relief map show's you the Pine Plains area as it appears today. Its mosaic of fields and forests is typical of most agricultural communities in the glaciated Northeast. Local variations in such factors as slope, soil texture and depth, nature of underlying rock and proximity of water table, underlie such a pattern and are the subject matter of the Hall.

GEOLOGICAL HISTORY AND STRUCTURE. Pine Plains' present mountains and valleys are the end product of many millions of years of weathering, rock formation and re-weathering, and earth movements that have folded and fractured, submerged and elevated. Here are displayed the various rocks that are now exposed at the surface and something of the forms of life that lived here when these rocks were being formed.

GLACIATION. Recently - geologically speaking - a great mass of ice flowed down from the north over this area. As it moved, it scoured away the soils and smoothed the rocky ridges. Some rock fragments were carried as great boulders; others were ground to claylike fineness. Then, some 10,000 years ago, the ice melted, leaving behind a rolling landscape of hills and marshes, ponds and lakes. Because of the glacier we have pockets of clay soil in one place, stony ones in another, and little or none on the exposed ridges.

THE WATER CYCLE. The course that rain water takes after it falls is indicated in a cross-section model of a typical rural landscape. The relation of wells, springs and flowing streams to the underground zone of saturation is indicated. Its upper level - the water table - is seen to vary with both topography and the nature of the underlying sub-strata. The sloping land on the right has been subjected to water erosion due to improper farming and will no longer yield a living for the owner.

STISSING MOUNTAIN SCENE. A landscape is a mosaic of distinctive plant-animal community units.

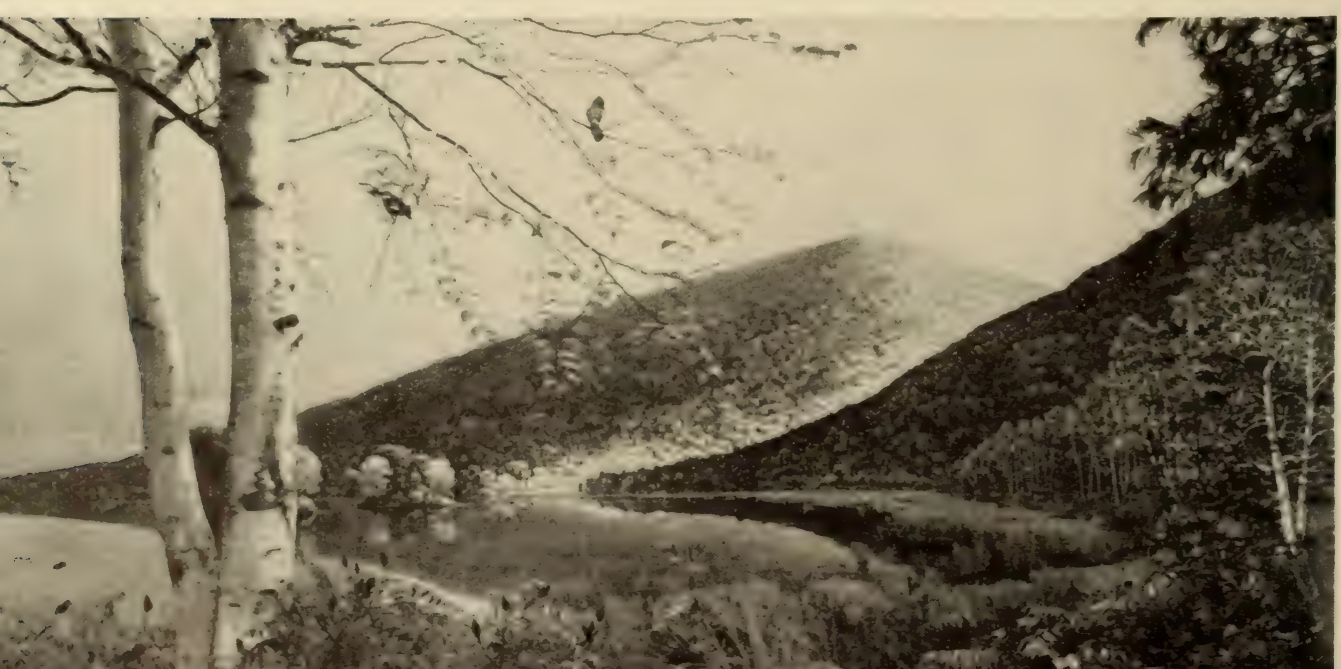




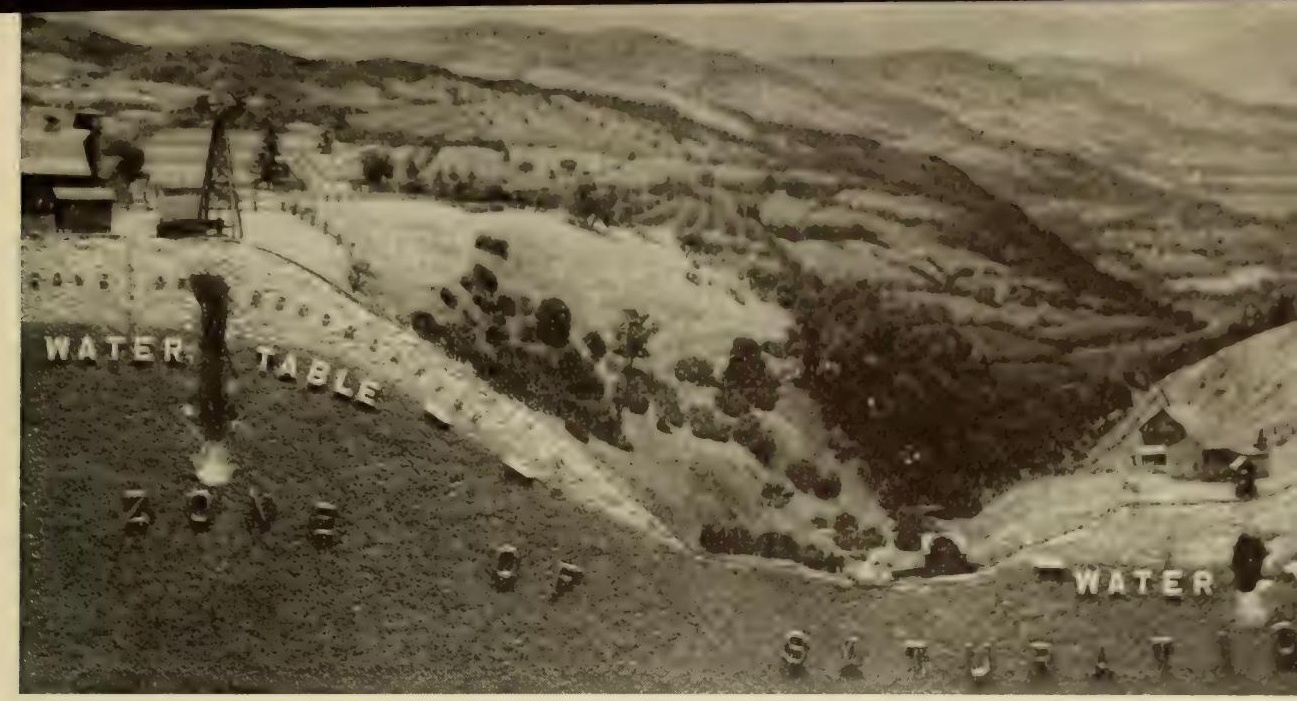

LANDSCAPE CROSS-SECTION. Water running downhill creates problems above ground, but is an asset below.

SOILS AND SOIL CONSERVATION. Weathered rock minerals, glacial debris and water-laid beds of sand and clay provided the raw materials for the area's soils. As these leached and plant remains became mixed with their surface lavers, soil was formed. Because of their diverse origins, sandy and clayey soils, or that ideal intermediary, loam soil, all occur within relatively small areas at Pine Plains.

LIFE IN THE SOIL. Beneath our feet lies a subterrancan world that teems with life. Here many insects spend part of their lives. Earthworms and hundreds of smaller animals feed on plant and animal remains, converting them into humus. Moles literally swim through the soil with the help of their powerful feet, leaving tunnels that provide runways and homes for chipmunks, mice, toads and insects.

ROOTS IN THE SOILS. The parts of a plant that occupy the soil are no less important than those that reach upward into the air. Here you see an enlarged feeding root and its absorbing root hairs. A magnified soil section shows such a hair creeping through the air and soil solution that occupies the spaces between the soil granules.

THE RELATION OF PLANTS TO GEOLOGY AND SOIL. In glaciated areas like Pine Plains much of the underlying rock is corered by deposits of rock debris that may have been carried many miles by the glacier. Soils derived from such material show no correlation with the underlying rock. On the higher areas such soil as may once have covered the rocks was scraped away. Now, with the passing of the glacier. weathering is slowly creating raw materials that pionecring plants are turning into soil. Immature soils of this sort vary greatly, as they are strongly influenced by the rock from which they have been derived. 


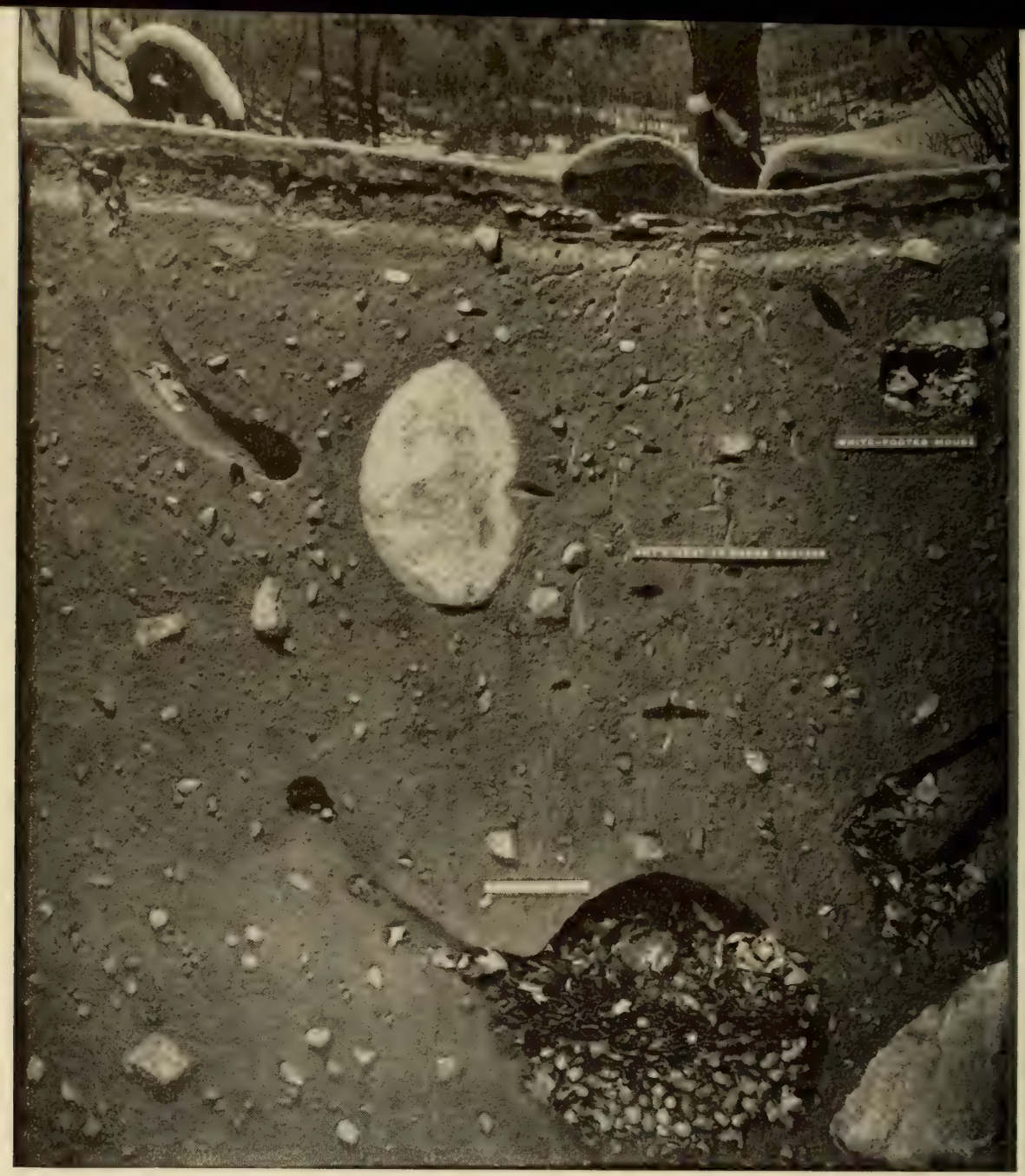

BELOW GROUND VIEW IN WINTER. The hibernating chipmunk sleeps out the winter, but the deer mouse must forage nightly for food.

Usually, only a few plants are adapted for life in a given soil of this sort and they serve as indicators of its presence. Here are samples of four such soils derived from four of the area's rock formations, together with a few of their plants. We also see two lowland areas where an excess of lime has created what are for this region most unusual environments.

ROTATION OF FARM CROPS IN DUTCHESS COUNTY, N. Y. Here are dioramas showing the appearance of the local crop-land in early June, mid-July and early October. Here, also, are samples of some of the commoner cultivated grasses - wheat, oats, rye, barley and timothy and various stages in the development of bean and pumpkin plants. By changing from year to year the type of crop that is grown, the humus content and fertility of the soil can be better maintained. 


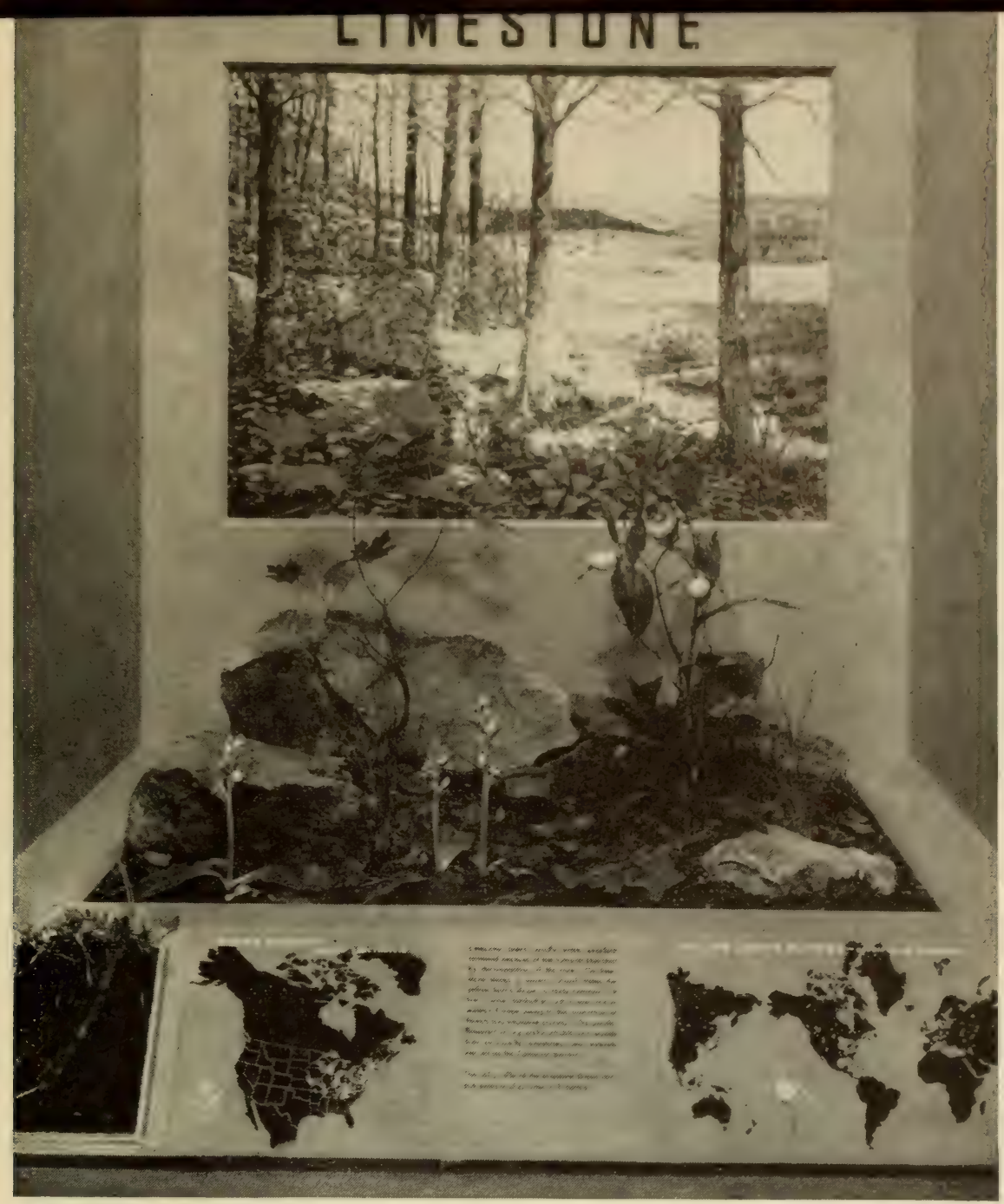

LIME LOVING PLANTS. Weathering limestone counteracts organic acids and produces the neutral soil needed by these orchids and other plants.

THE APPLE ORCHARD IN DUTCHESS COUNT Y, X. Y. Apples are the most important tree crop of Dutchess County. Here we see an orchard in bloom, during the spraying of trees, and finally at harvest time. Enlarged models show the steps in the fertilization of the blossoms by bees and in the life history of the Codling Moth that causes so man apples to be "wormy." Spraying to kill insect pests means the destruction of both beneficial and harmful forms. After spraying, honey bees are often placed in orchards to compensate for the loss of pollinating insects.

FERTILIZERS IN THE SOIL. Here two sods demonstrate the ditference that the application of needed fertilizers can make in the growth of pasture grasses. A model shows the appearance of the root of a legume (member of the Pea Family) with its nodules containing bacteria that 
convert atmospheric nitrogen into a form usable by plants. As other nutrient elements, if lacking, must come from fertilizers, some of their common sources are indicated.

CYCIE OF NUTRITION AND DECAY. This exhibit deals with photosynthesis and the circulation within a community of the inorganic nutrient elements that plants use as raw material in the manufacture of organic substances. It points out how first plants and then animals use these substances both as a source of energy and as building blocks for the construction of their own bodies. Ultimately, all organic materials are oxidized and their stored energy released. With this last step all the locked-up elements are freed and again available to plants to start the process over. Only the stored sun energy is lost, and as long as the sun shines a fresh supply of this is always at hand.

LIFE IN THE WATER. The cycling of nutrients in an aquatic environment follows the same pattern as on land. Here the most important plants are minute, often one-celled algae that cloud sunlit fertile waters with a green haze. Feeding on these plants are myriads of small animals like the abundant water flea. These in turn are consumed by small fish that soon become the food of larger ones. As on land, scavengers and bacteria finish the cycle and restore to the water the nutrient elements that were originally used by the algae.

CYCLE ON NUTRITION AND DËCAY. Only sun-energy is used up in nature's cycles or life and death.

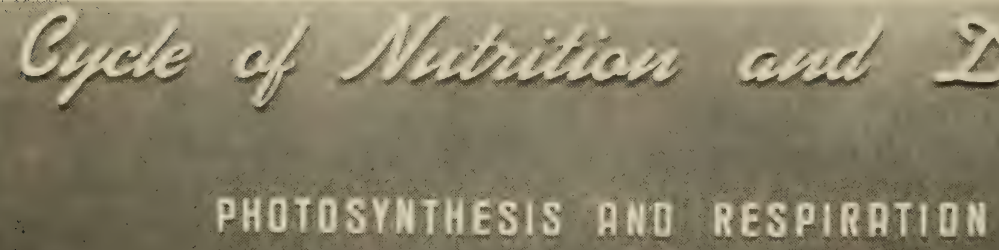

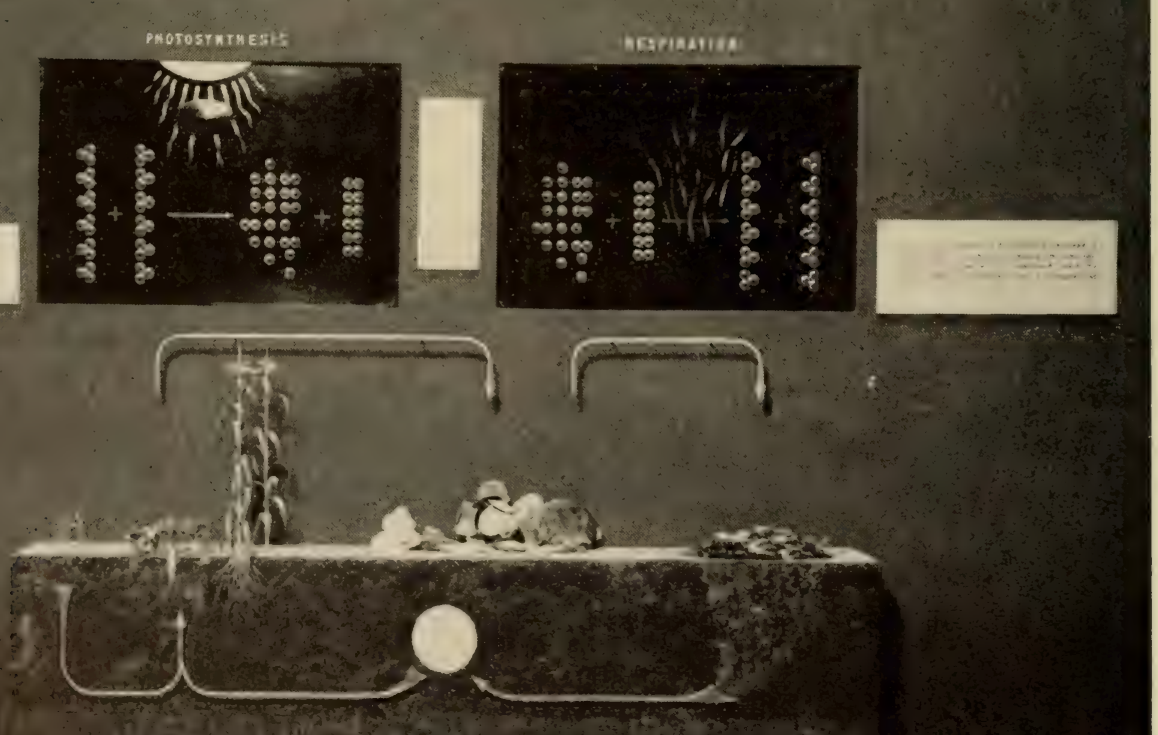


POND PREDATORS. A series of progressively larger predators forms an imporiant part of the cycle of life in any environment.

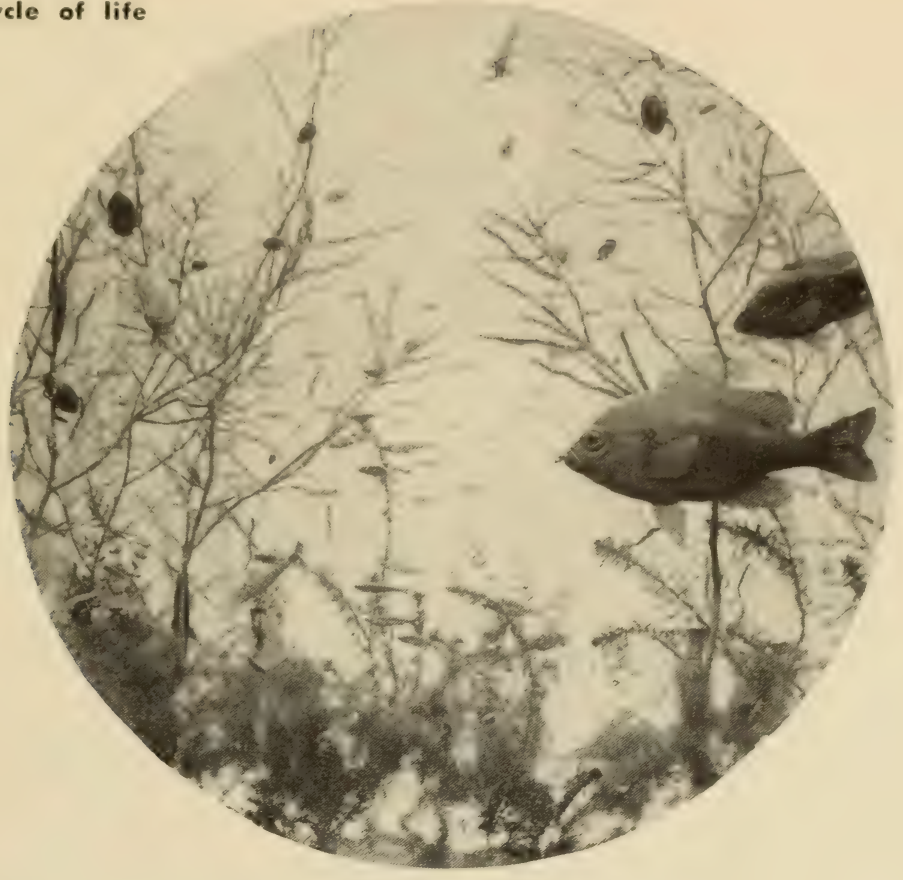

FROM FIELD TO LAKE. In a glacial area like Pine Plains the surface of the ground is very uneven. In many instances the top of the water table may be above the surface, creating a pond or stream, or close to the surface, creating a marsh. The roots of land plants cannot function in saturated soil and are therefore confined to the zone above the water table. Here we observe what a difference a few inches in elevation or in soil texture can make in the character of the plant-animal community that occupies the site. From left to right in this group we see:

1. A field with enough soil depth to raise corn, also a few crows that are more likely to be seeking grubs than pulling corn.

2. A running trout-brook fed by cool underground water that slowly seeps horizontally through the soil from points where the water table is higher than the level of the brook.

3. A sedge meadow, bordered by shrubs, where dead plant materiai, protected from oxidation by the high water table, is accumulating to form a pocket of organic, muck soil. Here we see the shrub-dwelling yellow-throat.

4. A red maple swamp growing on a muck pocket, with a ground cover of skunk cabbage and cinnamon fern. The box turtle and red eft are common inhabitants of moist woodlands. 
5. A ridge of coarse glacial material only deep enough for trees like paper birch, chestnut oak and hemlock. that are adapted to a thin soil laver.

6. I pond border where the ground is close enough to the surface for such emergent aquatic vegetation as cattails, and where muskrats, Virginia rails and bullfrogs are at home.

7. I shallow pond where catfish, vellow perch and pickerel thrive in the warm water and a painted turte suns itself among yellow water lilies.

SEASONS IN THE LAKE. Four lake cross-sections indicate the temperature variations that occur within a body of water throughout the year. Water reaches its maximum density at $39^{\circ}$ Fahrenheit. The effect this has on the circulation and oxygen content at various levels is indicated.

SEASONS IN THE WOODS. The progression of the seasons brings much more marked changes in a deciduous - leaf-shedding - than an evergreen woodland. In the spring the sunshine reaches the forest floor in almost its full strength. Many of the small plants of the forest bloom. produce a year's store of food, and ripen their seed in the short interval before the trees put on their leaves. Others, like the goldenrod and aster. grow slowly all summer on the small amount of light that filters through the canopy, and in the fall, as the leaves begin to drop, they burst into sudden activity, blooming and forming seed in the matter of a few. weeks. The activities of woodland animals also change with the seasons and many of the birds are only summer members of the community.

THE CHANGING FORESTS. For each of the earth's climates there is often one community that is more stable than anv other. It is called the climax communitv. At Pine Plains it is a deciduous forest community with more or less hemlock mixed through it. Local sites occupied at present by other communities tend to evolve towards this climax community if not disturbed. In the foreground of the exhibit we see an abandoned field in an early stage of a progression back to forest. On different sites the early stages of the succession of communities that leads ultimately to forest may vary greatly, as indicated in the small dioramas. The complete suppression of forest reproduction that results when cattle are allowed in a woodland is also shown.

MAN AND THE I.AND. Here are five panels showing important phases in the land-use history of the Pine Plains area: (1) The extensive forest broken only here and there by small Algoncpuin Indian settlements, Indians who practiced a primitive agriculture in order to supplement the wildlife ther harvested from the forest. (2) In the 1700 's the white settlers began to move in and clear away the forest to make fields.

(3) The soil, rich with the humus that had accumulated for centuries 
under the forest, grew bountiful crops for over a century. (4) By the 1880 's the failure to replace humus and the mutrient elements shipped away in the crops, led to soil erosion, exhaustion of fertility, and abandonment. (5) Today we see the area in a new cycle of argiculture based on the extensive use of soil-building, crosion-preventing grasses and other forage crops supplied with the nutricnt elements they need by the proper use of commercial fertilizers. The common agricultural tools of each period are shown in miniature.

RECORDS OF TIME. Here you see some of the methods that enable us to read the history of a landscape. Small ponds left by the melting of ice blocks gradually fill with plant remains in which are trapped wind-blown pollens. Protected from oxidation by water, this material gradually turns into layer after layer of peat. Spruce pollen in a peat layer bespeaks a cool. wet climate, while oak pollen indicates a warm, dry climatic interval.

Glacial waters are loaded with clay-forming rock flour. In quiet lakes this settles to the bottom. Seasonal variations in the character of the sediment enables us to distinguish each year's deposit. Thus, we can determine how long it took the glacial ice to disappear completely from the area.

\section{NORTH AMERICAN FORESTS}

A forest is far more than just an assemblage of trees. In this Hall we deal with forests as complete plant-animal communities. Because of local variations in such factors as slope, soil and moisture, a forest landscape will generally contain examples of more than one type of forest community. Each community will be dominated by tree species that have become especially adapted for life on a particular site. These dominant trees set the stage, as it were, for a host of smaller associated plants and a vast complex of animals that are supported by the over-all plant community.

Some types of forest communities are sharply separated from neighboring ones. More often, one type will merge into another over a broad transition area. In such transition zones the abundance or frequency of occurrence of certain trees will increase, while others decrease. Trees that may be dominant in one community will often persist in small numbers in an adjacent one.

The normal or characteristic forest of a region is the relatively stable, mature forest - capable of reproducing itself for generations on the same ground - that occupies the most farorable sites of the area, sites that provide deep, moist but well drained, fertile soil where wind and other climatic factors are normal.

The Hall of Forests will contain dioramas showing ten regional groups of forest communities. Many will portray not only the typical forest community of the most farorable sites, but one or more of the 
associated types that occur on dryer. wetter or otherwise less favorable areas for eree growth. The hall will aloo contain displavs that will acquaint you with such topics as -

1. The characteristic soil and soil life of various forest communities.

2. The wildfowers and other minor plants characteristic of different forests.

3. The forest animals and the food chains that link them to the plant community.

4. The value of forests to man and how forests should be treated.

5. How forests reproduce themselves.

At the entrance of the Hall you see a large 16 foot cross-section of a 1340-year-old Big Tree from the King's River sequoia grove on the west flank of the Sierra Mountains of California; also a smaller cross-section of a redwood log from the Coast Range of California.

Three of the dioramas are now on display:

The SUGAR MAPLE GROUP shows a scene in early spring on a farm in Black Dome Valley in the Catskill Mountains of New York. In the foreground is a sugar house where sap from the tapped maples is being boiled down to syrup. In the background you see the north flank of Blackhead Mountain covered with a Northern Hardwood Forest in which sugar maple, beech, yellow birch and hemlock are the dominant trees. In the valley the cutting of hemlock for tan bark and of leeech and birch for fuel has converted this forest into an almost pure stand of sugar maple.

The WHITE PINE-HEMLOCK-NORTHERN HARDWOODS FOREST GROUP is located near Lake Sumapee, N. H. Here we see a slope where lumbering, fire or a storm destroyed the forest 100 or so years ago, leaving the site open and sumny enough for seedlings of white pine and the very shade-intolerant red pine to thrive. Now we sec these pines maturing and the shade-tolerant hardwoods - beech. sugar maple. yellow birch - and hemlock coming in to re-establish the stable regional forest type.

The SOUTHERN HARDWOODS FOREST GROUP is located on the edge of a cove-like bench at about 3500 feet elevation on the Tennessec side of the Great Smokv Mountains National Park in the Southern Appalachians. In the group we see a sweet buckere, a tulip tree, a white basswood and a silver bell tree. The time is late April, and dogwood. Frazier's magnolia and silver bell are in bloom and the ground is carpeted with wildfowers. This area appears to have been continuously occupied by a forest community for the past sixty million years. It is one of the world's richest forests in specics, as some 130 trees occur within the park and some two dozen now reach their maximum size here. 


\section{POPULAR}

\section{VERSUS}

\section{SCIENTIFIC}

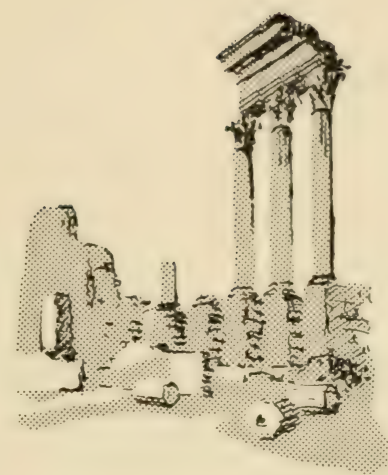

Every task of man has its own special words. Doctors, sailors, lawyers, shoemakers, scientists, cooks and cattlemen - all have their own word lists that they use in their work. Our trouble is that we cannot be familiar with all of these occupations and their special words.

Living languages grow and change in meaning with daily use. For example, take two English words, PREVENT and LET. PREVENT used to mean KNOW IN ADVANCE. "He prevented her every wish" did not mean that she didn't get what she wanted. It meant that he could tell beforehand what she wanted. Today. PREVENT means STOP SOMETHING BEFORE IT HAPPENS.

LET used to mean STOP. In Shakespeare's time a man might say, "Let me not!" meaning "Stop me not!" But today, LET means PERMIT or ALLOW.

Common names also change with locality. Every species of animal may have scores, if not hundreds, of local names. Even the same name may not mean the same thing in different regions that speak the same language. The WHITING of England is not found in America, but the HAKE of England is the WHITING of New England, while the HAKE of Delaware Bay is a totally different fish that has nothing to do with the other two. Again, the English LING and the LING of New Jersey are different fishes.

It is plain, then, that scientists must have an international language. The solution has been to make up a word list from one or two "dead" languages that will not grow and change as time goes by. Sometimes words from other languages may be employed. Sanskrit and Hebrew would have served, but early scientists knew Greek and Latin better. 
To avoid confusion. scientific names are given to animals and plants. All scientists will know these names. Our domestic dog is "dog" in Fnglish, "hund" in German, "hond" in Dutch, "(hien" in French, "perro" in Spanish and "cão" in Portuguese. But all scientists - American, English, German, Dutch, French, Spanish or Portuguese - will know that CANIS FAMILIARIS is a dog in any dialect.

The Museum visitor may be surprised to find, after reading a label, that after each common name of an animal there are two words in a foreign language - usualls Latin and Greck in combination. For instance, after Robin, you will find TURI)US MIGRATORIUS: after Herring. CLUPEA HARENGLS. Every known animal has been given scientific names whether it has a common name or not.

But why TIOO scientific names? The two names have two functions. The Black Duck is ANAS RUBRIPES. ANAS is the generic name - it indicates relationship. Every surface-feeding duck is ANAS, as the Mallard, ANAS PLATYRHYNCOS; the Pintail, ANAS ACUTA; the Teal, ANAS CRECC.A. The second name, beginning always with a small letter to set it off, is unique. It specifies the particular species. It is the specific name.

To apply the same system to human names, let's take John Smith. The scientist reverses his name thus - SMITH JOHN. SMITH is his generic or relationship name. All members of his family will be named SMITH. But when we add JOHN to his relationship name we now have a specific name, a unique name. SMITH JOHN cannot be confused with SMITH PETER, SMITH BILL or SMITH CHARLES.

In addition to using Latin and Greek names, scientists also use shortcut descriptive words. It is harder to write simple language than it is to write scientific language. It also takes more words and more space. Scientists compress their words to save time and space.

Let us take PROGNATHOL'S as an example. We may say that one type of primitive man was prognathous. PROGNATHOUS is a descriptive word made up of Latin and Greek words. PRO- is a prefix meaning BEFORE or FORWARD. GNATHOS is a Greek word meaning JAW: The suffix -OUS means HAVING THE QUALITY OR PRESENCE OF SOMETHING. Therefore, PROGNATHOUS, part by part, means FORWARD-JAI-PRESENCE Or, more simply, HAVING A JAW THAT STICKS OUT. PROGNATHOUS is a time-saving, short-cut word. But it takes many words to explain what it means.

We have gone around the fiftr-eight halls of the Museum, reading labels. We have picked out words that we thought were least familiar to evervone. If sou are reading a label and come across a word like PROGNATHOUS or PECTOR.AL, you can find what it means in the word list below. If you find words not on our list that you think ought to be there, please note them and pass them on to any Information Desk. Your suggestion will be given to the right people. 


\section{THE WORD LIST}

IBERR.ANT, straying from the usual course: differing from the type of its group.

AIBINO, a person. animal, or plant lacking normal coloring matter.

IILUVIAL. pertaining to formations deposited by rivers or floods. Alluvial plains are the flood-plains of rivers.

ARBOREAL, living or situated among trees.

ARCHAEOLOGY, the systematic study of man, his relics, remains and records.

AVIFAUNA, the birds of a given region.

BOREAL, northern.

CALCAREOUS, composed of, or containing, limestone or calcium carbonate. A clam shell is calcareous.

CARNIVORE, a meat-eater. A lion is a carnivore.

CELT, an ancient tool or weapon of stone, shaped like an axe.

CERAMIC, pertaining to pottery.

CRUSTACEAN, a lobster, crab, crawfish or shrimp is a crustacean.

CULM, stem or stalk, as of grasses.

CULTURE, the sum total of everything a group is, does, has, and believes in.

DECOCTION, the liquid produced by boiling a substance.

DETRITUS, loose fragments or particles of rock.

DIURNAL, active during the day. The eagle and the sparrow are diurnal birds.

DORSAL, pertaining to, or placed on or near, the back.

EFFIGY, a figure or image representing the whole or part of a person.

ENVIRONMENT, one's surroundings.

EPIPHYTIC, growing on the outside of another plant, mostly on trees.

EVERTED, turned backward or outward.

EVOLUTION, a succession of changes by which the forms of organisms are modified, usually from the simple to the complex.

FAUNA, all the animals living in a given area.

FLOR.A, all plant life growing without cultivation in a given area. 
GRAMINIVORE. a grass-eater. A horse is a graminivore.

GREGIRIOL'S, living in flocks, herds or communities. Pigcons, cows and men are gregarious.

HERBIVORE, feeding on herlos or other vegetable matter.

HIBERNATION, passing the winter in a secluded place, in sleep or near-sleep.

HIEROGLYPHIC, picture-writing in which the figures of objects take the place of signs or letters.

INSECTIVORE, insect-eater.

INTRUSION, the forcing of masses of molten rock into or between other rocks; a mass of such rock.

INVERTEBRATE, an animal without a backbone.

LATERAL, pertaining to, or placed near, the side.

LEGUMINOUS, related to the pea family.

MELANISTIC, excessive darkness of the eves, hair, fur, or skin, due to deposits of pigment; the opposite of albinistic.

METALLURGY, the art or science of extracting metal from its ore.

MET AMORPHOSIS, a change in form, structure and function resulting in development; the changes that occur from the larra and pupa to the fully developed insect.

NOCTURNAL, active after dark. The owl is a nocturnal bird.

OCCIPITAL. pertaining to the lower back part of the head.

PARASITIC, living on or in another organism and getting nourishment from it.

PECTORAL, pertaining to the breast.

PEDICELS, stalks or supporting parts.

PHYSIOGRAPHY, physical geography, dealing in description rather than in theory or explanation.

PREDATORY, preying on other animals.

PREHENSILE, formed to grasp or coil around, as the tail of a monkey.

PRIMEVAL, belonging to the first ages; ancient.

PROBOSCIS, a long, flexible snout, as the trunk of an clephant.

PROGNATHOUS, having a jaw that sticks out. 
RUMINANT, an animal that chews the cud, as deer or cows.

SAPROPHYTIC, living on dead organic matter.

SCANDENT, climbing or aiding to climb.

SEDIMENTARY, formed originally by material deposited by water or air.

SESSILE, fixed to or attached.

SHERDS, fragments of pottery.

STELA, an upright slab or tablet of stone.

STRATIGRAPHY, the order and relative position of the layers of the earth's crust.

TERRESTRIAL, pertaining to the earth.

TUNDRA, the treeless plains found in the arctic regions.

VENTRAL, pertaining to, or placed on or near, the abdomen.

VERTEBRATE, an animal with a backbone. 



\section{The Museum Shop}

Make your visit to the Museum still more memorable by visiting the Muscum Shop. It is one of the largest and most interesting musem shops in the world. Here, in several departments, you will find not only books, cards and sourenirs, but a wide assortment of merchandise of unusual interest that is seldom available elsewhere.

RARE AND EXOTIC GIFTS. Alert shoppers are rapidly "discovering" this unique, exciting source for gifts of special character. Original African woodcarvings, handsome reproductions of actual Muscum specimens, unusual jewelry, authentically-costumed dolls of all nations, fine native crafts of all kinds - these are only a few of the distinctive items to be found there. Many articles are the only ones of their kind, many are handsome decorators' items, and all are of a character not found in ordinary shops.

SOUVENIRS. Many interesting mementos of your Museum visit will be found such as models of prehistoric and present day animals in glass, plastic and metal, novel paper weights, beautiful full-color photographs of Museum exhibits, special natural history records of bird songs, native dances, etc. For children there are toys, games, arrow heads, shark teeth, sea horses, bird pictures, and numerous other inexpensive articles intriguing to youngsters.

SHELLS, MINERALS, INSECTS. The Museum Shop offers an outstanding collection of mineral specimens, semi-precious stones, sea shells from all parts of the world, and mounted butterflies and other insects for the amateur collector. These are available singly or in ready-made collections.

PUBLICATIONS. A large library of books and pamphlets is available for your examination and purchase. These cover the field of natural history from anthropology to zoology, for both the amateur and adranced naturalist.

The Museum Shop is located on the first floor in the 77th Street Entrance Hall.

\section{The Planeturium Shop}

In the American Museum-Hayden Planetarium you will find a shop catering to the interests of both young and old in astronomy. Hourglasses, barometers, meteorites, star finders, zodiac cards, small microscopes and souvenirs of many kinds are among the objects on sale. It is also an excellent source for books on the sun, moon and stars, on weather, space travel, life on other planets, telescope making, and other subjects in the field of astronomy. 


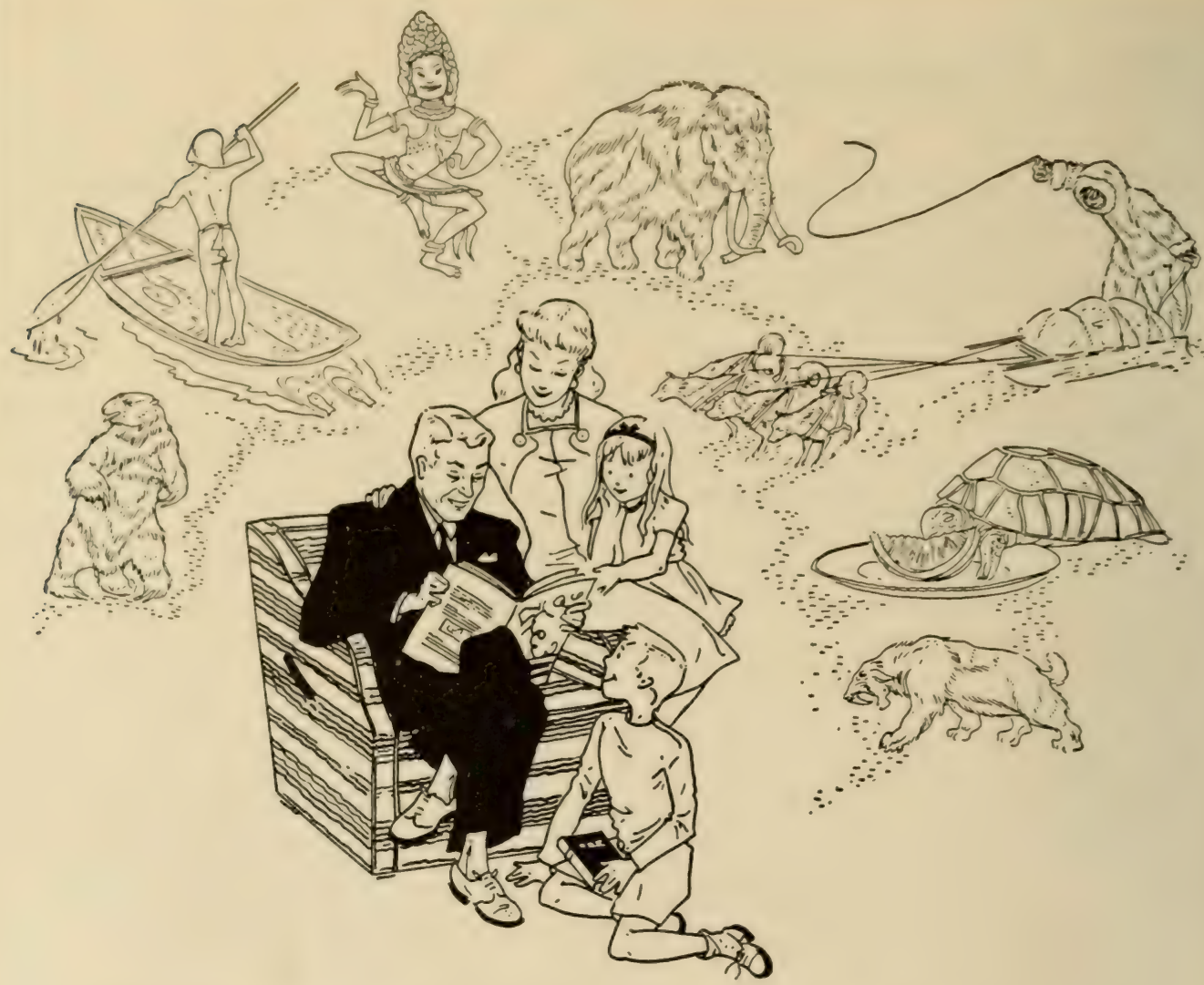

\section{Vatural History Magazine}

The American Museum of Natural History publishes one of the world's most distinctive and distinguished magazines, NATURAL HISTORY. In it cminent writers, scientists and explorers present in highly readable fashion the inside story of their research, travels, investigation and discoveries. From the floor of the oceans to the outermost stars of the galaxy, from the dim beginnings of life on prehistoric shores to the probable nature of life in the world of tomorrow - such is the reader's range of vision in a publication devoted at all times to truth and to the better understanding by man of the world in which he lives.

NATURAL HISTORY Magazine is filled with unusual photographs, maps and drawings. The handsome, full-color covers portraving natural history subjects of rare beauty and interest are prized by every subscriber. The subscription price of $\$ 5$ a vear enrolls you as an Associate Member of the Museum. You receive a Membership Card, Membership Certificate, and other desirable bencfits in addition to a year's subscription to NATURAL HISTORY Magazine.

The Muscum also publishes JUNIOR Natural History Magazine for young people between 8 and 14 years of age. This highly informative and entertaining publication is read avidly by both boys and girls and is valued by all adults who wish to see young people receive the right introduction to the infinite variety and inspiration of the world of nature. A year's subscription costs only $\$ 1.50$. 


\section{THE}

\section{AMEITICAN}

\section{MUSEUM}

DF

NA TURAL. HISTORY
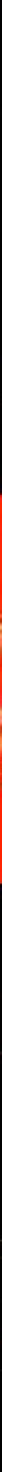

\section{general}
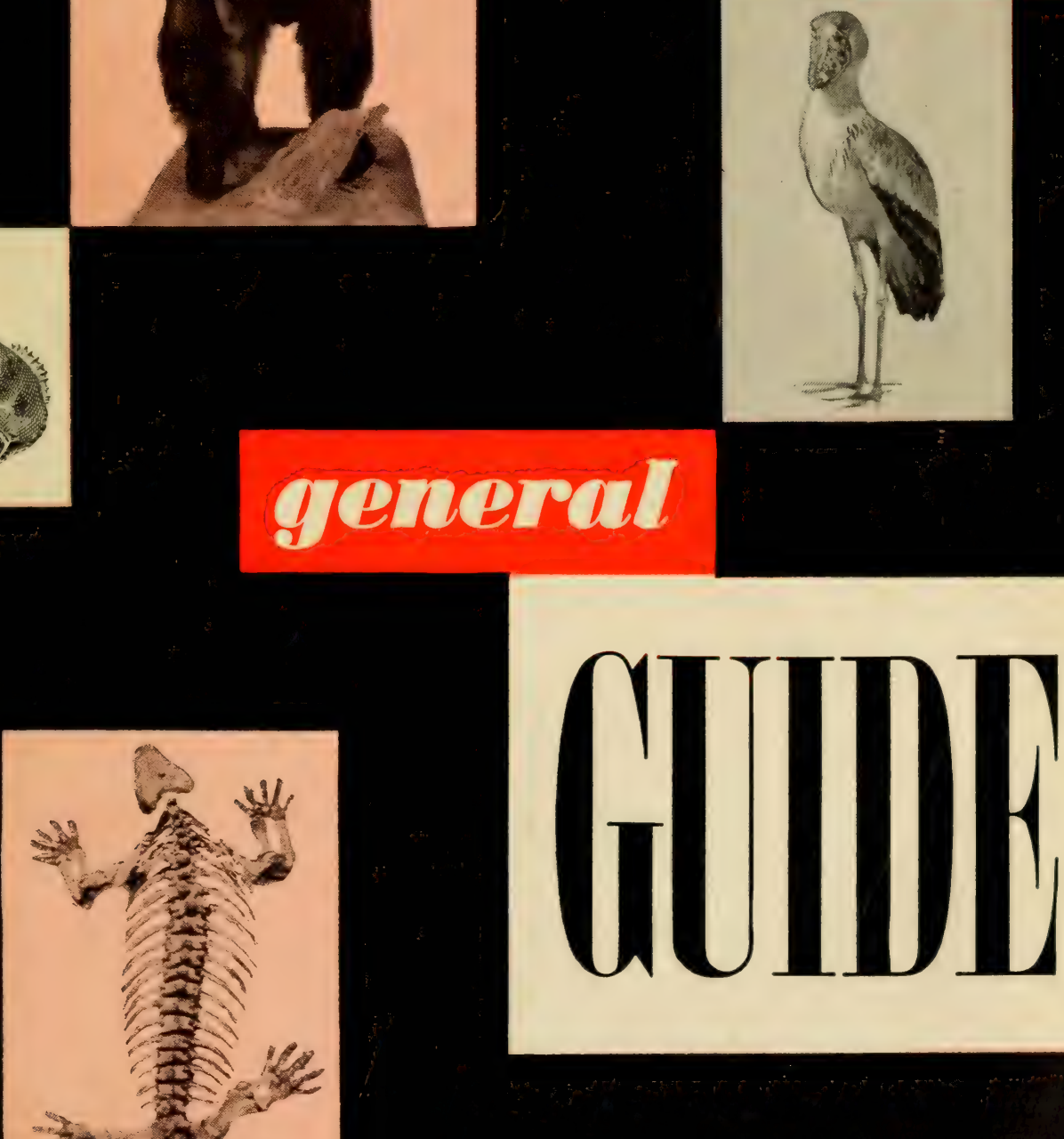



\section{Imvitation}

You are cordinally invited to enjoy the privileges and bencfits of membership in the AMERICAN MUSEUM OF NATURAL HISTORY.

Your Muscum is a powerful cultural influence in the nation, an invaluable asset to science and education, and a rewarding personal experience for all who wish to assist in its work by becoming Members. Your own participation is welcomed in any of the following Classes of Membership you choose.

\section{MEMIELIRSHIP CLASSES}

LIFE MEMBERSHIP — Benefits 1 through $10 \ldots \ldots \ldots \ldots$

SUPPORTING MEMBERSHIP - Benefits 1 through 9.

$\$ 100$ a year

CONTRIBUTING MEMBERSHIP - Benefits 1 through $9 \ldots$ \$ 50 a year SUSTAINING MEMBERSHIP - Benefits 1 through $9 \ldots \ldots$ \$ 25 a year ANNUAL MEMBERSHIP - Benefits 1 through 7 plus 8 or $9 \$ 15$ a year ASSOCIATE MEMBERSHIP - Benefits 1 through $6 \ldots \ldots$ \$ 5 a year

Interested people in all parts of the world find that distance is no barrier to their enjovment of Associate Membership status and benefits in the American Museum of Natural History. Residents of the Greater New York area find the Annual and Sustaining Memberships especially rewarding.

\section{MEMIEISHIP BENEFITS}

1. Membership Card for purse or wallet.

2. Membership Certificate suitable for framing.

3. Admission to Members' Room.

4. Subscription to NATURAL HISTORY Magazine, the Museum's unique and beautiful magazine, treasured by members as one of the most distinctive and interesting publications in the nation.

5. Ten per cent reduction on books purchased from the Museum Shop.

6. President's Annual Report on request.

7. Two admissions to Hayden Planetarium.

8. Admission for the Member and a guest to the Members' Lecture Series (10 or more annually). This Series brings to the Members the nation's foremost lecturers on natural history subjects. They present full-length natural color motion pictures of extraordinary beauty and interest. The lecture evenings are pleasant, relaxed social occasions at which the Members enjoy coffee, music, comfortable lounge chairs, and the opportunity of talking with well-known authors and scientists. They bring to all present rare and memorable insights into the infinite variety of nature. (At prevailing admission prices for programs of equal merit, this Series would cost at least \$30.)

9. Admission for the Member and two guests to Adventure Series (10 or more illustrated lectures annually). These Saturday morning lectures are of the same high calibre as the Members' Lecture Series. While they are presented especially for the children of Members, adults find them equally worthwhile. The Adventure Series has long been cherished by Members who value for their children a sound, constructive, stimulating introduction to the wonders of the world in which they live. (This Series, also, would cost at least $\$ 30.00$ at single admission prices to lectures of similar merit elsewhere.)

10. Admission to Staff Functions arranged for higher class Members.

To obtain your Membership Card, ask any Museum attendant to direct you to the office of the Membership Secretary. Or write to Membership Secretary, American Museum of Natural History, New York 24, New York. 
serthe

museum

is not

four walls

surrounding a

cloistered

lifes

it is the

lheart of a

system

circulating

throughout

the

world.99

DR ALBETt E. PARE.

Director 





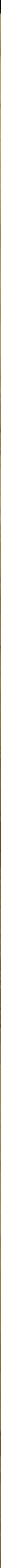




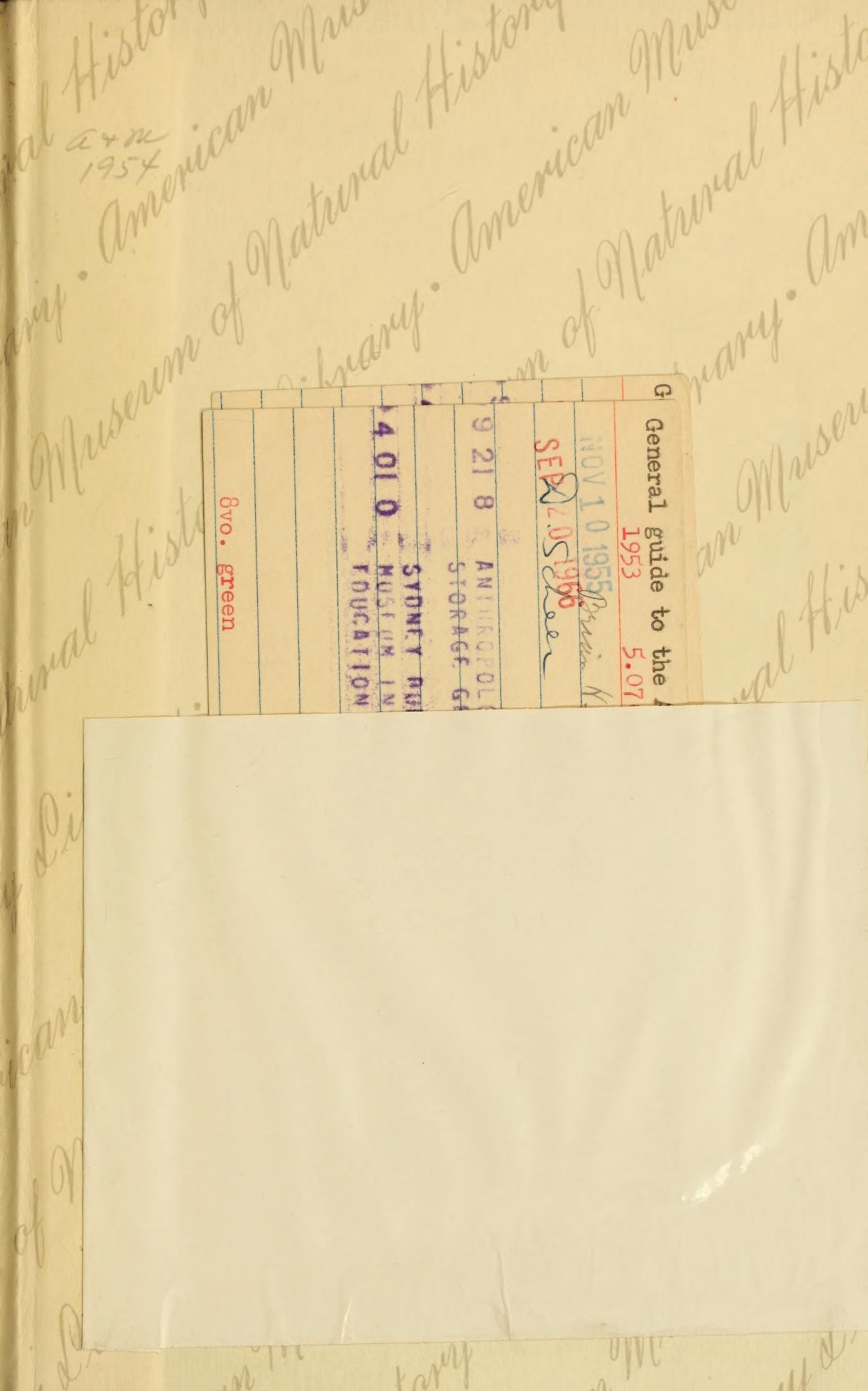


